Aus der Klinik für Gynäkologie und Geburtshilfe

(Prof. Dr. med. G. Emons)

im Zentrum Frauenheilkunde

der Medizinischen Fakultät der Universität Göttingen

\title{
Kisspeptin-10
}

\section{Ein potenzieller Inhibitor der Invasion humaner Endometriumkarzinomzellen}

\author{
INAUGURAL-DISSERTATION \\ zur Erlangung des Doktorgrades \\ der Medizinischen Fakultät \\ der Georg-August-Universität zu Göttingen
}

vorgelegt von

Elena Schmidt

aus

Sande

Göttingen 2013 
Dekan: Prof. Dr. rer. nat. H. K. Kroemer

I. Berichterstatter: Prof. Dr. rer. nat. C. Gründker

II. Berichterstatter/in: Prof. Dr. med. Claudia Binder

III. Berichterstatter/in: Prof. Dr. med. Michael Peter Schön

Tag der mündlichen Prüfung: 05.03.2014 


\section{Inhaltsverzeichnis:}

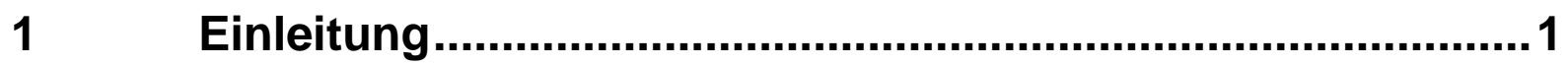

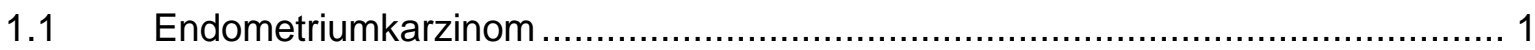

1.1.1 Epidemiologie ........................................................................... 1

1.1.2 Ätiologie und Histopathologie ............................................................. 2

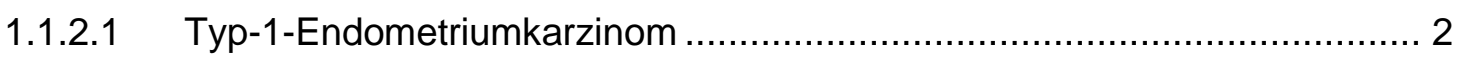

1.1.2.2 Typ-2-Endometriumkarzinom ........................................................... 3

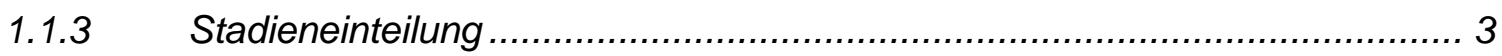

1.1.4 Therapie des Endometriumkarzinoms................................................... 5

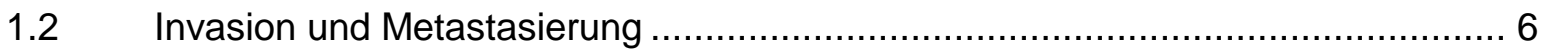

1.2.1 Prozess der Invasion und Metastasierung ............................................ 6

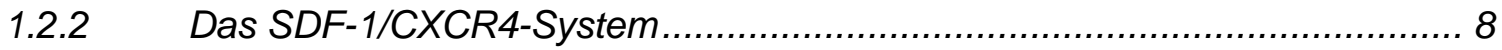

1.2.3 Lokale Invasion und Metastasierung beim Endometriumkarzinom ...............10

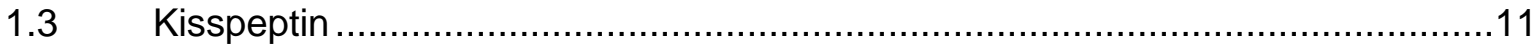

1.3.1 KISS1-Gen, Kisspeptine, GPR54................................................... 11

1.3.2 Kisspeptine in der Tumorbiologie .......................................................... 13

1.3.3 Physiologische Funktionen des Kisspeptins und seines Rezeptors .............14

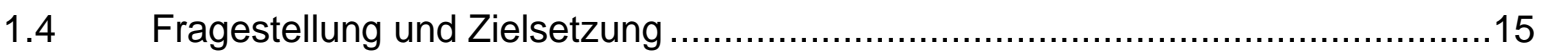

$2 \quad$ Material und Methoden ......................................................17

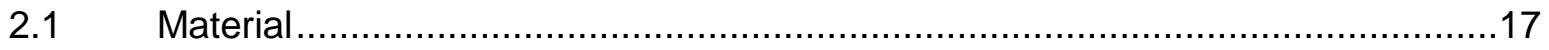

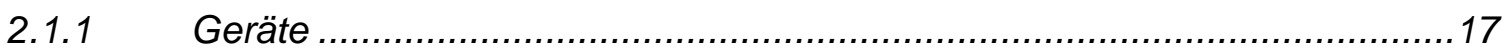

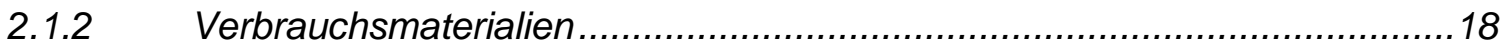

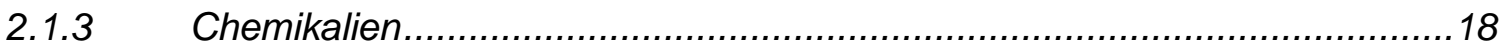

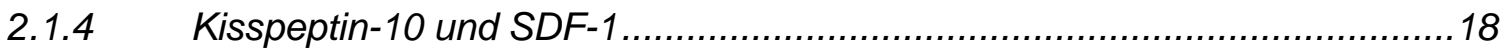

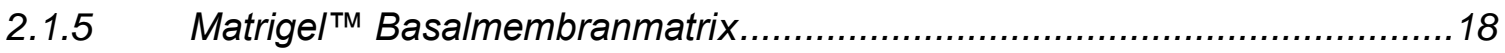

2.1.6 Puffer, Lösungen und weitere Substanzen ..........................................18

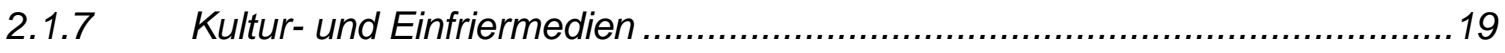

2.1.8 Zelllinien 


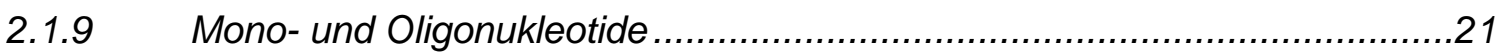

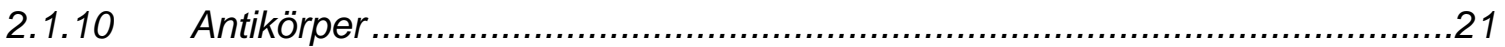

2.1.11 Kommerzielle Reaktionssysteme .................................................22

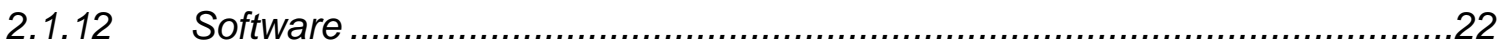

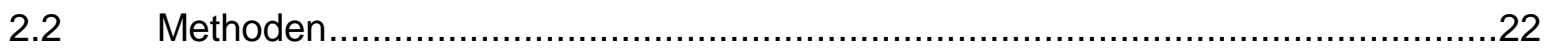

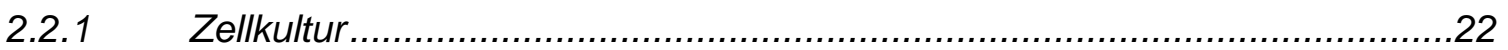

2.2.1.1 Kultivierung und Passagieren der Zellen ..........................................22

2.2.1.2 Bestimmung der Zellzahl ..............................................................24

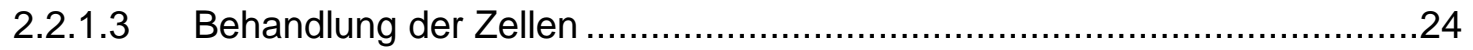

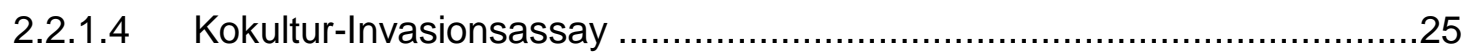

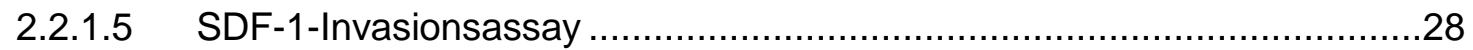

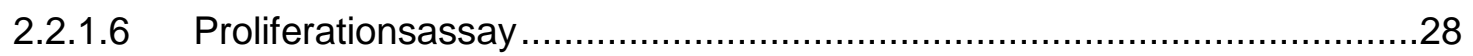

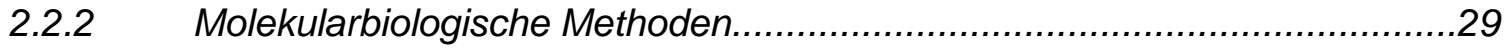

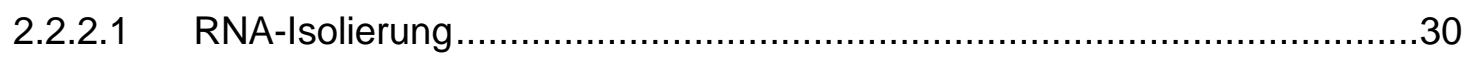

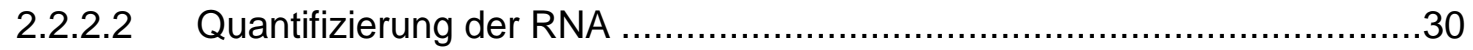

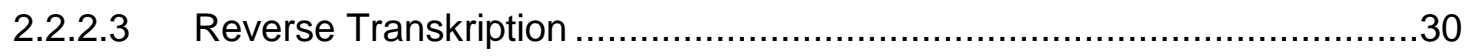

2.2.2.4 Polymerase-Ketten-Reaktion............................................................

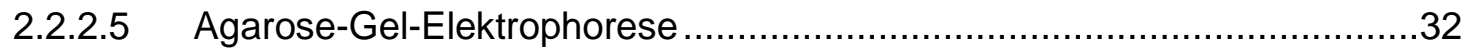

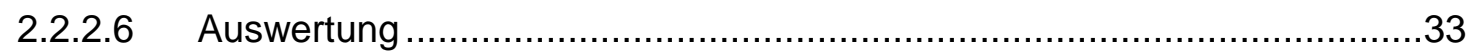

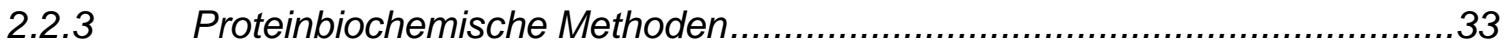

2.2.3.1 Zellkultivierung zur Proteinisolation .......................................................33

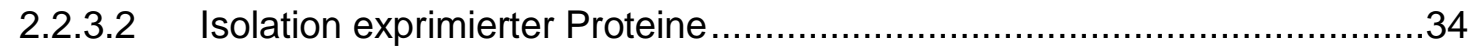

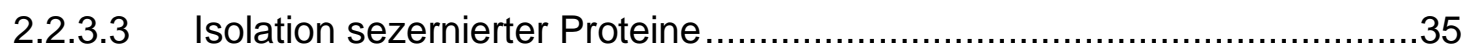

2.2.3.4 SDS-Polyacrylamid-Gel-Elektrophorese ..............................................36

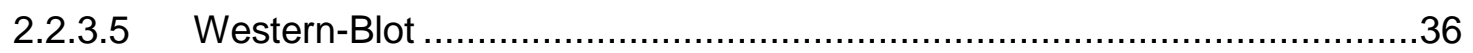

2.2.3.6 Detektion, Visualisierung und Auswertung …........................................37

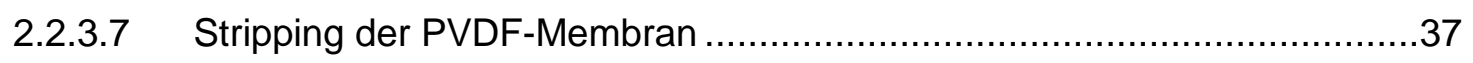

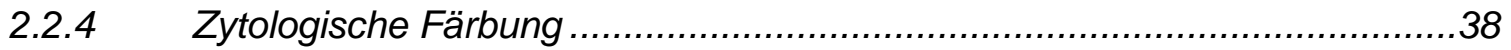

2.2.4.1 Immunzytologische Färbung der Zelllinien ..........................................38

2.2.4.2 Mikroskopische Auswertung der Invasionsassays .................................38 
2.2.5 Dokumentation und statistische Analysen.............................................39

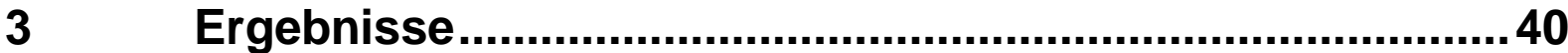

3.1 GPR54-Expression humaner Endometriumkarzinom- und Osteoblasten-ähnlicher Zellen .40

3.1.1 Molekularbiologischer Nachweis der GPR54-Expression..........................40

3.1.2 Proteinbiochemischer Nachweis der GPR54-Expression...........................40

3.1.3 Immunzytochemischer Nachweis der GPR54-Expression ........................41

3.2 KISS1-Expression humaner Endometriumkarzinomzellen .................................42

3.3 Invasionsverhalten humaner Endometriumkarzinomzellen..............................42

3.3.1 Zellspezifisches Invasionsverhalten von Ishikawa- und HEC-1a-Zellen .......42

3.3.2 Invasionsverhalten humaner Endometriumkarzinomzellen im Kokultur-

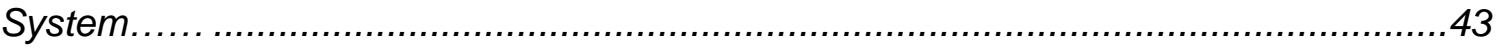

3.3.2.1 Invasionsverhalten von Ishikawa-Zellen im Kokultur-System....................44

3.3.2.2 Invasionsverhalten von HEC-1a-Zellen im Kokultur-System.....................45

3.3.3 Einfluss von SDF-1 auf das Invasionsverhalten humaner Endometriumkarzinomzellen. 46

3.3.3.1 Einfluss von SDF-1 auf das Invasionsverhalten von Ishikawa-Zellen .......47

3.3.3.2 Einfluss von SDF-1 auf das Invasionsverhalten von HEC-1a-Zellen.........48

3.4 Einfluss von Kisspeptin-10 auf das Invasionsverhalten humaner Endometriumkarzinomzellen

3.4.1 Einfluss von Kisspeptin-10 auf die Invasion humaner Endometriumkarzinomzellen im Kokultur-System

3.4.1.1 Einfluss von Kisspeptin-10 auf die Invasion von Ishikawa-Zellen im Kokultur-System

3.4.1.2 Einfluss von Kisspeptin-10 auf die Invasion von HEC-1a-Zellen im Kokultur-System .50

3.4.2 Einfluss von Kisspeptin-10 auf die SDF-1-induzierte Invasion humaner Endometriumkarzinomzellen

3.4.2.1 Einfluss von Kisspeptin-10 auf die SDF-1-induzierte Invasion von Ishikawa-Zellen 
3.4.2.2 Einfluss von Kisspeptin-10 auf die SDF-1-induzierte Invasion von HEC-1aZellen .53

3.5 Einfluss von Kisspeptin-10 auf die Proliferationsfähigkeit humaner Endometriumkarzinomzellen .55

3.5.1 Einfluss von Kisspeptin-10 auf die Proliferationsfähigkeit von IshikawaZellen. .55

3.5.2 Einfluss von Kisspeptin-10 auf die Proliferationsfähigkeit von HEC-1aZellen. .56

3.6 CXCR4-Expression humaner Endometriumkarzinomzellen .57

3.6.1 CXCR4-Expression auf molekularbiologischer Ebene .58

3.6.1.1 Einfluss von Kisspeptin-10 auf die CXCR4-mRNA-Expression von Ishikawa-Zellen im Kokultur-System .58

3.6.1.2 Einfluss von Kisspeptin-10 auf die CXCR4-mRNA-Expression von HEC-1a-Zellen im Kokultur-System .59

3.6.2 CXCR4-Expression auf proteinbiochemischer Ebene..... .60

3.6.2.1 Proteinbiochemischer Nachweis der CXCR4-Expression humaner Endometriumkarzinom- und Osteoblasten-ähnlicher Zellen . .60

3.6.2.2 Einfluss von Kisspeptin-10 auf die CXCR4-Protein-Expression von Ishikawa-Zellen im Kokultur-System

3.6.2.3 Einfluss von Kisspeptin-10 auf die CXCR4-Protein-Expression von HEC-1a-Zellen im Kokultur-System

3.7 SDF-1-Expression humaner Endometriumkarzinom- und Osteoblasten-ähnlicher Zellen

3.7.1 SDF-1-Expression auf molekularbiologischer Ebene .

3.7.1.1 Einfluss von Kisspeptin-10 auf die SDF-1-mRNA-Expression von MG-63Zellen im Kokultur-System mit Ishikawa-Zellen

3.7.1.2 Einfluss von Kisspeptin-10 auf die SDF-1-mRNA-Expression von MG-63Zellen im Kokultur-System mit HEC-1a-Zellen

3.7.2 SDF-1-Expression auf proteinbiochemischer Ebene.

3.7.2.1 Proteinbiochemischer Nachweis der SDF-1-Expression humaner Endometriumkarzinom- und Osteoblasten-ähnlicher Zellen .64

3.7.2.2 Einfluss von Kisspeptin-10 auf die SDF-1-Protein-Expression von Ishikawa-Zellen 
3.7.2.3 Einfluss von Kisspeptin-10 auf die SDF-1-Protein-Expression von MG-63Zellen im Kokultur-System mit Ishikawa-Zellen .66

3.7.2.4 Einfluss von Kisspeptin-10 auf die SDF-1-Sekretion von MG-63-Zellen im Kokultur-System mit Ishikawa-Zellen .66

3.7.2.5 Einfluss von Kisspeptin-10 auf die SDF-1-Protein-Expression von HEC-1aZellen.

3.7.2.6 Einfluss von Kisspeptin-10 auf die SDF-1-Protein-Expression von MG-63Zellen im Kokultur-System mit HEC-1a-Zellen .68

3.7.2.7 Einfluss von Kisspeptin-10 auf die SDF-1-Sekretion von MG-63-Zellen im Kokultur-System mit HEC-1a-Zellen

4.1 KISS1- und GPR54-Expression humaner Endometriumkarzinomzellen .70

4.2 Induktion der Invasion humaner Endometriumkarzinomzellen .72

4.2.1 Induktion der Invasion humaner Endometriumkarzinomzellen im KokulturSystem mit Osteoblasten-ähnlichen MG-63-Zellen .72

4.2.2 SDF-1-induzierte Invasion humaner Endometriumkarzinomzellen 73

4.3 Inhibition der Invasionsfähigkeit humaner Endometriumkarzinomzellen durch Kisspeptin-10. .76

4.3.1 Inhibition der Invasion humaner Endometriumkarzinomzellen im KokulturSystem durch Kisspeptin-10. .76 4.3.2 Inhibition der SDF-1-induzierten Invasion humaner Endometriumkarzinomzellen durch Kisspeptin-10. .78

4.4 Kisspeptin-10 und das prometastatische SDF-1/CXCR4-System......................79

4.4.1 Kisspeptin-10-vermittelte Effekte auf den Chemokinrezeptor CXCR4 ..........79

4.4.2 Kisspeptin-10-vermittelte Effekte auf das Chemokin SDF-1 ......................81

4.5 Resultierender Mechanismus der Kisspeptin-10-vermittelten Invasions- und Expressionsreduktion

4.6 Kisspeptin-10 und die Proliferationsfähigkeit humaner Endometriumkarzinomzellen .86

4.6.1 Kisspeptin-10-vermittelte Effekte auf die Proliferationsfähigkeit humaner Endometriumkarzinomzellen. .86 
4.6.2 Kisspeptin-10-vermittelte Effekte auf das proliferationsfördernde SDF-1 .....87

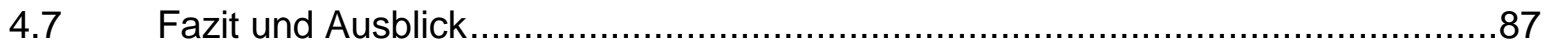

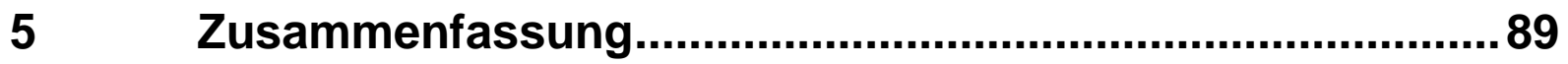

$6 \quad$ Literaturverzeichnis .......................................................91

$7 \quad$ Anhang

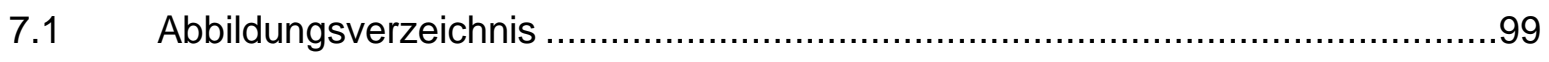

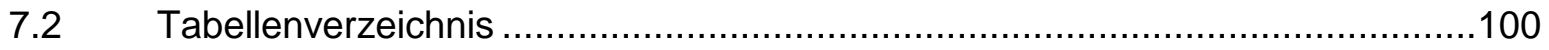

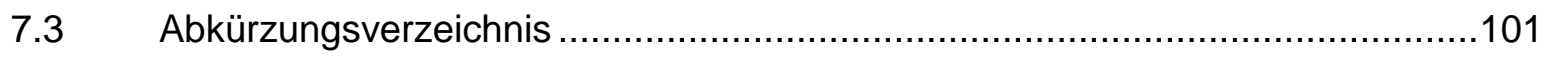

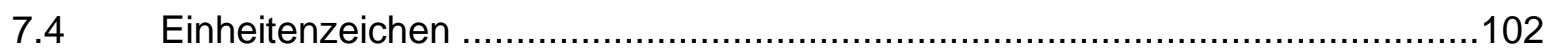

7.5 Aminosäurecode für natürliche Aminosäuren.............................................103

Publikation...................................................................................... 104 


\section{Einleitung}

\subsection{Endometriumkarzinom}

\subsubsection{Epidemiologie}

2008 erkrankten In Deutschland 11.280 Frauen erstmalig an einem Endometriumkarzinom (Synonym: Korpuskarzinom). Damit trägt dieses Malignom einen Anteil von $5,1 \%$ an allen bösartigen Neubildungen der Frau. Nach dem Mamma-, Bronchial- und kolorektalen Karzinom ist es nicht nur das 4.-häufigste Malignom der Frau, sondern auch das häufigste Malignom der weiblichen Genitalorgane. Die altersstandardisierte Erkrankungsrate liegt mit 17,2/10 Einwohnern deutlich über der des Zervixkarzinoms (9,5/10 Einwohner), zeigt aber seit 1980 eine leicht rückläufige Tendenz. Ähnlich hierzu verhält sich auch die altersstandardisierte Sterberate, welche von $6 / 10^{5} \mathrm{im}$ Jahr 1980 auf $3 / 10^{5}$ Einwohner im Jahr 2008 gesunken ist. Deutschlandweit erkrankt eine von 47 Frauen an einem Endometriumkarzinom und eine von 200 Frauen verstirbt an dessen Folgen (Robert KochInstitut und die Gesellschaft der epidemiologischen Krebsregister in Deutschland e.V. 2012). Betrachtet man die Inzidenz des Endometriumkarzinoms weltweit, sind große geographische und ethnische Unterschiede zu erkennen. In den Industrieländern ist es das 4.-häufigste weibliche Malignom, in den Entwicklungsländern hingegen liegt es lediglich auf Platz 7. Die Inzidenz des Endometriumkarzinoms ist in Nord-Amerika (22/10 $0^{5}$ Einwohner) um ein 5,5-faches höher als in den sogenannten Entwicklungsländern (3,88/10 5 Einwohner) (Parkin et al. 2009). Dies hängt vermutlich mit dem unterschiedlichen Lebensstil der Nationen, wie den differenten Ernährungsgewohnheiten, zusammen. Das Endometriumkarzinom wird daher auch als "Wohlstandserkrankung" bezeichnet (Fleisch und Bender 2003).

Da weltweit 91 \% der Diagnosen auf Frauen über dem 50. Lebensjahr fallen, kann man das Endometriumkarzinom als ein Karzinom der postmenopausalen Frau bezeichnen. Der Altersgipfel des Endometriumkarzinoms liegt bei 69 Jahren. Jedoch wird deutschlandweit in $5 \%$ der Fälle die Erkrankung auch bei prä- und perimenopausalen Frauen unter 45 Jahren diagnostiziert (Robert Koch-Institut und die Gesellschaft der epidemiologischen Krebsregister in Deutschland e.V. 2012).

Prognostisch günstig ist, dass $76,3 \%$ der Endometriumkarzinome im FIGO-(Fédération Internationale de Gynécologie et d'Obstétrique)-Stadium I erkannt werden (FIGO II: 9,5\%; FIGO III: 10,5\%; FIGO IV: 3,7\%). Dadurch beträgt die relative 5-Jahres-Überlebensrate gemittelt über alle Stadien in Deutschland $79 \%$. Karzinome des Stadiums FIGO la und Ib 
zeigen sogar eine relative 10-Jahres-Überlebensrate von über $90 \%$ (Schubert-Fritschle et al. 2007).

\subsection{2 Ätiologie und Histopathologie}

Histopathologisch und ätiologisch unterscheidet man heute allgemein zwei Typen des Endometriumkarzinoms (Bokhman 1983). Diese werden im Folgenden näher erläutert.

\subsubsection{Typ-1-Endometriumkarzinom}

Das Typ-1-Karzinom bezeichnet mit $80 \%$ das häufigere, östrogenassoziierte Endometriumkarzinom. Histopathologisch erscheint es meist als endometrioides Adenokarzinom, welches oft gut differenziert ist (Schmidt 2003; Kurman und McConnell 2009). Prognostisch liegt das Typ-1-Karzinom mit einer Überlebensrate von ca. $85 \%$ deutlich über dem des Typ-2-Karzinoms (Bokhman 1983).

In der Entwicklung dieses Endometriumkarzinoms wird ein endo- und exogener Östrogenüberschuss angenommen. Östrogene haben eine proliferative Wirkung auf das Endometrium, welche unter normalen Umständen durch Gestagene antagonisiert wird. Bei einem Östrogenüberschuss oder gar einer exogenen Zufuhr von Östrogenen reicht dieser Antagonismus jedoch nicht mehr aus und die proliferative Wirkung auf die Endometriumzellen überwiegt (Emons et al. 2011).

Auf diese Weise entsteht zunächst eine Endometriumhyperplasie, welche gemäß WHO (World Health Organization) weiter unterteilt wird. Unterschieden wird die einfache Hyperplasie, die komplexe Hyperplasie ohne Atypien, die einfache Hyperplasie mit Atypien und die komplexe Hyperplasie mit Atypien (Scully et al. 1994). Das Entartungsrisiko beträgt für diese Untergruppen jeweils 1\%, $2 \%, 8 \%$ und $30 \%$ (Lacey et al. 2010; Kurman et al. 1985). Die komplexe Hyperplasie mit Atypien gilt als Vorläuferläsion und obligate Präkanzerose des Typ-1-Endometriumkarzinoms (Emons et al. 2011).

Man nimmt an, dass nicht die direkte, anhaltende Stimulation des Endometriums durch Östrogen, sondern viel mehr sein proliferativer Reiz auf bereits atypisch veränderte Zellen ursächlich für die Entstehung eines Karzinoms aus der Hyperplasie ist (Stauber und Weyerstahl 2007; Emons et al. 2011).

Eine frühe Menarche, eine späte Menopause, Nulliparität, das polyzystische Ovarialsyndrom, Adipositas und menopausale Östrogen-Monotherapien führen unter anderem zu erhöhten Östrogenspiegeln und bilden somit die Risikofaktoren dieses Endometriumkarzinoms (Emons et al. 2011). 


\subsubsection{Typ-2-Endometriumkarzinom}

Das Typ-2-Karzinom des Endometriums kommt mit einer Häufigkeit von 10-15\% vor (Bokhman 1983). Es unterscheidet sich in vielerlei Hinsicht von dem Typ-1-Karzinom. Histopathologisch erscheint es vor allem als seröses oder klarzelliges Karzinom. Auch der maligne Müller-Mischtumor des Uterus (Synonym: maligner gemischter mesodermaler Tumor des Uterus), ein Karzinosarkom, zählt zu den Typ-2-Endometriumkarzinomen (Kurman und McConnell 2009). Außerdem sind sie zumeist gering differenziert und weisen ausgeprägte Kernatypien auf (Schmidt 2003).

In der Immunhistochemie werden sie meist als Östrogen- und Progesteronrezeptor-negativ klassifiziert. Darüber hinaus lässt sich bei über $90 \%$ dieser Karzinome eine Mutation des p53-Gens feststellen (Tashiro et al. 1997).

Hinsichtlich der Pathogenese unterscheidet sich das Typ-2-Karzinom ebenfalls vom Typ-1Karzinom. Zum einen ist es ein östrogenunabhängiger Tumor und zum anderen entsteht es aus atrophischem Endometrium und nicht aus einer Endometriumhyperplasie. Eine Vorläuferläsion und Präkanzerose des serösen Karzinoms könnte das endometriale intraephiteliale Karzinom sein (Ambros et al. 1995). Dieses ist im Gegensatz zur Endometriumhyperplasie sonographisch nicht zu erkennen (Emons et al. 2011). Zwar ist auch die dadurch bedingte fehlende Früherkennung ein Grund für die ungünstige Prognose des Typ-2-Endometriumkarzinoms, ausschlaggebend sind jedoch die Mutationen im p53Gen, die auch schon in frühen Stadien zu einer schlechten Prognose führen. Die gemittelte 5-Jahres-Überlebensrate beträgt ca. 58,8 \% (Bokhman 1983).

Die Patientinnen weisen, aufgrund der Östrogenunabhängigkeit des Karzinoms, nicht die typischen östrogenassoziierten Risikofaktoren des Typ-1-Karzinoms auf. Betroffene sind eher schlank und das durchschnittliche Erkrankungsalter liegt höher. Die einzigen bekannten Risikofaktoren sind das Alter und ein Zustand nach Bestrahlung des kleinen Beckens bei unter anderem Rektum-, Blasen- oder Zervixkarzinom (Kumar et al. 2009).

\subsubsection{Stadieneinteilung}

Die Stadien des Endometriumkarzinoms werden sowohl nach der FIGO- als auch nach der TNM-Klassifikation eingeteilt. Die FIGO-Stadien basieren auf einem klinisch-chirurgischen Staging. Die TNM-Stadien basieren hingegen auf einer klinischen und/oder pathologischen Klassifikation und beurteilen den Tumor, die Lymphknoten (englisch: lymphnodes) und Metastasen. Seit dem 01.01.2010 ist die neue, korrigierte Klassifikation, welche sich 
4 | Einleitung

zahlreichen, prognoseorientierenden Studienergebnissen zu den unterschiedlichen Stadien angepasst hat, veröffentlicht (Horn et al. 2010).

Tab. 1.1: Neue Stadieneinteilung des Endometriumkarzinoms (modifiziert nach Horn et al. 2010, S. 241)

\begin{tabular}{|c|c|c|}
\hline $\begin{array}{l}\text { TNM- } \\
\text { Kategorien }\end{array}$ & $\begin{array}{l}\text { FIGO- } \\
\text { Stadien }\end{array}$ & Beschreibung \\
\hline \multicolumn{3}{|c|}{ T- Tumorstadium } \\
\hline $\mathrm{TX}$ & & Primärtumor kann nicht beurteilt werden \\
\hline T0 & & Kein Anhalt für Primärtumor \\
\hline Tis & & Carcinoma in Situ \\
\hline $\mathrm{T} 1$ & I & Tumor begrenzt auf das Corpus uteri \\
\hline T1a & la & $\begin{array}{l}\text { Tumor auf das Endometrium begrenzt oder weniger als die Hälfte } \\
\text { des Myometriums infiltrierend }\end{array}$ \\
\hline $\mathrm{T} 1 \mathrm{~b}$ & $\mathrm{lb}$ & Tumor infiltriert die Hälfte oder mehr des Myometriums \\
\hline $\mathrm{T} 2$ & II & $\begin{array}{l}\text { Tumor infiltriert das Stroma der Cervix uteri, breitet sich jedoch nicht } \\
\text { jenseits des Uterus aus }\end{array}$ \\
\hline T3 u/o N1 & III & $\begin{array}{l}\text { Lokale und/oder regionäre Ausbreitung, wie nachfolgend } \\
\text { beschrieben }\end{array}$ \\
\hline T3a & Illa & Tumor befällt Serosa und/oder Adnexe \\
\hline T3b & IIlb & Vaginalbefall und/oder Befall der Parametrien \\
\hline T3c o N1 & IIlc & Regionäre Lymphknotenmetastasen \\
\hline T3c1 & Illc1 & Pelvine Lymphknotenmetastasen \\
\hline T3c2 & Illc2 & $\begin{array}{l}\text { Paraaortale Lymphknotenmetastasen mit/ohne pelvine } \\
\text { Lymphknotenmetastasen }\end{array}$ \\
\hline $\mathrm{T} 4$ & Iva & Tumor infiltriert Blasen- und/oder Rektumschleimhaut \\
\hline \multicolumn{3}{|c|}{$\mathrm{N}$ - regionäre Lymphknoten } \\
\hline NX & & Regionäre Lymphknoten können nicht beurteilt werden \\
\hline No & & Keine regionären Lymphknotenmetastasen \\
\hline N1 & & Regionäre Lymphknotenmetastasen \\
\hline \multicolumn{3}{|c|}{ M - Fernmetastasen } \\
\hline M0 & & Keine Fernmetastasen \\
\hline M1 & $\mathrm{IVb}$ & $\begin{array}{l}\text { Fernmetastasen (ausgenommen in der Vagina, der Beckenserosa } \\
\text { oder den Adnexen, einschließlich in inguinalen Lymphknoten } \\
\text { und/oder Metastasen in anderen intraabdominalen Lymphknoten als } \\
\text { den paraaortalen und/oder pelvinen Lymphknoten) }\end{array}$ \\
\hline
\end{tabular}

Darüber hinaus hat die FIGO auch das Grading (G) des Endometriumkarzinoms definiert, welches durch die WHO anerkannt wurde (Silverberg et al. 2003). Die Bezeichnung Grading 
wird benutzt, um zum einen den Anteil an Tumorzellen in der suspekten Gewebeprobe anzugeben und zum anderen den Differenzierungsgrad des Tumorgewebes zu ermitteln, d.h. das Ausmaß, in dem es von den normalen Geweben abweicht. Bei den Endometriumkarzinomen werden G1- bis G3-Tumore unterschieden (Horn et al. 2010), die in Tab. 1.2 näher beschrieben werden.

Tab. 1.2: Grading der Endometriumkarzinome

\begin{tabular}{ll}
\hline Grading & Beschreibung \\
\hline G1 & $<5 \%$ solides, glanduläres Tumorwachstum, eine eventuelle plattenepitheliale \\
& Komponente wird vernachlässigt; hoch differenziert \\
G2 & $6-50 \%$ solides, glanduläres Tumorwachstum; mittelgradig differenziert \\
G3 & $>50 \%$ solides, glanduläres Tumorwachstum; gering differenziert \\
\hline
\end{tabular}

Starke nukleäre Atypien erhöhen dabei das Grading eines G1- oder G2-Tumors um jeweils einen Grad. Bei dem Typ-2-Karzinom sind für das Grading die nukleären Atypien entscheidend (Horn et al. 2010).

\subsubsection{Therapie des Endometriumkarzinoms}

Das folgende Unterkapitel bezieht sich auf die Empfehlungen der interdisziplinären S2KLeitlinien zur Diagnostik und Therapie des Endometriumkarzinoms der Kommission Uterus der Arbeitsgemeinschaft für Gynäkologische Onkologie e. V. (2008).

Die operative Versorgung der Patientinnen stellt mit der Hysterektomie und der beidseitigen Adnexexstirpation die entscheidende Basistherapie des Endometriumkarzinoms dar, die je nach Stadium des Karzinoms erweitert werden sollte.

Die Erweiterungen beinhalten eine pelvine und aortale Lymphadenektomie bei Tumoren im Stadium $\geq \mathrm{pT} 1 \mathrm{~b}$, G3-Grading oder bei serösen beziehungsweise klarzelligen Karzinomen.

Eine radikale Hysterektomie (totale Entfernung des Uterus unter Mitnahme des Halteapparates, des oberen Drittels der Vagina und der pelvinen Lymphknoten) wird bei gesicherter Zervixstromainfiltration (Stadium T2) empfohlen.

Eine Omentektomie wird sowohl ab Stadium T3a als auch bei einer serösen oder klarzelligen Karzinomkomponente angestrebt. Im Stadium T3 und T4 sollte über eine möglichst komplette Resektion aller Tumormanifestationen diskutiert werden, um die Effizienz der adjuvanten systemischen und strahlentherapeutischen Maßnahmen zu verbessern.

Eine primäre Strahlentherapie des Endometriumkarzinoms ist nur indiziert, wenn durch Komorbidität eine Operation unmöglich ist. Eine adjuvante Radiotherapie ist lediglich bei Patientinnen mit hohem Lokalrezidivrisiko in Form einer vaginalen Brachy- oder Teletherapie indiziert. 
Bei Endometriumkarzinomen des Stadiums T1b, G3 und T2, G3 kann eine adjuvante Chemotherapie angezeigt sein. Für die meisten Patientinnen im Stadium T3 und T4a sowie für Patientinnen mit seröser oder klarzelliger Histologie ist eine adjuvante platinhaltige Chemotherapie sinnvoll. Eventuell profitieren betroffene Patientinnen auch von einer zusätzlichen Strahlentherapie.

Aktuell wird an einer S3-Leitlinie gearbeitet, die neueste Studien zur Therapie und Prognose des Endometriumkarzinoms berücksichtigt.

\subsection{Invasion und Metastasierung}

\subsubsection{Prozess der Invasion und Metastasierung}

Metastasen (griechisch) bezeichnen Absiedlungen eines bösartigen Tumors in entfernte Gewebe, welche die Prognose betroffener Tumorpatienten drastisch verschlechtern. Deshalb sind die Mechanismen hinter dem Metastasierungsprozess ein wichtiger Bestandteil der onkologischen Forschung.

Obwohl viele verschiedene Krebsarten existieren, gibt es vermutlich sechs wesentliche Veränderungen der normalen Zellphysiologie, die gemeinsam Proliferation und Metastasierung der meisten Tumoren ermöglichen. Diese sechs „Malignom-Kennzeichen“ beinhalten die Aufrechterhaltung ständiger proliferativer Signale, Resistenz gegenüber Wachstums-Suppressoren, Aktivierung von Invasion und Metastasierung, replikative Unsterblichkeit, Induktion der Angiogenese und Resistenz gegenüber Apoptose (Hanahan und Weinberg 2000).

Metastasierung beschreibt die Migration und Invasion von Tumorzellen eines primären Tumors in das umliegende Gewebe mit folgendem Durchbruch in Blut- und Lymphgefäße, sodass sich neue Tumorabsiedlungen in entfernte Gewebe bilden können (Coghlin und Murray 2010).

Die Fähigkeit des Tumors zur Metastasenbildung verschlechtert die Heilungschancen erheblich. Das wird dadurch deutlich, dass ungefähr $90 \%$ der Patienten, die an einem malignen Tumoren versterben, an den Folgen der Metastasen sterben (Chambers 1999). Im Folgenden wird daher näher erläutert, welche Mechanismen die Tumorzellen dazu befähigen, Invasion und Metastasierung zu aktivieren.

Der Prozess von Invasion und Metastasierung wird häufig als eine Folge von Schritten betrachtet, die als "Invasions-Metastasierungs-Kaskade“ bezeichnet wird (Fidler 2003). Diese Kaskade beinhaltet eine Reihe von zellbiologischen Veränderungen, beginnend mit einer Invasion in das Nachbargewebe durch Destruktion der Basalmembran und die damit 
verbundene Invasion in die extrazelluläre Matrix. Anschließend folgt die Intravasation der Krebszellen in nahegelegene Blut-und Lymphgefäße. Die Zellen müssen im lymphatischen und hämatogenen System zirkulieren und überleben, wobei dies unter anderem eine Umgehung der körperlichen Immunantwort erfordert. Dann treten die Tumorzellen im Rahmen der Extravasation aus dem Blut- und Lymphsystem in die entfernten Gewebe aus. Dort kommt es zur Adhäsion und Proliferation der Tumorzellen, wodurch Mikrometastasen entstehen. Dies führt letztendlich zum Wachstum von makroskopischen Tumoren. Dieser letzte Schritt wird als Kolonisation bezeichnet. Die Bildung von Mikro- und Makrometasten setzt auch die Fähigkeit zur Aktivierung der Angiogenese voraus (Chambers 1999; Talmadge und Fidler 2010).

In den letzten Jahren rückte ein Prozess zur Regulierung der Entwicklung und Embryogenese in den Fokus der onkologischen Forschung, die sogenannte epithelialemesenchymale Transition (EMT). EMT beschreibt einen Vorgang, durch den neoplastische epitheliale Zellen einen mobilen, invasiven mesenchymalen Phänotyp einnehmen können. Dadurch lässt sich die Fähigkeit der epithelialen Karzinomzellen zur Invasion erklären (Thiery 2003; Thiery et al. 2009).

EMT wird durch Transkriptionsfaktoren induziert, die den Verlust von Adhärenzverbindungen zwischen den Zellen und damit verbunden eine Konversion von polygonalen, epithelialen Zellen zu spindelförmigen Fibroblasten bewirken. Außerdem führen diese Transkriptionsfaktoren zur Expression Matrix abbauender Enzyme, erhöhter Zellmotilität und erhöhter Resistenz gegenüber Apoptose (Yang und Weinberg 2008). Diese, der EMT zu Grunde liegenden Vorgänge, beantworten zum Teil die oben genannte Fragestellung nach beteiligten Mechanismen in dem Prozess der Invasion und Metastasierung.

Aktueller Diskussionsgegenstand der Forschung ist die Aktivierung der Expression der oben genannten Transkriptionsfaktoren. Vermutet wird eine Wechselwirkung der malignen Tumorzellen mit ihrer Mikroumgebung samt benachbarten tumorassoziierten Stromazellen, die zu einer Transkriptionsfaktoraktivierung und somit zu einer Induktion der EMT führt (Brabletz et al. 2001; Karnoub und Weinberg 2006).

EMT wird auch als ein reversibles Phänomen beschrieben (Brabletz et al. 2001). Es wird angenommen, dass die mesenchymal transformierten Zellen nach Erreichen des Zielgewebes eine mesenchymal-epitheliale Transition (MET) durchlaufen, um sich in diesem Gewebe erfolgreich ansiedeln zu können (Hugo et al. 2007).

EMT und die reverse EMT erklären jedoch nicht die Fähigkeit der disseminierten Tumorzellen den letzten Schritt der „Invasions-Metastasierungs-Kaskade“, die Kolonisation, zu bewerkstelligen. Ein entscheidender Punkt für eine erfolgreiche Kolonisation ist unter anderem die Aktivierung der Angiogenese durch die disseminierten Tumorzellen (Hanahan und Weinberg 2011). 
Auf welche Weise die disseminierten Tumorzellen den Weg zu ihren Zielgeweben finden, wird im folgenden Kapitel eingehend erläutert.

\subsubsection{Das SDF-1/CXCR4-System}

In der Vergangenheit wurde versucht die an der Invasion und Metastasierung beteiligten Gene und Proteine ausfindig zu machen. Dabei rückten Chemokine und deren Rezeptoren als mögliche prometastatische Faktoren zunehmend in das Blickfeld der Wissenschaftler. Chemokine sind chemotaktisch wirksame Zytokine, deren physiologische Funktion unter anderem darin besteht, sowohl die Migration von Leukozyten in inflammatorisches Gewebe, als auch die Migration von hämatopoetischen Stammzellen in das Knochenmark zu bewirken. Es zeigte sich jedoch, dass Chemokine neben dieser Funktionen auch eine wichtige Rolle in der Angiogenese spielen und im Rahmen der Tumorbiologie das Tumorwachstum, die Invasion und die Metastasierung unterstützen (Rossi und Zlotnik 2000; Wang JM et al. 1998).

Ein kompliziertes Netzwerk vieler Chemokine und deren Rezeptoren, welches sich je nach Art des Tumors unterscheiden kann, scheint die Entwicklung von Primärtumoren und deren Metastasen zu beeinflussen. Dabei wurde CXCR4 (Chemokine (CXC-motif) rezeptor 4) als häufigster Chemokinrezeptor auf den Tumorzellen gefunden (Balkwill 2004).

CXCR4 ist ein Rezeptor mit sieben Transmembrandomänen. Damit erfüllt er die klassischen Kriterien eines G-Protein-assoziierten Membranproteins, dessen Effekt über eine Kaskade von second messengern übertragen wird. Codiert ist CXCR4 auf Chromosom 2 (Caruz et al. 1998; Hamm 1998). Mittlerweile sind mehr als 23 Malignome bekannt, die diesen Rezeptor überexprimieren (Balkwill 2004).

Studien ergaben, dass die CXCR4-mRNA-(messenger ribonucleic acid)-Expression in endometrialen Karzinomen, im Vergleich zum gesunden Endometrium, erhöht ist (Gelmini et al. 2009). Dies bestätigte sich auch Jahre zuvor für die CXCR4-Expression anderer gynäkologischer Malignome, wie dem Mamma- und Ovarialkarzinom (Müller et al. 2001; Hall und Korach 2003).

Es zeigte sich, dass die CXCR4-Expression positiv mit dem metastatischen Potenzial und der Differenzierung vieler unterschiedlicher Malignome korreliert (Balkwill 2004). Die Blockade des CXCR4 mit monoklonalen Antikörpern führte zu einer Hemmung der Fernmetastasierung von Endometrium- und Mammakarzinomzellen in Geweben mit hohen SDF-1-Konzentrationen im Xenograft-Maus-Modell, was die Vermutung einer Beteiligung des CXCR4 im Metastasierungsprozess erhärten konnte (Gelmini et al. 2009; Müller et al. 2001). 
SDF-1 (stromal derived factor-1; Synonym: CXCL12), der chemotaktische Ligand des CXCR4, führt durch Bindung und Aktivierung der CXCR4 exprimierenden Zelle zu einer Invasion eben dieser Zellen entlang des ligandenabhängigen Gradienten in Richtung des SDF-1 sezernierenden Gewebes. Sezerniert wird SDF-1 von Stromazellen verschiedener Gewebetypen. In Studien wurde auffällig, dass sich die Fernmetastasen vieler Malignome am häufigsten in SDF-1 sezernierenden Geweben manifestieren, wie zum Beispiel in Knochen, Lunge, Leber und lymphatischem Gewebe (Wang J et al. 2006; Burger und Peled 2009).

Viele maligne Tumorzellen selbst scheinen ebenfalls SDF-1 zu sezernieren. Versuchsergebnisse zeigen jedoch, dass diese Expression in einigen Tumoren, wie auch in dem Endometriumkarzinom, im Vergleich zum gesunden Gewebe erniedrigt ist. Ein typisches Tumor-Expressionsprofil ist demnach eine vermehrte CXCR4-Expression mit gleichzeitiger verminderter SDF-1-Expression (Gelmini et al. 2009). Auf diese Weise entsteht ein positiver SDF-1-Gradient zwischen dem Tumor und dem Rest des Körpers. Zusammenfassend zeigt eine Metastase demnach kein passives und zufälliges Auftreten, sondern ist das Ergebnis eines aktiven Migrationsprozesses (Janowski 2009).

Es lassen sich verschiedene humane SDF-1-Isoformen verzeichnen, die durch alternatives Spleißen der SDF-1-RNA entstehen. Die beiden häufigsten und am besten untersuchten Isoformen sind SDF-1 $\alpha$ und $\beta$. Darüber hinaus wurde die Existenz weiterer Spleißvarianten, wie SDF-1 $\gamma, \delta, \varepsilon$ und $\varphi$ gezeigt (Yu et al. 2006).

Die Isoformen bestehen aus drei gleichen Exons und einem, je nach Spleißvariante unterschiedlichen, vierten Exon am C-terminalen Rest (Janowski 2009). Der N-Terminus ist verantwortlich für die Interaktion mit CXCR4 (Crump et al. 1997).

Die Isoformen zeigen, trotz unterschiedlicher Gewebeverteilung, agonistische Aktivität am CXCR4 (Janowski 2009). Da die Funktionen der neu entdeckten Varianten noch nicht genau geklärt werden konnte, werden sich die folgenden Ausführungen auf SDF-1 $\alpha$ und $\beta$ beschränken.

SDF-1 $\alpha$ ist die am weitesten verbreitete Isoform in allen Organen und ist an vielen lokalen, physiologischen Prozessen, wie zum Beispiel der Organisation der Stammzellbesiedlung im Knochenmark, beteiligt (Davis et al. 2005; Weidt et al. 2007).

SDF-1 $\beta$ wird insgesamt in geringeren Mengen als SDF-1 a sezerniert und soll eine Rolle im Gefäßsystem spielen. Es stimuliert die Angiogenese und wird vor allem in stark vaskularisierten Organen wie der Leber, Milz und Niere exprimiert (Manetti et al. 2009; Yu et al. 2006).

Die Funktionen von SDF-1 $\alpha$ und $\beta$ könnten durch die unterschiedliche Prozessierung und den damit zusammenhängenden unterschiedlichen Abbauvorgang erklärt werden (De La Luz Sierra et al. 2004). SDF-1 $\alpha$ wird im Blut schnell proteolysiert, wohingegen SDF-1 $\beta$ 
resistenter gegenüber diesem blutabhängigen Abbau ist (Davis et al. 2005). Dies erhärtet die Vermutung einer Beteiligung von SDF-1 $\beta$ im Gefäßsystem.

Das SDF-1/CXCR4-System spielt jedoch nicht nur im Rahmen der Metastasierung eine Rolle, sondern beeinflusst auch die Mikroumgebung des Primärtumors. Diese wird von Fibroblasten, Endothelzellen, Zellen des Immunsystems und extrazellulärer Matrix gebildet. Gemeinsam unterstützen diese Komponenten die Struktur des Tumors, aber auch die Angiogenese und dadurch bedingt die Tumorzellproliferation (Olumi et al. 1999). Von Tumorzellen und tumorassoziierten Stromazellen sezerniertes SDF-1 stimuliert sowohl autokrin als auch parakrin die Proliferation und die Invasivität von Mammakarzinomzellen (Orimo et al. 2005).

Die Rolle des SDF-1/CXCR4-Systems in der Tumorbiologie wird in Abb. 1.1 schematisch zusammengefasst.

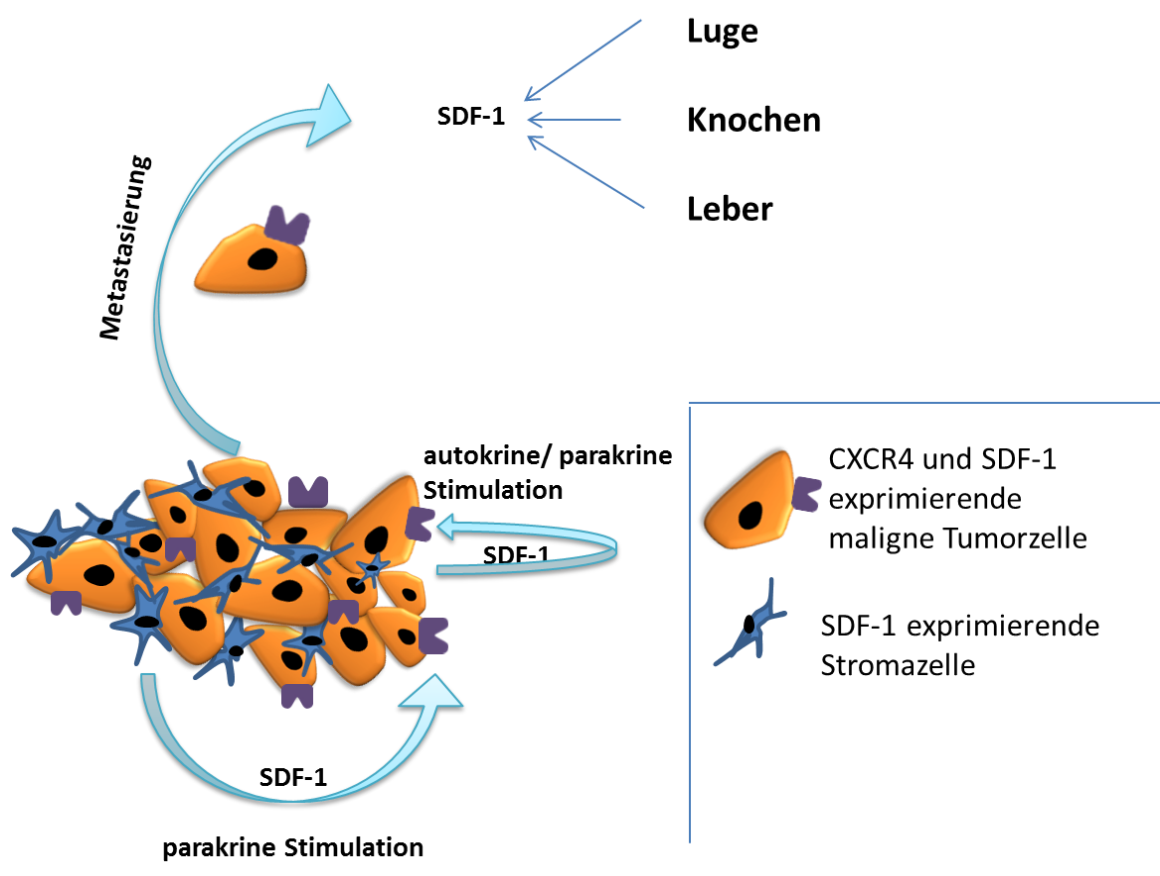

Abb. 1.1: Schematische Darstellung der Rolle des SDF-1/CXCR4-Systems in der Tumorbiologie. Rolle von SDF-1 und CXCR4 in der Interaktion von Tumorzellen und tumorassoziierten Zellen in ihrer Mikroumgebung. SDF-1/CXCR4 spielt eine Rolle im Wachstum des Primärtumors und in seiner Metastasierung. Tumorassoziierte Stromazellen (blau) exprimieren SDF-1. Dieses parakrine Signal stimuliert die Proliferation und das Überleben CXCR4-positiver Tumorzellen (orange). Viele Tumorzellen selbst sezernieren ebenfalls SDF-1 und aktivieren sich autokrin und Nachbarzellen parakrin. CXCR4 exprimierende Tumorzellen migrieren entlang eines SDF-1Gradienten zu entfernten, sezernierenden Organen und können dadurch Metastasen bilden. Modifiziert nach Domanska et al. (2013, S. 222).

\subsubsection{Lokale Invasion und Metastasierung beim Endometriumkarzinom}

Das primäre Endometriumkarzinom wächst fokal oder diffus und auch bei tiefer Myometriuminfiltration meist exophytisch. Es bevorzugt eine flächenhafte Ausdehnung und breitet sich lokal invasiv aus. Dabei sind, vor allem in fortgeschrittenen Stadien, eine 
Durchsetzung der Uteruswand und ein Einbruch in die freie Bauchhöhle oder benachbarte Organe möglich. Eine intrakanalikuläre Ausbreitung in die Zervix und in die Tuben ist ebenfalls bekannt (Stauber und Weyerstahl 2007).

Die Dissemination des Endometriumkarzinoms erfolgt meist lymphogen und erst spät hämatogen (Stauber und Weyerstahl 2007; Johann et al. 2010). Bei etwa $10 \%$ aller Betroffenen liegen, über alle Stadien gemittelt, Lymphknotenmetastasen vor. Risikofaktoren für eine lymphogene Ausbreitung sind die Infiltration von über 2/3 der Dicke des Myometriums, Gefäßeinbrüche, Metastasierung in Zervix und Adnexen, der histologische Typ und das Grading. Je höher das Grading, desto höher ist auch die Wahrscheinlichkeit einer pelvinen und/oder paraaortalen Lymphknotenmetastasierung (Johann et al. 2010; Finas et al. 2007). Bei 2/3 aller Patientinnen mit positiven Lymphknoten lassen sich diese im Becken nachweisen. Bei ungefähr $10 \%$ der Patientinnen hingegen treten positive Lymphknoten lediglich isoliert paraaortal auf (Mariani et al. 2008). Dies hängt vermutlich vom Sitz des Karzinoms im Uterus ab.

Nur 3,7\% der Endometriumkarzinome werden im FIGO-Stadium IV, also in einem metastasierten Stadium, erstdiagnostiziert (Schubert-Fritschle et al. 2007). Das Endometriumkarzinom neigt dementsprechend vergleichsweise selten und spät zu einer Ausbildung von Fernmetastasen. Meist treten sie in Form von Tumorrezidiven auf. In der Literatur finden sich, gemittelt über alle Stadien, Rezidiv- und Fernmetastasierungsraten von 11 bis $25 \%$ (Böing und Kimmig 2007; Kommission Uterus der Arbeitsgemeinschaft für Gynäkologische Onkologie 2008). Bei den Rezidiven entfallen $17 \%$ auf die Vagina, $32 \%$ auf das kleine Becken und $51 \%$ manifestieren sich als Fernmetastasen (Sartori et al. 2003). Die Fernmetastasen treten in Lunge (ca. 51\%), Leber (ca. $24 \%$ ), Knochen (ca. 17\%) und Gehirn (7\%) auf (Blecharz et al. 2011). Fortgeschrittene Endometriumkarzinome stellen demnach eine heterogene Tumorgruppe dar.

Ungefähr 70 \% der Rezidive des Endometriumkarzinoms treten in den ersten beiden Jahren nach Primärtherapie auf (Sartori et al. 2003).

\subsection{Kisspeptin}

\subsubsection{KISS1-Gen, Kisspeptine, GPR54}

Bei dem Versuch verantwortliche Gene für die scheinbar antimetastatischen Effekte des Chromosoms 6 humaner Melanomzellen zu entschlüsseln, wurde 1996 das KISS1-Gen als Metastase-Suppressor-Gen entdeckt. Das spezifische Gen mit der antimetastatischen Wirkung wurde schließlich auf Chromosom 1q32 gefunden, wobei lediglich regulatorische 
Sequenzen auf Chromosom 6 lagen. Der Verdacht einer antimetastatischen Wirkung wurde durch das Ergebnis erhärtet, dass nicht-metastatische Zellen KISS1-mRNA exprimierten, wohingegen diese Expression bei metastatischen Zellen ausblieb. Zunächst wurde ein Vorläuferpeptid mit 164 Aminosäuren als Produkt des KISS1-Gens erwartet (Lee J-H et al. 1996). Diese Vermutung konnte mit der Veröffentlichung der korrekten Sequenz von 145 Aminosäuren revidiert werden (West et al. 1998). Dieses Produkt wird Prä-Pro-Kisspeptin genannt.

Der Kisspeptin-Rezeptor GPR54 (G Protein coupled receptor 54, Synonym: KISS1R) wurde erstmals 1999, zunächst ohne bekannten Liganden, aus dem Rattengehirn isoliert. Er besteht aus 396 Aminosäuren, besitzt sieben Transmembrandomänen und zeigt mit $45 \%$ Homologie einen hohen Verwandtschaftsgrad zu der Galanin-Rezeptorfamilie. Dennoch besitzt GPR54 keine Bindungsaffinität zu dem Neuropeptid Galanin (Lee DK et al. 1999). Da der Rezeptor $G_{\mathrm{q} / 11}$-gekoppelt ist, führt eine Ligandenbindung des Rezeptors zu einer Aktivierung des Phospholipase-C-Signalweges mit folgender intrazellulären Calciumerhöhung (Kotani et al. 2001).

Der Ligand des GPR54 ist das biologisch aktive Produkt des KISS1-Gens, Kisspeptin-54 (Synonym: Metastin). Es wurde 2001 erstmals von Ohtaki et al. aus der Plazenta isoliert und beschrieben. Kisspeptine (KP) sind C-terminal amidierte Spaltprodukte des Vorläuferpeptids Prä-Pro-KP und gehören zu der Familie der Arg-Phe-(RF)-Amine. Sie sind benannt nach der Länge ihrer Aminosäurekette. KP-54 entsteht vermutlich durch Prozessierung des KP-145 mit Hilfe von Furin- oder Prohormonkonvertasen. Die kürzeren Kisspeptine, KP-14 und $\mathrm{KP}-13$, zeigen in vitro eine ähnliche biologische Aktivität und Affinität zum Rezeptor wie KP-54 (Kotani et al. 2001). KP-10 ist das kürzeste Peptid, das den Rezeptor aktivieren kann. Im Vergleich zu den anderen biologisch aktiven Kisspeptinen besitzt es die höchste Affinität und Potenz zum GPR54 mit den gleichen Bindungs- und Funktionseigenschaften (Ohtaki et al. 2001; Muir et al. 2001).

Kontrovers diskutiert wird allerdings noch, welche dieser Kisspeptin-Isoformen tatsächlich endogen wirksam sind und ob KP-14, KP-13 und KP-10 lediglich Abbauprodukte des instabilen KP-54 sind (Kotani et al. 2001). Dafür spricht, dass sowohl KP-145 als auch KP-54 eine Aminosäuresequenz aufweisen, die auf eine rasche Ubiquitinierung mit anschließendem Abbau im Proteasomen hindeutet. Dies lässt eine sehr geringe Halbwertszeit der Peptide vermuten (Harms et al. 2003).

Die Expression der Isoformen des Kisspeptins und dessen Rezeptor wurden in vielen Geweben, wie zum Beispiel Hypophyse, Pankreas, Testis, Leber und Dünndarm nachgewiesen (Muir et al. 2001; Lee, J-H et al. 1996; Ohtaki et al. 2001). In der humanen Plazenta jedoch wurde sowohl die größte Kisspeptin-Expression als auch die größte biologische Aktivität des Rezeptors gezeigt (Kotani et al. 2001). 


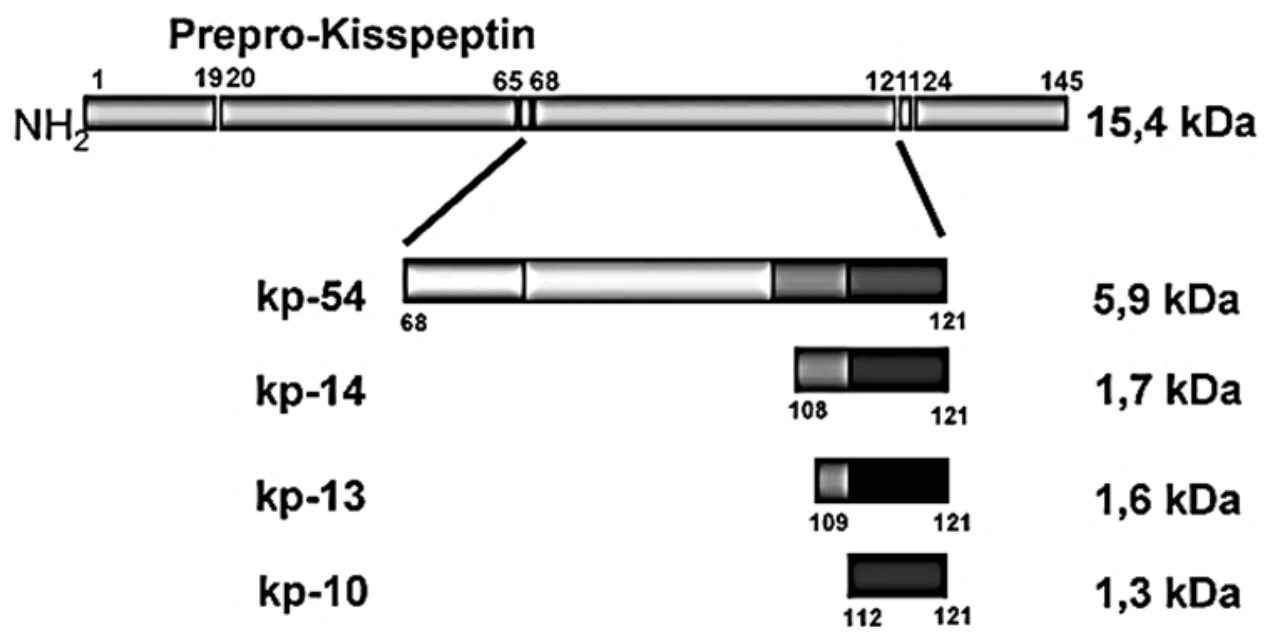

Abb. 1.2: Struktur des Prä-Pro-Kisspeptin (kodiert durch das KISS1-Gen) und seinen Peptid-Produkten. Die proteolytische Prozessierung von Prä-Pro-KP generiert KP-54. Durch weitere Spaltung des KP-54 entstehen Kisspeptine mit niedrigerem Molekulargewicht: KP-14, Kp-13 und KP-10. Modifiziert nach Castaño et al. (2009, S.11).

Tab. 1.3: Nomenklatur für Kisspeptin und seinen Rezeptor (modifiziert nach Kirby et al. 2010, S. 567).

\begin{tabular}{llll}
\hline Kisspeptin & Spezies & Gen & Proteine \\
\hline Rezeptor & Mensch & KISS1R & Kisspeptin Rezeptor \\
& nicht-menschlich & Kiss1r & Kisspeptin Rezeptor \\
\multirow{2}{*}{ Peptid } & Mensch & KISS1 & Kisspeptin/KP-54/ KP-14/KP-13/KP-10 \\
& nicht-menschlich & Kiss1 & Kisspeptin/KP-54/KP-14/KP-13/KP-10 \\
\hline
\end{tabular}

\subsubsection{Kisspeptine in der Tumorbiologie}

Lee J-H et al. (1996) entdeckten das KISS1-Gen als Metastase-Suppressor-Gen humaner Melanomzellen. Diese Arbeitsgruppe zeigte nicht nur, dass die KISS1-mRNA-Expression in metastasierten Zellen signifikant geringer ist als in Zellen des Primärtumors, sondern auch, dass transfizierte Zellen ein geringeres metastatisches Potenzial aufweisen (Lee $\mathrm{J}-\mathrm{H}$ et al. 1996; Lee J-H und Welch 1997a). Studien zeigten, dass auch Mammakarzinomzellen ähnliche Expressionsmuster des KISS1-Gens aufweisen und dass Transfektion der Zellen mit dem KISS1-Gen die Fähigkeit zur Metastasierung stark verringert (Lee J-H und Welch 1997b).

Jiang et al. (2005) verglichen die KISS1-mRNA-Expression von Endometriumkarzinomen mit gesundem Endometriumgewebe, wobei eine signifikant geringere KISS1-mRNA-Expression in Endometriumkarzinomgewebe nachweisbar war. Außerdem ging aus dieser Untersuchung hervor, dass die KISS1-mRNA-Expression des Tumors mit dem FIGO-Stadium, der Invasion ins Myometrium und der Lymphknotenmetastasierung korreliert. Die GPR54-mRNAExpression zeigte hingegen keinen signifikanten Unterschied und keine Korrelation. 
Viele weitere maligne Tumore wurden auf diese Fragestellung untersucht und die meisten Berichte assoziierten einen Funktionsverlust des KISS1-Gens mit einer schlechteren Prognose für die Patienten.

Die Metastasen supprimierende Wirkung des KISS1-Gens und seines Produktes Kisspeptin könnte durch einen Effekt auf die Invasivität von Tumorzellen, die den Kisspeptin-Rezeptor GPR54 exprimieren, erklärt werden. Olbrich et al. belegten 2010, dass Kisspeptin-10 eine dosisabhängige Inhibition der Invasionsfähigkeit GPR54-positiver Mammakarzinomzellen bewirkt. Dabei soll die antiinvasive Wirkung des Kisspeptin-10 in einer Expressionsreduktion des prometastatischen SDF-1/CXCR4-System begründet sein. Außerdem wurde der SDF-1induzierte CXCR4-vermittelte Signalweg herabreguliert. Eine weitere Arbeitsgruppe publizierte eine Reduktion der Invasivität GPR54-positiver humaner Endometriumkarzinomzellen nach einer Kisspeptin-10-Behandlung (Kang et al. 2011).

Die GPR54-Aktivierung durch Kisspeptin verursacht zudem eine Phosphorylierung der focal adhesion kinase und Paxillin, was zur Bildung von fokalen Adhäsionen und Stressfasern führt (Kotani et al. 2001; Ohtaki et al. 2001). Dies ist vereinbar mit der Rolle des Kisspeptins bei der Hemmung der Chemotaxis. Der Kisspeptin-Rezeptorweg scheint außerdem die Fähigkeit der Signalisierung über den CXCR4 zu reduzieren, indem die SDF-1-induzierte Phosphorylierung der Akt-Proteinkinase inhibiert wird. Dadurch wird die prometastatische Aktivität des SDF-1 reduziert (Navenot et al. 2005).

Neue Daten zeigen darüber hinaus eine Beteiligung von Kisspeptin an der Apoptose (Navenot et al. 2009a), möglicherweise durch Aktivierung von Rho und der Rho-assoziierten Kinase (Navenot et al. 2009b).

Ein Effekt der Kisspeptine auf die Proliferation von Tumorzellen ist ebenfalls Diskussionsgegenstand der Forschung. Zum einen wurde eine Inhibition der Proliferation von Mammakarzinomzellen und CHO-(Chinese Hamster Ovary)-Zellen (Becker et al. 2005; Kotani et al. 2001) gezeigt, zum anderen wurde eine Proliferationshemmung von Endometrium- und Mammakarzinomzellen abgestritten (Kang et al. 2011; Ziegler et al. 2013). Ein antiproliferativer Effekt des Kisspeptins scheint tumorzellspezifisch zu sein.

\subsubsection{Physiologische Funktionen des Kisspeptins und seines Rezeptors}

Obwohl anfänglich das Interesse an dem Kisspeptin-System auf die tumorbiologischen Funktionen beschränkt war, zeigten weitere Untersuchungen eine Beteiligung des Kisspeptin/GPR54-Systems an physiologischen Prozessen. 2003 fanden zwei unabhängige Arbeitsgruppen heraus, dass viele Patienten, die unter idiopathischen hypogonadotropen Hypogonadismus litten, eine loss-of-function-Mutation im GPR54 aufwiesen (Seminara et al. 2003; de Roux et al. 2003). Anschließende Berichte lassen die Schlussfolgerung zu, dass für 
die neuroendokrine Regulation der Reproduktion ein funktionierendes Kisspeptin/GPR54System nötig ist. Kisspeptine sollen eine $\mathrm{GnRH}$-(Gonadotropin-Releasing Hormon)-Sekretion aktivieren und somit die Ausschüttung von LH (luteinisierendes Hormon) und FSH (follikelstimulierendes Hormon) stimulieren können (Seminara et al. 2003).

Kisspeptine haben nicht nur direkten Einfluss auf die Hypothalamus-Hypophysen-GonadenAchse, sondern sind nach Studien mit Tierversuchen auch in der Lage photoperiodische Signale sowie den Ernährungsstatus in die Regulation der GnRH- und GonadotropinSekretion und somit in den Reproduktionszyklus zu integrieren (Castellano et al. 2005).

Den Kisspeptinen wird auch ein hemmender Einfluss auf die Invasion der Trophoblasten zugesprochen. Dadurch erklärt sich die bereits erwähnte hohe GPR54-Expressionsrate im Plazentagewebe. Trophoblasten durchlaufen während der Plazentaentwicklung einen Prozess, ähnlich dem der Invasion maligner Tumorzellen. Ein Unterschied ist jedoch, dass die Trophoblasten-Invasion kontrolliert abläuft (Bilban et al. 2004). Untersuchungen an Schwangeren ergaben eine hohe Konzentration des zirkulierenden Kisspeptins, die vom ersten bis zum dritten Trimenon um das 1000-fache anstieg und sich fünf Tage postpartum auf die Ausgangswerte von vor der Schwangerschaft reduzierte (Horikoshi et al. 2003). Weitere Analysen zeigten, dass im Vergleich zur späten, reifen Plazenta im frühen Plazentagewebe ein höherer GPR54-Genexpressionslevel erreicht wird. Dies wird durch eine höhere und aggressivere Invasionsfähigkeit der Trophoblasten, die eine Gegenregulation benötigen, erklärt (Janneau et al. 2002).

Außerdem wird über einen möglichen Einfluss des Kisspeptin/GPR54-Systems bei der Insulinsekretion humaner Inselzellen des Pankreas diskutiert (Hauge-Evans et al. 2006). Weiterhin gibt es Hinweise auf eine vasokonstriktorische Funktion der Kisspeptine (Mead et al. 2007).

\subsection{Fragestellung und Zielsetzung}

Endometriumkarzinome sind Malignome, die vor allem lokal invasiv wachsen. Die Diagnose einer lokal fortgeschrittenen Invasion macht eine große operative Therapie meist unumgänglich, wodurch die Morbidität der Patientinnen stark ansteigen kann. Das Endometriumkarzinom neigt vergleichsweise selten zur Ausbildung von Metastasen. Diese sind jedoch insofern von großer Bedeutung, als dass die Mortalität der Patientinnen drastisch zunimmt.

Die vorliegende Arbeit beschäftigt sich mit der Frage, in welchem Zusammenhang die antimetastatisch geltenden Kisspeptine und das prometastatische SDF-1 mit dem Invasionsverhalten humaner Endometriumkarzinomzellen in vitro stehen. 
Im Fokus der Arbeit steht die Untersuchung, ob das kürzeste Peptid des MetastaseSuppressor-Gens KISS1, das Kisspeptin-10, in der Lage ist, die Invasionsfähigkeit humaner Endometriumkarzinomzellen zu inhibieren.

Dazu muss anfänglich der Nachweis erbracht werden, ob die zu untersuchenden Zellen positiv für den Kisspeptin-Rezeptor GPR54 sind.

Anschließend werden mögliche Unterschiede in dem Invasionsverhalten der beiden Endometriumkarzinomzellinien herausgearbeitet. Dazu wird zum einen die unbeeinflusste Invasionsfähigkeit untersucht. Zum anderen wird ein in-vitro-Modell, das sogenannte Kokultur-System, verwendet, welches eine gerichtete Invasion der Endometriumkarzinomzellen induzieren soll. Zu diesem Zweck werden die Endometriumkarzinomzellen gemeinsam mit humanen Osteoblasten-ähnlichen Zellen „kokultiviert“. Der Gedanke hinter dem Kokultur-System ist die Annahme, dass Osteoblastenähnliche Zellen chemotaktische und prometastatische Faktoren exprimieren und sezernieren, welche die Invasionsfähigkeit der Endometriumkarzinomzellen in Richtung der Osteoblasten-ähnlichen Zellen steigern. Dadurch könnten Hinweise und Rückschlüsse auf das invasive und metastatische Verhalten der Endometriumkarzinomzellen in vivo gewonnen werden. Es soll jedoch kein realitätsidentisches Verhalten simuliert werden, denn Endometriumkarzinome metastasieren eher spät und selten in die Knochen. Das KokulturSystem stellt vielmehr ein Modell dar, das mit Hilfe der Osteoblasten-ähnlichen Zellen die entsprechenden invasionsfördernden Faktoren liefern soll.

Um potenzielle prometastatische Faktoren zu entschlüsseln, die eine Invasionssteigerung der Endometriumkarzinomzellen verursachen, wird der Einfluss von SDF-1 als Chemokin auf diese Zellen analysiert.

Im nächsten Schritt werden die zu untersuchenden Zellen im Kokultur-Invasionsassay und auch im SDF-1-Invasionsassay mit Kisspeptin-10 behandelt. Dadurch soll ein möglicher antiinvasiver Effekt des Kisspeptins sowie die dafür notwendige Konzentration überprüft werden.

Um weitere Funktionen des Kisspeptin-10 in der Tumorbiologie herauszufiltern, wird zusätzlich sein Einfluss auf die Proliferation der Endometriumkarzinomzellen untersucht.

Eine Analyse der KISS1-Expression beider Endometriumkarzinomzelllinien soll die Interpretation ihres Invasionsverhaltens unterstützen.

Danach soll ein möglicher Mechanismus des invasions- und proliferationshemmenden Effekts des Kisspeptin-10 identifiziert und überprüft werden. Dabei wird die Expression der prometastatischen Faktoren SDF-1 und CXCR4 sowohl auf molekularbiologischer als auch auf proteinbiochemischer Ebene in den Endometriumkarzinom- und Osteoblasten-ähnlichen Zellen untersucht. 


\section{Material und Methoden}

\subsection{Material}

\subsubsection{Geräte}

\section{Geräte}

Analysenwaage BP161 Sartorius

Autoklav, $2540 \mathrm{EL}$

Biofuge pico

Brutschrank, Modell 3121 S/N28439532

Elektrophoresekammer, DNA

Elektrophoresekammer, Maxicell® Primo EC 340

Labofuge 400R

Laborzentrifuge Sigma 3K30

Mini-ProteanTM III Electrophoresis Cell Systems

Mikroskop Axiovert 25

Mikroskop BH-2

Mikroskop IX51

Mikrowaage, elektronisch, M2P

pH-Meter CG22

Power Supply, Pac Basic ${ }^{\mathrm{TM}}$

Power Supply, Standard Power Pack P25

Schüttler Titramax 1000

Spektralphotometer

Sterilwerkbank, LaminAir® LFM $2472 S$

Synergy ${ }^{\text {TM }}$ HT Multi-Detektions-Reader

Thermocycler T3000

Thermomixer compact

Ultrazentrifuge $3 \mathrm{~K} 30$

UV-Transilluminator, BioDocAnalyze

Wasserbad 1083

X-Ray Film Prozessor, SRS-101A

\section{Hersteller}

Sartorius

Tuttnauer

Heraeus Holding

Forma Scientific

OWL Seperation Systems

E-C Apparatus Corporation

Heraeus Holding

Sigma Laborzentrifugen $\mathrm{GmbH}$

Bio-Rad

Zeiss

Olympus

Olympus

Sartorius

Schott Geräte

Bio-Rad

Biometra

Heidolph

Eppendorf

Heraeus Holding

BioTek Instruments, Inc.

Biometra

Eppendorf

Sigma

Biometra

GFL

Konica 


\subsubsection{Verbrauchsmaterialien}

Die Verbrauchsmaterialien (Einmalartikel), die in dieser Arbeit verwendet wurden, haben folgende Firmen in ihrem Sortiment: Eppendorf, Greiner bio-one, WU Mainz, Millipore, Nunc und Sarstedt.

\subsubsection{Chemikalien}

Die in dieser Arbeit verwendeten Chemikalien wurden von folgenden Firmen bezogen: Aventis, Merck, PAA, Roth und Sigma-Aldrich.

\subsubsection{Kisspeptin-10 und SDF-1}

Kisspeptin-10 (Sequenz: Tyr-Asn-Trp-Asn-Ser-Phe-Gly-Leu-Arg-Phe) wurde von Peptide Specialty Laboratories, Heidelberg synthetisiert. Die Anlieferung erfolgte als Lyophilisat, aus dem mit sterilem $\mathrm{H}_{2} \mathrm{O}$ eine Stammlösung mit einer Konzentration von $1 \times 10^{-2} \mathrm{M}$ hergestellt wurde. Zum Lösen des Lyophilisats wurde DMSO verwendet.

SDF-1 $\alpha$ und SDF-1 $\beta$ wurden von der Firma Sigma Aldrich bezogen. Es wurde als Lyophilisat geliefert, welches in $1 \mathrm{ml}$ sterilem $\mathrm{H}_{2} \mathrm{O}$ gelöst wurde, um eine Stammlösung mit einer Konzentration von $10 \mu \mathrm{g} / \mathrm{ml}$ herzustellen.

\subsubsection{Matrigel $^{\mathrm{TM}}$ Basalmembranmatrix}

Matrigel $^{\mathrm{TM}}$ Basalmembranmatrix (BD Biosience) ist eine gelöste Basalmembranvorbereitung, die aus Engelbreth-Holm-Swarm-Maus-Sarkom extrahiert wurde.

\subsubsection{Puffer, Lösungen und weitere Substanzen}

\section{Puffer und Lösungen}

Anodenpuffer

Anodenpuffer, konzentriert

Antikörper-Stripping-Puffer

Blockierungsreagenz

\section{Komponenten; Firma}

$1,82 \mathrm{~g}$ Tris, $100 \mathrm{ml} 20 \%$ Methanol, ad $500 \mathrm{ml}$ $\mathrm{dd}_{2} \mathrm{O}$ (doppelt destilliertes $\mathrm{H} 2 \mathrm{O}$ ), $\mathrm{pH} 10,4$ $18,2 \mathrm{~g}$ Tris, $100 \mathrm{ml} 20 \%$ Methanol, ad $500 \mathrm{ml}$ ddH2O, pH 10,4

Uptima

TBST + $5 \%(w / v)$ Magermilchpulver 
19 | Material und Methoden

CellLytic ${ }^{\mathrm{TM} M}$ Cell Lysis Reagent
Ethidiumbromid-Bad
Hämalaun-Lösung, Mayers
Kathodenpuffer

NuPAGE® LDS Sample Buffer (2x)

PBS

SDS-Elektrophoresepuffer (10x)

$\operatorname{TBE}(0,5 x)$

TBS (10x)

TBST

Transferpuffer

\section{Inhibitoren}

Protease-Inhibitor

RNasin $\AA$ plus RNase Inhibitor

\section{Enzyme}

DNAse I recombinant, RNase-frei KAPA2G ${ }^{\text {TM }}$ Fast 2x ReadyMix with Dye SuperScript ${ }^{\mathrm{TM}}$ II Reverse Transcriptase Trypsin/EDTA

\section{Größenstandard-Marker}

100 bp DNA-Leiter

PeqGOLD Protein-Marker V
Sigma-Aldrich

0,007\% (v/v) Ethidiumbromid

Merck

2,62 g 6-Amino-Hexansäure, $1,51 \mathrm{~g}$ Tris, $100 \mathrm{ml}$

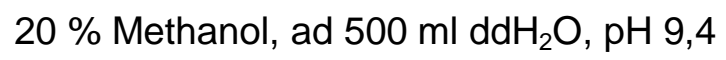

Invitrogen

$140 \mathrm{mM} \mathrm{NaCl}, 2,7 \mathrm{mM} \mathrm{KCl}, 8,6 \mathrm{mM} \mathrm{Na}_{2} \mathrm{HPO}_{4}$, $1,5 \mathrm{mM} \mathrm{KH}_{2} \mathrm{HPO}_{4}, \mathrm{pH} 7,4$

$25 \mathrm{mM}$ Tris, $192 \mathrm{mM}$ Glycin, 0,1\% (w/v) SDS

90 mM Tris, 90 mM Borsäure, 1 mM EDTA, pH 8

1,5 M NaCl, 0,5 M Tris, pH 7,5

TBS + 0,1\%(v/v) Tween

$48 \mathrm{mM}$ Tris, $39 \mathrm{mM}$ Glycin, 0,0375\% (w/v) SDS, $20 \%(v / v)$ Methanol

\section{Firma}

Sigma Aldrich

Promega

\section{Firma}

Roche

Peqlab

Invitrogen

PAA

\section{Firma}

Invitrogen

Peqlab

\subsubsection{Kultur- und Einfriermedien}

Die Medien und deren Zusätze wurden von den Firmen Biochrom, Invitrogen, PAA und Sigma-Aldrich bezogen.

Für die jeweiligen Zelllinien wurden verschiedene Komplettmedien als Nährlösung in der Zellkultur verwendet (Nährmedium). 
Das fertig bezogene MEM-Earl (Minimum Essential Medium) w Phenolrot wurde für die Kultivierung der Endometriumkarzinomzellen verwendet.

Die Osteoblasten-ähnlichen Zellen hingegen wurden in dem fertig bezogenen DMEM (Dulbecco's Modified Eagle's Medium) w Phenolrot kultiviert.

Für die in-vitro-Versuche wurde DMEM w/o Phenolrot verwendet (Versuchsmedium). So konnten Farbumschläge während des Versuchs detektiert werden.

Für die Isolation des sezernierten SDF-1 wurde das Versuchsmedium ohne FCS (fetales Kälberserum) verwendet.

Den Medien wurden die folgenden Zusätze hinzugefügt (Tab. 2.1).

Das Einfriermedium wurde aus MEM-Earl w Phenolrot, $20 \%$ FCS und $5 \%$ DMSO (Dimethylsulfoxid) hergestellt.

Tab. 2.1: Kulturmedien - Funktion, Zelllinien und Zusätze (P/S: Penicillin/ Streptomycin, L-GIn: L-Glutamin, CD-FCS: charcoal dextran-treated FCS)

\begin{tabular}{|c|c|c|c|}
\hline & MEM-Earl w Phenolrot & DMEM w Phenolrot & DMEM w/o Phenolrot \\
\hline Funktion & Nährmedium & Nährmedium & Versuchsmedium \\
\hline \multirow[t]{3}{*}{ Zelllinie } & Ishikawa & MG-63 & Ishikawa \\
\hline & HEC1a & & HEC1a \\
\hline & & & MG-63 \\
\hline \multirow[t]{5}{*}{ Zusätze } & $10 \%(v / v)$ FCS & $10 \%(v / v)$ FCS & $10 \%(v / v)$ CD-FCS \\
\hline & $1 \%(v / v) P / S$ & $1 \%(v / v) P / S$ & $1 \%(v / v) P / S$ \\
\hline & $0,1 \%$ Insulin & - & - \\
\hline & $0,1 \%(v / v)$ Transferrin & - & - \\
\hline & - & $1 \%(v / v)$ L-Gln & $1 \%(v / v)$ L-Gln \\
\hline
\end{tabular}

\subsubsection{Zelllinien}

Für die in-vitro-Versuche wurden folgende etablierte Zelllinien von der ATCC (American Type Culture Collection) bezogen.

Tab. 2.2: verwendete Zelllinien

\begin{tabular}{llll}
\hline Zelllinie & Herkunft & Histologie & Referenz \\
\hline Ishikawa & Primärtumor & $\begin{array}{l}\text { Endometriales Adenokarzinom, gut } \\
\text { differenziert }\end{array}$ & Nishida et al. 1985 \\
HEC-1a & Primärtumor & $\begin{array}{l}\text { Endometriales Adenokarzinom, } \\
\text { schwach differenziert }\end{array}$ & Kuramoto et al. 1972 \\
MG-63 & Primärtumor & Osteoblasten-ähnliches Osteosarkom & Billiau et al. 1977 \\
\hline
\end{tabular}




\subsubsection{Mono- und Oligonukleotide}

Die Desoxynukleosid-Triphosphate (Synonym: Mononukleotid; kurz: dNTPs (dATP, dCTP, dTDP, dGDP)) wurden von der Firma Roche bezogen und für die Reverse Transkription (Kapitel 2.2.2.3) benötigt.

Die Oligonukleotide wurden von der Firma MWG Biotech AG synthetisiert und als Senseund Antisense-Primer im Rahmen der Polymerase-Ketten-Reaktion (Kapitel 2.2.2.4) verwendet.

CXCR4: $\quad$ for 5 ‘ - AGC TGT TGG TGA AAA GGT CTA TG - 3‘

rev 5' - GCG CTT CTG GTG GCC CTT GGA GTG TG - 3'

GPR54: for 5' - CGA CTT CAT GTG CAA GTT CGT C - 3’

rev 5' - CAC ACT CAT GGC GGT CAG AG - 3'

KISS1: $\quad$ for $5^{\prime}$ - ACC TGG CTC TTC TCA CCA AG - $3^{\prime}$

rev 5' - TAG CAG CTG GCT TCC TCT C - 3

L7: $\quad$ for 5' - AGA TGT ACA GAA CTC AAA TTC - 3'

rev 5' - ATT TAC CAA GAG ATC GAG CAA - 3'

SDF-1: for 5' - CCG CGC TCT GCC TCA GCG ACG GGA AG - 3'

rev 5' - CTT GTT TAA AGC TTT CTC CAG GTA CT - 3'

\subsubsection{Antikörper}

Die in dieser Arbeit verwendeten Antikörper wurden nach modifizierten Angaben des Herstellers eingesetzt.

Tab. 2.3: Primärantikörper

\begin{tabular}{lll}
\hline Primärantikörper & Herkunft; Verdünnung & Referenz \\
\hline Anti-Aktin & Kaninchen, monoklonal; 1:1000 & Epitomics \\
Anti-CXCR4 & Kaninchen, polyklonal; 1:500 & Abcam \\
Anti-GPR54 & Kaninchen, polyklonal; 1:4000 & Acris Antibodies \\
Anti-SDF-1 & Kaninchen, polyklonal; 1:2000 & Abcam \\
\hline
\end{tabular}

Tab. 2.4: Sekundärantikörper

\begin{tabular}{lll}
\hline Sekundärantikörper & Herkunft; Verdünnung & Referenz \\
\hline Kaninchen IgG horseradish & Donkey; 1:20.000-1:50.000 & GE Healthcare \\
Peroxidase-gekoppelt & & \\
\hline
\end{tabular}




\subsubsection{Kommerzielle Reaktionssysteme}

Tab. 2.5: Kommerzielle Reaktionssysteme

\begin{tabular}{ll}
\hline Reaktionssystem/ Kit & Firma \\
\hline AEC + High Sensitivity Substrate Chromogen-Lösung & Dako \\
$\mathrm{dT}_{15}$-Primer $\left[1,1 \times 10^{-5} \mathrm{M}\right]$ als Lyophilisat & Roche \\
$\mathrm{ECL}_{\text {Immobilon }}{ }^{\mathrm{TM}}$ Western & Millipore \\
Histostain® Bulk Kit & Invitrogen \\
Qproteome ${ }^{\circledR}$ Cell Compartment Kit & Qiagen \\
RNeasy® Mini Kit & Qiagen \\
\hline
\end{tabular}

\subsubsection{Software}

Tab. 2.6: verwendete Software

\begin{tabular}{ll}
\hline Software & Firma \\
\hline Adobe Photoshop 7.0 & Adobe Systems \\
Axio Vision 3.1 & Carl Zeiss Vision GmbH \\
Bio Doc Analyze 2.1 & Software Biometra \\
GEN5 & BioTek Instruments, Inc. \\
GraphPad Prism ${ }^{\circledR}$ (Version 5.00) & GraphPad Software, Inc. \\
Kodak Digital Science 1D $_{\text {Microsoft }}^{\circledR}$ Office 2010 & Eastman Kodak Company \\
Zotero & Microsoft Corporation \\
\hline
\end{tabular}

\subsection{Methoden}

\subsubsection{Zellkultur}

\subsubsection{Kultivierung und Passagieren der Zellen}

Die verwendeten Zelllinien wurden in Zellkulturflaschen bei $37^{\circ} \mathrm{C}$ in einer wassergesättigten Atmosphäre von $95 \%$ Luft mit $5 \%$ Kohlendioxid kultiviert. 
Die Zellkulturflaschen hatten eine Bodenfläche von $75 \mathrm{~cm}^{2}$ und $175 \mathrm{~cm}^{2}$. Im Folgenden werden die Volumina angegeben, die der $75 \mathrm{~cm}^{2}$ Zellkulturflasche entsprechen. Die Volumina für die $175 \mathrm{~cm}^{2}$ Flaschen werden in Klammern aufgeführt.

Die Zellkulturflaschen wurden mit $10 \mathrm{ml}(25 \mathrm{ml})$ des Nährmediums gefüllt. Das Medium wurde alle 2-4 d erneuert. Hatten die Zellen eine Konfluenz von 70-90 \% erreicht, wurden sie passagiert. Hierfür wurden die Zellen, nach Entfernung des Nährmediums, zunächst 5 min mit $10 \mathrm{ml}(25 \mathrm{ml})$ PBS gewaschen. Das Trypsin/EDTA wurde währenddessen bereits auf $37^{\circ} \mathrm{C}$ aufgewärmt, da dies die optimale Temperatur der Trypsinwirkung ist. Anschließend wurden $3 \mathrm{ml}(7,5 \mathrm{ml})$ Trypsin/EDTA in die Kulturflasche gegeben, nachdem das PBS abgenommen wurde. Die Zellen wurden nun im Brutschrank 10-15 min inkubiert, bis die adhärenten Zellen vom Flaschenboden dissoziierten. Nach dieser Zeit wurde durch Serumzusatz eine sofortige Inaktivierung des Trypsins und eine Bindung des zytotoxischen EDTAs erreicht. Dafür wurde der Flascheninhalt mit Nährmedium auf $10 \mathrm{ml}$ (25 ml) aufgefüllt. Diese Zellsuspension wurde dann mit Hilfe einer Pipette in ein $15 \mathrm{ml}$ Reagenzröhrchen umgefült und bei $400 \mathrm{~g}$ zentrifugiert. Nach der Zentrifugation wurde der Überstand verworfen, sodass nur das herunterzentrifugierte Zellpellet in dem Reagenzröhrchen verblieb.

Je nachdem, ob die Zellen lediglich passagiert wurden oder für Zellversuche weiter zur Verfügung stehen sollten, unterschied sich das weitere Vorgehen.

Für ein reines Passagieren der Zellen wurde das Zellpellet in $1 \mathrm{ml}$ Nährmedium resuspendiert. Daraufhin wurde diese Zellsuspension mit dem Nährmedium auf $10 \mathrm{ml}(25 \mathrm{ml})$ aufgefüllt. Je nach gewünschter Zelldichte wurden nun 0,5-4 ml der neuen Zellsuspension in die alte Zellkulturflasche gegeben. Auch dieses Volumen wurde innerhalb der Zellkulturflasche wieder mit Nährmedium auf $10 \mathrm{ml}(25 \mathrm{ml})$ aufgefüllt. Die Zellkulturflasche wurde im Brutschrank weiter kultiviert. Nach fünf bis zehn Passagen wurde die Zellkulturflasche nach dem Passagiervorgang verworfen und ersetzt.

Wurden die Zellen für einen Zellversuch benötigt, so wurde das Zellpellet in $1 \mathrm{ml}$ Versuchsmedium resuspendiert. Daraufhin wurde die Zellsuspension mit diesem Medium auf $10 \mathrm{ml}$ aufgefüllt. Nun wurden $10 \mu \mathrm{l}$ dieser Zellsuspension in eine Neubauer-Zählkammer gegeben, um die Zellzahl der Suspension zu ermittelt (Kapitel 2.2.1.2). Mit dieser Suspension wurde weitergearbeitet. Der verbliebene Rest wurde erneut zentrifugiert. Nach Verwerfen des Überstandes wurde das Zellpellet in Nährmedium resuspendiert und wie oben beschrieben weiter verfahren.

Alle Arbeiten mit den Zellkulturen wurden an Sterilwerkbänken durchgeführt. 


\subsubsection{Bestimmung der Zellzahl}

Bevor eine Zellsuspension nach dem Passagieren weitere Verwendung in Versuchen fand, wurde ihre Zellzahl mittels Hämocytometer (Neubauer-Zählkammer) bestimmt. $10 \mu \mathrm{l}$ Zellsuspension wurden dafür auf eine Neubauer-Zählkammer aufgetragen.

Die Neubauer-Zählkammer besteht aus neun Quadraten, wobei jede Fläche eine Größe von $1 \mathrm{~mm}^{2}$ besitzt. Bei einer Tiefe von $0,1 \mathrm{~mm}$ beträgt das Volumen $0,1 \mu \mathrm{l}$.

Es wurden vier große Quadrate ausgezählt. Von diesen Ergebnissen wurde dann der Mittelwert errechnet.

Der Mittelwert der gezählten Zellen der vier großen Quadrate wurde mit dem Faktor $10^{4}$ multipliziert. Dies ergab die Zellzahl pro ml. Die Gesamtzellzahl ergab sich aus dem Volumen der Zellsuspension multipliziert mit der Zellzahl pro ml:

$$
\text { Konzentration }\left[\frac{\text { Zellen }}{m l}\right]=\frac{\text { Zellzahl }}{4} \times 10^{4}
$$

\subsubsection{Behandlung der Zellen}

Die in-vitro-Versuche wurden mit Kisspeptin-10-Lösungen unterschiedlicher Konzentration zu unterschiedlichen Zeitpunkten behandelt. Die angegebenen Konzentrationen wurden in einer Verdünnungsreihe mit sterilem $\mathrm{H}_{2} \mathrm{O}$ hergestellt.

Zudem wurde in dem SDF-1-Invasionsassay das Versuchsmedium mit zwei SDF-1Isoformen unterschiedlicher Konzentration als Lockmittel versetzt. Die Konzentrationen wurden ebenfalls in einer Verdünnungsreihe mit sterilem $\mathrm{H}_{2} \mathrm{O}$ hergestellt.

\section{Proliferationsassay:}

KP-10 [M]: $1 \times 10^{-5}, 1 \times 10^{-7}, 1 \times 10^{-9}, 1 \times 10^{-11}, 1 \times 10^{-13}$

Behandlungszeitpunkte $[h]: t_{0}, t_{12}, t_{24}, t_{36}, t_{48}, t_{60}, t_{72}, t_{84}, t_{96}, t_{108}, t_{120}, t_{132}, t_{144}, t_{156}$ Versuchsendpunkt $[\mathrm{h}]: \mathrm{t}_{72}$ und $\mathrm{t}_{168}$

Kokultur-Invasionsassay (mikroskopische Auswertung):

KP-10 [M], Ishikawa: $1 \times 10^{-6}, 1 \times 10^{-7}, 1 \times 10^{-9}, 1 \times 10^{-11}, 1 \times 10^{-12}, 1 \times 10^{-13}, 1 \times 10^{-14}, 1 \times 10^{-15}$

KP-10 [M], HEC-1a: $1 \times 10^{-7}, 1 \times 10^{-9}, 1 \times 10^{-11}, 1 \times 10^{-12}, 1 \times 10^{-13}, 1 \times 10^{-14}$

Behandlungszeitpunkte $[h]: t_{0}, t_{12}, t_{24}, t_{36}, t_{48}, t_{60}, t_{72}, t_{84}$

Versuchsendpunkt [h]: t96 $_{9}$ 
SDF-1-Invasionsassay (mikroskopische Auswertung):

SDF-1 $\alpha$ [ng/ml]: 50, 100

SDF-1 $\beta[\mathrm{ng} / \mathrm{ml}]: 50,100$

SDF-1 $\alpha / \beta$ [ng/ml]: 50 (je $25 \mathrm{~g} / \mathrm{ml}$ SDF-1 $\alpha$ und $\beta$ ), 100 (je $50 \mathrm{ng} / \mathrm{ml}$ SDF- $1 \alpha$ und $\beta$ )

Behandlungszeitpunkte $[\mathrm{h}]: \mathrm{t}_{0}$

Versuchsendpunkt [h]: t96

KP-10 [M], Ishikawa: 1x10-13

KP-10 [M], HEC-1a: $1 \times 10^{-11}$

Behandlungszeitpunkte $[h]: t_{0}, t_{12}, t_{24}, t_{36}, t_{48}, t_{60}, t_{72}, t_{84}$

Versuchsendpunkt [h]: t96 $_{96}$

Kokultur-Invasionsassay (RNA-Gewinnung):

KP-10 [M], Ishikawa: 1×10-13

KP-10 [M], HEC-1a: $1 \times 10^{-11}$

Behandlungszeitpunkte $[\mathrm{h}]: \mathrm{t}_{0}, \mathrm{t}_{12}$

Versuchsendpunkt [h]: $\mathrm{t}_{24}$

Kokultur-Invasionsassay (Proteingewinnung):

KP-10 [M], Ishikawa: $1 \times 10^{-13}$

KP-10 [M], HEC-1a: $1 \times 10^{-11}$

Behandlungszeitpunkte $[h]: t_{0}, t_{12}$

Versuchsendpunkt [h]: $\mathrm{t}_{24}$

Der jeweilige Kontrollansatz wurde mit einer äquivalenten Menge sterilem $\mathrm{H}_{2} \mathrm{O}$ behandelt, um Volumenunterschiede zu vermeiden.

\subsubsection{Kokultur-Invasionsassay}

Die Zellen für die mikroskopische Auswertung sowie die Zellen für die RNA- und Proteingewinnung wurden zusammen mit humanen Osteoblasten-ähnlichen MG-63-Zellen in einem Zellinvasionsassay kokultiviert.

Das Kokultur-System ist ein in-vitro-Modell der gerichteten Invasion und kann so Hinweise zum Invasions- und Metastasierungsverhalten in vivo liefern (von Alten et al. 2006). 
Das Kokultur-System macht sich das Prinzip der modifizierten Boyden-Kammer zunutze, indem ein Insert (Filter mit einer porösen Membran) in ein Well (Kulturschale) einer WellPlatte gesetzt wird, wodurch Kultur- und Invasionskammer gebildet werden (Boyden 1962).

Der Boden der Kulturkammer, also die poröse Insert-Membran, wurde mit einem MatrigelGemisch beschichtet, um die Endometriumkarzinomzellen zu kultivieren.

Matrigel $^{\mathrm{TM}}$ Basalmembranmatrix ist eine gelöste Basalmembranvorbereitung, die aus Engelbreth-Holm-Swarm-Maus-Sarkom extrahiert wird und aus vielen extrazellulären Matrixproteinen besteht. Es polymerisiert bei Raumtemperatur und ähnelt dann der zellulären Basalmembranmatrix und der Extrazellulärmatrix von Säugetieren. In diesem Versuch simulierte es die Extrazellulärmatrix in vitro. In die Invasionskammer wurden die humanen Osteoblasten-ähnlichen MG-63-Zellen als Lockzellen ausgesät.

Invasive Zellen hatten nun die Möglichkeit durch die beschichtete Filtermembran in die Invasionskammer zu invadieren (Abb. 2.1).

A

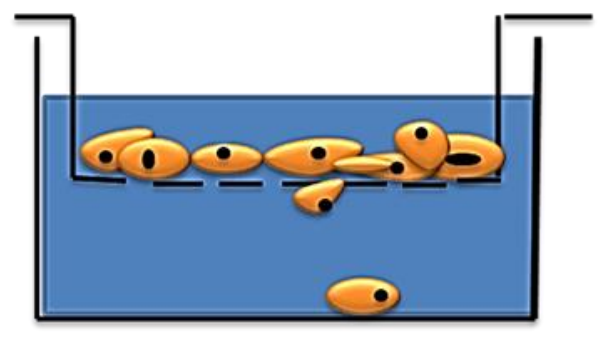

B

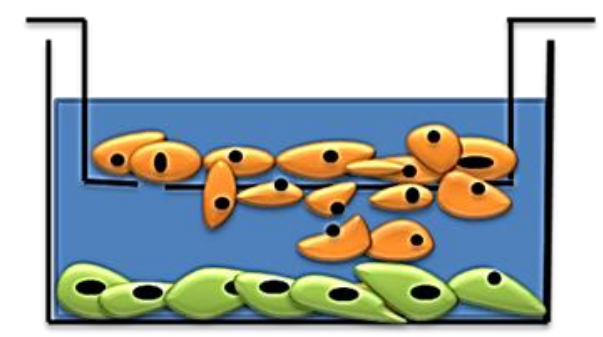

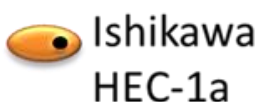

MG-63 HEC-1a
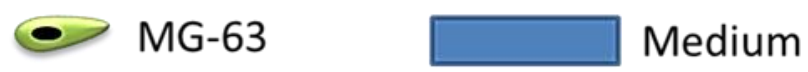

Abb. 2.1: Schematische Darstellung des Kokultur-Systems. Die Endometriumkarzinomzellen sind orange dargestellt und werden auf poröse Inserts ausgesät, die mit Matrigel beschichtet sind. In der Well-Platte befindet sich Medium (Kontrolle) (A). Unterhalb der auf dem Insert sitzenden Endometriumkarzinomzellen befinden sich grün dargestellt die Osteoblasten-ähnlichen MG-63-Zellen. Dies entspricht dem mit Mammakarzinomzellen etablierten Kokultur-System (B).

Für die Aussaat der Zellen wurde eine 6- oder 24-Well-Platte mit den entsprechenden porösen Inserts (Porendurchmesser: $8 \mu \mathrm{m}$ ) verwendet, wobei die 6-Well-Platten für die Gewinnung von RNA und Proteinen benötigt wurden und die 24-Well-Platten der mikroskopischen Auswertung der Invasionsassays dienten.

Je nach Größe der Inserts wurde eine unterschiedliche Menge des mit DMEM w/o Phenolrot verdünnten Matrigels bei $4{ }^{\circ} \mathrm{C}$ aufgetragen und für 30 min bei $37^{\circ} \mathrm{C}$ ausgehärtet (Tab. 2.7).

Bei Erreichen einer Konfluenz von 70-80\% wurden die Zellen in den Zellkulturflaschen trypsiniert, zentrifugiert und sorgfältig in Versuchsmedium resuspendiert (Kapitel 2.2.1.1). Die Anzahl der Zellen in der jeweiligen Zellsuspension wurde mit Hilfe der NeubauerZählkammer bestimmt (Kapitel 2.2.1.2). 
Zunächst wurden die Osteoblasten-ähnlichen Zellen in die Well-Platten und die Endometriumkarzinomzellen separat in die Inserts laut Tab. 2.8 ausgesät. Diese Wells wurden für das Kokultur-System verwendet. Anschließend wurden die Zellen in den Inserts und Wells für $12 \mathrm{~h}$ getrennt voneinander kultiviert. Danach wurden die Inserts luftblasenfrei in die Well-Platten überführt und die Zellen von diesem Zeitpunkt $\left(t_{0}\right)$ an kokultiviert beziehungsweise monokultiviert. Endometriumkarzinomzellen, die in den Inserts über den Wells mit Versuchsmedium monokultiviert wurden, dienten als Kontrolle.

Es wurde direkt mit der Behandlung der Zellen mit Kisspeptin-10-Lösungen unterschiedlicher Konzentrationen begonnen. Die Behandlung wurde zweimal täglich alle $12 \mathrm{~h}$ durchgeführt (Kapitel 2.2.1.3). Um eine Aussage über das Kokultur-System machen zu können, gab es je Versuchsansatz auch eine Kokultur, welche nicht mit Kisspeptin-10 behandelt wurden. Diese Ansätze wurden lediglich mit sterilem $\mathrm{H}_{2} \mathrm{O}$ behandelt, um Volumenunterschiede zu vermeiden.

Die Versuche wurden zum Zeitpunkt $\mathrm{t}_{24}$ (RNA- und Proteinisolierung) und $\mathrm{t}_{96}$ (mikroskopische Auswertung) beendet und weiter verarbeitet (Kapitel 2.2.2.1 und 2.2.3.2) beziehungsweise mikroskopisch ausgewertet (Kapitel 2.2.4.2).

Tab. 2.7: Aufbereitung des Matrigels

\begin{tabular}{lll}
\hline Substanz & 6-Well-Platte & 24-Well-Platte \\
\hline Matrigel & $106 \mu$ & $15 \mu l$ \\
DMEM w/o Phenolrot & $106 \mu \mathrm{l}$ & $15 \mu \mathrm{l}$ \\
\hline
\end{tabular}

Tab. 2.8: verwendete Zellzahlen für Wells und Inserts im Invasionsassay

\begin{tabular}{llll}
\hline $\begin{array}{l}\text { Versuchsaufbau des } \\
\text { Invasionsassays }\end{array}$ & $\begin{array}{l}\text { Insert-Größe } \\
\text { Well-Platte }\end{array}$ & Zellinie & Zellzahl/Volumen $\left[\mu \mathrm{I}^{-1}\right]$ \\
\hline Mikroskopische Auswertung & 24-Well Insert & Ishikawa & $0,8 \times 10^{4} / 400$ \\
& & HEC-1a & $0,5 \times 10^{4} / 400$ \\
& 24-Well-Platte & MG-63 & $2 \times 10^{4} / 600$ \\
RNA- und Protein-Gewinnung & 6 -Well Insert & Ishikawa & $4 \times 10^{5} / 1500$ \\
& & HEC-1a & $4 \times 10^{5} / 1500$ \\
& 6-Well-Platte & MG-63 & $2 \times 10^{5} / 2000$ \\
\hline
\end{tabular}




\subsubsection{SDF-1-Invasionsassay}

Die Zellen wurden zunächst wie in Kapitel 2.2.1.1 beschrieben trypsiniert, zentrifugiert und in Versuchsmedium resuspendiert.

Nun wurden in die matrigelbeschichteten Inserts der 24-Well-Platte Endometriumkarzinomzellen laut Tab. 2.8 ausgesät. Diese wurden für $12 \mathrm{~h}$ im Wärmeschrank kultiviert.

In die Wells der 24-Well-Platte wurden $600 \mu$ l einer chemotaktisch wirksamen SDF-1 Lösung laut Kapitel 2.2.1.3 pipettiert. Endometriumkarzinomzellen die lediglich in Inserts über den Wells mit Versuchsmedium kultiviert wurden, dienten als Kontrolle.

Zum Zeitpunkt $t_{0}$ wurden die Inserts mit Hilfe einer sterilen Pinzette luftblasenfrei in die Wells gesetzt und für weitere $96 \mathrm{~h}$ im Wärmeschrank kultiviert.

Ein weiterer identischer Versuchsansatz wurde zusätzlich mit Kisspeptin-10-Lösungen behandelt. Die Behandlung wurde zweimal täglich alle $12 \mathrm{~h}$ durchgeführt (Kapitel 2.2.1.3). Nach Versuchsende $\left(t_{96}\right)$ wurde wie in Kapitel 2.2.4.2 beschrieben weiterverfahren.

\subsubsection{Proliferationsassay}

Der alamarBlue $\AA^{\circ}$ assay wurde entwickelt um quantitativ die Vitalität von Zellen zu messen und damit Rückschluss auf ihr Proliferationsverhalten zu ziehen.

alamarBlue ${ }^{\circledR}$ ist eine Indigo gefärbte Flüssigkeit, die den fluorometrischen/ kolorimetrischen Redox-Indikator Resazurin enthält. Das oxidierte, nicht fluoreszierende Resazurin wird durch Reduktion irreversibel zum rosafarbenen, fluoreszierenden Resorufin umgesetzt.

Der Farbstoff dient als Nachweis für die Stoffwechselaktivität, denn metabolisch aktive Zellen sind in der Lage den Indikator zu reduzieren. Die Lösung wird lila/rosa. Beschädigte und nicht lebensfähige Zellen haben einen niedrigeren Stoffwechsel und erzeugen so ein verhältnismäßig niedrigeres Signal. Die Lösung ist blau. alamarBlue ${ }^{\circledR}$ kann unter anderem durch Fluoreszenzmessung mit Hilfe eines Multi-Detektions-Readers erkannt werden.

Der Proliferationsassay wurde über $72 \mathrm{~h}$ und $168 \mathrm{~h}$ durchgeführt. Die Zellen wurden regelmäßig alle $12 \mathrm{~h}$ mit Kisspeptin-10 unterschiedlicher Konzentrationen behandelt (Kapitel 2.2.1.3). Für den Versuch wurden 96-Well-Platten verwendet.

Die Zellen wurden zunächst wie in Kapitel 2.2.1.1 beschrieben trypsiniert, zentrifugiert und in Versuchsmedium resuspendiert. Dann wurde die Zellzahl der Suspension bestimmt (Kapitel 2.2.1.2), um die entsprechende Zellzahl in die Wells auszusäen (Tab. 2.9). Dabei wurden alle äußeren Wells frei gelassen um Verdunstungsphänomene zu vermeiden. In die 
ersten sechs vertikalen Wells wurden lediglich $200 \mu \mathrm{l}$ des Versuchsmediums eingebracht. Diese Wells wurden für die Berechnung des Leerwertes am Ende des Versuchs benötigt.

Die 96-Well-Platte wurde nun für $12 \mathrm{~h}$ kultiviert, damit die Zellen auf dem Boden der Wells anwachsen konnten.

Nach dieser Zeit $\left(t_{0}\right)$ wurde mit der Kisspeptin-10-Behandlung der Zellen begonnen. Der Kontrollansatz wurde äquivalent zu dieser Behandlung mit sterilem $\mathrm{H}_{2} \mathrm{O}$ behandelt, um Volumenunterschiede zu vermeiden.

Nach $t_{72}$ und $t_{168}$ wurde der Versuch beendet. Dafür wurden $20 \mu \mathrm{l}$ alamarBlue ${ }^{\circledR}$ in jedes Well pipettiert. Nach 4-6 h Inkubation konnte der Farbumschlag mit Hilfe des Synergy ${ }^{\text {TM }}$ HT MultiDetektions-Reader für Mikroplatten detektiert werden und mit der Software GEN5 ausgewertet werden.

Tab. 2.9: verwendete Zellzahlen im Proliferationsassay

\begin{tabular}{ll}
\hline Zelllinie & Zellzahl/Volumen $\left[\mu^{-1}\right]$ \\
\hline Ishikawa & $1 \times 10^{3} / 200$ \\
HEC-1a & $0,8 \times 10^{3} / 200$ \\
\hline
\end{tabular}

\subsubsection{Molekularbiologische Methoden}

Um die mRNA-Expression der Endometriumkarzinom- und Osteoblasten-ähnlichen Zellen zu untersuchen, wurde die RT-PCR (Reverse Transkription-Polymerase-Ketten-Reaktion) verwendet.

Hierbei wurde sowohl die GPR54-mRNA-Expression qualitativ, als auch die CXCR4- und SDF-1-mRNA-Expression semiquantitativ untersucht. Der semiquantitative Abgleich der RTPCR erfolgte mit Hilfe des housekeeping gene L7. Ein housekeeping gene ist ein Gen, welches unabhängig von Zelltyp, Zellstadium und äußeren Einflüssen konstitutiv exprimiert wird. Es unterliegt keinen regulatorischen Prozessen und dient somit als Kontrolle der semiquantitativen RT-PCR-Methode. Die Daten wurden aus mindestens drei voneinander unabhängig durchgeführten Versuchen erhoben, wobei die RT-PCR eines Versuchs jeweils mindestens dreimal voneinander unabhängig wiederholt und anschließend gemittelt wurde.

Es wurde das Kokultur-Invasionsassay verwendet, um Unterschiede in der mRNAExpression zu untersuchen (Kapitel 2.2.1.4). 


\subsubsection{1 $\underline{\text { RNA-Isolierung }}$}

Die Zellen wurden zunächst wie in Kapitel 2.2.1.1 beschrieben trypsiniert, zentrifugiert, anschließend ausgezählt und wie in Kapitel 2.2.1.4 und Tab. 2.8 beschrieben ausgesät und für $24 \mathrm{~h}$ in Versuchsmedium mono-und kokultiviert.

Die Lyse der Zellen aus der Zellkultur wurde durch direktes Aufgeben eines Gemisches aus $\beta$-Mercaptoethanol und RLT-Puffer im Verhältnis von 1:100 erreicht.

RNA aus den Zellen der Kokultur-Invasionsassays wurde gewonnen, indem das MatrigelGemisch und die darauf kultivierten Endometriumkarzinomzellen mit Hilfe eines Spatels von dem Insert abgeschabt und in das $\beta$-Mercaptoethanol-RLT-Gemisch überführt wurden. Die MG-63-Zellen wurden direkt in der Well-Platte mit dem Gemisch inkubiert.

Die Isolierung der RNA wurde mit Hilfe des RNeasy® Mini Kits durchgeführt. Hierbei wird die RNA spezifisch an eine Silika-Gel-Membran gebunden, durch mehrere Waschschritte gereinigt und anschließend mit $\mathrm{ddH}_{2} \mathrm{O}$ eluiert. Die Aufarbeitung der Zellen erfolgte nach Angaben des Herstellers. Die anschließende Lagerung der Proben erfolgte bei $-80^{\circ} \mathrm{C}$.

\subsubsection{Quantifizierung der RNA}

Die Quantifizierung der Nukleinsäuren wurde im UV-Photometer durchgeführt. Die Bestimmung der Konzentration erfolgt bei $\lambda=260 \mathrm{~nm}$ (A260), da Nukleinsäuren bei dieser Wellenlänge ihre Absorptionsmaxima besitzen. Proteine, die während der Aufbereitung als Verunreinigung auftreten, weisen ein Absorptionsmaximum bei $\lambda=280 \mathrm{~nm}$ (A280) auf. Das Verhältnis der Extinktionen von A260 zu A280 spiegelt die Reinheit der Nukleinsäureprobe wider und sollte zwischen 1,8 und 2 liegen.

\subsubsection{Reverse Transkription}

Bei der RT (reverse Transkription) wird die RNA mit Hilfe einer RNA-abhängigen DNAPolymerase (Bestandteil von SuperScript ${ }^{\text {TM }}$ II Reverse Transcriptase) in cDNA (complementary deoxyribonucleic acid; deutsch: komplementäre Desoxyribonukleinsäure) umgeschrieben. Dieser bildet die Grundlage der Polymerase-Ketten-Reaktion.

Für die Reaktion wurde $1 \mu \mathrm{g}$ RNA mit $12 \mu \mathrm{dH}_{2} \mathrm{O}$ (destilliertes $\mathrm{H}_{2} \mathrm{O}$ ) aufgefüllt. Zu dieser Lösung wurden weiterhin $1 \mu \mathrm{l}$ DNAse I recombinant [10 $\mathrm{U} / \mu \mathrm{l}]$ (enthält unter anderem eine DNA-spezifische Endonuklease) sowie $1 \mu \mathrm{l}$ RNasin® plus RNase Inhibitor $\quad[40 \mathrm{U} / \mu \mathrm{l}]$ hinzugegeben. 
Die Probe wurde im Thermocycler für 30 min bei $37^{\circ} \mathrm{C}$ und für 3 min bei $70{ }^{\circ} \mathrm{C}$ erhitzt und anschließend wieder auf $4^{\circ} \mathrm{C}$ herunter gekühlt.

Daraufhin wurden der Probe $26 \mu \mathrm{l}$ des in Tab. 2.10 aufgeführten Enzym-Mix hinzugefügt. Nun erfolgte eine Erhitzung auf $37^{\circ} \mathrm{C}$ für $60 \mathrm{~min}$ und dann eine Denaturierung bei $95^{\circ} \mathrm{C}$ für 5 min. Anschließend wurde der Ansatz erneut auf $4^{\circ} \mathrm{C}$ herunter gekühlt.

Die entstandene cDNA konnte nach erwünschter Verdünnung bei $-20^{\circ} \mathrm{C}$ gelagert werden.

Tab. 2.10: Substanzen zur Herstellung des Enzym-Mix für die Reverse Transkription

\begin{tabular}{|c|c|c|}
\hline Substanzen & Pro Probe $[\mu \mathrm{l}]$ & Ausgangskonzentration \\
\hline $\mathrm{dT}_{15}$-Primer & 8 & $1,1 \times 10^{-5} \mathrm{M}$ \\
\hline dNTPs & 4 & $0,01 \mathrm{M}$ \\
\hline FS-Puffer & 8 & $5 x$ \\
\hline DTT & 4 & $0,1 \mathrm{M}$ \\
\hline SuperScript ${ }^{\mathrm{TM}}$ II Reverse Transcriptase & 2 & $200 \mathrm{U} / \mu \mathrm{l}$ \\
\hline
\end{tabular}

\subsubsection{Polymerase-Ketten-Reaktion}

Die PCR (polymerase chain reaction, deutsch: Polymerase-Ketten-Reaktion) ist eine Methode, um gewünschte DNA-Fragmente in vitro zu vervielfältigen. Mit Hilfe einer DNAabhängigen Polymerase und DNA-Oligonukleotiden wird ein komplementärer DNA-Strang des Matrizenstranges erzeugt. Mit Hilfe spezifischer Primer wird nur der gesuchte DNAAbschnitt vervielfältigt. Die PCR besteht aus drei Schritten, welche im Folgenden genauer erläutert werden.

Zunächst wird die doppelsträngige DNA auf $95^{\circ} \mathrm{C}$ erhitzt, um die Stränge voneinander zu trennen. Dabei werden die Wasserstoffbrückenbindungen der DNA aufgebrochen (Denaturierung).

Dann wird eine Primer-spezifische Temperatur gewählt, die eine spezifische Anlagerung der Primer an die DNA ermöglicht. Die genaue Temperatur wird hierbei durch die Länge und die Sequenz der Primer bestimmt. Sie liegt normalerweise unter dem Schmelzpunkt der PrimerSequenzen; dies entspricht meist einer Temperatur von $55-65^{\circ} \mathrm{C}$ (Annealing).

Schließlich synthetisiert die DNA-Polymerase die fehlenden Stränge mit Hilfe freier dNTPs. Sie beginnt am 3'-Ende des angelagerten Primers und folgt dann dem DNA-Strang (Elongation). Die Elongation erfolgt bei $72{ }^{\circ} \mathrm{C}$, dem Temperatur-Optimum der KAPA2G ${ }^{\text {TM }}$ Fast DNA-Polymerase, die in dieser Arbeit als DNA-Polymerase eingesetzt wurde. Die KAPA2G ${ }^{\mathrm{TM}}$ Fast DNA-Polymerase $[0,04 \mathrm{U} / \mu \mathrm{l}]$ ist ein Bestandteil des gebrauchsfertigen KAPA2G ${ }^{\mathrm{TM}}$ Fast 2x ReadyMix mit Farbstoff. Der Mix enthält außerdem den KAPA2G ${ }^{\text {TM }}$ Fast PCR Puffer, dNTPs (0,2 mM eines jeden dNTPs in finaler Verdünnung) 
und $\mathrm{MgCl}_{2}$ (1,5 mM in finaler Verdünnung). Weiterhin enthält der Mix zwei Farbstoffe (blau und gelb), die eine Analyse der PCR-Produkte mittels Gel-Elektrophorese direkt nach Beendigung der PCR ermöglichen. Anschließend werden die Reaktionsansätze auf $4{ }^{\circ} \mathrm{C}$ herunter gekühlt. Diese Schritte werden zwischen 17- bis 35-mal wiederholt, um die Matrize exponentiell zu vervielfältigen.

Der verwendete PCR-Standardreaktionsansatz ist in Tabelle 2.11 aufgeführt und die PCRProgramme der jeweiligen zu untersuchenden Gene sind in Tabelle 2.12 zusammengefasst.

Tab. 2.11: Substanzen zur Herstellung des PCR-Reaktionsansatzes

\begin{tabular}{lll}
\hline Substanzen & Pro Probe $[\mu \mathrm{ll}]$ & Ausgangskonzentration \\
\hline $\mathrm{H}_{2} \mathrm{O}$ & 5,55 oder 6,15 & \\
KAPA2G ${ }^{\text {TM }}$ Fast 2x ReadyMix with Dye & 7,5 & $2 \mathrm{x}$ \\
Sense-Primer & 0,375 & $20 \mathrm{pM}$ \\
Anitsense-Primer & 0,375 & $20 \mathrm{pM}$ \\
cDNA & $0,6-1,2$ & $6,25-25 \mathrm{ng} / \mu \mathrm{l}$ \\
\hline Gesamtvolumen & 15 & \\
\hline
\end{tabular}

Tab. 2.12: PCR-Programme - Zeiten und Temperaturen

\begin{tabular}{llllll}
\hline Gen & Denaturierung & Annealing & Elongation & Zyklen & Target-Größe [bp] \\
\hline GPR54 & $15 \mathrm{sec}, 95^{\circ} \mathrm{C}$ & $15 \mathrm{sec}, 61,5^{\circ} \mathrm{C}$ & $5 \mathrm{sec}, 72^{\circ} \mathrm{C}$ & 35 & 80 \\
$\mathrm{CXCR} 4$ & $15 \mathrm{sec}, 95^{\circ} \mathrm{C}$ & $15 \mathrm{sec}, 58^{\circ} \mathrm{C}$ & $5 \mathrm{sec}, 72^{\circ} \mathrm{C}$ & 27 & 260 \\
SDF-1 & $15 \mathrm{sec}, 95^{\circ} \mathrm{C}$ & $15 \mathrm{sec}, 60^{\circ} \mathrm{C}$ & $5 \mathrm{sec}, 72^{\circ} \mathrm{C}$ & $33-34$ & 227 \\
$\mathrm{KISS} 1$ & $15 \mathrm{sec}, 95^{\circ} \mathrm{C}$ & $15 \mathrm{sec}, 60^{\circ} \mathrm{C}$ & $5 \mathrm{sec}, 72^{\circ} \mathrm{C}$ & 35 & 201 \\
$\mathrm{~L} 7$ & $15 \mathrm{sec}, 95^{\circ} \mathrm{C}$ & $15 \mathrm{sec}, 54^{\circ} \mathrm{C}$ & $5 \mathrm{sec}, 72^{\circ} \mathrm{C}$ & 19 & 357 \\
\hline
\end{tabular}

\subsubsection{Agarose-Gel-Elektrophorese}

Die Agarose-Gel-Elektrophorese ist eine Methode, um DNA-Stränge ihrer Größe nach zu aufzutrennen und ihre Größe zu bestimmen.

Je höher die Agarose konzentriert ist, desto kleiner sind die Poren, durch die sich die DNA bewegen muss. Indem ein elektrisches Feld angelegt wird, wandern die negativ geladenen Nukleinsäure-Moleküle durch die Gelmatrix, wobei sich die kleineren Moleküle schneller durch das Gel bewegen können und somit eine Auftrennung der Amplifikate nach ihrer Größe ermöglicht wird. 
Es wurden 1,5\%-ige und $2 \%$-ige Agarose-Gele hergestellt. Dafür wurde die Agarose gemeinsam mit 0,5x TBE aufgekocht und je $30 \mathrm{ml}$ in die vorgesehene Gelkammer mit eingestecktem Kamm gegossen. Dabei wurde auf Luftblasenfreiheit geachtet. Nach Aushärtung des Gels wurde die Kammer mit 0,5x TBE aufgefültt und der Kamm entfernt. Je $10 \mu \mathrm{l}$ der Proben wurden in die Geltaschen pipettiert. Als Größenstandard wurde ein DNAFragmentlängen-Standard (100 bp DNA-Leiter) verwendet.

Anschließend lief der Strom bei $95 \mathrm{~V}$ für durchschnittlich $45 \mathrm{~min}$.

\subsubsection{Auswertung}

Nach der Auftrennung der DNA durch die Agarose-Gel-Elektrophorese, wurden die Nukleinsäuren durch den interkalierenden und fluoreszierenden Farbstoff Ethidiumbromid nachgewiesen. Dafür wurden die Gele für $20 \mathrm{~min}$ im Ethidiumbromid-Bad gefärbt und anschließend in $\mathrm{dd}_{2} \mathrm{O}$ gewaschen. Die Wellenlänge der UV-Strahlung zur Detektion liegt bei $\lambda=302 \mathrm{~nm}$.

Die Ergebnisse wurden mit der Software Bio Doc Analyze 2.1 festgehalten und ausgewertet.

\subsubsection{Proteinbiochemische Methoden}

Um die Protein-Expression der Endometriumkarzinom- und Osteoblasten-ähnlichen Zellen zu untersuchen, wurde der Western-Blot verwendet.

Hierbei wurden sowohl die an der Oberfläche exprimierten Proteine GPR54 und CXCR4, als auch das im Zytosol exprimierte und in das Medium sezernierte Protein SDF-1 qualitativ und semiquantitativ untersucht. Der semiquantitative Abgleich erfolgte mittels eines AktinNachweises. Aktin ist ein Protein, welches unabhängig von Zelltyp, Zellstadium und äußeren Einflüssen konstitutiv im Zytosol exprimiert wird. Es unterliegt keinen regulatorischen Prozessen und dient somit als Kontrolle der semiquantitativen Western-Blot-Methode. Die Daten wurden aus mindestens drei voneinander unabhängig durchgeführten Versuchen erhoben.

\subsubsection{Zellkultivierung zur Proteinisolation}

Es wurden zum einen Zellen aus der Zellkultur verarbeitet, um GPR54, SDF-1 und CXCR4 qualitativ und semiquantitativ untersuchen zu können. Zum anderen wurden Zellen aus dem 
Kokultur-Invasionsassay verwendet, um Unterschiede in der CXCR4- und in der SDF1Expression semiquantitativ zu analysieren.

Dafür wurden die Zellen zunächst wie in Kapitel 2.2.1.1 beschrieben trypsiniert, zentrifugiert, in Versuchsmedium resuspendiert, anschließend ausgezählt und laut Kapitel 2.2.1.4 und Tab. 2.8 ausgesät und für $24 \mathrm{~h}$ in Versuchsmedium mono-und kokultiviert.

\subsubsection{Isolation exprimierter Proteine}

\section{Trennung von membranständigen und zytosolischen Proteinen}

Zur Trennung von membranständigen und zytosolischen Proteinen, wie es für den Nachweis von SDF-1, CXCR4 und GPR54 nötig war, wurde das Qproteome® Cell Compartment Kit nach Angaben des Herstellers verwendet. Es wurden $1 \times 10^{6}$ Zellen aus der Zellkultur verwendet. Die aufgetrennten Proteinpellets wurden anschließend in $80 \mu \mathrm{l} 2 \mathrm{x}$ NuPAGE® LDS Sample Buffer resuspendiert und für $10 \mathrm{~min}$ bei $95^{\circ} \mathrm{C}$ und $800 \mathrm{rpm}$ im Thermomixer denaturiert. Am Ende diese Vorganges wurden die Proben auf Eis gestellt und danach entweder sofort verarbeitet oder bei $-20^{\circ} \mathrm{C}$ gelagert.

\section{Zellen aus matrigelbeschichteten Inserts}

Die Zellen wurden zunächst wie in Kapitel 2.2.1.1 passagiert, anschließend ausgezählt, laut Kapitel 2.2.1.4 ausgesät und für $24 \mathrm{~h}$ mono- und kokultiviert. Es wurden die in Tab. 2.8 angegebenen Zellzahlen verwendet.

Zunächst wurde das Medium der Inserts verworfen. Nun wurde mit Hilfe eines Spatels das Matrigel von der Insert-Membran abgeschabt und in ein 1,5 ml-Eppendorfcup pipettiert in welchem $200 \mu$ PBS vorgelegt waren. Danach wurde die Membran mit $200 \mu$ l PBS gespült. Auch diese Flüssigkeit wurde dem Eppendorfcup zugeführt. Der ganze Vorgang wurde auf Eis durchgeführt.

Jetzt wurden die Proben bei $700 \mathrm{~g}$ für 10 min zentrifugiert. Dabei trennten sich die Zellen von dem Matrigel und dem PBS und setzten sich auf dem Boden des Gefäßes ab. Der Überstand wurde verworfen und das Zellpellet mit einem Restbestand Matrigel verblieben in dem Eppendorfcup.

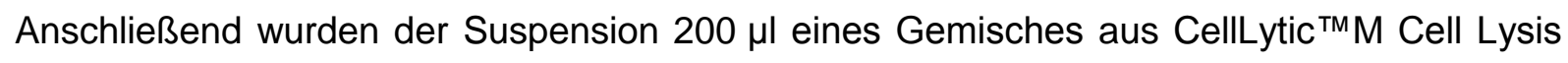
Reagent und Protease-Inhibitor in einem Verhältnis von 1:100 hinzugegeben. Dann wurden die Proben über Nacht bei $4^{\circ} \mathrm{C}$ in einem Überkopfschüttler inkubiert. Dabei wurden die Zellen im Matrigel lysiert und die Proteine wurden freigesetzt. Am nächsten Tag wurden die Proben für $25 \mathrm{~min}$ bei $12000 \mathrm{~g}$ und $4{ }^{\circ} \mathrm{C}$ zentrifugiert. Nach der Zentrifugation wurden jeweils 
$200 \mu \mathrm{l}$ des Überstandes in ein neues Eppendorfcup überführt und mit $800 \mu \mathrm{l}$ Aceton zur Fällung der Proteine aufgefüllt. Die Fällung fand bei $-20^{\circ} \mathrm{C}$ für eine weitere Nacht statt. Nun wurden die Proben erneut nach oben gemachten Angaben zentrifugiert. Der Überstand wurde verworfen und das Proteinpellet, welches sich am Boden des Eppendorfcups abgesetzt hatte, wurde in 2x NuPAGE® LDS Sample Buffer resuspendiert und für 10 min bei $95^{\circ} \mathrm{C}$ und $800 \mathrm{rpm}$ im Thermomixer denaturiert. Am Ende diese Vorganges wurden die Proben auf Eis gestellt und danach entweder sofort verarbeitet oder bei $-20^{\circ} \mathrm{C}$ gelagert.

\section{Zellen aus den Wells}

Die Zellen wurden zunächst wie in Kapitel 2.2.1.1 passagiert, anschließend ausgezählt und wie in Kapitel 2.2.1.4 und Tab. 2.8 beschrieben ausgesät und für $24 \mathrm{~h}$ mono- oder kokultiviert und mit Kisspeptin-10 behandelt. Nach Versuchsende wurde $1 \mathrm{ml}$ Trypsin/EDTA auf die Zellen der Wells gegeben. Nach der Inkubationszeit von 5-10 min wurde die Reaktion durch Zugabe von $4 \mathrm{ml}$ Nährmedium gestoppt. Die Zellsuspension wurde zentrifugiert. Der Überstand wurde verworfen und das Zellepellet in $1 \mathrm{ml}$ PBS resuspendiert. Es folgte eine weitere Zentrifugation mit anschließender Resuspension in $1 \mathrm{ml}$ PBS. Nach einer letzten Zentrifugation wurde der Überstand verworfen und das Zellpellet in 2x NuPAGE® LDS Sample Buffer resuspendiert und für $10 \mathrm{~min}$ bei $95^{\circ} \mathrm{C}$ und $800 \mathrm{rpm}$ im Thermomixer denaturiert. Am Ende diese Vorganges wurden die Proben auf Eis gestellt und danach entweder sofort verarbeitet oder bei $-20^{\circ} \mathrm{C}$ gelagert.

\subsubsection{Isolation sezernierter Proteine}

Abweichend vom sonstigen Vorgehen wurden die Zellen, welche auf ihre Protein-Sekretion untersucht werden sollten, in FCS-freiem Versuchsmedium kultiviert.

SDF-1 wurde aus dem Überstand der MG-63-Zellen gewonnen, da es sich um ein sekretorisches Protein handelt. Dazu wurden die Überstände von drei unabhängig voneinander durchgeführten Experimenten gepoolt und bei $4500 \mathrm{~g}$ für mindestens $90 \mathrm{~min}$ ultrazentrifugiert, um das Protein in $100 \mu \mathrm{l}$ des Überstandes aufzukonzentrieren. Das Ultrazentrifugieren der Proben wurde mittels Vivaspin-6 ml (Sartorius Biotech) durchgeführt. Hierbei handelt es sich um Zentrifugen-Röhrchen mit zwei Kammern, die durch eine Membran getrennt sind. Diese Membran ist so konfiguriert, dass sie für alle Proteine $<5 \mathrm{kDa}$ durchlässig ist. SDF-1 weist eine Größe von $11 \mathrm{kDa}$ auf und kann somit in der oberen Kammer aufkonzentriert werden.

Die Probe wurde anschließend mit $100 \mu$ 2x NuPAGE® LDS Sample Buffer gemischt und für $10 \mathrm{~min}$ bei $95^{\circ} \mathrm{C}$ und $800 \mathrm{rpm}$ im Thermomixer denaturiert. 
Am Ende diese Vorganges wurden die Proben auf Eis gestellt und danach entweder sofort verarbeitet oder bei $-20^{\circ} \mathrm{C}$ gelagert.

\subsubsection{SDS-Polyacrylamid-Gel-Elektrophorese}

Die SDS-PAGE (sodium dodecyl sulfate-Polyacrylamid-Gel-Elektrophorese) ist eine Methode, welche Proteine nach ihrer Größe auftrennt. SDS ist ein anionisches Detergens, das an Proteine bindet, wodurch diese eine negative Ladung erhalten.

Bei dem verwendeten Verfahren nach Laemmli werden die Proben in einem Sammelgel mit $5 \%$ Polyacrylamid konzentriert und danach in einem 10-15\%-igen Trenngel separiert. Es wurden $12 \%$-SDS-Polayacrylamid-Fertiggele der Firma Bio-Rad bezogen. Für die SDSPAGE wurde die Mini-PROTEAN III Electrophoresis Cell Apparatur von Bio-Rad verwendet, nach Angaben des Herstellers aufgebaut und mit $500 \mathrm{ml}$ SDS-Elektrophoresepuffer befüllt. Die Taschen der Gele wurden mit 20-40 $\mu$ l der Protein-Puffer-Lösung bestückt. Außerdem wurden $5 \mu \mathrm{l}$ des PeqGOLD Protein-Markers $V$ als Größenstandard aufgetragen. Danach wurden die Proteine bei $80 \mathrm{~V}$ für 30 min konzentriert und bei $150 \mathrm{~V}$ für 40 min ihrer Größe nach aufgetrennt.

Die aufgetrennten Proteine konnten nun im Western-Blot-Verfahren auf eine PVDF(Polyvinylidenfluorid)-Membran transferiert und nachgewiesen werden.

\subsubsection{Western-Blot}

Das Western-Blot-Verfahren dient dazu, die elektrophoretisch aufgetrennten Proteine auf eine Trägermembran zu übertragen und diese im Anschluss über spezifische Antikörper nachzuweisen.

Eine PVDF-Membran (Immobilon®-P Membrane, Millipore) wurde zunächst für $1 \mathrm{~min}$ in Methanol, $5 \mathrm{~min}$ in $\mathrm{ddH}_{2} \mathrm{O}$ und $10 \mathrm{~min}$ in Transferpuffer geschwenkt. In dem Transferpuffer wurde die Membran aktiviert.

Nach Ende der Elektrophorese wurde das SDS-Polyacrylamid-Gel von den Scheiben gelöst und das Sammelgel wurde verworfen. Das Trenngel wurde zunächst mit $\mathrm{ddd}_{2} \mathrm{O}$ gewaschen und anschließend 2-5 min in Transferpuffer geschwenkt.

Der Western-Blot wurde in einer sogenannten Halbtrockenzelle durchgeführt. Die dafür notwenige Apparatur (Bio-Rad) wurde nach Angaben des Herstellers aufgebaut. Es wurden vier Lagen Filterpapier (Whatman, Schleicher und Schuell) mit konzentriertem Anodenpuffer getränkt, zusätzlich wurden weitere vier Lagen mit Anodenpuffer getränkt. Auf diese Filterpapiere wurden luftblasenfrei das Gel und anschließend die PVDF-Membran gegeben 
und mit Transferpuffer bestrichen. Vier Lagen Filterpapier getränkt mit Kathodenpuffer bildeten den Abschluss. Die Proteine wurden für $1,5 \mathrm{~h}$ bei $100 \mathrm{~V}$ auf die PVDF-Membran transferiert.

\subsubsection{Detektion, Visualisierung und Auswertung}

Nach dem Blotting wurde die Membran kurz mit TBST gewaschen. Anschließend wurde sie für $1 \mathrm{~h}$ bei Raumtemperatur in dem Blockierungsreagens inkubiert. Die in dem Reagens enthaltenden Proteine besetzten die noch freien Bindungsstellen der Membran.

Nach Beendigung der Blockierung wurden die Membran und die Schale mit TBST gewaschen. Die Inkubation mit dem mit TBST verdünnten Primärantikörper erfolgte über Nacht bei $4^{\circ} \mathrm{C}$.

Dieser wurde am nächsten Tag nach der Inkubation verworfen. Die Membran wurde dreimal für 20 min in TBST gewaschen. Während des Waschvorganges wurde der Peroxidasegekoppelte-Sekundärantikörper in gewünschter Konzentration angesetzt. Die Membran wurde dann für $1 \mathrm{~h}$ bei Raumtemperatur mit dem Sekundärantikörper inkubiert.

Nach Durchführung einer erneuten Waschganges von 2x30 min mit TBST konnte nun die Detektion des gebundenen Sekundärantikörpers mittels ECL (enhanced chemiluminescens reaction; Immobilon ${ }^{\mathrm{TM}}$ Western) erfolgen. ECL zeigt bei der katalytischen Umsetzung durch die Peroxidase eine Chemilumineszenz mit einem Maximum bei $\lambda=430 \mathrm{~nm}$, mit der Röntgenfilme (Amersham Hyperfilm ${ }^{\mathrm{TM}}$ MP, GE Healthcare Limited) belichtet werden können. Die Exposition erfolgte in einer Röntgenfilmkassette (X-Ray $\mathrm{GmbH}$ ) und der Film wurde anschließend in einer Dunkelkammer im X-Ray Film Prozessor SRS-101A entwickelt. Die Ergebnisse wurden mit der Kodak Digital Science 1D Software festgehalten und ausgewertet.

\subsubsection{Stripping der PVDF-Membran}

Durch das Stripping wurden die gebundenen Antikörper vollständig von der PVDF-Membran entfernt, um sie für eine Reaktion mit einem weiteren Antikörper vorzubereiten.

Dazu wurde ein fertig bezogener Antikörper-Stripping-Puffer verwendet. Die Membran wurde 15 min mit diesem Puffer inkubiert und daraufhin mit $\mathrm{ddH}_{2} \mathrm{O}$ und dreimalig für 5 min mit TBST gewaschen. Dann wurde die Membran wie in Kapitel 2.2.3.6 beschrieben geblockt und weiter verfahren. 


\subsubsection{Zytologische Färbung}

\subsubsection{Immunzytologische Färbung der Zelllinien}

Der immunzytologische GPR54-Nachweis in den Endometriumkarzinom- und Osteoblastenähnlichen Zellen wurde mittels eines polyklonalen Primärantikörpers gegen GPR54 gezeigt. Die Zellen wurden auf einen Objektträger (Lab-Tek ${ }^{\text {TM }}$ Chamber Slides ${ }^{\text {TM }}$ Systeme, Nunc) mit einer Konfluenz von $70 \%$ ausgesät und über 24 h kultiviert. Für die immunzytochemische Färbung wurde der Histostain ${ }^{\circledR}$ Bulk Kit nach Angaben des Herstellers verwendet. Der polyklonale Primärantikörper gegen GPR54 inkubierte über Nacht bei $4{ }^{\circ} \mathrm{C}$. Die Detektion des Primärantikörpers erfolgte mit der AEC + High Sensitivity Substrate Chromogen-Lösung. Nach einer belichtungsfreien Einwirkungszeit von 30 min, wurde der Objektträger mit $\mathrm{dH}_{2} \mathrm{O}$ gewaschen. Daraufhin folgte der Färbevorgang mit der Hämalaun-Lösung für $30 \mathrm{sec}$. Durch Leitungswasser wurden die Proben gebläut. Das Eindecken der Objektträger erfolgte mit Aquatex®. Die gefärbten Zellen wurden am Mikroskop IX 51, Olympus ausgewertet und fotografiert.

\subsubsection{Mikroskopische Auswertung der Invasionsassays}

Für die Auswertung der Invasionsassays wurden die Zellen laut Kapitel 2.2.1.4 und 2.2.1.5 in einer 24-Well-Platte kultiviert und $96 \mathrm{~h}$ inkubiert.

Es wurde die Anzahl der Endometriumkarzinomzellen bestimmt, die sich nach $96 \mathrm{~h}$ adhärent an der Unterseite der Insert-Membran befanden. Dafür mussten die Endometriumkarzinomzellen unterhalb des Filters mit Methanol fixiert und mit Mayers Hämalaun-Lösung angefärbt werden (Tab. 2.13). Nach dem Färbevorgang wurde das Matrigel mit Hilfe eines Wattestäbchens vorsichtig von der Insert-Membran entfernt. Dadurch blieben nur die Zellen haften, die durch das Matrigel und die Membran hindurch gewandert und auf der Membranunterseite verblieben sind.

Die Membran wurde nun aus dem Insert herausgelöst und auf einen Objektträger gegeben. Ein Deckglas wurde mittels Aquatex® auf den Objektträger aufgebracht.

Die eingefärbten Membranen wurden schließlich optisch in vier Quadranten unterteilt. Jeder Quadrant wurde vollständig am Mikroskop IX 51, Olympus angeschaut, fotografiert und mit Hilfe der Software Axio Vision 3.1 selbstständig ausgezählt. 
Tab. 2.13: Zytologische Färbung

\begin{tabular}{ll}
\hline Ablauf & Zeit [min] \\
\hline PBS Waschschritt & 5 \\
Spülung mit $\mathrm{dH}_{2} \mathrm{O}$ & 1 \\
Fixierung mit Methanol $100 \%$ & $10-15$ \\
Spülung mit $\mathrm{dH}_{2} \mathrm{O}$ & 1 \\
Hämalaun- $\mathrm{Lösung}_{\text {Spülung mit } \mathrm{dH}_{2} \mathrm{O}}$ & $5-10$ \\
Bläuung mit $\mathrm{Leitungswasser}_{\text {Spülung mit } \mathrm{dH}_{2} \mathrm{O}}$ & 1 \\
\hline
\end{tabular}

\subsubsection{Dokumentation und statistische Analysen}

Die mikroskopische Auswertung und die Aufnahmen der Invasionsassays erfolgten mit Hilfe des Mikroskops IX51 der Firma Olympus, die Auszählung der Zellen wurde durch die Software Axio Vision 3.1. erleichtert. Die Daten wurden aus mindestens drei unabhängig voneinander durchgeführten Versuchen gewonnen $(n=3)$.

Mit Hilfe des UV-Transilluminators von Biometra und der Software Bio Doc Analyze 2.1 erfolgten die Dokumentation sowie die Auswertung der Agarose-Gele. Die Daten wurden aus mindestens drei voneinander unabhängig durchgeführten Versuchen erhoben, wobei die RTPCR eines Versuchs jeweils mindestens dreimal voneinander unabhängig wiederholt und anschließend gemittelt wurde $(n=3)$.

Die Dokumentation und Analyse der Western-Blots wurde mit der Software Kodak Digital Science 1D durchgeführt. Die Daten wurden aus mindestens drei unabhängig voneinander durchgeführten Versuchen gewonnen $(n=3)$.

Zur statistischen Auswertung und graphischen Darstellung der Ergebnisse diente die Software GraphPad Prism® (Version 5.00). Als statistische Tests wurden der one-way ANOVA (one-way Analysis of variance), gefolgt vom Student-Newman-Keuls Test oder der t-Test (gepaart oder ungepaart) angewendet. Es wurden nur Signifikanzen gegen die Kontroll-, Kokultur- und SDF-1 x-Daten angegeben. Weitere Signifikanzen zwischen den Daten wurden vernachlässigt und nur in gesonderten Einzelfällen graphisch und schriftlich dargestellt. 


\section{Ergebnisse}

\subsection{GPR54-Expression humaner Endometriumkarzinom- und Osteoblasten-ähnlicher Zellen}

Für die folgenden in-vitro-Experimente sollte zunächst die Frage beantwortet werden, ob die Zellinien Ishikawa, HEC-1a und MG-63 positiv für den Kisspeptin-10-Rezeptor GPR54 sind. Aufgrund kontroverser Ergebnisse in der Literatur, erfolgte der Nachweis mit Hilfe molekularbiologischer und proteinbiochemischer Methoden.

\subsubsection{Molekularbiologischer Nachweis der GPR54-Expression}

Der molekularbiologische GPR54-Nachweis erfolgte mittels RT-PCR, wobei diese zur Kontrolle mit dem housekeeping gene L7 abgeglichen wurde.

Mit Hilfe der RT-PCR konnte eine eindeutige GPR54-mRNA-Expression in den IshikawaZellen nachgewiesen werden. Die HEC-1a-Zellen zeigten lediglich in einer Zellpassage eine schwache mRNA-Expression des Kisspeptin-Rezeptors. In den Osteoblasten-ähnlichen MG-63-Zellen war keine GPR54-mRNA-Expression nachweisbar (Abb. 3.1).

GPR-54 (80 bp) -

L7 (357 bp) -

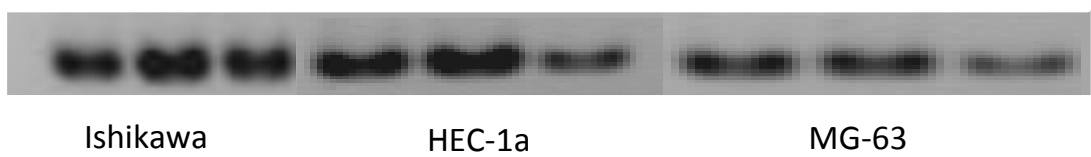

Abb. 3.1: Molekularbiologischer GPR54-Nachweis in den Endometriumkarzinomzellen Ishikawa und HEC-1a sowie in den Osteoblasten-ähnlichen MG-63-Zellen. Die qualitative Bestimmung der GPR54-mRNAExpression erfolgte mittels RT-PCR in Bezug auf das housekeeping gene L7. Ishikawa-Zellen zeigten eine deutliche GPR54-mRNA-Expression, wohingegen diese in den HEC-1a- und MG-63-Zellen nicht nachweisbar war. Es wurden pro Zelllinie Proben aus drei voneinander unabhängig durchgeführten Versuchen untersucht $(n=3)$.

\subsubsection{Proteinbiochemischer Nachweis der GPR54-Expression}

Mit Hilfe des Western-Blots ließ sich GPR54 auf proteinbiochemischer Ebene in der Membran aller drei Zelllinien nachweisen. Zur Kontrolle wurde ein zytosolischer AktinNachweis erbracht (Abb. 3.2). 


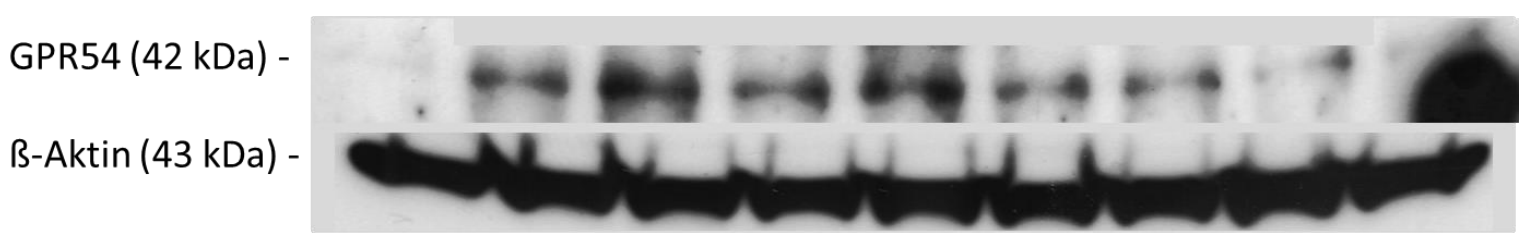

Ishikawa, Hec -1a, Mg-63, Ishikawa, HEC-1a, MG-63, Ishikawa, HEC-1a, MG-63

n1

$\mathrm{n} 2$

n3

Abb. 3.2: Proteinbiochemischer GPR54-Nachweis in den Endometriumkarzinomzellen Ishikawa und HEC-1a sowie in den Osteoblasten-ähnlichen MG-63-Zellen. Die qualitative Bestimmung der GPR54-ProteinExpression in der Membran erfolgte mittels Western-Blot in Bezug auf den zytosolischen Aktin-Nachweis. GPR54 ließ sich in allen drei Zelllinien nachweisen. Es wurden pro Zelllinie Proben aus drei voneinander unabhängig durchgeführten Versuchen untersucht $(n=3)$.

\subsubsection{Immunzytochemischer Nachweis der GPR54-Expression}

Dieser qualitative Nachweis erfolgte mit Hilfe einer immunzytochemischen Färbung. Der verwendete Primärantikörper war dabei gegen GPR54 gerichtet. Sowohl die Osteoblastenähnliche Zelllinie MG-63 als auch die humanen Endometriumkarzinomzellinien Ishikawa und HEC-1a zeigten eine deutliche Rotfärbung, also eine eindeutige GPR54-Expression (Abb. 3.3, B, D, F).
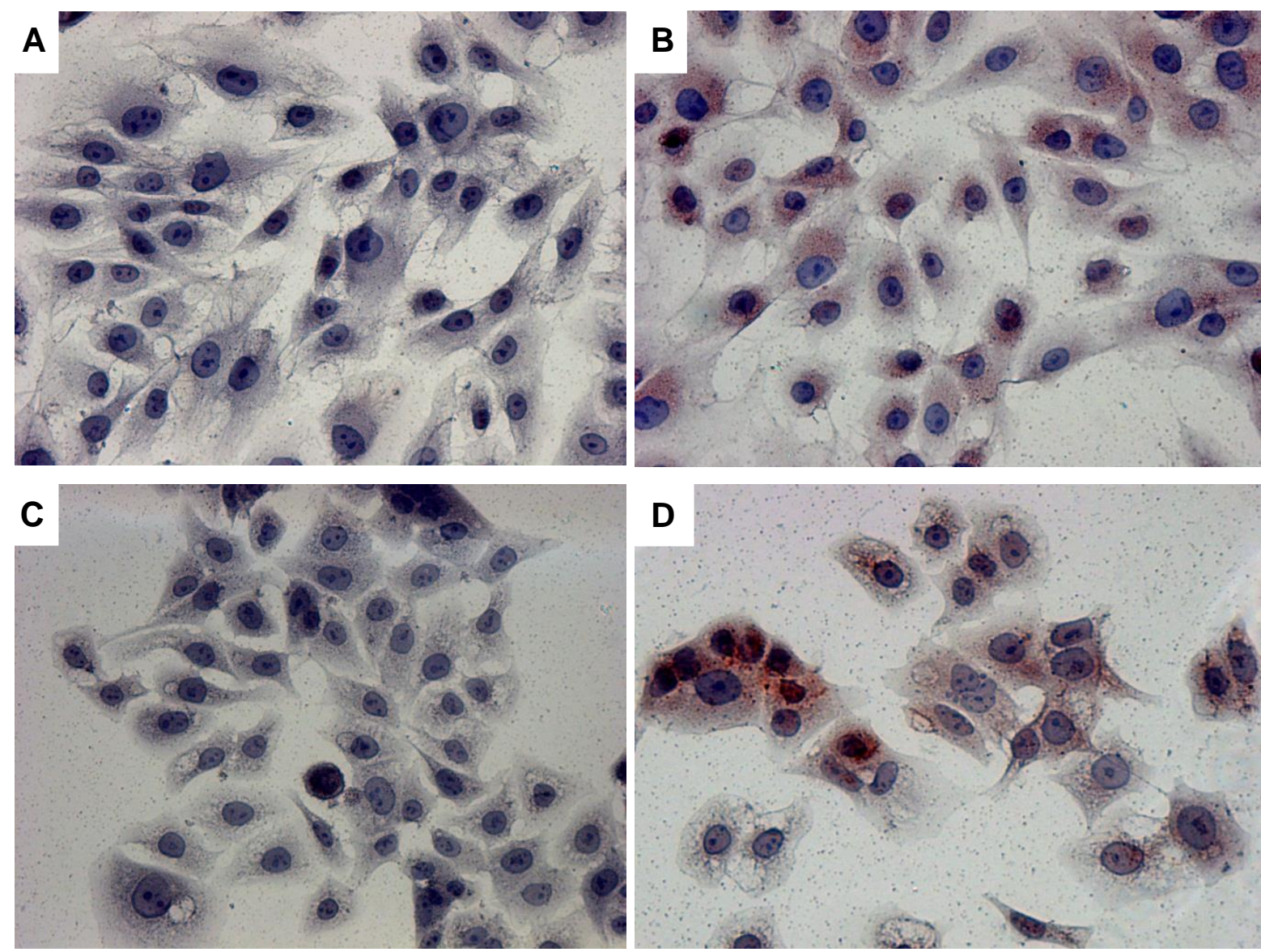

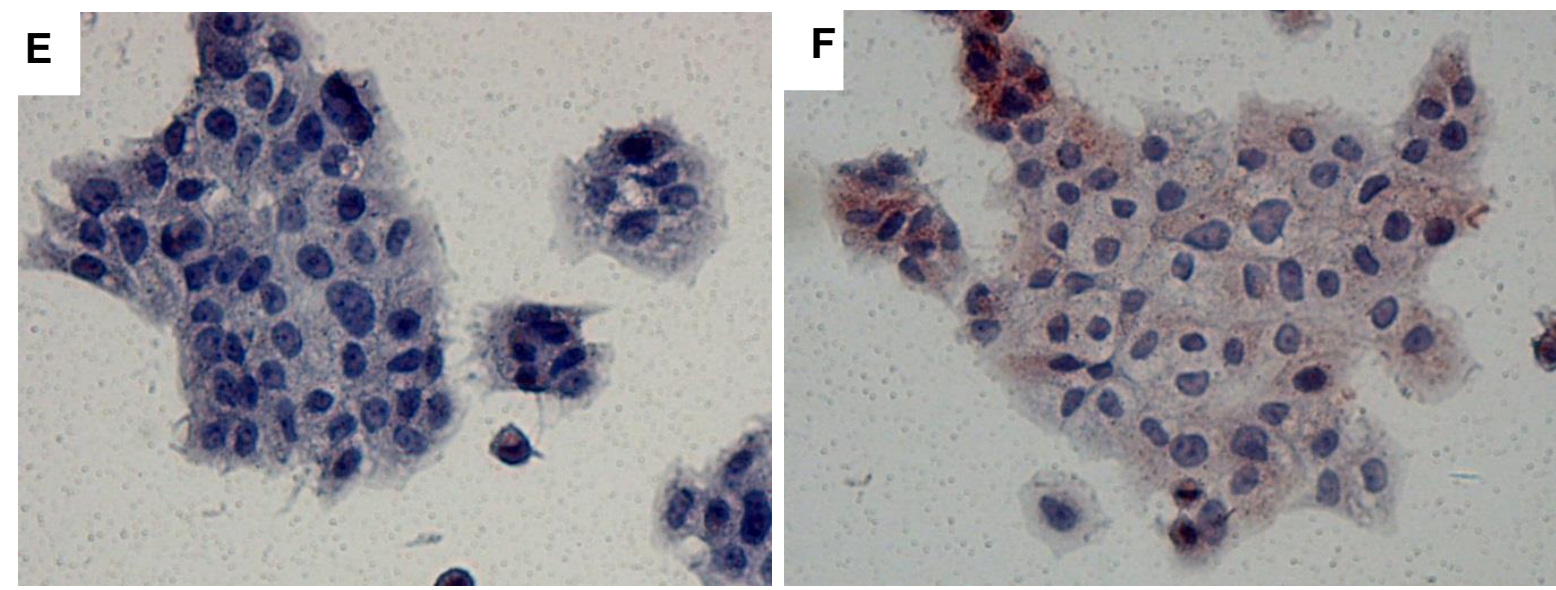

Abb. 3.3: Immunzytochemischer GPR54-Nachweis in den Endometriumkarzinomzellen Ishikawa und HEC-1a sowie in den Osteoblasten-ähnlichen MG-63-Zellen. Die Rezeptor-positiven MG-63-Zellen (B) sind ebenso wie die Rezeptor-positiven Ishikawa-Zellen (D) und die Rezeptor-positiven HEC-1a-Zellen (F) durch ihre rötliche Färbung im Vergleich zur Kontrolle (MG-63-Zellen (A), Ishikawa-Zellen (C) und HEC-1a-Zellen (E)), in der die Zellen ohne Primärantikörpern inkubiert wurden, deutlich zu erkennen.

\subsection{KISS1-Expression humaner Endometriumkarzinomzellen}

Der Nachweis der KISS1-Expression erfolgte molekularbiologisch mittels RT-PCR, wobei diese zur Kontrolle mit dem housekeeping gene $\mathrm{L} 7$ abgeglichen wurde.

Mit Hilfe der RT-PCR konnte eine eindeutige KISS1-mRNA-Expression in den HEC-1aZellen, nicht aber in den Ishikawa-Zellen nachgewiesen werden (Abb. 3.4).

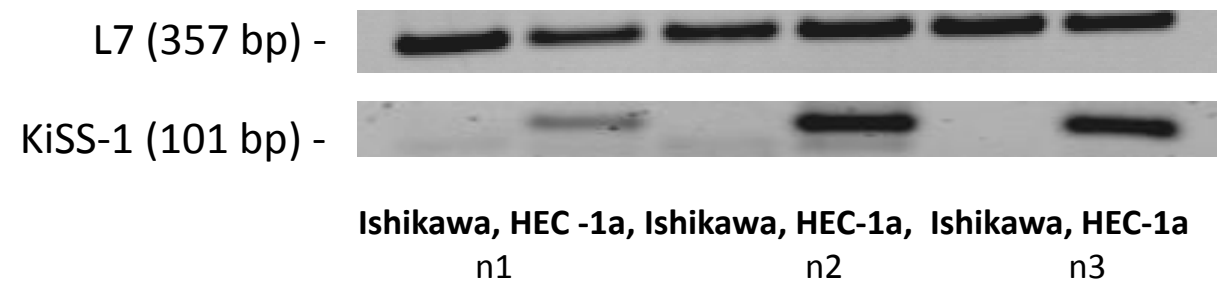

Abb. 3.4: Molekularbiologischer KISS1-Nachweis in den Endometriumkarzinomzellen Ishikawa und HEC-1a. Der qualitative Nachweis der KISS1-Expression erfolgte auf molekularbiologischer Ebene mittels RTPCR in Bezug auf das housekeeping gene L7. HEC-1a-Zellen zeigten im Vergleich zu den Ishikawa-Zellen eine deutliche KISS1-mRNA-Expression. Es wurden pro Zellinie Proben aus drei voneinander unabhängig durchgeführten Versuchen untersucht $(n=3)$.

\subsection{Invasionsverhalten humaner Endometriumkarzinomzellen}

\subsubsection{Zellspezifisches Invasionsverhalten von Ishikawa- und HEC-1a-Zellen}

Die beiden Endometriumkarzinomzelllinien Ishikawa und HEC-1a wurden jeweils für $96 \mathrm{~h}$ in matrigelbeschichteten Inserts über einem mit Medium gefüllten Well kultiviert. Nach Versuchsende wurden die Zellen, die durch das Matrigel und die Insert-Membran 
invadierten, mikroskopisch ausgezählt, um das zellspezifische, unbeeinflusste Invasionsverhalten der Zellen zu untersuchen. Es wurden mindestens drei voneinander unabhängig durchgeführte Versuche ausgewertet.

Hierbei invadierten $702 \pm 76$ Ishikawa-Zellen die matrigelbeschichtete Insert-Membran (Daten nicht gezeigt). Im gleichen Versuchsaufbau invadierten hingegen nur $37 \pm 5$ HEC-1aZellen (Daten nicht gezeigt).

Dabei muss berücksichtigt werden, dass diesem Versuch eine unterschiedliche Anzahl

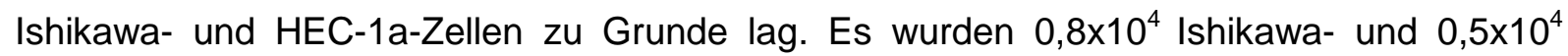
HEC-1a-Zellen verwendet. Deshalb war es nicht sinnvoll die erhobenen Daten mittels eines statistischen Tests auszuwerten. Die beiden genannten Ergebnisse waren nicht direkt miteinander vergleichbar, sondern mussten auf die Invasion pro $0,1 \times 10^{4}$ Zellen korrigiert werden. Dabei ergab sich für Ishikawa eine rechnerisch korrigierte Zellinvasion von $81 \pm 11$ Zellen und für HEC-1a von $18 \pm 11$ Zellen $(p=0,0006)$ (Abb. 3.5). Unter dieser Berücksichtigung zeigten Ishikawa-Zellen eine signifikante, um den Faktor 4,5 höhere Grundinvasivität gegenüber HEC-1a-Zellen.

Die Zellzahl der invadierten Endometriumkarzinomzellen wurde in Absolutzahlen wiedergegeben, um ein möglichst realitätsnahes Ergebnis zu erhalten.

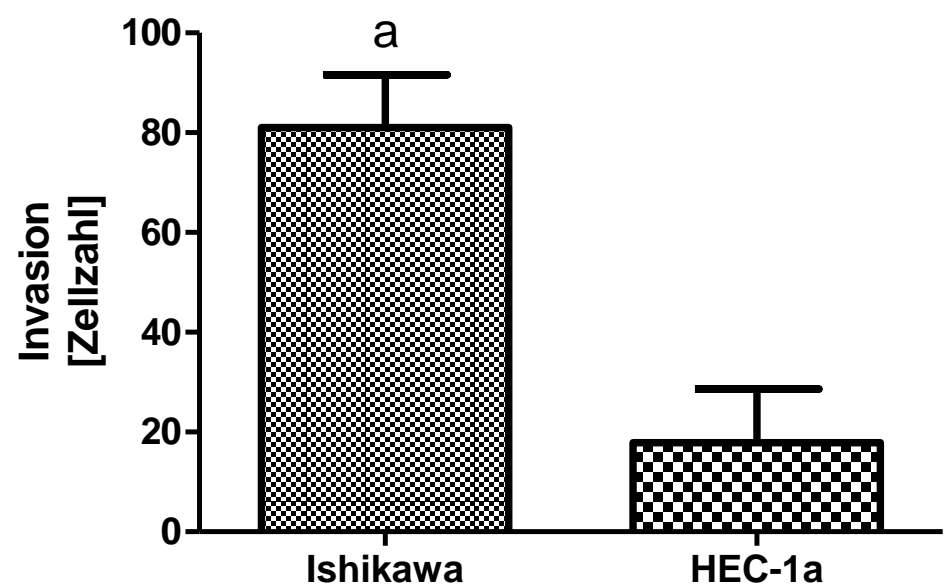

Abb. 3.5: Zellspezifisches Invasionsverhalten von Ishikawa- und HEC-1a-Zellen. Die Endometriumkarzinomzellen wurden für $96 \mathrm{~h}$ mit Medium in matrigelbeschichteten Inserts kultiviert. Es zeigte sich eine deutlich höhere Anzahl invadierter Ishikawa-Zellen als HEC-1a-Zellen. Angegeben sind die rechnerisch korrigierten $\mathrm{MW} \pm \mathrm{SEM}$ der Invasion pro $0,1 \times 10^{4}$ Zellen, die Daten wurden mittels $\mathrm{t}$-Test (ungepaart) auf signifikante Unterschiede geprüft: $a, p=0,0006$ vs. HEC-1a (Ishikawa, $n=39$; HEC-1a, $n=18$ ).

\subsubsection{Invasionsverhalten humaner Endometriumkarzinomzellen im Kokultur-System}

In vorangegangenen Arbeiten zeigte sich, dass während Kokultivierung der Mammakarzinomzellen MCF-7 mit humanen Osteoblasten-ähnlichen Zellen MG-63 eine Steigerung der Invasivität der MCF-7-Zellen erreicht wurde (Von Alten et al. 2006). 
Aufgrund dieser Ergebnisse sollte untersucht werden, ob dieses, mit Mammakarzinomzellen bereits etablierte, Kokultur-System auch mit den Endometriumkarzinomzelllinien Ishikawa und HEC-1a angewendet werden kann. Außerdem sollten eventuelle Unterschiede in dem Invasionsverhalten der beiden Endometriumkarzinomzelllinien im Kokultur-System herausgearbeitet werden. Dafür wurden die beiden Endometriumkarzinomzelllinien Ishikawa und HEC-1a für $96 \mathrm{~h}$ in matrigelbeschichteten Inserts mono- und kokultiviert. Nach Versuchsende wurden die Zellen, die durch das Matrigel und die Insert-Membran invadierten, mikroskopisch ausgezählt. In mindestens drei voneinander unabhängig durchgeführten Versuchen wurde in den Kokultur-Invasionsassays der Einfluss der Kokultivierung auf das Invasionsverhalten der Endometriumkarzinomzellen untersucht.

\subsubsection{Invasionsverhalten von Ishikawa-Zellen im Kokultur-System}

Um zum einen das Invasionsverhalten der Endometriumkarzinomzellen während der Monound Kokultivierung realitätsnah darstellen zu können, wurden die Absolutzahlen der invadierten Ishikawa-Zellen dargestellt. Die Endometriumkarzinomzellen Ishikawa zeigten monokultiviert eine hohe Anzahl invadierter Zellen (Kontrolle= $648 \pm 85$ Zellen), welche während der Kokultivierung mit MG-63-Zellen signifikant anstieg (Kokultur= $877 \pm 108$ Zellen $(p<0,0001$ vs. Kontrolle) (Abb. 3.6, A). Es lässt sich festhalten, dass Ishikawa-Zellen, welche in der Kontrolle bereits ein starkes invasives Verhalten zeigten, dieses in der Kokultur um den Faktor 1,35 erhöhten.

Zwecks Vergleichbarkeit der Daten untereinander wurden zum anderen auch die relativen Zahlen invadierter Ishikawa-Zellen dargestellt. Es zeigte sich ein Anstieg der Invasionsfähigkeit kokultivierter Ishikawa-Zellen auf 155,3 $\pm 9,9 \%$ ( $p<0,0001$ vs. Kontrolle) im Vergleich zu monokultivierten Ishikawa-Zellen (Kontrolle= $100 \%$ ) (Abb. 3.6, B).

Dabei ist zu erwähnen, dass diese Ergebnisse lediglich die Daten beinhalten, in denen sich eine Invasionssteigerung während der Kokultivierung nachweisen ließ (Voraussetzung: Kokultur $>100 \%$ im Vergleich zur Kontrolle). Dies war in ca. $70 \%$ der durchgeführten Versuche der Fall. Fasste man alle erhobenen Daten zusammen, zeigte sich weiterhin ein signifikanter Anstieg (Kokultur=129,12 $\pm 9,03 \%(p=0,0021$ vs. Kontrolle)) der invadierten Ishikawa-Zellen im Vergleich zu monokultivierten Ishikawa-Zellen (Kontrolle= $100 \%$ ) (Daten nicht gezeigt). 

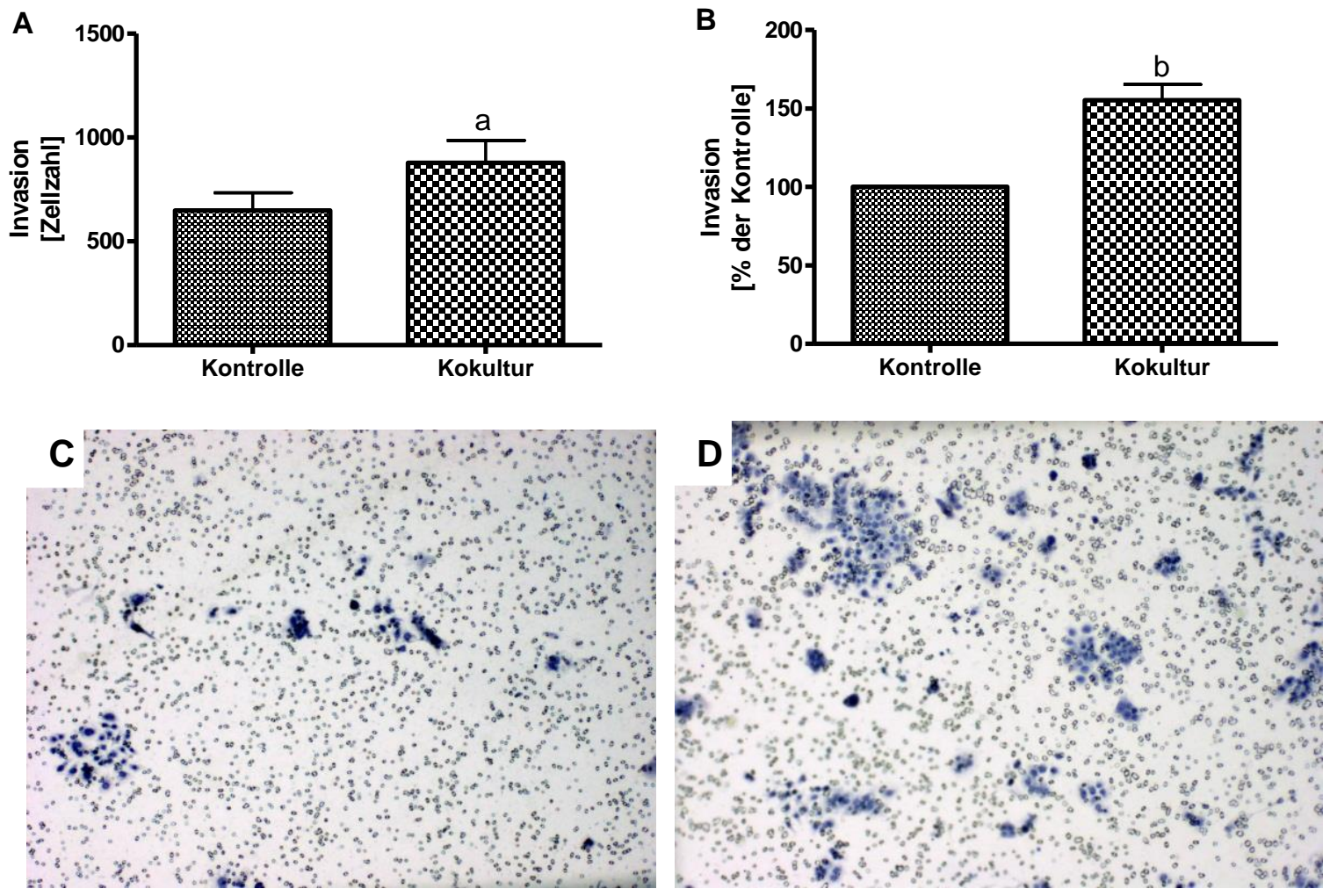

Abb. 3.6: Invasionsverhalten mono- und kokultivierter Ishikawa-Zellen. In der Kontrolle wurden die IshikawaZellen über $96 \mathrm{~h}$ mit Medium monokultiviert und in der Kokultur mit der humanen Osteoblasten-ähnlichen Zelllinie MG-63 kokultiviert. Während der Kokultivierung wurde ein signifikanter Anstieg der invadierten Ishikawa-Zellen gegenüber der Kontrolle erreicht. Angegeben sind MW \pm SEM, die Daten wurden mittels t-Test (gepaart) auf signifikante Unterschiede geprüft: $a, p<0,0001$ vs. Kontrolle $(n=39)(A) ; b, p=0,0021$ vs. Kontrolle $(n=39)(B)$. Auf der Insert-Membran ließ sich mikroskopisch während der Kokultivierung eine deutliche Zunahme der invadierten Zellen (D) im Vergleich zur Kontrolle (C) erkennen (Hämalaunfärbung).

\subsubsection{Invasionsverhalten von HEC-1a-Zellen im Kokultur-System}

Um zum einen das Invasionsverhalten der Endometriumkarzinomzellen während der Monound Kokultivierung realitätsnah darstellen zu können, wurden die Absolutzahlen der invadierten HEC-1a-Zellen dargestellt. Monokultivierte HEC-1a-Zellen zeigten, im Vergleich zu den Ishikawa-Zellen, eine geringere Anzahl invadierter Zellen (Kontrolle $=37 \pm 5$ Zellen), welche in der Kokultur signifikant anstieg (Kokultur=1793 $\pm 287(p<0,0001$ vs. Kontrolle)) (Abb. 3.7, A). Die HEC-1a-Zellen zeigten einen drastischen Invasionsanstieg in der Kokultur um den Faktor 48,5.

Zwecks Vergleichbarkeit der Daten untereinander wurden zum anderen auch die relativen Zahlen invadierter HEC-1a-Zellen abgebildet. HEC-1a-Zellen zeigten während der Kokultivierung mit den Osteoblasten-ähnlichen MG-63-Zellen eine signifikante Steigerung der Invasionsfähigkeit auf $8459 \pm 1785 \% \quad(p=0,0002$ vs. Kontrolle $)$ gegenüber monokultivierter HEC-1a-Zellen (Kontrolle=100\%) (Abb. 3.7, B). 
A
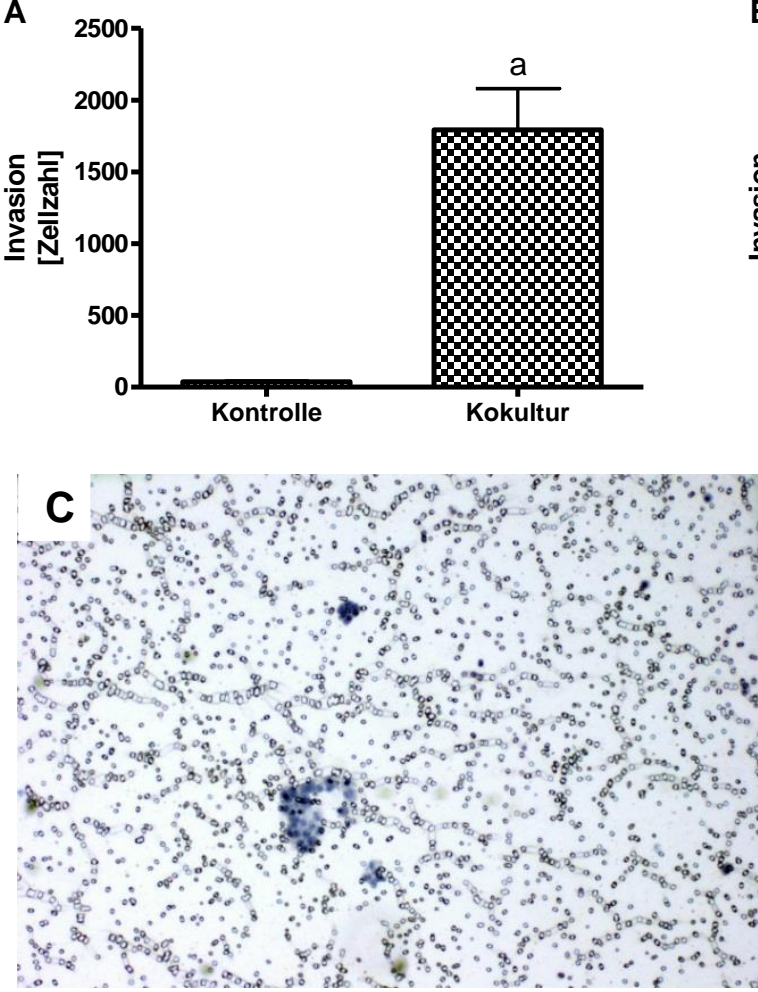

B
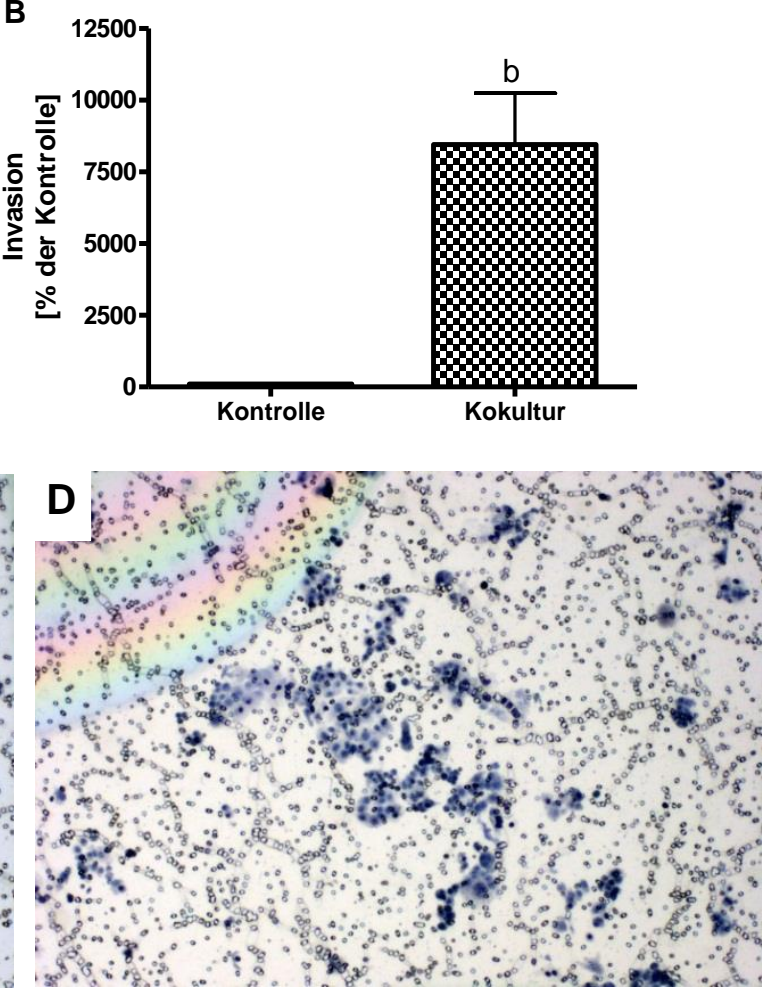

Abb. 3.7: Invasionsverhalten mono- und kokultivierter HEC-1a-Zellen. In der Kontrolle wurden die HEC-1aZellen über $96 \mathrm{~h}$ mit Medium monokultiviert und in der Kokultur mit der humanen Osteoblasten-ähnlichen Zelllinie MG-63 kokultiviert. Während der Kokultivierung wurde ein signifikanter Anstieg der invadierten HEC-1a-Zellen gegenüber der Kontrolle erreicht. Angegeben sind MW $\pm \mathrm{SEM}$, die Daten wurden mittels t-Test (gepaart) auf signifikante Unterschiede geprüft: $a, p<0,0001$ vs. Kontrolle $(n=18)(A) ; b, p=0,0002$ vs. Kontrolle $(n=18)(B)$. Auf der Insert-Membran lässt sich mikroskopisch während der Kokultivierung eine deutliche Zunahme der invadierten Zellen (D) im Vergleich zur Kontrolle (C) erkennen (Hämalaunfärbung).

\subsubsection{Einfluss von SDF-1 auf das Invasionsverhalten humaner}

\section{Endometriumkarzinomzellen}

Die beiden Endometriumkarzinomzellinien Ishikawa und HEC-1a wurden für $96 \mathrm{~h}$ in matrigelbeschichteten Inserts kultiviert. Das Versuchsmedium der Wells wurde mit dem chemotaktischen SDF-1 unterschiedlicher Isoformen und Konzentrationen angereichert. Nach Versuchsende wurden die Zellen, die durch das Matrigel und die Insert-Membran invadierten, mikroskopisch ausgezählt, um die Wirkung des Chemokins SDF-1 auf das Invasionsverhalten der Zellen zu untersuchen. In mindestens drei voneinander unabhängig durchgeführten Versuchen wurden in den SDF-1-Invasionsassays folgende Ergebnisse erhoben. 


\subsubsection{Einfluss von SDF-1 auf das Invasionsverhalten von Ishikawa-Zellen}

Nach Zugabe der SDF-1-Isoformen wurde ein Anstieg der Invasionsfähigkeit der IshikawaZellen gegenüber unstimulierter Ishikawa-Zellen (K (Kontrolle)= $100 \%$ ) erreicht (Abb. 3.8). SDF-1 a $[50 \mathrm{ng} / \mathrm{ml}]$ führte zu einer signifikanten Steigerung der invadierten Zellen auf $288,3 \pm 54 \%$ ( $p<0,001$ vs. K). Eine Konzentration von $100 \mathrm{ng} / \mathrm{ml}$ führte zu einem geringeren, signifikanten Anstieg der Invasionsfähigkeit der Ishikawa-Zellen (SDF-1 a $[100 \mathrm{ng} / \mathrm{ml}]=222,4 \pm 72,75 \%(p<0,05$ vs. K)) gegenüber der Kontrolle.

Sowohl SDF-1 $\beta[50 \mathrm{ng} / \mathrm{ml}]$ als auch SDF-1 $\beta[100 \mathrm{ng} / \mathrm{ml}]$ führten zu einem signifikanten Anstieg invadierter Ishikawa-Zellen (SDF-1 $\beta \quad[50 \mathrm{ng} / \mathrm{ml}]=259 \pm 50,2 \% \quad(p<0,05$ vs. K); SDF-1 $\beta[100 \mathrm{ng} / \mathrm{ml}]=324,2 \pm 92,76 \%(p<0,001$ vs. K) gegenüber der Kontrolle.

Nach Zugabe von SDF-1 $\alpha / \beta$ wurde ebenfalls eine signifikante Induktion der IshikawaZellinvasion $\quad(S D F-1 \alpha / \beta \quad[50 \mathrm{ng} / \mathrm{ml}]=246,3 \pm 48,43 \% \quad(p<0,05 \quad$ vs. $\quad K) ; \quad S D F-1 \alpha / \beta$ $[100 \mathrm{ng} / \mathrm{ml}]=303,4 \pm 83,13 \%(p<0,001$ vs. K)) im Vergleich zu der Kontrolle erzielt.

Sowohl SDF-1 $\alpha$ und $\beta$ als auch die gleichzeitige Verwendung beider Isoformen erzielten eine signifikante Zunahme invadierter Ishikawa-Zellen. Die Zugabe von SDF-1 $\beta$ und SDF-1 $\alpha / \beta$ führte in einer Konzentration von $100 \mathrm{ng} / \mathrm{ml}$ zu einem höheren Anstieg der Invasion als mit $50 \mathrm{ng} / \mathrm{ml}$, wobei dieser Anstieg keine Signifikanz gegenüber der geringeren Konzentration zeigte. SDF-1 $\alpha$ und SDF-1 $\beta$ [50 ng/ml] induzierten eine ähnlich starke Invasionssteigerung.

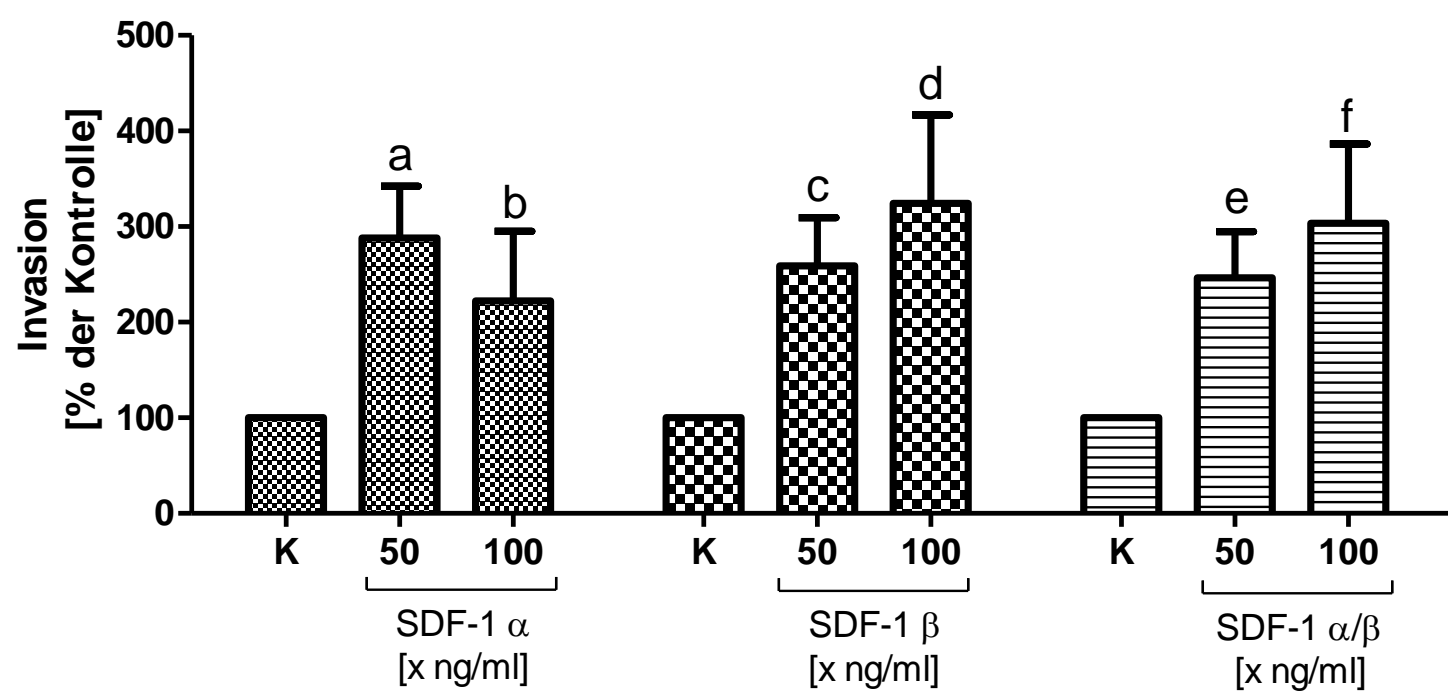

Abb. 3.8: Einfluss von SDF-1 auf das Invasionsverhalten von Ishikawa-Zellen. In der Kontrolle (K) wurden die Ishikawa-Zellen über $96 \mathrm{~h}$ mit Medium kultiviert. Durch Zugabe von SDF-1 $\alpha, \beta$ und $\alpha / \beta$ [50 ng/ml] und [100 ng/ml] wurde eine signifikante Steigerung der Invasionsfähigkeit der Ishikawa-Zellen gegenüber unbehandelter Ishikawa-Zellen erreicht. Angegeben sind MW $\pm \mathrm{SEM}$, die Daten wurden mittels one-way ANOVA, gefolgt vom Student-Newman-Keuls Test auf signifikante Unterschiede geprüft: $a, p<0,001$ vs. K; $b, p<0,05$ vs. K; $c, p<0,05$ vs. $K$; $d, p<0,001$ vs. $K$; $e, p<0,05$ vs. $K ; f, p<0,001$ vs. $K(n=13,14)$. 


\subsubsection{Einfluss von SDF-1 auf das Invasionsverhalten von HEC-1a-Zellen}

Nach Zugabe der SDF-1-Isoformen wurde ein Anstieg der Invasionsfähigkeit der HEC-1aZellen gegenüber unstimulierter HEC-1a-Zellen (K (Kontrolle) $=100 \%$ ) erreicht (Abb. 3.9).

SDF-1 a $[50 \mathrm{ng} / \mathrm{ml}]$ steigerte die Invasionsfähigkeit der HEC-1a-Zellen signifikant auf $297,7 \pm 57,53 \%$ sowohl gegenüber der Kontrolle $(p<0,0001)$ als auch gegenüber der mit SDF-1 a $[100 \mathrm{ng} / \mathrm{ml}]$ behandelten Zellen $(p<0,001)$. SDF-1 a $[100 \mathrm{ng} / \mathrm{ml}]$ führte zu einem nicht signifikanten Anstieg der Invasion auf 174,4 $\pm 24,12 \%$ im Vergleich zu der Kontrolle.

Sowohl SDF-1 $\beta$ [50 ng/ml] (286,1 $\pm 41,00 \%(p<0,0001$ vs. K)) als auch SDF-1 $\beta$ [100 ng/ml] $(201,1 \pm 39,35 \%(p<0,001$ vs. K)) führten zu einem signifikanten Anstieg der invadierten HEC-1a-Zellen. Darüber hinaus ließ sich eine Signifikanz des SDF-1 $\beta-[50 \mathrm{ng} / \mathrm{ml}]$-bedingten Anstiegs im Vergleich zu SDF-1 $\beta[100 \mathrm{ng} / \mathrm{ml}]$ nachweisen $(p<0,05)$.

Durch die Zugabe von SDF1 $\alpha / \beta$ [50 ng/ml] wurde ein signifikanter invasionsfördernder Effekt auf $296,7 \pm 49,07 \%$ ( $p<0,0001$ vs. K) und durch SDF-1 $\alpha / \beta[100 \mathrm{ng} / \mathrm{ml}]$ auf $202,0 \pm 34,18 \%$ $(p<0,05$ vs. K) gegenüber der Kontrolle gezeigt. Der Unterschied der erreichten Invasionssteigerung von SDF1 $\alpha / \beta[50 \mathrm{ng} / \mathrm{ml}]$ gegenüber SDF1 $\alpha / \beta[100 \mathrm{ng} / \mathrm{ml}]$ war ebenfalls signifikant $(p<0,05)$.

SDF-1 x [50 ng/ml] bewirkte eine signifikant stärkere Invasionssteigerung als SDF-1x [100 ng/ml]. Die jeweiligen Isoformen führten zu einer ähnlich hohen Invasionssteigerung.

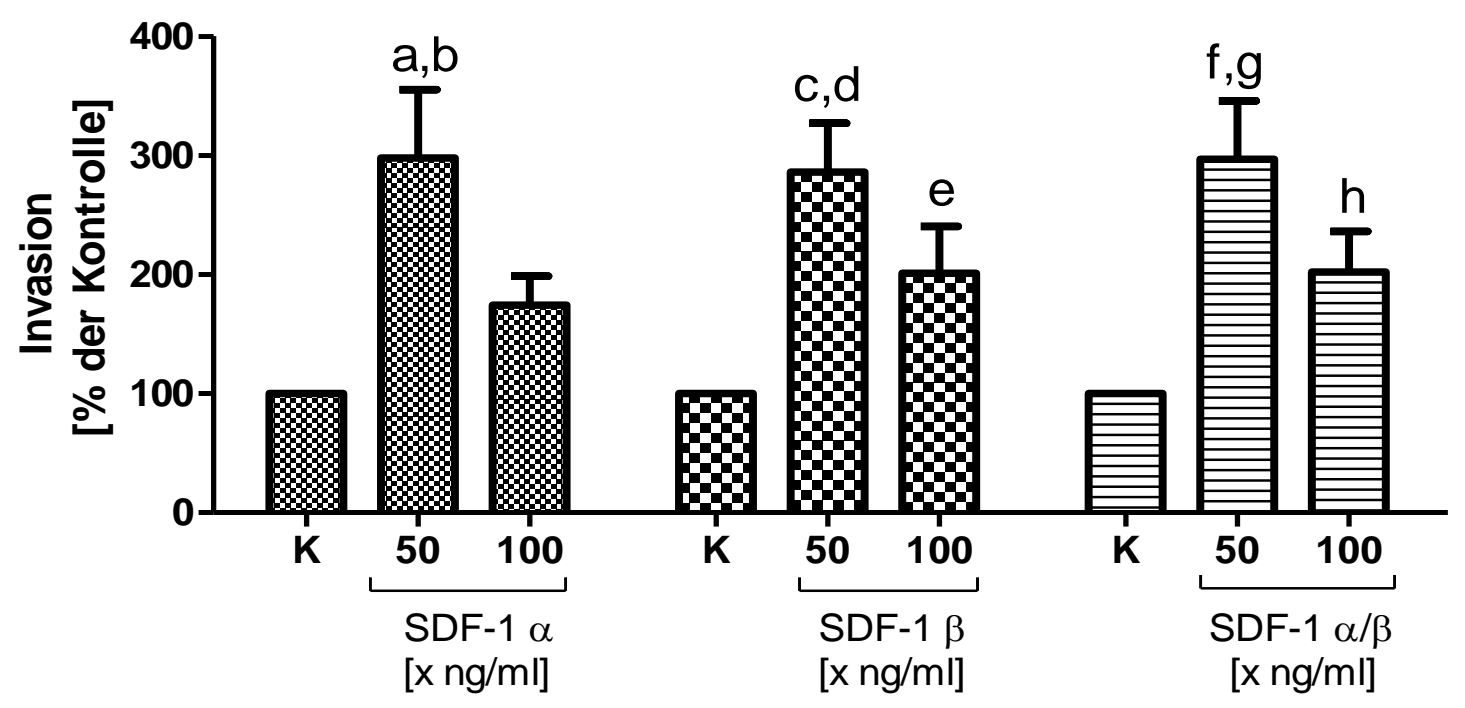

Abb. 3.9: Einfluss von SDF-1 auf das Invasionsverhalten von HEC-1a-Zellen. In der Kontrolle (K) wurden die HEC-1a-Zellen über $96 \mathrm{~h}$ mit Medium kultiviert. Durch Zugabe von SDF-1 $\alpha, \beta$ und $\alpha / \beta[50 \mathrm{ng} / \mathrm{ml}]$ und SDF-1 $\beta$ und $\alpha / \beta[100 \mathrm{ng} / \mathrm{ml}]$ wurde eine signifikante Steigerung der Invasionsfähigkeit der HEC-1a-Zellen gegenüber unbehandelter HEC-1a-Zellen erreicht. Der Invasionsanstieg, der durch SDF-1 $\alpha, \beta$ und $\alpha / \beta$ [50 ng/ml] erreicht wurde, war gegenüber [100 ng/ml] signifikant. Angegeben sind MW $\pm \mathrm{SEM}$, die Daten wurden mittels one-way ANOVA, gefolgt vom Student-Newman-Keuls Test auf signifikante Unterschiede geprüft: $a, p<0,0001$ vs. K; $b$, $p<0,001$ vs. SDF-1 a [100 ng/ml]; c, $p<0,0001$ vs. K; d, $p<0,05$ vs. SDF-1 $\beta$ [100 ng/ml]; e, $p<0,001$ vs. K; f, $p<0,0001$ vs. $K ; g, p<0,05$ vs. SDF-1 $\alpha / \beta[100 \mathrm{ng} / \mathrm{ml}] ; \mathrm{h}, \mathrm{p}<0,05$ vs. $K(n=14)$. 


\title{
3.4 Einfluss von Kisspeptin-10 auf das Invasionsverhalten humaner Endometriumkarzinomzellen
}

\author{
3.4.1 Einfluss von Kisspeptin-10 auf die Invasion humaner \\ Endometriumkarzinomzellen im Kokultur-System
}

In vorangegangenen Arbeiten zeigte sich, dass Kisspeptin-10 dosisabhängig einen inhibierenden Einfluss auf die Invasionsfähigkeit kokultivierter MCF-7-Mammakarzinomzellen besitzt (Olbrich et al. 2010). Aufgrund dieser Ergebnisse sollte untersucht werden, ob und in welchen Konzentrationen Kisspeptin-10 einen Effekt auf die Invasionsfähigkeit kokultivierter humaner Endometriumkarzinomzellen zeigt.

Die beiden Endometriumkarzinomzellinien Ishikawa und HEC-1a wurden für $96 \mathrm{~h}$ in matrigelbeschichteten Inserts mit Osteoblasten-ähnlichen MG-63-Zellen kokultiviert. Kisspeptin-10-Behandlungen unterschiedlicher Konzentration wurden in einem 12-h-Intervall durchgeführt. Nach Versuchsende wurden die Zellen, die durch das Matrigel und die InsertMembran invadierten, mikroskopisch ausgezählt. In mindestens drei voneinander unabhängig durchgeführten Versuchen pro Kisspeptin-10-Konzentration wurden in den Kokultur-Invasionsassays folgende Ergebnisse erhoben.

\subsubsection{Einfluss von Kisspeptin-10 auf die Invasion von Ishikawa-Zellen im Kokultur-}

\section{System}

In diesem Versuch zeigte sich, dass die Invasionsfähigkeit kokultivierter Ishikawa-Zellen durch eine Behandlung mit Kisspeptin-10, im Vergleich zu unbehandelten kokultivierten Ishikawa-Zellen (Kokultur $=100 \%$ dosisabhängig reduziert wurde (KP-10 $\left[1 \times 10^{-15} \mathrm{M}\right]=103,6 \pm 9,312 \%$ (n.s. vs. Kokultur); KP-10 $\left[1 \times 10^{-14} \mathrm{M}\right]=124,3 \pm 9,18 \%$ (n.s. vs. Kokultur); KP-10 $\left[1 \times 10^{-13} \mathrm{M}\right]=46,03 \pm 7,099 \% \quad(\mathrm{p}<0,0001 \quad$ vs. Kokultur $) ; \quad \mathrm{KP}-10$ $\left[1 \times 10^{-12} \mathrm{M}\right]=56,56 \pm 6,7 \% \quad(\mathrm{p}<0,001 \quad$ vs. Kokultur $) ; \quad \mathrm{KP}-10 \quad\left[1 \times 10^{-11} \mathrm{M}\right]=55,83 \pm 4,6 \%$ $\left(p<0,001\right.$ vs. Kokultur); KP-10 $\left[1 \times 10^{-9} \mathrm{M}\right]=85,86 \pm 11,4 \%$ (n.s. vs. Kokultur); KP-10 $\left[1 \times 10^{-7} \mathrm{M}\right]=100,8 \pm 11,4 \%$ (n.s. vs. Kokultur)) (Abb. 3.10). Der Konzentrationsbereich, in dem die signifikante Reduktion der Invasionsfähigkeit zu beobachten war, befand sich zwischen $1 \times 10^{-13} \mathrm{M}$ und $1 \times 10^{-11} \mathrm{M}$. Dieses Phänomen wird als Fenstereffekt bezeichnet, da Kisspeptin-10 nur in diesem bestimmten Bereich seine hemmende Wirkung auf die Invasion entfaltet. 
Zusätzlich zeigte sich, dass die Invasionsfähigkeit bei einer Behandlung mit einer Kisspeptin10-Konzentration von $1 \times 10^{-6} \mathrm{M}$ im Vergleich zur unbehandelten Kokultur (Kokultur= $100 \%$ ) signifikant gesteigert wurde (KP-10 $\left[1 \times 10^{-6} \mathrm{M}\right]=141,1 \pm 16,55 \%(\mathrm{p}<0,05$ vs. Kokultur)).

Diese Ergebnisse beinhalten lediglich die Daten, in denen während der Kokultivierung eine invasionsfördernde Wirkung gegenüber der Kontrolle bewirkt wurde (Voraussetzung: Kokultur $>100 \%$ im Vergleich zur Kontrolle= $100 \%$ ) (Kapitel 3.3.2.1).

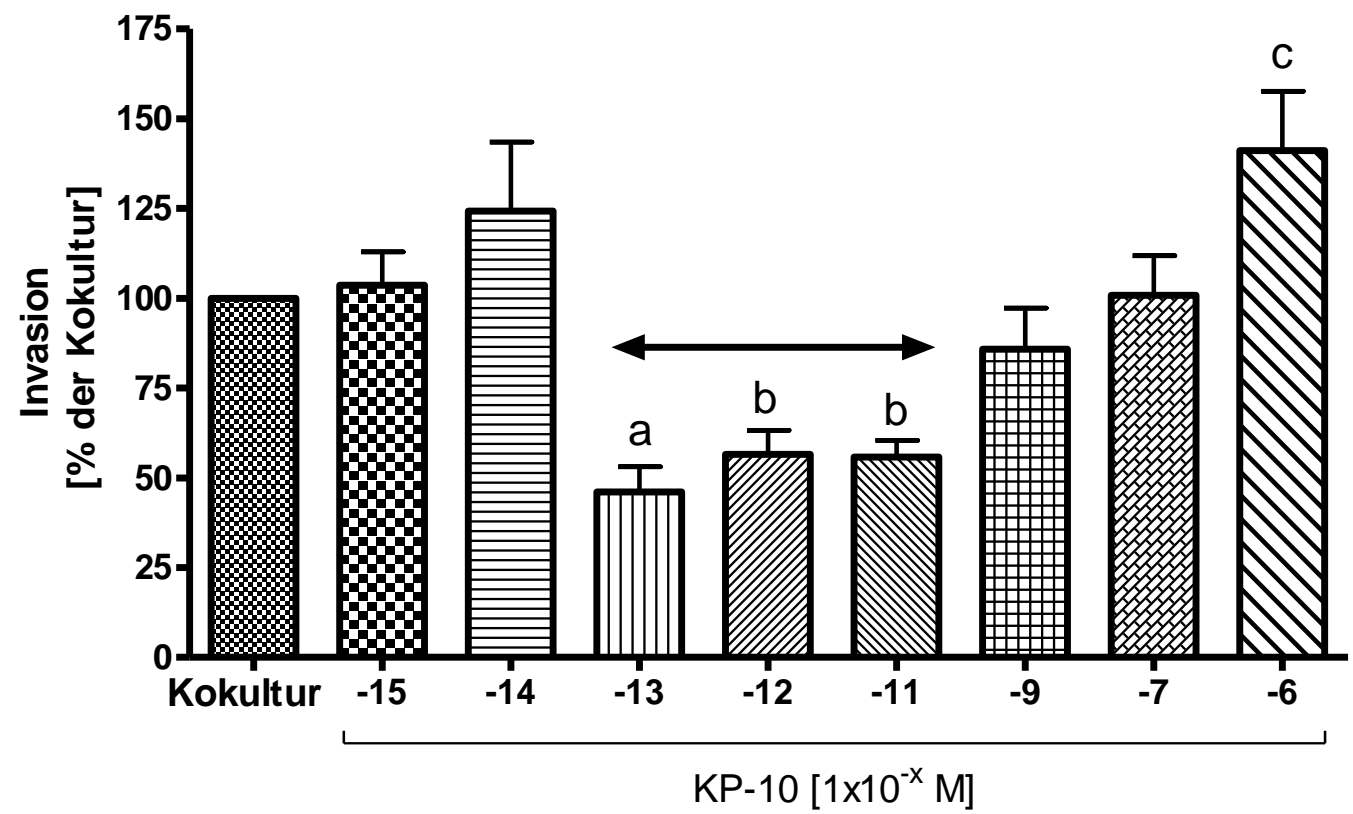

Abb. 3.10: Einfluss von Kisspeptin-10 auf die Invasion kokultivierter Ishikawa-Zellen. In der Kokultur wurden die Ishikawa-Zellen über 96 h mit der humanen Osteoblasten-ähnlichen Zelllinie MG-63 kokultiviert. Die Behandlung der kokultivierten Ishikawa-Zellen mit KP-10 alle $12 \mathrm{~h}$ führte zu einer signifikanten dosisabhängigen Reduktion der während der Kokultivierung gesteigerten Invasion in einem Konzentrationsbereich zwischen $1 \times 10^{-13} \mathrm{M}$ und $1 \times 10^{-11} \mathrm{M}$. Hierbei handelt es sich um einen Fenstereffekt, da KP-10 nur in diesem Konzentrationsbereich seine antiinvasive Wirkung entfaltet. Ein signifikanter Anstieg der Invasionsfähigkeit zeigte sich mit einer KP-10-Konzentration von $1 \times 10^{-6} \mathrm{M}$. Angegeben sind MW $\pm \mathrm{SEM}$, die Daten wurden mittels one-way ANOVA gefolgt vom Student-Newman-Keuls Test auf signifikante Unterschiede geprüft: $a, p<0,0001$ vs. Kokultur; b, $p<0,001$ vs. Kokultur; $c, p<0,05$ vs. Kokultur $(n=8-9)$.

\subsubsection{Einfluss von Kisspeptin-10 auf die Invasion von HEC-1a-Zellen im Kokultur-}

\section{System}

Bei einer Behandlung der kokultivierten HEC-1a-Zellen mit Kisspeptin-10 wurde eine Reduktion der Invasionsfähigkeit der HEC-1a-Zellen gegenüber der unbehandelten Kokultur (Kokultur $=100 \%)$ gezeigt $\left(\mathrm{KP}-10\left[1 \times 10^{-14} \mathrm{M}\right]=86,85 \pm 13,84 \%\right.$ (n.s. vs. Kokultur); KP-10 $\left[1 \times 10^{-11} M\right]=65,85 \pm 9,36 \%$ (p<0,05 vs. Kokultur); KP-10 $\left[1 \times 10^{-9} M\right]=85,28 \pm 7,26 \%$ (n.s. vs. Kokultur); KP-10 $\left[1 \times 10^{-7} \mathrm{M}\right]=88,31 \pm 10,62 \%$ (n.s. vs. Kokultur)). Eine Signifikanz des hemmenden Einflusses von Kisspeptin-10 auf die Invasionsfähigkeit von HEC-1a zeigte sich bei einer Kisspeptin-10-Konzentration von $1 \times 10^{-11} \mathrm{M}$. Ein geringer, nicht signifikanter Anstieg 
invadierter HEC-1a-Zellen gegenüber der Kontrolle war bei Kisspeptin-10-Konzentrationen von $1 \times 10^{-13} \mathrm{M}$ und $1 \times 10^{-12} \mathrm{M}$ zu erkennen (KP-10 $\left[1 \times 10^{-13} \mathrm{M}\right]=113,5 \pm 11,19 \%$ (n.s. vs. Kokultur); KP-10 $\left[1 \times 10^{-12} \mathrm{M}\right]=106,3 \pm 7,66 \%$ (n.s. vs. Kokultur)) (Abb. 3.11).

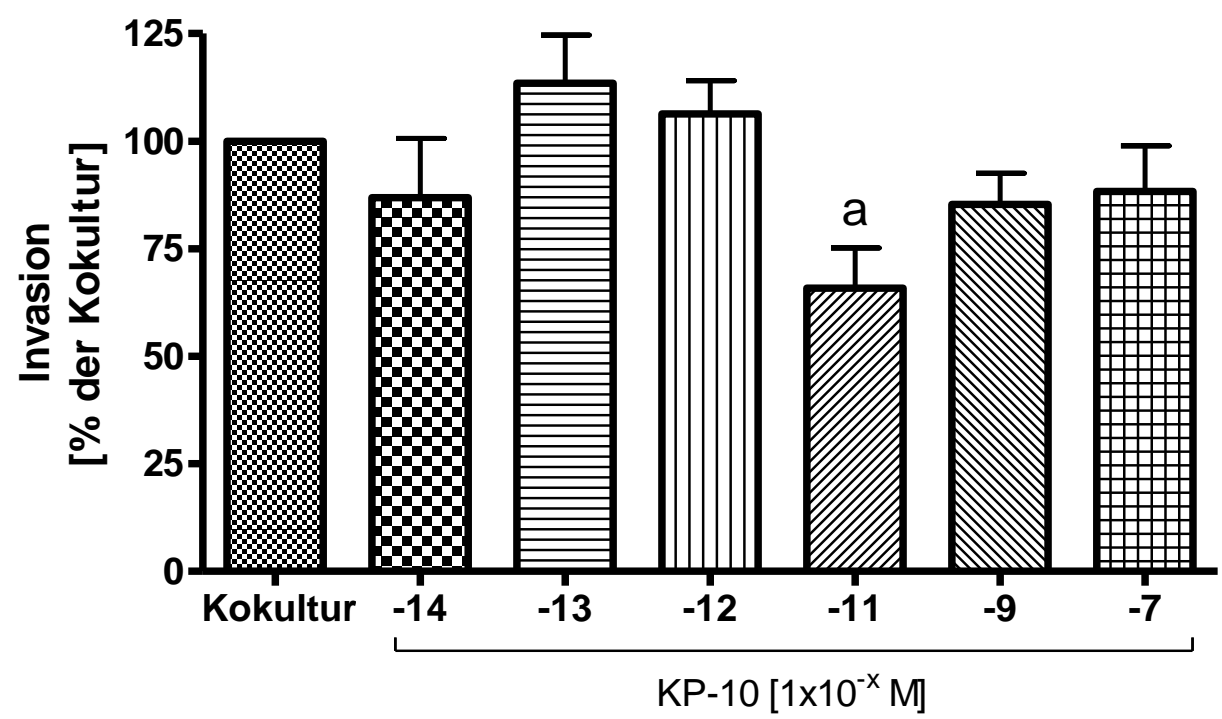

Abb. 3.11: Einfluss von Kisspeptin-10 auf die Invasion kokultivierter HEC-1a-Zellen. In der Kokultur wurden die HEC-1a-Zellen über $96 \mathrm{~h}$ mit der humanen Osteoblasten-ähnlichen Zelllinie MG-63 kokultiviert. Die Behandlung der kokultivierten HEC-1a-Zellen mit KP-10 alle $12 \mathrm{~h}$ führte zur einer signifikanten Reduktion der während der Kokultivierung gesteigerten Invasion bei einer Konzentration von $1 \times 10^{-11} \mathrm{M}$. Angegeben sind $\mathrm{MW} \pm \mathrm{SEM}$, die Daten wurden mittels one-way ANOVA, gefolgt vom Student-Newman-Keuls Test auf signifikante Unterschiede geprüft: $a, p<0,05$ vs. Kokultur $(n=9)$.

\subsubsection{Einfluss von Kisspeptin-10 auf die SDF-1-induzierte Invasion humaner}

\section{Endometriumkarzinomzellen}

Die beiden Endometriumkarzinomzelllinien Ishikawa und HEC-1a wurden für $96 \mathrm{~h}$ in matrigelbeschichteten Inserts kultiviert. Das Versuchsmedium in den Wells wurde mit SDF-1 unterschiedlicher Isoformen und Konzentrationen angereichert. Kisspeptin-10-Behandlungen wurden in einem 12-h-Intervall durchgeführt, wobei die Konzentration gewählt wurde, die im vorherigen Versuchsaufbau die stärkste antiinvasive Wirkung zeigte (Kapitel 3.4.1.1 und 3.4.1.2). Nach Versuchsende wurden die Zellen, die durch das Matrigel und die InsertMembran invadierten, mikroskopisch ausgezählt, um den Effekt von Kisspeptin-10 auf die SDF-1-induzierte Invasionsfähigkeit der Zellen zu untersuchen. In mindestens drei voneinander unabhängig durchgeführten Versuchen wurden in den SDF-1-Invasionsassays folgende Ergebnisse erhoben. 


\subsubsection{Einfluss von Kisspeptin-10 auf die SDF-1-induzierte Invasion von Ishikawa-}

\section{Zellen}

Durch die Kisspeptin-10-Behandlung $\left[1 \times 10^{-13} \mathrm{M}\right]$ zeigte sich eine Reduktion der SDF-1induzierten Invasionsfähigkeit der Ishikawa-Zellen (SDF-1 $\alpha+\mathrm{KP}-10$ $\left[1 \times 10^{-13} \mathrm{M}\right]=62,13 \pm 9,54 \% \quad(\mathrm{p}=0,0054 \quad$ vs. SDF-1 $\alpha \quad[50 \mathrm{ng} / \mathrm{ml}]) ; \quad$ SDF $-1 \beta+\mathrm{KP}-10$ $\left[1 \times 10^{-13} \mathrm{M}\right]=75,77 \pm 18,43 \% \quad$ (n.s. $\quad$ vs. SDF-1 $\left.\beta \quad[50 \mathrm{ng} / \mathrm{ml}]\right) ; \quad$ SDF-1 $\alpha / \beta+\mathrm{KP}-10$ $\left[1 \times 10^{-13} \mathrm{M}\right]=77,13 \pm 6,3 \% \quad(p=0,0084$ vs. SDF $\left.1 \alpha / \beta \quad[50 \mathrm{ng} / \mathrm{ml}])\right) \quad \mathrm{im}$ Vergleich $\mathrm{zu}$ den unbehandelten, mit SDF-1 $x \quad[50 \mathrm{ng} / \mathrm{ml}]$ stimulierten, Ishikawa-Zellen (SDF-1 $\mathrm{x}$ $[50 \mathrm{~g} / \mathrm{ml}]=100 \%)($ Abb. $3.12, \mathrm{~A})$.

Durch die Kisspeptin-10-Behandlung $\left[1 \times 10^{-13} \mathrm{M}\right]$ wurde die SDF-1-[100 ng/ml]-induzierte Invasionsfähigkeit der Ishikawa-Zellen (SDF-1 x [100 ng/ml]=100\%) nicht signifikant verändert (SDF-1 $\alpha+\mathrm{KP}-10\left[1 \times 10^{-13} \mathrm{M}\right]=150,7 \pm 26,22 \%$ (n.s. vs. SDF-1 $\alpha \quad[100 \mathrm{ng} / \mathrm{ml}]$ ); SDF $-1 \beta+\mathrm{KP}-10 \quad\left[1 \times 10^{-13} \mathrm{M}\right]=93,81 \pm 9,1 \% \quad$ (n.s. $\quad$ vs. $\quad$ SDF $\left.-1 \beta \quad[100 \mathrm{ng} / \mathrm{ml}]\right)$; SDF-1 $\alpha / \beta+K P-10 \quad\left[1 \times 10^{-13} \mathrm{M}\right]=88,04 \pm 19,15 \% \quad$ (n.s. $\quad$ vs. $\quad$ SDF $\left.\left.-1 \alpha / \beta \quad[100 \mathrm{ng} / \mathrm{ml}]\right)\right)$ (Abb. 3.12, B).

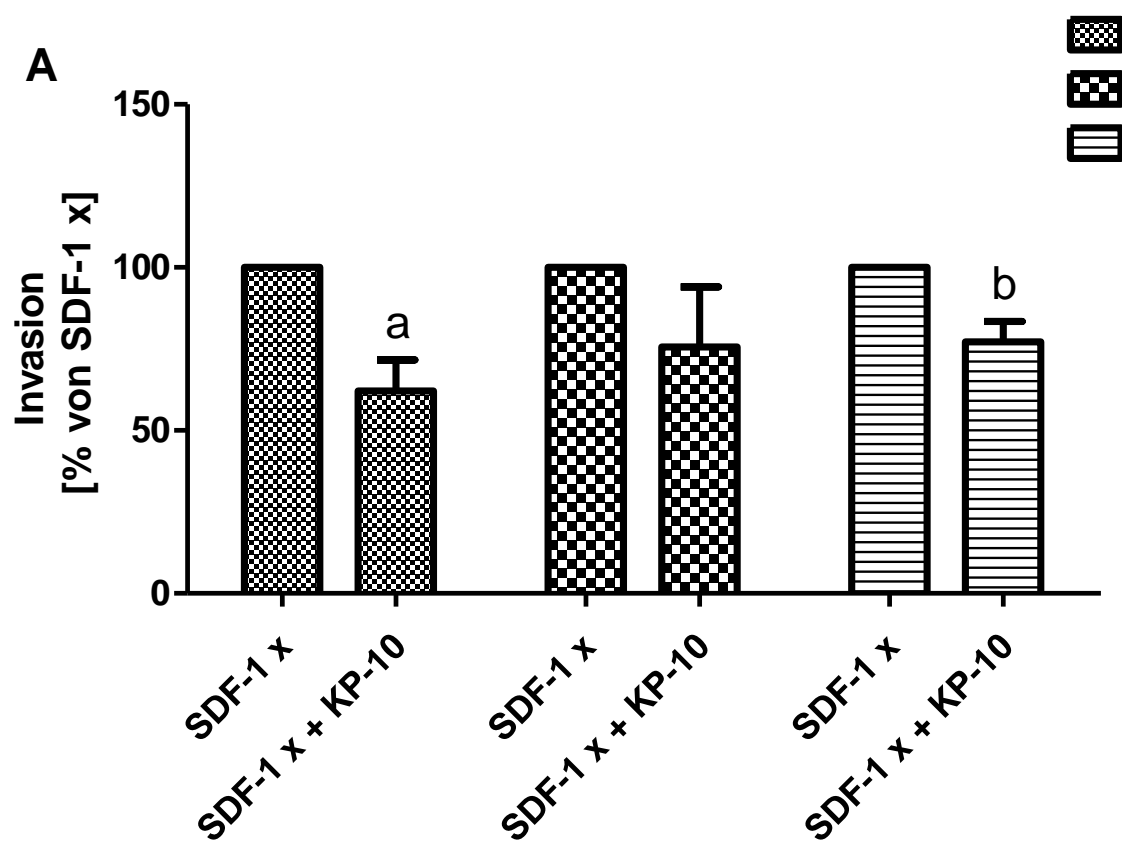




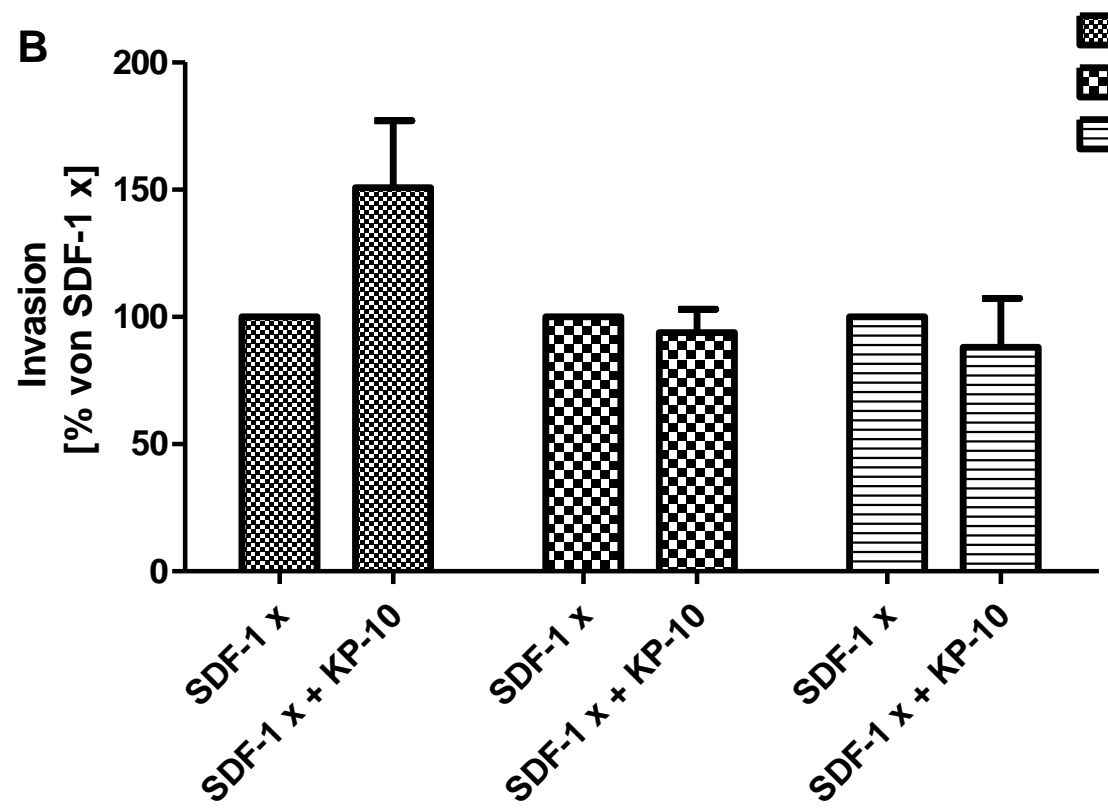

Abb. 3.12: Einfluss von Kisspeptin-10 auf die SDF-1-induzierte Invasion von Ishikawa-Zellen. Der Versuch wurde über $96 \mathrm{~h}$ angesetzt. Das Medium wurde mit SDF-1 x [50 ng/ml] angereichert. Eine gleichzeitige Behandlung der Ishikawa-Zellen mit KP-10 $\left[1 \times 10^{-13} \mathrm{M}\right]$ alle $12 \mathrm{~h}$ führte zu einer Reduktion der SDF-1 $\alpha-$ und $\alpha / \beta-$ $[50 \mathrm{ng} / \mathrm{ml}$ ]-induzierten Invasion. Angegeben sind $\mathrm{MW} \pm \mathrm{SEM}$, die Daten wurden mittels t-Test (gepaart) auf signifikante Unterschiede geprüft: $a, p=0,0054$ vs. SDF-1 $\alpha$ [50 ng/ml]; b, $p=0,0084 \mathrm{vs.} \mathrm{SDF-1} \mathrm{\alpha / \beta}$ [50 ng/ml] $(n=8)(A)$. Das Medium wurde mit SDF-1 x [100 ng/ml] angereichert. Eine gleichzeitige Behandlung der IshikawaZellen mit KP-10 $\left[1 \times 10^{-13} \mathrm{M}\right]$ alle $12 \mathrm{~h}$ führte zu keiner signifikanten Veränderung der SDF-1 x-[100 ng/ml]induzierten Invasion. Angegeben sind $\mathrm{MW} \pm \mathrm{SEM}$, die Daten wurden mittels $\mathrm{t}-\mathrm{Test}$ (gepaart) auf signifikante Unterschiede geprüft: n.s. vs. SDF-1 x [100 ng/ml] $(n=7)(B)$.

\subsubsection{Einfluss von Kisspeptin-10 auf die SDF-1-induzierte Invasion von HEC-1a-}

\section{$\underline{\text { Zellen }}$}

Durch die Kisspeptin-10-Behandlung $\left[1 \times 10^{-11} \mathrm{M}\right]$ zeigte sich eine signifikante Reduktion der SDF-1-induzierten Invasionsfähigkeit der HEC-1a-Zellen (SDF-1 $\alpha+$ KP-10 $\left[1 \times 10^{-11} \mathrm{M}\right]=54,23 \pm 11,25 \% \quad(p=0,0047 \quad$ vs. SDF-1 $\alpha \quad[50 \mathrm{ng} / \mathrm{ml}]) ; \quad S D F-1 \beta+K P-10$ $\left[1 \times 10^{-11} \mathrm{M}\right]=64,31 \pm 13,29 \% \quad(p=0,0313 \quad$ vs. SDF-1 $\beta \quad[50 \mathrm{ng} / \mathrm{ml}]) ; \quad S D F-1 \alpha / \beta+K P-10$ $\left[1 \times 10^{-11} \mathrm{M}\right]=67,88 \pm 15,65 \%$ (n.s. vs. SDF-1 $\left.\alpha / \beta[50 \mathrm{ng} / \mathrm{ml}]\right)$ ) im Vergleich $z u$ den unbehandelten, mit SDF-1 x [50 ng/ml] stimulierten, HEC-1a-Zellen (SDF-1 $x$ $[50 \mathrm{ng} / \mathrm{ml}]=100 \%)($ Abb. 3.13, A).

Durch die Kisspeptin-10-Behandlung $\left[1 \times 10^{-11} \mathrm{M}\right]$ zeigte sich ebenfalls eine Veränderung der SDF-1-induzierten Invasionsfähigkeit der HEC-1a-Zellen (SDF-1 $\alpha+$ KP-10 $\left[1 \times 10^{-11} \mathrm{M}\right]=92,82 \pm 20,31 \% \quad$ (n.s. $\quad$ vs. $\quad$ SDF-1 $\left.\alpha \quad[100 \mathrm{ng} / \mathrm{ml}]\right) ; \quad$ SDF-1 $\beta+\mathrm{KP}-10$ $\left[1 \times 10^{-11} \mathrm{M}\right]=74,07 \pm 5,94 \% \quad$ (n.s. $\quad$ vs. $\quad$ SDF-1 $\left.\beta \quad[100 \mathrm{ng} / \mathrm{ml}]\right) ; \quad S D F-1 \alpha / \beta+K P-10$ $\left[1 \times 10^{-11} \mathrm{M}\right]=68,01 \pm 9,29 \%(p=0,018$ vs. SDF-1 $\left.\alpha / \beta[100 \mathrm{ng} / \mathrm{ml}])\right)$ im Vergleich zu den 
unbehandelten, mit SDF-1 $x \quad[100 \mathrm{ng} / \mathrm{ml}]$ stimulierten, HEC-1a-Zellen (SDF-1 $\mathrm{x}$ $[100 \mathrm{ng} / \mathrm{ml}]=100 \%$, wobei eine signifikante Reduktion der SDF-1 a/ $\beta$-induzierten Invasionssteigerung zu erkennen war (Abb. 3.13, B).
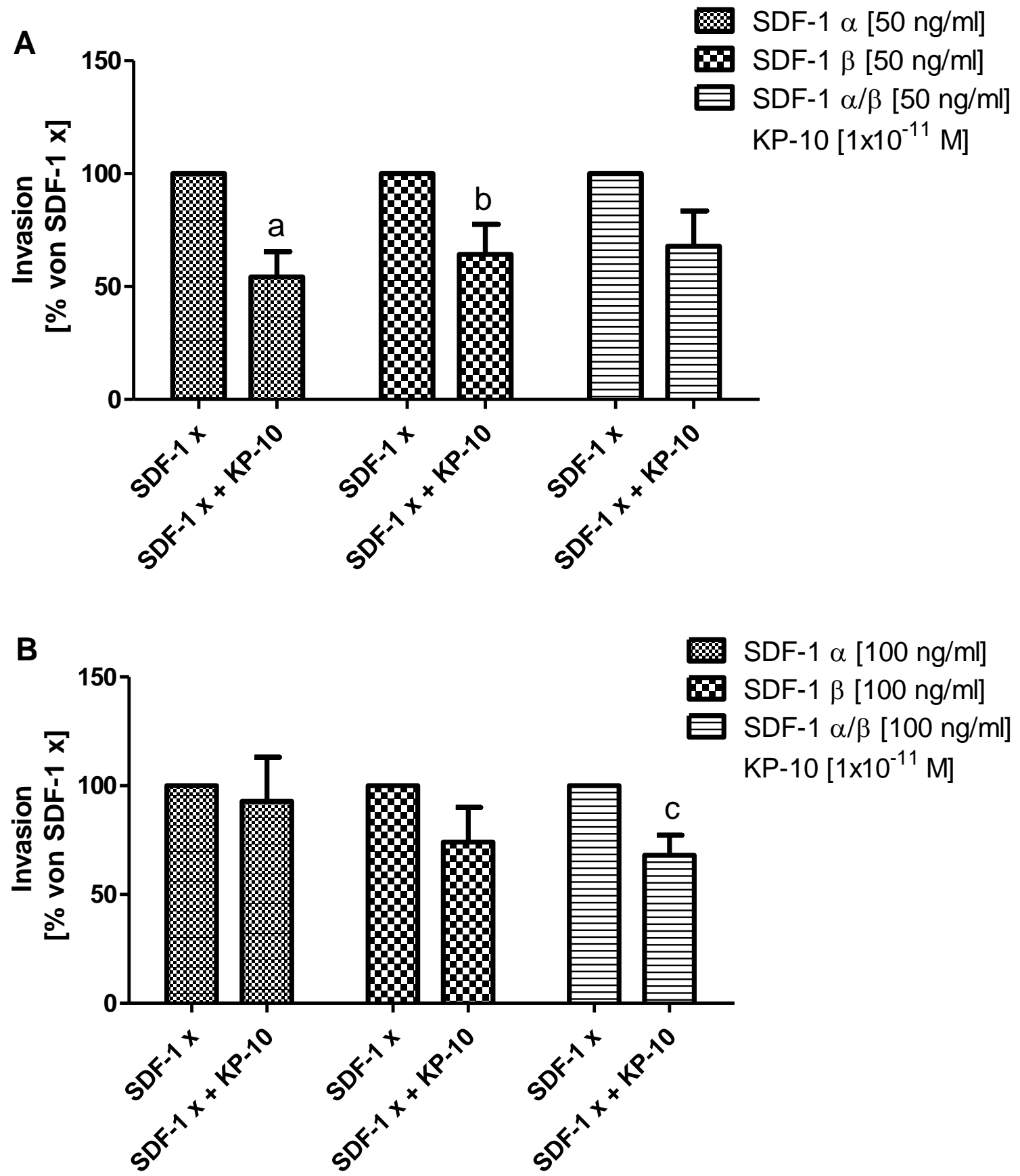

Abb. 3.13: Einfluss von Kisspeptin-10 auf die SDF-1-induzierte Invasion von HEC-1a-Zellen. Der Versuch wurde über $96 \mathrm{~h}$ angesetzt. Das Medium wurde mit SDF-1 x [50 ng/ml] angereichert. Eine gleichzeitige Behandlung der HEC-1a-Zellen mit KP-10 $\left[1 \times 10^{-11} \mathrm{M}\right]$ alle $12 \mathrm{~h}$ führte zu einer Reduktion der SDF-1 $\alpha-$ und $\beta$ $[50 \mathrm{ng} / \mathrm{ml}]$-induzierten Invasion. Angegeben sind $\mathrm{MW} \pm \mathrm{SEM}$, die Daten wurden mittels $\mathrm{t}$-Test (gepaart) auf signifikante Unterschiede geprüft: $a, p=0,0047$ vs. SDF-1 a [50 ng/ml]; b, $p=0,0313$ vs. SDF-1 $\beta$ [50 ng/ml] $(n=8)$ (A). Das Medium wurde mit SDF-1 x [100 ng/ml] angereichert. Eine gleichzeitige Behandlung der HEC-1a-Zellen mit KP-10 $\left[1 \times 10^{-11} \mathrm{M}\right]$ alle $12 \mathrm{~h}$ führte zu einer signifikanten Reduktion der SDF-1 $\alpha / \beta-[100 \mathrm{ng} / \mathrm{ml}]$-induzierten Invasion. Angegeben sind $\mathrm{MW} \pm \mathrm{SEM}$, die Daten wurden mittels $\mathrm{t}$-Test (gepaart) auf signifikante Unterschiede geprüft: $C=0,018$. vs. SDF-1 $\alpha / \beta[100 \mathrm{ng} / \mathrm{ml}](\mathrm{n}=8)(B)$. 


\subsection{Einfluss von Kisspeptin-10 auf die Proliferationsfähigkeit humaner Endometriumkarzinomzellen}

In der vorliegenden Arbeit wurde mit Hilfe des Farbstoffs alamarblue ${ }^{\circledR}$ der Effekt von Kisspeptin-10 auf die Proliferation der Endometriumkarzinomzellen untersucht. Beide Endometriumkarzinomzellinien wurden über $72 \mathrm{~h}$ und $168 \mathrm{~h}$ in einem $12 \mathrm{~h}$-Intervall mit unterschiedlichen Kisspeptin-10-Konzentrationen behandelt. In mindestens drei voneinander unabhängig durchgeführten Versuchen pro Konzentration wurden in den Proliferationsassays folgende Ergebnisse erhoben.

\subsubsection{Einfluss von Kisspeptin-10 auf die Proliferationsfähigkeit von Ishikawa-Zellen}

Die Ishikawa-Zellen zeigten nach 72-stündiger Kultivierung und 12-stündiger Behandlung mit unterschiedlichen Kisspeptin-10-Konzentrationen eine nicht signifikant veränderte Proliferationsfähigkeit $\quad\left(\mathrm{KP}-10 \quad\left[1 \times 10^{-13} \mathrm{M}\right]=93,0 \pm 2,78 \% \quad\right.$ (n.s. vs. Kontrolle); KP-10 $\left[1 \times 10^{-11} M\right]=89,55 \pm 3,33 \%$ (n.s. vs. Kontrolle); KP-10 $\left[1 \times 10^{-9} M\right]=93,76 \pm 3,82 \%$ (n.s. vs.

Kontrolle); KP-10 $\left[1 \times 10^{-7} \mathrm{M}\right]=88,21 \pm 6,06 \% \quad$ (n.s. vs. Kontrolle); KP-10 $\left[1 \times 10^{-5} \mathrm{M}\right]=93,58 \pm 3,94 \%$ (n.s. vs. Kontrolle)) gegenüber unbehandelter Ishikawa-Zellen $($ Kontrolle $=100 \%)($ Abb. 3. 14, A).

Auch eine Behandlung der Zellen mit Kisspeptin-10 über $168 \mathrm{~h}$ zeigte bei keiner Konzentration eine signifikante Veränderung der Proliferation (KP-10 $\left[1 \times 10^{-13} M\right]=115,8 \pm 5,14 \%$ (n.s. vs. Kontrolle); KP-10 $\left[1 \times 10^{-11} M\right]=100,1 \pm 5,4 \%$ (n.s. vs. Kontrolle); KP-10 $\left[1 \times 10^{-9} \mathrm{M}\right]=101,8 \pm 6,9 \% \quad$ (n.s. vs. Kontrolle); KP-10 $\left[1 \times 10^{-7} M\right]=101,2 \pm 4,3 \%$ (n.s. vs. Kontrolle); KP-10 $\left[1 \times 10^{-5} M\right]=97,32 \pm 4,7 \%$ (n.s. vs. Kontrolle)) (Abb. 3.14, B).

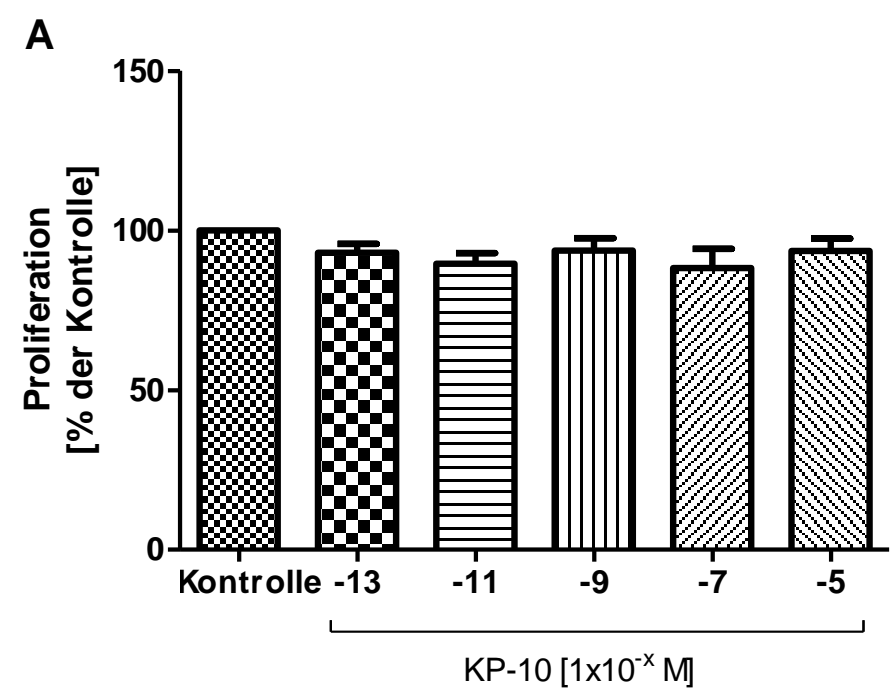




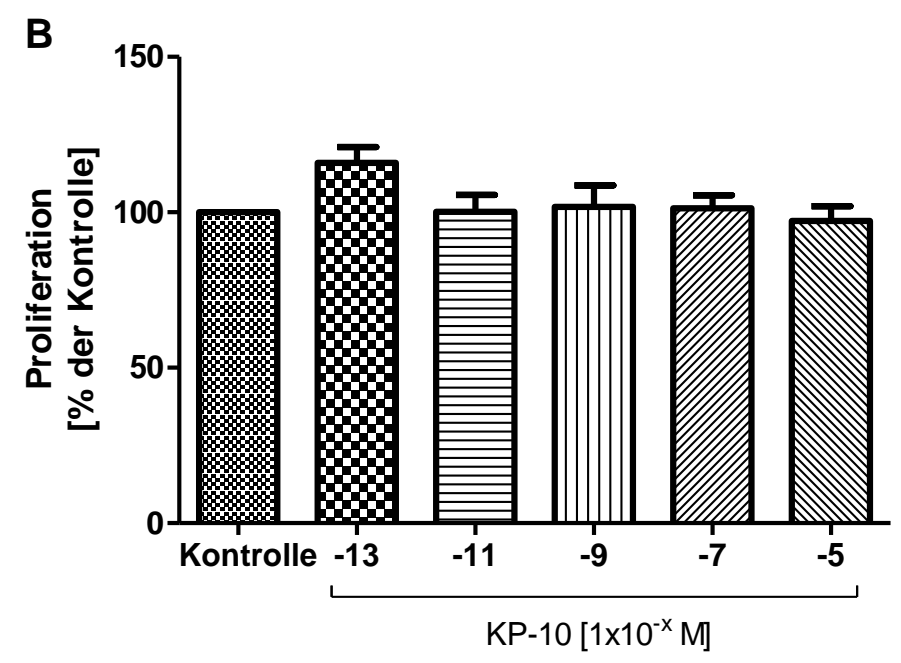

Abb. 3.14: Einfluss von Kisspeptin-10 auf die Proliferationsfähigkeit von Ishikawa-Zellen. Die Kultivierung der Zellen erfolgte über $72 \mathrm{~h}(\mathrm{~A})$ und über $168 \mathrm{~h}(\mathrm{~B})$. Die Zellen wurden alle $12 \mathrm{~h}$ mit KP-10 unterschiedlicher Konzentration behandelt. Die Proliferationsfähigkeit der Ishikawa-Zellen wurde nicht signifikant verändert. Angegeben sind MW \pm SEM, die Daten wurden mittels one-way ANOVA, gefolgt von Student-Newman-Keuls Test auf signifikante Unterschiede geprüft: n.s. vs. Kontrolle $(n=8)(A)$. n.s. vs. Kontrolle $(n=10-16)(B)$.

\subsubsection{Einfluss von Kisspeptin-10 auf die Proliferationsfähigkeit von HEC-1a-Zellen}

Die HEC-1a-Zellen zeigten, wie die Ishikawa-Zellen, nach 72-stündiger Kultivierung und 12stündiger Behandlung mit Kisspeptin-10 unterschiedlicher Konzentration keine signifikante Veränderung ihrer Proliferationsfähigkeit $\left(K P-10 \quad\left[1 \times 10^{-13} M\right]=94,08 \pm 3,2 \% \quad\right.$ (n.s. vs. Kontrolle); KP-10 $\left[1 \times 10^{-11} \mathrm{M}\right]=95,55 \pm 3,63 \% \quad$ (n.s. vs. Kontrolle); KP-10 $\left[1 \times 10^{-9} \mathrm{M}\right]=105,5 \pm 2,28 \%$ (n.s. vs. Kontrolle); KP-10 $\left[1 \times 10^{-7} \mathrm{M}\right]=104,09 \pm 1,88 \%$ (n.s. vs. Kontrolle); KP-10 $\left[1 \times 10^{-5} \mathrm{M}\right]=103,2 \pm 1,19 \%$ (n.s. vs. Kontrolle)) gegenüber unbehandelter HEC-1a-Zellen (Kontrolle= $100 \%$ ) (Abb. 3.15, A).

Bei einer 12-stündigen Behandlung der Zellen mit Kisspeptin-10 über $168 \mathrm{~h}$ hingegen zeigte sich eine dosisabhängige Reduktion der Zellproliferation (KP-10 $\left[1 \times 10^{-13} \mathrm{M}\right]=103,7 \pm 4,73 \%$ (n.s. vs. Kontrolle); KP-10 $\left[1 \times 10^{-11} \mathrm{M}\right]=103,2 \pm 5,53 \%$ (n.s. vs. Kontrolle); KP-10 $\left[1 \times 10^{-9} \mathrm{M}\right]=88,59 \pm 5,38 \%$ ( $\mathrm{p}<0,05$ vs. Kontrolle); KP-10 $\left[1 \times 10^{-7} \mathrm{M}\right]=96,72 \pm 2,0 \%$ (n.s. vs. Kontrolle); KP-10 $\quad\left[1 \times 10^{-5} \mathrm{M}\right]=87,74 \pm 3,27 \% \quad(\mathrm{p}<0,05 \quad$ vs. Kontrolle $\left.)\right)$ gegenüber unbehandelter HEC-1a-Zellen (Kontrolle=100\%). Eine signifikante Reduktion der Proliferationsfähigkeit der HEC-1a-Zellen wurde bei Kisspeptin-10-Konzentrationen von $1 \times 10^{-9} \mathrm{M}$ und $1 \times 10^{-5} \mathrm{M}$ erreicht (Abb. 3.15, B). 

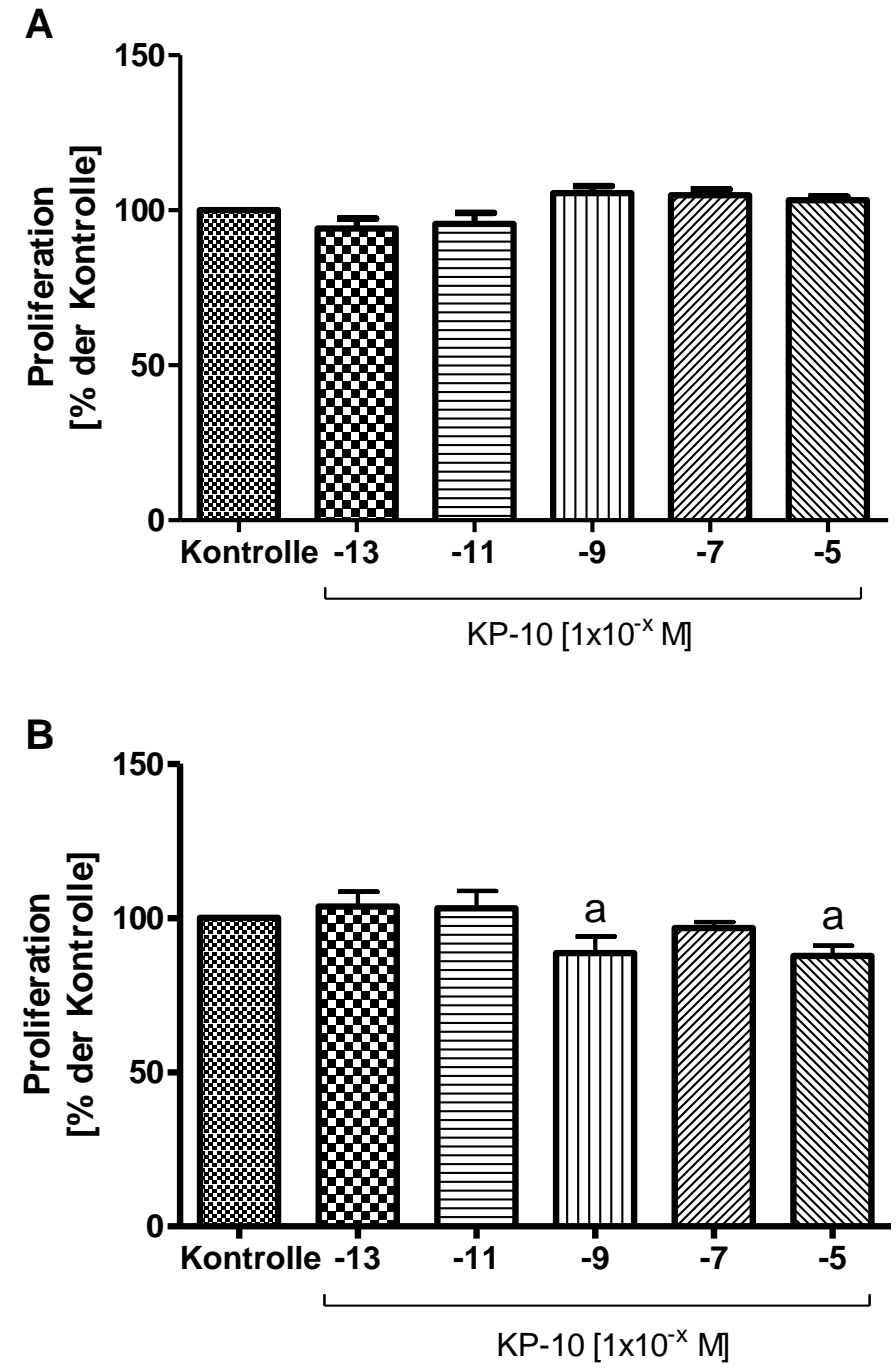

Abb. 3.15: Einfluss von Kisspeptin-10 auf die Proliferationsfähigkeit von HEC-1a-Zellen. Die Kultivierung der Zellen erfolgte über $72 \mathrm{~h}(\mathrm{~A})$ und $168 \mathrm{~h}(\mathrm{~B})$, wobei die KP-10-Behandlung alle $12 \mathrm{~h}$ durchgeführt wurde. Angegeben sind $\mathrm{MW} \pm \mathrm{SEM}$, die Daten wurden mittels one-way ANOVA, gefolgt von Student-Newman-Keuls Test auf signifikante Unterschiede geprüft: n.s. vs. Kontrolle $(n=8)(A)$. Bei einer Behandlung mit KP-10 $1 \times 10^{-9} M$ und $1 \times 10^{-5} \mathrm{M}$ zeigte sich über $168 \mathrm{~h}$ eine signifikante Reduktion der Proliferationsfähigkeit der HEC-1a-Zellen: a, $p<0,05$ vs. Kontrolle $(n=6)(B)$.

\subsection{CXCR4-Expression humaner Endometriumkarzinomzellen}

Die beiden Endometriumkarzinomzelllinien Ishikawa und HEC-1a wurden für $24 \mathrm{~h}$ in matrigelbeschichteten Inserts mono- und mit Osteoblasten-ähnlichen MG-63-Zellen kokultiviert. Die Kisspeptin-10-Behandlung wurde in einem 12-h-Intervall durchgeführt, wobei die Konzentration gewählt wurde, die in dem Kokultur-Invasionsassay die stärkste antiinvasive Wirkung zeigte (Kapitel 3.4.1.1 und 3.4.1.2). Nach Versuchsende wurden die Zellen weiter verarbeitet und semiquantitativ auf ihre molekularbiologische und proteinbiochemische CXCR4-Expression untersucht. 


\subsubsection{CXCR4-Expression auf molekularbiologischer Ebene}

Die Untersuchung der CXCR4-Expression auf molekularbiologischer Ebene erfolgte mittels RT-PCR in Bezug auf das housekeeping gene L7. Die Daten wurden jeweils aus mindestens drei voneinander unabhängig durchgeführten Versuchen erhoben, wobei die RT-PCR eines Versuchs jeweils mindestens dreimal voneinander unabhängig wiederholt und anschließend gemittelt wurde.

\subsubsection{Einfluss von Kisspeptin-10 auf die CXCR4-mRNA-Expression von Ishikawa-}

\section{Zellen im Kokultur-System}

Während der 24-stündigen Kokultivierung mit MG-63-Zellen war keine signifikante Veränderung der CXCR4-mRNA-Expression in den Ishikawa-Zellen (Kokultur $=94,49 \pm 2,48 \%$ (n.s. vs. Kontrolle)) im Vergleich zu den monokultivierten Ishikawa-Zellen (Kontrolle $=100 \%$ ) zu erkennen (Abb. 3.16, A).

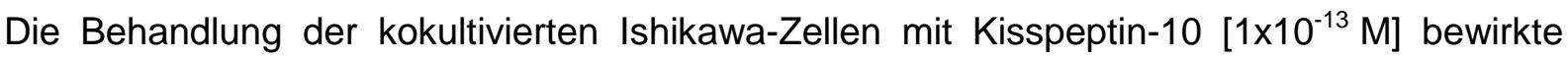
eine signifikante Reduktion der CXCR4-mRNA-Expression auf 80,18 $\pm 0,96 \%$ ( $p=0,0003$ vs. Kokultur) gegenüber unbehandelter kokultivierter Ishikawa-Zellen (Kokultur $=100 \%$ ) (Abb. 3.16, B).
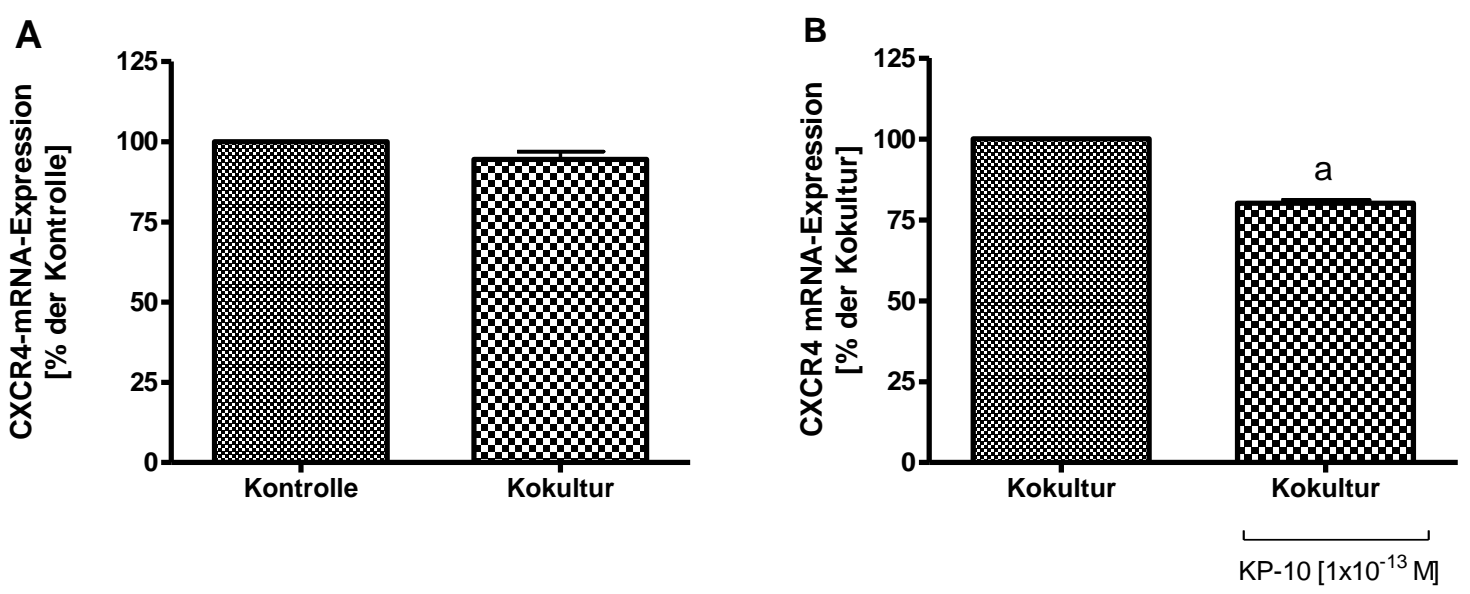

Abb. 3.16: Einfluss von Kokultivierung und Kisspeptin-10 auf die CXCR4-mRNA-Expression von IshikawaZellen. In der Kontrolle wurden die Ishikawa-Zellen über $24 \mathrm{~h}$ mit Medium kultiviert und in der Kokultur mit der Osteoblasten-ähnlichen Zelllinie MG-63 kokultiviert. Die semiquantitative Bestimmung erfolgte mittels RT-PCR im Verhältnis zum housekeeping gene L7. Es war keine Veränderung der CXCR4-mRNA-Expression in der Kokultur im Vergleich zur Kontrolle zu beobachten. Angegeben sind MW \pm SEM, die Daten wurden mittels t-Test (gepaart) auf signifikante Unterschiede geprüft: n.s. vs. Kontrolle $(n=4)(A)$. Durch die Behandlung der Kokultur mit KP-10 $\left[1 \times 10^{-13} \mathrm{M}\right]$ alle $12 \mathrm{~h}$ wurde, gegenüber der unbehandelten Kokultur, eine signifikante Reduktion der CXCR4mRNA-Expression erreicht. Angegeben sind $\mathrm{MW} \pm \mathrm{SEM}$, die Daten wurden mittels t-Test (gepaart) auf signifikante Unterschiede geprüft: $a, p=0,0003$ vs. Kokultur $(n=4)(B)$. 


\subsubsection{Einfluss von Kisspeptin-10 auf die CXCR4-mRNA-Expression von HEC-1a-}

\section{Zellen im Kokultur-System}

Während der 24-stündigen Kokultivierung mit MG-63-Zellen war kein Unterschied der CXCR4-mRNA-Expression in den HEC-1a-Zellen (Kokultur $=97,44 \pm 7,12 \%$ (n.s. vs. Kontrolle)) im Vergleich zu monokultivierten HEC-1a-Zellen (Kontrolle=100\%) zu verzeichnen (Abb. 3.17, A).

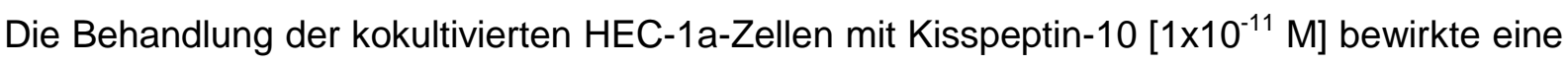
signifikante Reduktion der CXCR4-mRNA-Expression auf 77,01 $\pm 2,83 \%$ ( $p=0,0149$ vs. Kokultur) gegenüber unbehandelter kokultivierter HEC-1a-Zellen (Kokultur=100\%) (Abb. 3.17, B).
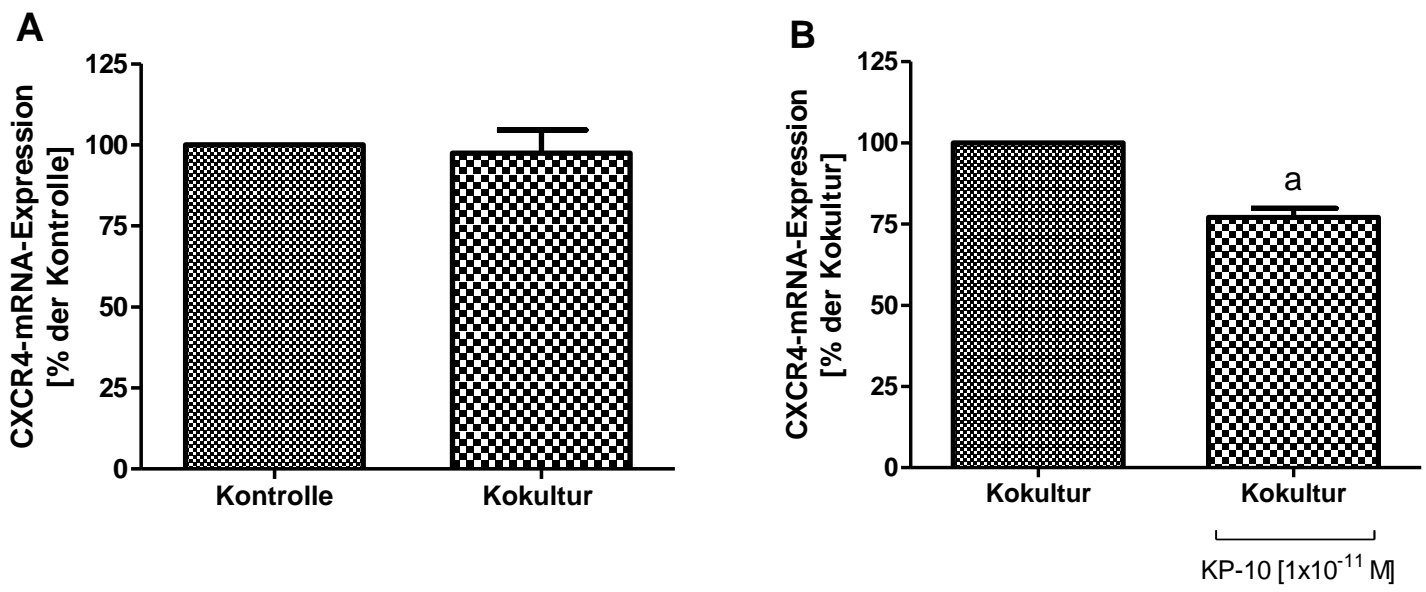

Abb. 3.17: Einfluss von Kokultivierung und Kisspeptin-10 auf die CXCR4-mRNA-Expression von HEC-1aZellen. In der Kontrolle wurden die HEC-1a-Zellen über $24 \mathrm{~h}$ mit Medium kultiviert und in der Kokultur mit der Osteoblasten-ähnlichen Zelllinie MG-63 kokultiviert. Die semiquantitative Bestimmung der CXCR4-mRNAExpression erfolgte mittels RT-PCR im Verhältnis zum housekeeping gene L7. Es war keine Veränderung der CXCR4-mRNA-Expression in der Kokultur im Vergleich zur Kontrolle zu beobachten. Angegeben sind $\mathrm{MW} \pm \mathrm{SEM}$, die Daten wurden mittels t-Test (gepaart) auf signifikante Unterschiede geprüft: n.s. vs. Kontrolle

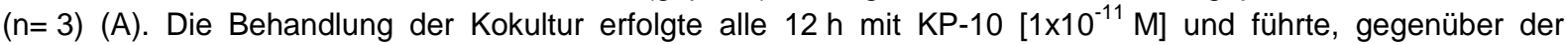
unbehandelten Kokultur, zu einer signifikante Reduktion der CXCR4-mRNA-Expression. Angegeben sind $\mathrm{MW} \pm \mathrm{SEM}$, die Daten wurden mittels t-Test (gepaart) auf signifikante Unterschiede geprüft: $a, p=0,0149$ vs. Kokultur $(n=3)(B)$. 


\subsubsection{CXCR4-Expression auf proteinbiochemischer Ebene}

Der membranständige Rezeptor CXCR4 wurde mit Hilfe des Western-Blots in Bezug auf das zytosolische Aktin ausgewertet. Die Daten wurden aus mindestens drei voneinander unabhängig durchgeführten Versuchen erhoben.

\subsubsection{Proteinbiochemischer Nachweis der CXCR4-Expression humaner Endometriumkarzinom- und Osteoblasten-ähnlicher Zellen}

Mit Hilfe des Western-Blots ließ sich die CXCR4-Expression auf proteinbiochemischer Ebene in der Membran der Endometriumkarzinomzellen Ishikawa und HEC-1a und den Osteoblasten-ähnlichen Zellen MG-63 nachweisen. Zur Kontrolle wurde ein Aktin-Nachweis aus der zytosolischen Fraktion erbracht (Abb. 3.18).

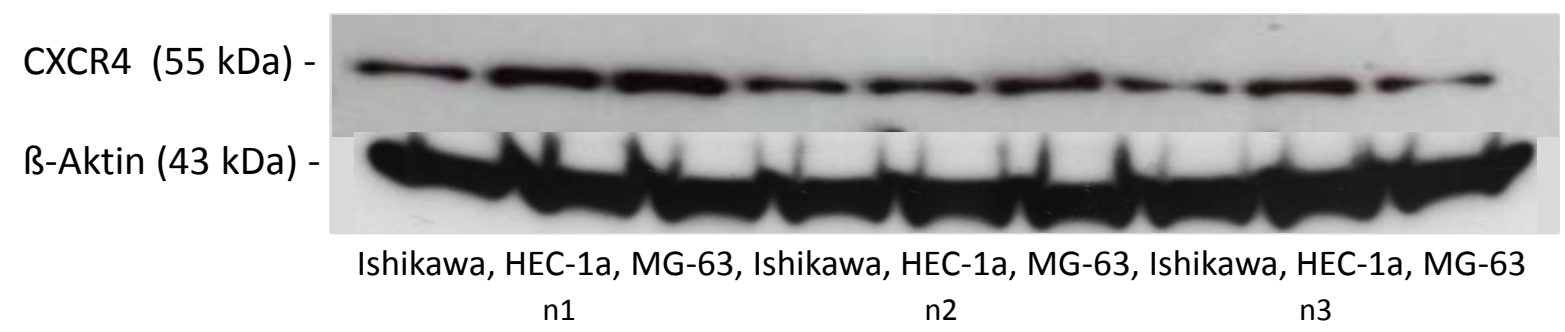

Abb. 3.18: Proteinbiochemischer CXCR4-Nachweis in den Endometriumkarzinomzellen Ishikawa und HEC-1a sowie in den Osteoblasten-ähnlichen MG-63-Zellen. Die qualitative Bestimmung der CXCR4-ProteinExpression in der Membran erfolgte mittels Western-Blot in Bezug auf den zytosolischen Aktin-Nachweis. CXCR4 ließ sich in allen drei Zelllinien nachweisen. Es wurden pro Zelllinie Proben aus drei voneinander unabhängig durchgeführten Versuchen untersucht $(n=3)$.

\subsubsection{Einfluss von Kisspeptin-10 auf die CXCR4-Protein-Expression von Ishikawa- Zellen im Kokultur-System}

Die CXCR4-Protein-Expression der Ishikawa-Zellen wurde während der 24-stündigen Kokultivierung mit den Osteoblasten-ähnlichen MG-63-Zellen auf 111,4 \pm 8,25 \% gegenüber monokultivierter Ishikawa-Zellen (Kontrolle=100\%) gesteigert, wobei keine Signifikanz erreicht wurde (Abb. 3.19, A).

Behandelte man die kokultivierten Ishikawa-Zellen 12-stündig mit Kisspeptin-10 [1 $\left.1 \times 10^{-13} \mathrm{M}\right]$, wurde CXCR4 signifikant auf $70,34 \pm 4,45 \% \quad(p=0,0218$ vs. Kokultur) gegenüber unbehandelter kokultivierter Ishikawa-Zellen (Kokultur= $100 \%)$ reduziert (Abb. 3.19, B). 

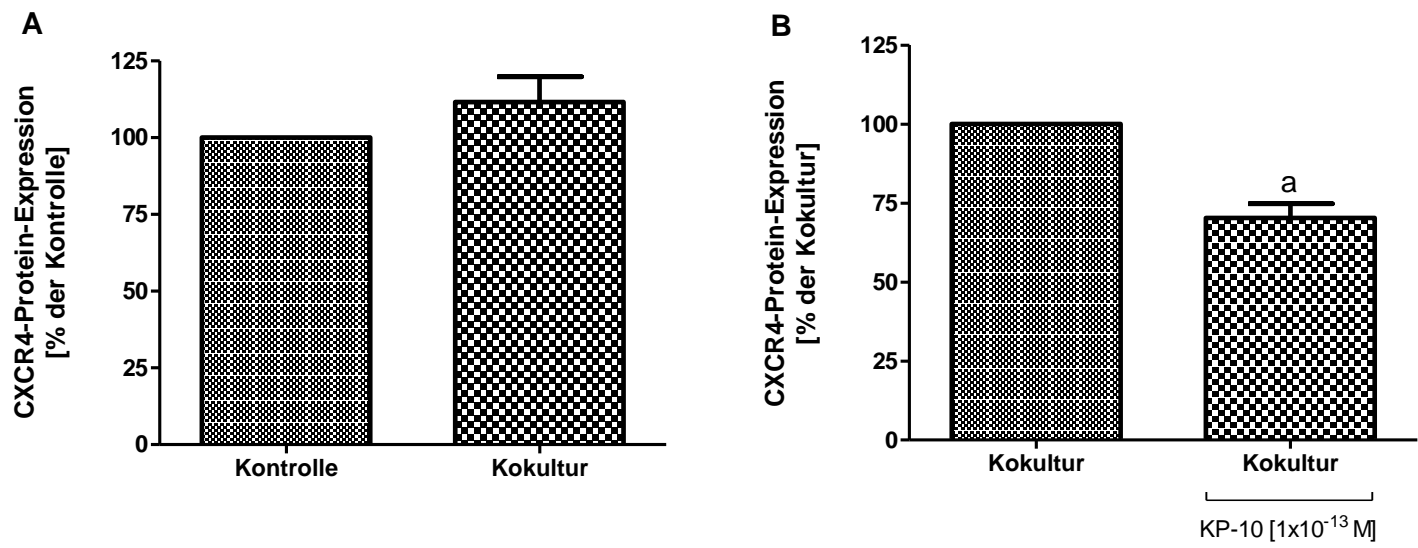

Abb. 3.19: Einfluss von Kokultivierung und Kisspeptin-10 auf die CXCR4-Protein-Expression von Ishikawa-Zellen. In der Kontrolle wurden die Ishikawa-Zellen über $24 \mathrm{~h}$ mit Medium kultiviert und in der Kokultur mit der Osteoblasten-ähnlichen Zelllinie MG-63 kokultiviert. Die semiquantitative Bestimmung erfolgte mittels Western-Blot in Bezug auf den Aktin-Nachweis. Es war kein signifikanter Anstieg der CXCR4-Protein-Expression in der Kokultur im Vergleich zur Kontrolle zu beobachten. Angegeben sind MW \pm SEM, die Daten wurden mittels t-Test (gepaart) auf signifikante Unterschiede geprüft: n.s. vs. Kontrolle $(n=3)(A)$. Durch Behandlung der Kokultur

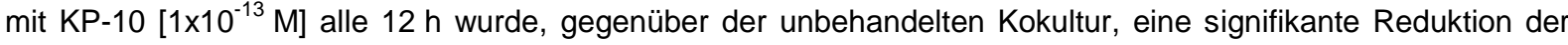
CXCR4-Protein-Expression erreicht. Angegeben sind MW \pm SEM, die Daten wurden mittels t-Test (gepaart) auf signifikante Unterschiede geprüft: $a, p=0,0218$ vs. Kokultur $(n=3)(B)$.

\subsubsection{Einfluss von Kisspeptin-10 auf die CXCR4-Protein-Expression von HEC-1a-}

\section{Zellen im Kokultur-System}

Die CXCR4-Protein-Expression der HEC-1a-Zellen wurde während der 24-stündigen Kokultivierung mit MG-63-Zellen auf 121,4 \pm 9,87\% gegenüber monokultivierter HEC-1aZellen (Kontrolle $=100 \%$ ) gesteigert, wobei keine Signifikanz erreicht wurde (Abb. 3.20, A).

Behandelte man die kokultivierten HEC-1a-Zellen 12-stündig mit Kisspeptin-10 [1 $\left.1 \times 10^{-11} \mathrm{M}\right]$, wurde CXCR4 signifikant auf $74,14 \pm 6,45 \% \quad(p=0,0103$ vs. Kokultur $)$ gegenüber unbehandelter kokultivierter HEC-1a-Zellen (Kokultur= $100 \%$ ) reduziert (Abb. 3.20, B).

A

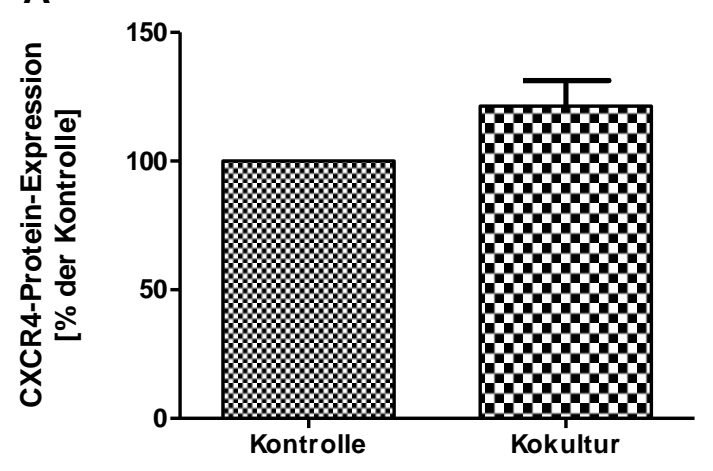

B

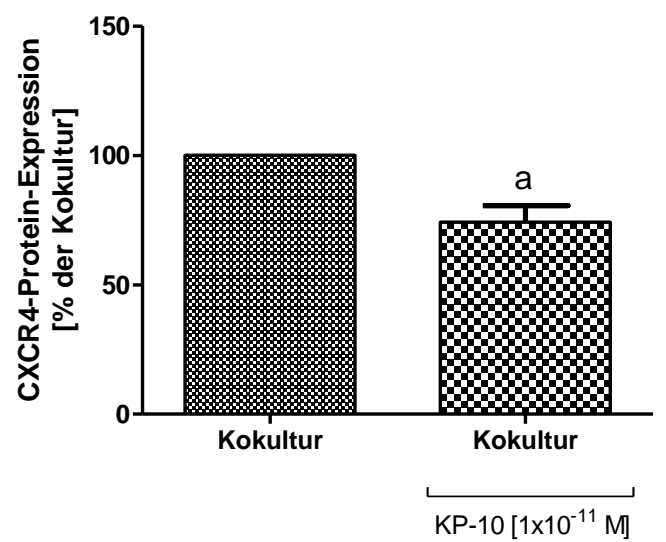

Abb. 3.20: Einfluss von Kokultivierung und Kisspeptin-10 auf die CXCR4-Protein-Expression von HEC-1aZellen. In der Kontrolle wurden die HEC-1a-Zellen über $24 \mathrm{~h}$ mit Medium kultiviert und in der Kokultur mit der 
Osteoblasten-ähnlichen Zelllinie MG-63 kokultiviert. Die semiquantitative Bestimmung erfolgte mittels WesternBlot in Bezug auf den Aktin-Nachweis. Es ließ sich ein nicht signifikanter Anstieg der CXCR4-Protein-Expression kokultivierter HEC-1a-Zellen im Vergleich zur Kontrolle beobachten. Angegeben sind MW \pm SEM, die Daten wurden mittels t-Test (gepaart) auf signifikante Unterschiede geprüft: n.s. vs. Kontrolle $(n=6)(A)$. Durch Behandlung der Kokultur mit KP-10 $\left[1 \times 10^{-11} \mathrm{M}\right]$ alle $12 \mathrm{~h}$ wurde, gegenüber der unbehandelten Kokultur, eine signifikante Reduktion der CXCR4-Protein-Expression erreicht. Angegeben sind MW \pm SEM, die Daten wurden mittels t-Test (gepaart) auf signifikante Unterschiede geprüft: $a, p=0,0103$ vs. Kokultur $(n=6)(B)$.

\subsection{SDF-1-Expression humaner Endometriumkarzinom- und Osteoblasten-ähnlicher Zellen}

Zum einen wurden die Osteoblasten-ähnlichen Zellen MG-63 für $24 \mathrm{~h}$ in Well-Platten monokultiviert und mit den, in den Inserts befindlichen, Endometriumkarzinomzellinien Ishikawa und HEC-1a kokultiviert. Zum anderen wurden auch die Endometriumkarzinomzellen monokultiviert. Die Kisspeptin-10-Behandlung wurde in einem 12-h-Intervall durchgeführt, wobei die Konzentration gewählt wurde, die im KokulturInvasionsassay die stärkste antiinvasive Wirkung zeigte (Kapitel 3.4.1.1 und 3.4.1.2). Nach Versuchsende wurden die Zellen weiter verarbeitet und qualitativ sowie semiquantitativ auf ihre molekularbiologische und proteinbiochemische SDF-1-Expression untersucht.

\subsubsection{SDF-1-Expression auf molekularbiologischer Ebene}

Die Untersuchung der SDF-1-Expression auf molekularbiologischer Ebene erfolgte mittels RT-PCR in Bezug auf das housekeeping gene L7. Die Daten wurden aus mindestens drei voneinander unabhängig durchgeführten Versuchen erhoben, wobei die RT-PCR eines Versuchs jeweils mindestens dreimal voneinander unabhängig wiederholt und anschließend gemittelt wurde.

\subsubsection{Einfluss von Kisspeptin-10 auf die SDF-1-mRNA-Expression von MG-63-}

$$
\text { Zellen im Kokultur-System mit Ishikawa-Zellen }
$$

Während der Kokultivierung mit Ishikawa-Zellen zeigte sich in den Osteoblasten-ähnlichen MG-63-Zellen keine Veränderung der SDF-1-mRNA-Expression (Kokultur=100,3 \pm 15,76\% (n.s. vs. Kontrolle)) im Vergleich zu monokultivierten MG-63-Zellen (Kontrolle $=100 \%$ ) (Abb. 3.21, A).

Durch die 12-stündige Kisspeptin-10-Behandlung $\left[1 \times 10^{-13} \mathrm{M}\right]$ zeigte sich eine signifikante Reduktion der SDF-1-mRNA-Expression kokultivierter MG-63-Zellen auf 74,65 $\pm 5,76 \%$ 
( $p=0,048$ vs. Kokultur) gegenüber unbehandelter, mit Ishikawa kokultivierter MG-63-Zellen (Kokultur= $100 \%)($ Abb. 3.21, B).
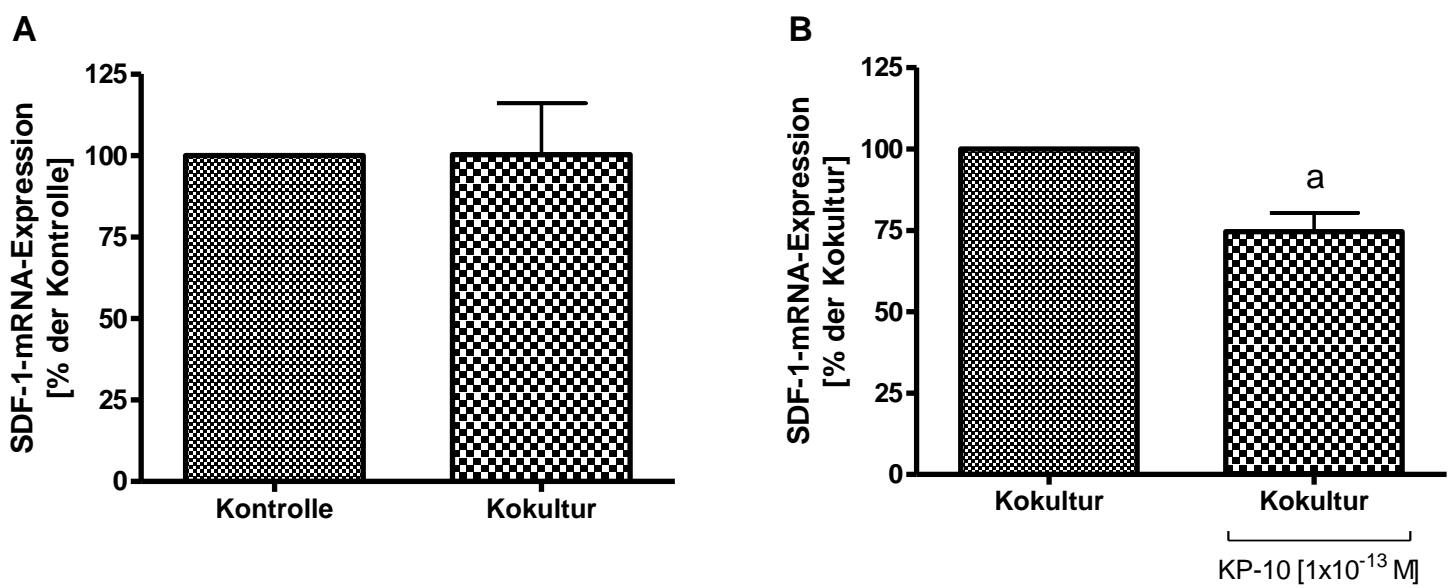

Abb. 3.21: Einfluss von Kokultivierung und Kisspeptin-10 auf die SDF-1-mRNA-Expression von MG-63Zellen im Kokultur-System mit Ishikawa-Zellen. In der Kontrolle wurden MG-63-Zellen über $24 \mathrm{~h}$ mit Medium kultiviert und in der Kokultur mit Ishikawa kokultiviert. Die semiquantitative Bestimmung erfolgte mittels RT-PCR im Verhältnis zum housekeeping gene L7. Mit Ishikawa kokultivierte MG-63-Zellen zeigten keine Veränderung der SDF-1-mRNA-Expression im Vergleich zu monokultivierten MG-63-Zellen. Angegeben sind MW \pm SEM, die Daten wurden mittels t-Test (gepaart) auf signifikante Unterschiede geprüft: $n$.s. vs. Kontrolle $(n=3)(A)$. Durch die 12-stündige Behandlung der Kokultur mit KP-10 $\left[1 \times 10^{-13} \mathrm{M}\right]$ wurde eine signifikante Abnahme der SDF-1-mRNAExpression der MG-63-Zellen gezeigt. Angegeben sind MW \pm SEM, die Daten wurden mittels $t-T e s t$ (gepaart) auf signifikante Unterschiede geprüft: $a, p=0,048$ vs. Kokultur $(n=3)(B)$.

\subsubsection{Einfluss von Kisspeptin-10 auf die SDF-1-mRNA-Expression von MG-63-}

\section{Zellen im Kokultur-System mit HEC-1a-Zellen}

Die SDF-1-mRNA-Expression der MG-63-Zellen wurde durch Kokultivierung mit HEC-1aZellen nicht signifikant auf 201,5 $\pm 30,33 \%$ gegenüber monokultivierter MG-63-Zellen $($ Kontrolle $=100 \%)$ gesteigert (Abb. 3.22, A). Durch die 12-stündige Kisspeptin-10Behandlung $\left[1 \times 10^{-11} \mathrm{M}\right]$ wurde die SDF-1-mRNA-Expression kokultivierter MG-63-Zellen auf $81,38 \pm 3,9 \%$ ( $p=0,0417$ vs. Kokultur) gegenüber unbehandelter, mit HEC-1a kokultivierter MG-63-Zellen (Kokultur= $100 \%$ ) reduziert (Abb. 3.22, B). 
A

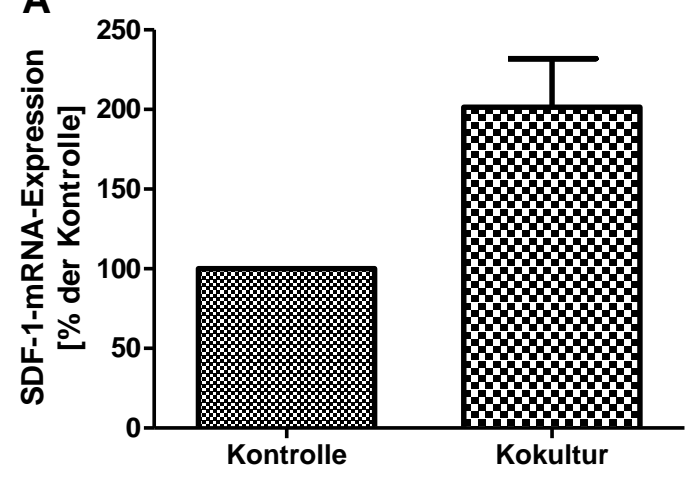

B

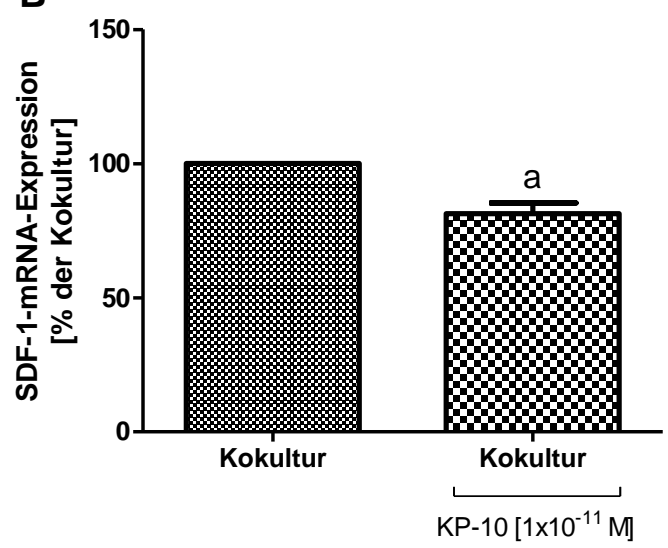

Abb. 3.22:Einfluss von Kokultivierung und Kisspeptin-10 auf die SDF-1-mRNA-Expression von MG-63Zellen im Kokultur-System mit HEC-1a-Zellen. In der Kontrolle wurden MG-63-Zellen über $24 \mathrm{~h}$ mit Medium kultiviert und in der Kokultur mit HEC-1a kokultiviert. Die semiquantitative Bestimmung erfolgte mittels RT-PCR im Verhältnis zum housekeeping gene L7. Osteoblasten-ähnliche MG-63-Zellen, die mit HEC-1a kokultiviert wurden, zeigten keinen signifikanten Anstieg der SDF-1-mRNA-Expression im Vergleich zu monokultivierten MG-63Zellen. Angegeben sind $\mathrm{MW} \pm \mathrm{SEM}$, die Daten wurden mittels t-Test (gepaart) auf signifikante Unterschiede geprüft: n.s. vs. Kontrolle $(n=3)(A)$. Durch die 12-stündige Behandlung der Kokultur mit KP-10 $\left[1 \times 10^{-11} M\right]$ wurde eine signifikante Abnahme der SDF-1-mRNA-Expression der MG-63-Zellen gezeigt. Angegeben sind MW \pm SEM, die Daten wurden mittels t-Test (gepaart) auf signifikante Unterschiede geprüft: $b, p=0,0417$ vs. Kokultur ( $n=3$ ) (B).

\subsubsection{SDF-1-Expression auf proteinbiochemischer Ebene}

Das zytosolisch exprimierte und sezernierte Protein SDF-1 wurde mit Hilfe des WesternBlots nachgewiesen. Das zytosolisch exprimierte SDF-1 wurde in Bezug auf den zytosolischen Aktin-Nachweis ausgewertet. Die Daten wurden aus mindestens drei voneinander unabhängig durchgeführten Versuchen erhoben.

\subsubsection{Proteinbiochemischer Nachweis der SDF-1-Expression humaner}

\section{Endometriumkarzinom- und Osteoblasten-ähnlicher Zellen}

Mit Hilfe des Western-Blots ließ sich die Expression des Chemokins SDF-1 auf proteinbiochemischer Ebene im Zytosol der Endometriumkarzinomzellen Ishikawa und HEC-1a und der Osteoblasten-ähnlichen Zelllinie MG-63 nachweisen. Zum qualitativen Abgleich wurde ein Aktin-Nachweis erbracht (Abb. 3.23). 


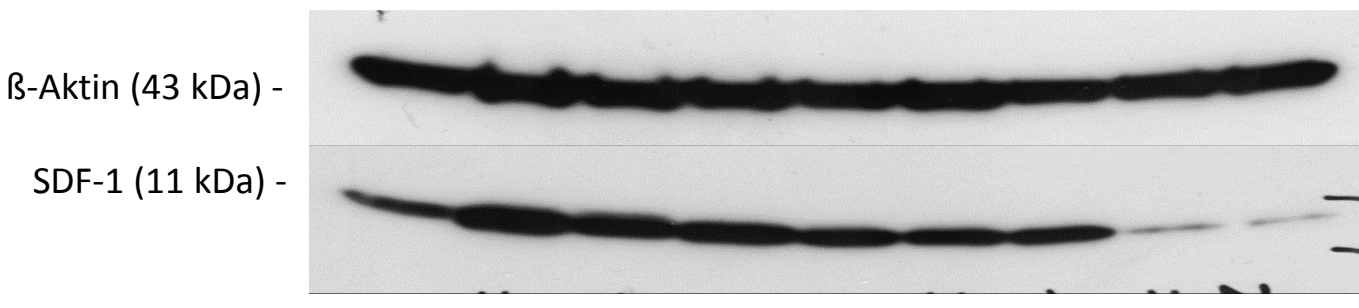

Ishikawa, HEC-1a, MG-63, Ishikawa, HEC-1a, MG-63, Ishikawa, HEC-1a, MG-63

n1

$\mathrm{n} 2$

n3

Abb. 3.23: Proteinbiochemischer SDF-1-Nachweis in den Endometriumkarzinomzellen Ishikawa und HEC-1a sowie in den Osteoblasten-ähnlichen MG-63-Zellen. Die qualitative Bestimmung der SDF-1-ProteinExpression im Zytosol erfolgte mittels Western-Blot in Bezug auf den zytosolischen Aktin-Nachweis. SDF-1 ließ sich in allen drei Zelllinien nachweisen. Es wurden pro Zelllinie Proben aus drei voneinander unabhängig durchgeführten Versuchen untersucht $(n=3)$.

\subsubsection{Einfluss von Kisspeptin-10 auf die SDF-1-Protein-Expression von Ishikawa-}

\section{Zellen}

Die Ishikawa-Zellen wurden für $24 \mathrm{~h}$ mit Medium monokultiviert (Kontrolle= 100 \%). Eine 12 stündige Kisspeptin-10-Behandlung $\left[1 \times 10^{-13} \mathrm{M}\right]$ führte $z u$ keiner signifikanten Veränderung der SDF-1-Protein-Expression in den Ishikawa-Zellen (KP-10 $\left[1 \times 10^{-13} \mathrm{M}\right]=101,5 \pm 10,62 \%$ (n.s. vs. Kontrolle)) (Abb. 3.24).

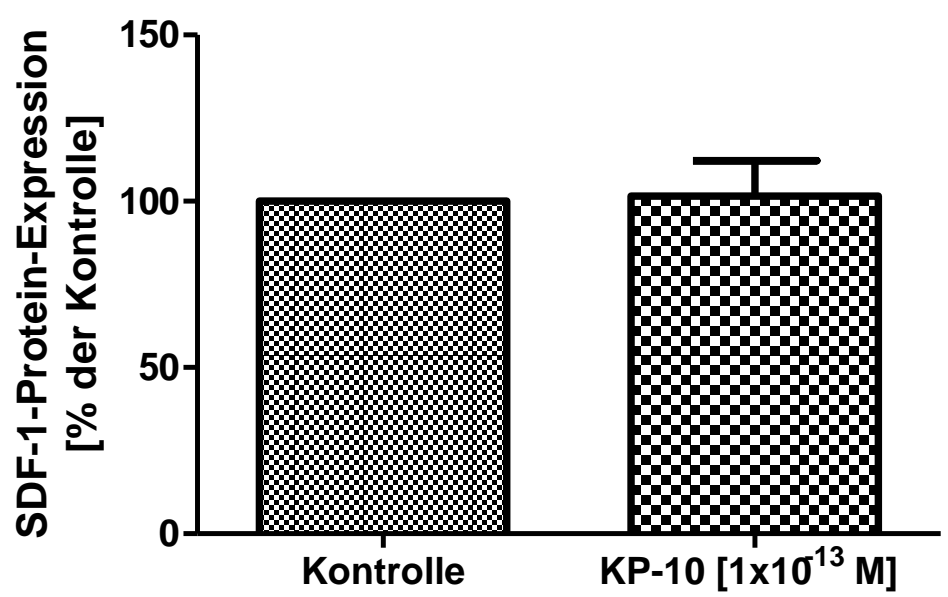

Abb. 3.24: Einfluss von Kisspeptin-10 auf die SDF-1-Protein-Expression monokultivierter Ishikawa-Zellen. Die Kultivierung erfolgte über $24 \mathrm{~h}$ mit KP-10-Behandlungen $\left[1 \times 10^{-13} \mathrm{M}\right]$ alle $12 \mathrm{~h}$. Die semiquantitative Bestimmung erfolgte mittels Western-Blot in Bezug auf den Aktin-Nachweis. Monokultivierte Ishikawa-Zellen zeigten nach der KP-10-Behandlung keine signifikante Veränderung der SDF1-Protein-Expression im Vergleich zu unbehandelten monokultivierten Ishikawa-Zellen. Angegeben sind MW $\pm \mathrm{SEM}$, die Daten wurden mittels $\mathrm{t}-\mathrm{Test}$ (gepaart) auf signifikante Unterschiede geprüft: n.s. vs. Kontrolle $(n=3)$. 


\subsubsection{Einfluss von Kisspeptin-10 auf die SDF-1-Protein-Expression von MG-63-}

\section{Zellen im Kokultur-System mit Ishikawa-Zellen}

Während der 24-stündigen Kokultivierung mit Ishikawa-Zellen wurde in den Osteoblastenähnlichen MG-63-Zellen ein signifikanter Anstieg der SDF-1-Protein-Expression (Kokultur $=261,1 \pm 30,99 \% \quad(p=0,035$ vs. Kontrolle $)$ im Vergleich zu monokultivierten MG-63-Zellen (Kontrolle $=100 \%$ ) erzielt (Abb. 3.25, A).

Gegenüber unbehandelter kokultivierter MG-63-Zellen (Kokultur=100\%) führte eine Behandlung mit Kisspeptin-10 $\left[1 \times 10^{-13} \mathrm{M}\right] \mathrm{zu}$ einer signifikanten Reduktion der SDF-1Expression kokultivierter MG-63-Zellen auf 70,38 $\pm 6,0 \% \quad(p=0,038$ vs. Kokultur) (Abb. 3.25, B).
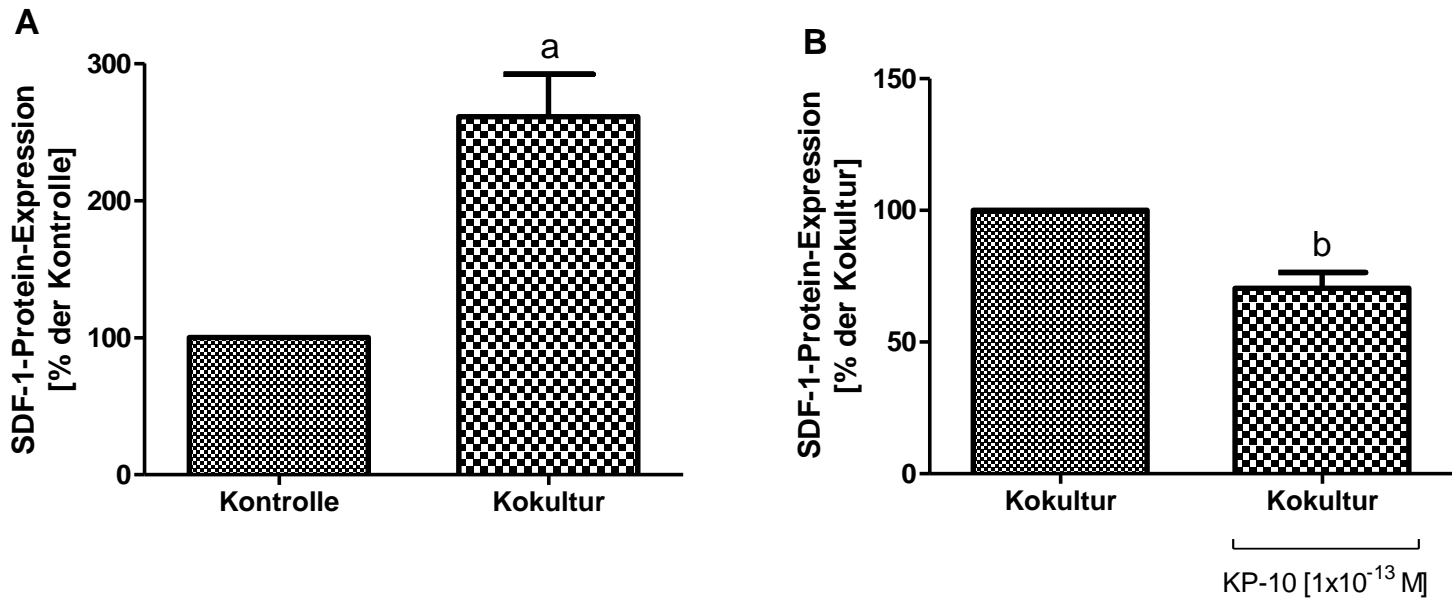

Abb. 3.25: Einfluss von Kokultivierung und Kisspeptin-10 auf die SDF-1-Protein-Expression von MG-63Zellen im Kokultur-System mit Ishikawa-Zellen. In der Kontrolle wurden die MG-63-Zellen über $24 \mathrm{~h}$ mit Medium kultiviert und in der Kokultur mit Ishikawa kokultiviert. Die semiquantitative Bestimmung erfolgte mittels Western-Blot in Bezug auf den Aktin-Nachweis. Mit Ishikawa kokultivierte MG-63-Zellen zeigten einen signifikanten Anstieg der SDF-1-Protein-Expression im Vergleich zu monokultivierten MG-63-Zellen. Angegeben sind $M W \pm S E M$, die Daten wurden mittels t-Test (gepaart) auf signifikante Unterschiede geprüft: $a, p=0,035$ vs. Kontrolle $(n=3)(A)$. Während der Behandlung der Kokultur mit KP-10 $\left[1 \times 10^{-13} \mathrm{M}\right]$ alle $12 \mathrm{~h}$ wurde eine signifikante Reduktion der SDF-1-Protein-Expression in den MG-63-Zellen gezeigt. Angegeben sind MW \pm SEM, die Daten wurden mittels t-Test (gepaart) auf signifikante Unterschiede geprüft: $b, p=0,038$ vs. Kontrolle $(n=3)(B)$.

\subsubsection{Einfluss von Kisspeptin-10 auf die SDF-1-Sekretion von MG-63-Zellen im}

\section{Kokultur-System mit Ishikawa-Zellen}

Monokultivierte Osteoblasten-ähnliche MG-63-Zellen sezernierten ohne den Einfluss der Ishikawa-Zellen kein oder nur so geringe Mengen SDF-1, dass es mittels Western-Blot nicht zu detektieren war (Kontrolle= $0 \%$ ). 
Während der 24-stündigen Kokultivierung mit Ishikawa-Zellen wurde eine SDF-1-Sekretion durch die Osteoblasten-ähnlichen Zellen MG-63 nachweisbar (Kokultur=100\%). Mittels Kisspeptin-10-Behandlungen $\left[1 \times 10^{-13} \mathrm{M}\right]$ wurde diese Sekretionszunahme gegenüber der unbehandelten Kokultur auf 82,8\% reduziert (Abb. 3.26).

Da dieser Western-Blot lediglich einmal durchgeführt wurde, konnten die erhobenen Daten nicht mittels eines statistischen Tests ausgewertet werden. Die aufgetragenen Proben enthielten jedoch Proteine vom gepoolten Medium dreier voneinander unabhängig durchgeführter Zellversuche. Das Pooling der Medien erwies sich als notwendig, da die SDF-1-Konzentration aus einem Zellversuch zu gering war, um dies mittels Western-Blot nachweisen zu können.

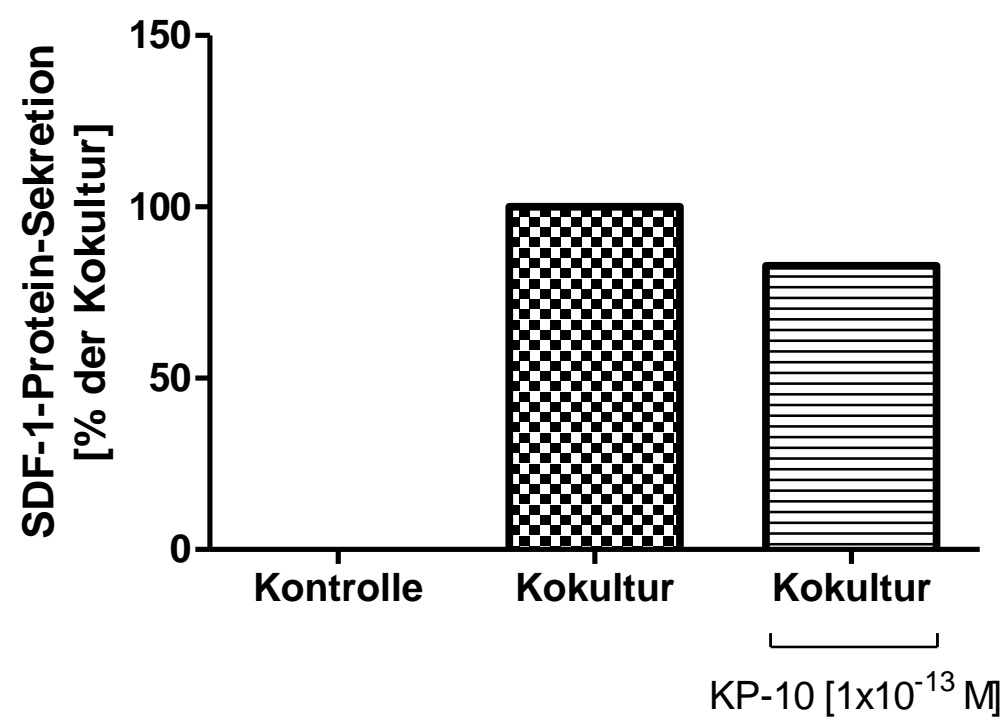

Abb. 3.26: Einfluss von Kisspeptin-10 auf die SDF-1-Protein-Sekretion von MG-63-Zellen im KokulturSystem mit Ishikawa-Zellen. In der Kontrolle wurden Osteoblasten-ähnliche MG-63-Zellen über $24 \mathrm{~h}$ mit FCSfreiem Medium kultiviert und in der Kokultur mit den Ishikawa kokultiviert. Die KP-10-Behandlungen [1x10 $\left.0^{-13} \mathrm{M}\right]$ wurden alle $12 \mathrm{~h}$ durchgeführt. Die Bestimmung erfolgte mittels Western-Blot. Monokultivierte MG-63-Zellen sezernierten kein SDF-1. In der Kokultur zeigte sich ein Anstieg der SDF-1-Protein-Sekretion der MG-63-Zellen, die durch die Kisspeptin-10-Behandlungen teilweise reduziert wurde.

\subsubsection{Einfluss von Kisspeptin-10 auf die SDF-1-Protein-Expression von HEC-1a-}

\section{Zellen}

HEC-1a-Zellen wurden für $24 \mathrm{~h}$ monokultiviert (Kontrolle=100\%). Eine zweimalige

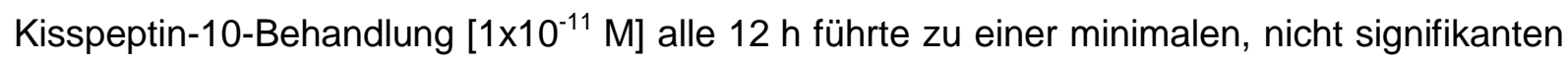
Reduktion der SDF-1-Protein-Expression dieser Zellen (KP-10 $\left[1 \times 10^{-11} \mathrm{M}\right]=95,92 \pm 6,52 \%$ (n.s. vs. Kontrolle)) (Abb. 3.27). 


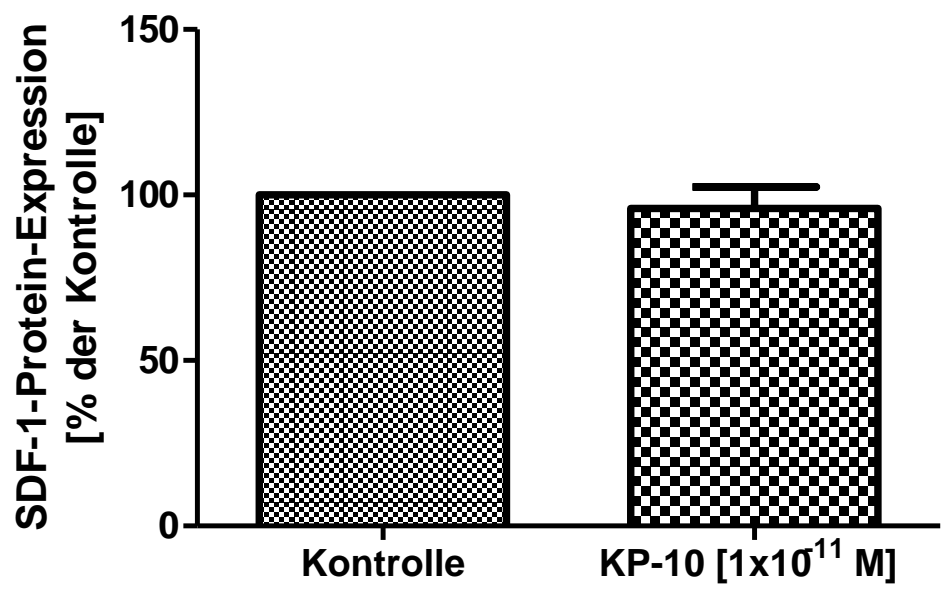

Abb. 3.27: Einfluss von Kisspeptin-10 auf die SDF-1-Protein-Expression monokultivierter HEC-1a-Zellen. Die Kultivierung erfolgte über $24 \mathrm{~h}$ mit Kisspeptin-10-Behandlungen $\left[1 \times 10^{-11} \mathrm{M}\right]$ alle $12 \mathrm{~h}$. Die semiquantitative Bestimmung erfolgte mittels Western-Blot in Bezug auf den Aktin-Nachweis. Monokultivierte HEC-1a-Zellen zeigten nach der KP-10-Behandlung eine nicht signifikante Reduktion der SDF1-Protein-Expression im Vergleich zu unbehandelten monokultivierten HEC-1a-Zellen. Angegeben sind MW $\pm \mathrm{SEM}$, die Daten wurden mittels $\mathrm{t}-T e s t$ (gepaart) auf signifikante Unterschiede geprüft: n.s. vs. Kontrolle $(n=3)$.

\subsubsection{Einfluss von Kisspeptin-10 auf die SDF-1-Protein-Expression von MG-63-}

\section{Zellen im Kokultur-System mit HEC-1a-Zellen}

Monokultivierte Osteoblasten-ähnliche MG-63-Zellen exprimierten SDF-1 auf proteinbiochemischer Ebene (Kontrolle= $100 \%$ ). Die SDF-1-Protein-Expression der MG-63Zellen wurde während der Kokultivierung mit HEC-1a-Zellen gegenüber der Kontrolle auf $1155 \pm 355,2 \%$ gesteigert (Abb. 3.28, A).

Durch die 12-stündige Kisspeptin-10-Behandlung $\left[1 \times 10^{-11} \mathrm{M}\right]$ wurde diese Expressionssteigerung $z u$ einem Großteil auf 29,8 $\pm 12,84 \%$ ( $p=0,0319$ vs. Kokultur) gegenüber der unbehandelten Kokultur (Kokultur= $100 \%$ ) reduziert (Abb. 3.28, B).
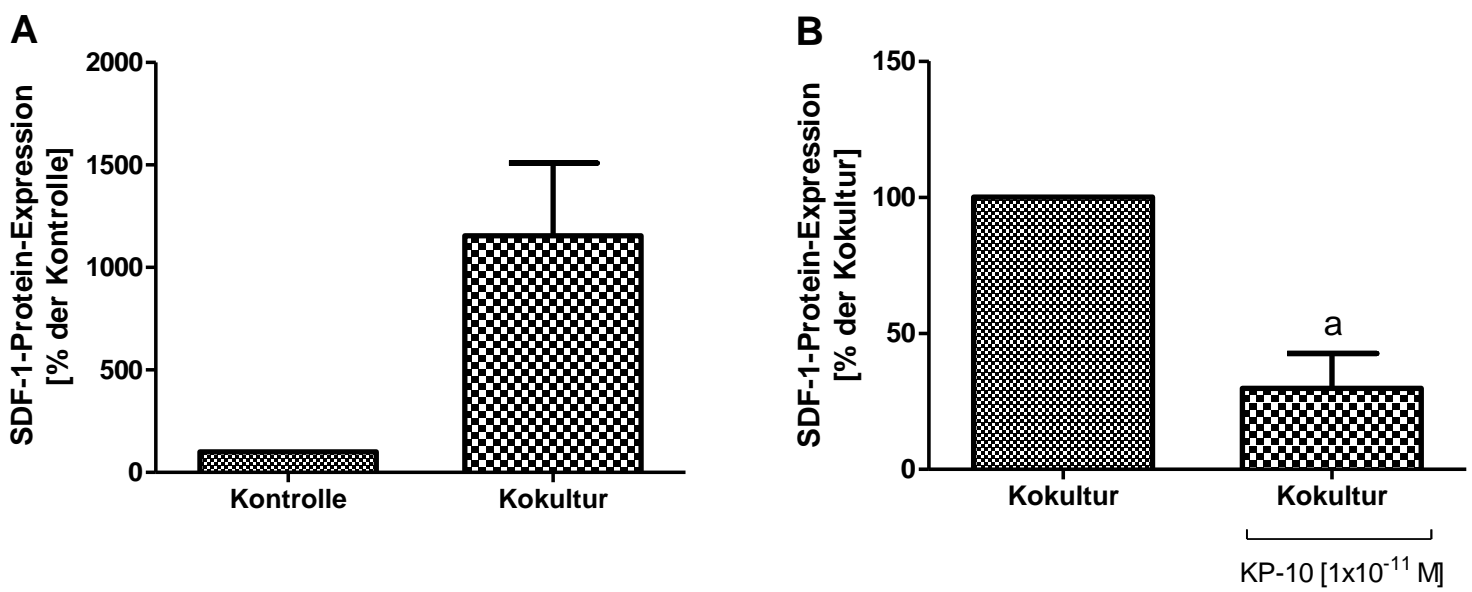

Abb. 3.28: Einfluss von Kokultivierung und Kisspeptin-10 auf die SDF-1-Protein-Expression von MG-63Zellen im Kokultur-System mit HEC-1a-Zellen. In der Kontrolle wurden MG-63-Zellen über $24 \mathrm{~h}$ mit Medium 
kultiviert und in der Kokultur mit HEC-1a kokultiviert. Die semiquantitative Bestimmung erfolgte mittels WesternBlot in Bezug auf den Aktin-Nachweis. Mit HEC-1a kokultivierte MG-63-Zellen zeigten einen Anstieg der SDF-1Protein-Expression im Vergleich zu monokultivierten MG-63-Zellen. Angegeben sind MW \pm SEM, die Daten wurden mittels t-Test (gepaart) auf signifikante Unterschiede geprüft: n.s. vs. Kontrolle $(n=3)(A)$. Während der 12-stündigen Behandlung der Kokultur mit KP-10 $\left[1 \times 10^{-11} \mathrm{M}\right]$ wurde eine signifikante Reduktion der zuvor gesteigerten SDF-1-Protein-Expression der MG-63-Zellen gezeigt. Angegeben sind MW \pm SEM, die Daten wurden mittels t-Test (gepaart) auf signifikante Unterschiede geprüft: $a, p=0,0319$ vs. Kokultur $(n=3)(B)$.

\subsubsection{Einfluss von Kisspeptin-10 auf die SDF-1-Sekretion von MG-63-Zellen im}

\section{Kokultur-System mit HEC-1a-Zellen}

Monokultivierte Osteoblasten-ähnliche MG-63-Zellen sezernierten ohne den Einfluss der HEC-1a-Zellen kein oder nur so geringe Mengen SDF-1, dass es mittels Western-Blot nicht zu detektieren war (Kontrolle= $0 \%$ ). Während der 24-stündigen Kokultivierung mit HEC-1a wurde eine SDF-1-Sekretion durch die MG-63-Zellen nachweisbar (Kokultur=100 \%). Diese Sekretionszunahme reduzierte sich zum Teil durch die zweimalige Kisspeptin-10Behandlung [1×10-11 M] gegenüber der unbehandelten Kokultur auf 84,11 \% (Abb. 3.29).

Da dieser Western-Blot lediglich einmal durchgeführt wurde, konnten die erhobenen Daten nicht mittels eines statistischen Tests ausgewertet werden. Die aufgetragenen Proben enthielten jedoch Proteine vom gepoolten Medium dreier voneinander unabhängig durchgeführter Zellversuche. Das Pooling der Medien erwies sich als notwendig, da die SDF-1-Konzentration aus einem Zellversuch zu gering war, um dies mittels Western-Blot nachweisen zu können.

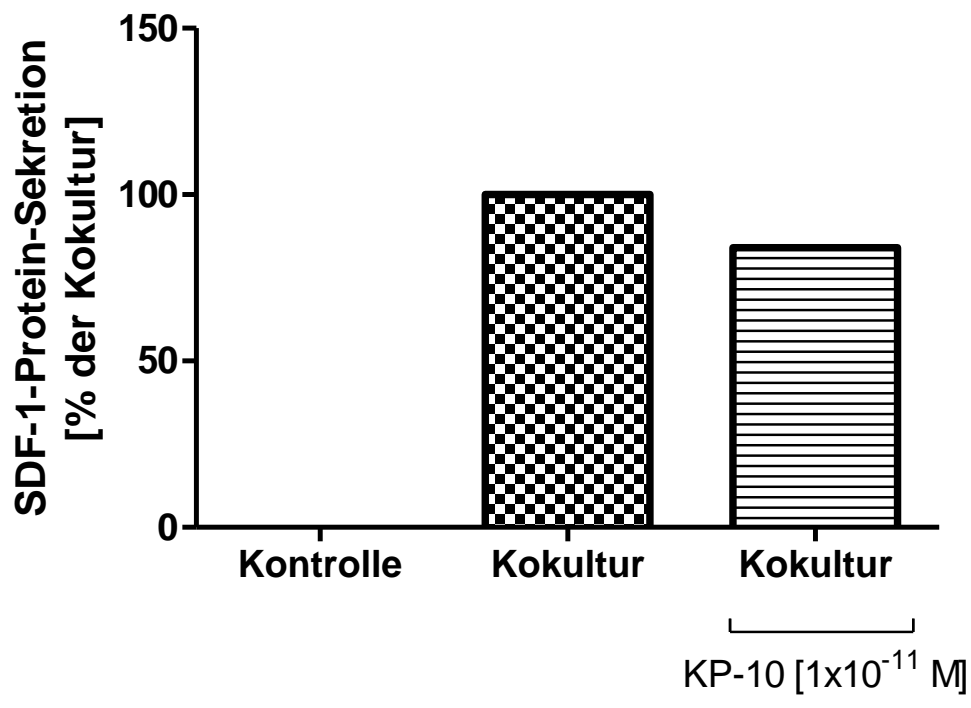

Abb. 3.29: Einfluss von Kisspeptin-10 auf die SDF-1-Protein-Sekretion kokultivierter MG-63-Zellen im Kokultur-System mit HEC-1a-Zellen. In der Kontrolle wurden Osteoblasten-ähnliche MG-63-Zellen über $24 \mathrm{~h}$ mit Medium kultiviert und in der Kokultur mit HEC-1a kokultiviert. Die KP-10-Behandlungen [1×10-11 $\mathrm{M}]$ wurden alle $12 \mathrm{~h}$ durchgeführt. Die Bestimmung erfolgte mittels Western-Blot. Monokultivierte MG-63-Zellen sezernierten kein nachweisbares SDF-1. In der Kokultur zeigte sich ein Anstieg der SDF-1-Protein-Sekretion der MG-63Zellen, die durch die KP-10-Behandlungen teilweise reduziert wurde. 


\section{Diskussion}

\subsection{KISS1- und GPR54-Expression humaner \\ Endometriumkarzinomzellen}

Der Verlust von KISS1, dem Gen dessen Endprodukte die Kisspeptine sind, ist im Allgemeinen mit steigender Tumorprogression und Metastasenbildung assoziiert. Eine Überexpression des KISS1-Gens hingegen verringert die Fähigkeit von Tumorzellen zur Metastasenbildung (Lee J-H und Welch 1997b).

Jiang et al. publizierten 2005, dass die Expression der KISS1-mRNA im Endometriumkarzinom gegenüber gesundem Endometrium signifikant erniedrigt sei. Die KISS1-mRNA-Expression des Tumors korreliere außerdem negativ mit wichtigen prognostischen Faktoren wie Tumorstadium, Invasion ins Myometrium und Lymphknotenmetastasierung. Die mRNA-Expression des Kisspeptin-Rezeptors GPR54 hingegen zeige keinen signifikanten Unterschied und keine Korrelation. Im Gegensatz dazu zeigte der Bericht einer weiteren Arbeitsgruppe, dass lediglich die immunhistochemische GPR54-Expression, nicht aber die KISS1-Expression mit den bekannten Prognosefaktoren, wie FIGO-Stadium, Grading und Tiefe der myometrialen Invasion assoziiert ist (Kang et al. 2011). Eine Erklärung für diese kontroversen Ergebnisse könnte durch die unterschiedlichen Methoden der Arbeitsgruppen geliefert werden.

Die Daten der zuvor aufgeführten Arbeitsgruppen könnten Hinweise auf das Invasionsverhalten der in der vorliegenden Arbeit untersuchten Endometriumkarzinomzellinien (Ishikawa und HEC-1a) geben.

Die hier erhobenen Ergebnissen zeigten, dass die Endometriumkarzinomzellinie HEC-1a eine geringere Grundinvasivität aufweist als die Endometriumkarzinomzellinie Ishikawa. Da dieser Versuch mit FCS enthaltendem Medium durchgeführt wurde, sollte berücksichtigt werden, dass bei der Invasion der Zellen eine chemotaktische Wirkung des FCS nicht ausgeschlossen werden kann. Sowohl im Insert als auch im Well befand sich jedoch die gleiche FCS-Konzentration, wodurch kein FCS-Konzentrationsgefälle entstehen konnte. Somit ist die Möglichkeit einer chemotaktischen Wirkung des FCS gering.

Eine mögliche Erklärung für die unterschiedliche Grundinvasivität der Endometriumkarzinomzellen könnte durch das ermittelte KISS1-mRNA-Expressionsmuster geliefert werden. Die erhobenen Daten zeigten, dass die weniger invasiven HEC-1a-Zellen eine starke KISS1-mRNA-Expression aufweisen. Im Gegensatz dazu stehen die stärker invasiven Ishikawa-Zellen, die keine KISS1-mRNA exprimieren. Dieses Ergebnis ist zu 
vereinbaren mit den Daten von Jiang et al., die 2005 nachwiesen, dass die KISS-1-mRNAExpression negativ mit der Tiefe der myometrialen Invasion von Endometriumkarzinomen korreliert.

Die Ergebnisse der Rezeptorstatus-Untersuchung zeigten, dass die verwendeten Zelllinien (Ishikawa, HEC-1a und MG-63) positiv für GPR54 sind.

Aufgrund kontroverser Ergebnisse in der Literatur, wurde die GPR54-Expression auf verschiedenen Ebenen untersucht. Molekularbiologisch zeigte sich mit Hilfe der RT-PCR lediglich in den Ishikawa-Zellen eine positive GPR54-Expression. Auf proteinbiochemischer Ebene hingegen ließ sich GPR54 in allen drei Zelllinien nachweisen. Auch eine immunzytochemische Färbung führte in allen drei Zelllinien zu einem positiven Ergebnis. Da der Nachweis mit zwei unterschiedlichen Methoden eindeutig positiv war, deuten die Ergebnisunterschiede in der GPR54-Expression am ehesten auf ungünstige Primer für den Nachweis der GPR54-mRNA-Expression hin. Entscheidend ist letztendlich das Ergebnis der Protein-Expression, denn dieses spiegelt das Ergebnis von Transkription, posttranskriptionaler Modifizierung der mRNA, Translation und posttranslationaler Modifizierung des Proteins bis hin zum endgültigen Einbau in die Membran wider.

Exogen zugeführtes Kisspeptin-10 führt nachweislich zu einer Reduktion der Invasionsfähigkeit GPR54-positiver Karzinomzellen (Navenot et al. 2005; Olbrich et al. 2010; Kang et al. 2011). Dementsprechend könnte die Hypothese aufgestellt werden, dass die, in den HEC-1a-Zellen nachgewiesene, intrinsische KISS1-mRNA-Expression zu einer Sekretion aktiven Kisspeptins und aufgrund der GPR54-Positivität zu einer autokrinen und/oder parakrinen Aktivierung der HEC-1a-Zellen in Form einer verminderten Invasionsfähigkeit führt.

Eine abschließende Aussage über den Zusammenhang der KISS1-mRNA-Expression und der Invasionsfähigkeit der Endometriumkarzinomzellen Ishikawa und HEC-1a kann jedoch nicht sicher getroffen werden, da diese Daten nur auf molekularbiologischer und nicht auch auf proteinbiochemischer Ebene erhoben wurden. Eine Überprüfung der quantitativen Kisspeptin-Protein-Expression und -Sekretion als Produkt des KISS1-Gens wäre eine nötige Ergänzung dieses Versuchs und sollte in zukünftigen Arbeiten untersucht werden. 


\subsection{Induktion der Invasion humaner Endometriumkarzinomzellen}

\subsubsection{Induktion der Invasion humaner Endometriumkarzinomzellen im Kokultur- System mit Osteoblasten-ähnlichen MG-63-Zellen}

Zellinvasion spielt eine wichtige Rolle in vielen physiologischen und pathophysiologischen Prozessen, wie embryonale Entwicklung, Immunantworten, Wundheilung und Tumorigenese. Methoden zur Untersuchung der Zellinvasion sind demnach von großer Bedeutung, um ein besseres Verständnis über die zu Grunde liegenden biologischen Mechanismen zu erlangen. In der vorliegenden Arbeit wurde gezeigt, dass monokultivierte Endometriumkarzinomzellen ein unterschiedliches Invasionsverhalten aufweisen. Ishikawa-Zellen zeigten eine deutlich stärkere Grundinvasivität als HEC-1a-Zellen.

Für die Durchführung eines weiteren Zellinvasionsassays wurde das Kokultur-System verwendet. Das Kokultur-System wurde mit Mammakarzinomzellen etabliert, welche mit Osteoblasten-ähnlichen Zielzellen interagieren (von Alten et al. 2006). In diesem System invadieren kokultivierte Karzinomzellen gerichtet durch eine poröse, matrigelbeschichtete Membran. Der Kokultur-Invasionsassay bildet somit eine Methode zur Untersuchung der Interaktion zweier unterschiedlicher Zellspezies hinsichtlich involvierter chemotaktischer Faktoren und zellulärer Stimuli. Darüber hinaus lassen sich anhand dieses Modells Substanzen bezüglich ihres potenziellen Einflusses auf die Invasion untersuchen.

Während der Kokultivierung von MCF-7-Mammakarzinomzellen mit humanen Osteoblastenähnlichen MG-63-Zellen wurde eine Steigerung der Invasivität von MCF-7-Zellen nachgewiesen und Evidenz über eine dosisabhängige Reduktion der knochengerichteten Invasion von Mammakarzinomzellen durch GnRH-Analoga und Kisspeptin-10 erbracht (von Alten et al. 2006; Olbrich et al. 2010).

In einer vorangegangen wissenschaftlichen Arbeit wurde untersucht, ob dieses KokulturModell auf verschiedene Endometriumkarzinomzelllinien übertragen werden kann. Die Kokultivierung mit Osteoblasten-ähnlichen MG-63-Zellen ließ die Tendenz einer Invasionssteigerung der Endometriumkarzinomzelllinien Ishikawa, KLE und MFE-296 erkennen (Seeber 2009).

Die Versuche in der vorliegenden Arbeit führen zu der Erkenntnis, dass die Invasionsfähigkeit von Endometriumkarzinomzellen (Ishikawa und HEC-1a) während der Kokultivierung mit der Osteoblasten-ähnlichen Zelllinie MG-63 signifikant zunimmt. Endometriumkarzinomzellen unterliegen demnach auch einer gerichteten Invasion im Kokultur-System. 
Jedoch wurde die Invasion der beiden Zelllinien unterschiedlich stark durch die MG-63Zellen induziert. HEC-1a-Zellen steigerten ihre Invasivität um den Faktor 48,5, wohingegen die Ishikawa-Zellen diese nur um den Faktor 1,35 steigerten. Mögliche Ursachen für die Unterschiede in der Invasionssteigerung der beiden Zelllinien werden anschließend aufgeführt (Kapitel 4.4).

Hinsichtlich der erhobenen Ergebnisse ist zu berücksichtigen, dass dieser beschriebene „Kokultur-Effekt“ bei den Ishikawa-Zellen in nur $70 \%$ der durchgeführten Experimente nachweisbar war. Im Mittel führte die Kokultivierung trotzdem zu einer signifikanten Zunahme der Invasion.

Mit Hilfe einer ähnlichen Methode untersuchte eine weitere Arbeitsgruppe ebenfalls das invitro-Invasionsverhalten von Endometriumkarzinomzellen (AMEC und RL95), wobei sich die Lockzellen zu der vorliegenden Arbeit unterschieden. Sie publizierten, dass die Kokultivierung mit Uterus-Myozyten signifikant die Migration der Endometriumkarzinomzellen stimuliere. Die Experimente zeigten eine deutliche Steigerung der Tumorzellmigration in Folge einer Tumor-Stroma-Interaktion. Dabei wurde das Chemokin SDF-1 als wichtiger Bestandteil dieser Interaktion genannt (Tsukamoto et al. 2007). Anhand dieser Daten wird die Bedeutung der Mikroumgebung des Tumors mit seinen Einflüssen auf die Invasion der Tumorzellen aufgezeigt. Die Tumor-Mikroumgebung wird gebildet von Fibroblasten, Endothelzellen, Zellen des Immunsystems und von extrazellulärer Matrix. Gemeinsam unterstützen diese Komponenten die Struktur des Tumors, fördern die Angiogenese und dadurch bedingt auch die Tumorproliferation (Olumi et al. 1999). Von Tumorzellen und tumorassoziierten Stromazellen sezerniertes SDF-1 stimuliert dabei sowohl autokrin als auch parakrin die Invasivität und die Proliferation von Karzinomzellen (Orimo et al. 2005). Die Bedeutung des SDF-1/CXCR4-Systems in der Tumorbiologie des Endometriumkarzinoms wird im Folgenden detaillierter diskutiert (Kapitel 4.2.2 und Kapitel 4.4).

\subsubsection{SDF-1-induzierte Invasion humaner Endometriumkarzinomzellen}

Maligne Tumorzellen nutzen ein breites Spektrum an Signalwegen, um die eigene Proliferation, Invasion und Metastasierung zu fördern. Beteiligte Signalmoleküle stehen häufig im Fokus der onkologischen Forschung und werden auch als prometastatische Faktoren bezeichnet. Die Aufschlüsselung ihrer Funktionsweise bildet die Basis für die Entstehung und Entwicklung moderner und gezielter onkologischer Therapien.

$\mathrm{Zu}$ diesen Signalmolekülen gehören unter anderem Chemokine. Dies sind chemotaktische Zytokine, die die Bewegung von Zellen lenken. Zellen, die die entsprechenden ChemokinRezeptoren exprimieren, migrieren entlang eines Gradienten zu hohen Konzentrationen der sezernierten Chemokine (Balkwill 2004). 
Obwohl Chemokine erstmals im Zusammenhang mit Leukozyten, Entzündungsprozessen und anschließend bei dem, für die Hämatopoese essentiellen, Homing entdeckt wurden, zeigte sich bald eine wichtige Rolle der Chemokine bei der Tumorzellinvasion und Metastasierung (Rossi und Zlotnik 2000; Wang JM et al. 1998). Oft wird in diesem Zusammenhang das SDF-1/CXCR4-System genannt, welches aus dem membranständigen Rezeptor CXCR4 und seinem sekretorischen Liganden SDF-1 besteht.

SDF-1 wird bezüglich der Tumorbiologie vor allem von Geweben sezerniert, in denen sich häufig Metastasen ansiedeln, darunter zum Beispiel Leber, Lunge und Knochen (Wang $\mathrm{J}$ et al. 2006; Burger und Peled 2009). SDF-1 wird unter anderem von Osteoblasten-ähnlichen MG-63-Zellen, wie auch von anderen humanen Osteosarkomzelllinien synthetisiert und in die Umgebung sezerniert (Ponomaryov et al. 2000).

Auch in dieser Arbeit wurde gezeigt, dass die zu untersuchenden Endometriumkarzinomund Osteoblasten-ähnlichen Zellen sowohl auf molekularbiologischer als auch auf proteinbiochemischer Ebene die Komponenten des SDF-1/CXCR4-Systems exprimieren.

Das chemotaktische SDF-1, als nachweisliches Sekretionsprodukt der Osteoblastenähnlichen Zellen und somit als fragliche Komponente der invasionssteigernden Prozesse im Kokultur-System, wurde in einem weiteren Zellinvasionsassay hinsichtlich seiner Effekte auf die Endometriumkarzinomzellen untersucht.

SDF-1 führte zu dem erwarteten Anstieg der Invasionsfähigkeit beider CXCR4-positiver Endometriumkarzinomzellinien. Somit kann davon ausgegangen werden, dass das SDF-1/CXCR4-System für die Invasionsfähigkeit von Endometriumkarzinomzellen eine bedeutsame Rolle spielt. Sowohl SDF-1 a und SDF-1 $\beta$ als auch die gleichzeitige Verwendung beider Isoformen erzielten in einer Konzentration von $50 \mathrm{ng} / \mathrm{ml}$ und $100 \mathrm{ng} / \mathrm{ml}$ eine signifikante Zunahme der Invasionsfähigkeit der Ishikawa- und HEC-1a-Zellen. Dabei war bei den Ishikawa-Zellen zwischen den verwendeten SDF-1-Konzentrationen kein signifikanter Unterschied im Invasionsanstieg zu erkennen. Bei den HEC-1a-Zellen führte jedoch SDF-1 in einer Konzentration von $50 \mathrm{ng} / \mathrm{ml}$ zu einem signifikant größeren Anstieg der invadierten Zellen, als SDF-1 in einer Konzentration von 100 ng/ml. Die jeweiligen Isoformen führten letztendlich bei beiden Zelllinien zu einer vergleichbar hohen Invasionssteigerung; zwischen innen war kein signifikanter Unterschied feststellbar. Zudem zeigte die gleichzeitige Verwendung beider Isoformen keine Potenzierung der jeweiligen Einzeleffekte.

Ein direkter stimulierender Effekt von SDF-1 auf die gerichtete Invasion von Tumorzellen konnte in der Vergangenheit unter anderem bereits für Rhabdomyosarkom-, Mamma-, Ovarial-, und Pankreaskarzinomzellen nachgewiesen werden (Libura 2002; Müller et al. 2001; Scotton et al. 2002; Koshiba et al. 2000). Dies ist die erste Arbeit, die zeigt, dass auch Endometriumkarzinomzellen durch eine Stimulation mit exogenem SDF-1 eine Induktion der gerichteten Invasion durch eine matrigelbeschichtete Membran erfahren. 
Die SDF-1-Konzentrationen, die laut Literatur nachweislich zu einer Steigerung der Invasion führten, lagen zwischen $10 \mathrm{ng} / \mathrm{ml}$ und $300 \mathrm{ng} / \mathrm{ml}$. Einige Arbeitsgruppen zeigten, dass die Verwendung höherer SDF-1-Konzentrationen zu einer dosisabhängigen, stärkeren Invasionssteigerung führte (Libura 2002; Müller et al. 2001; Scotton et al. 2002; Koshiba et al. 2000). Dies konnte in dieser Arbeit nicht einheitlich bestätigt werden. Es ist jedoch schwierig, die verwendeten Konzentrationen und deren Wirkspektrum zu vergleichen, da der Effekt des exogenen SDF-1 vermutlich zellspezifisch ist und auch von dem SDF-1/CXCR4Expressionsmuster der untersuchten Zelllinien und Tumorspezies abhängig sein könnte.

Diese Arbeit ist auch die Erste, in der der Effekt von SDF-1 $\beta$ auf Endometriumkarzinomzellen untersucht wurde. In der Literatur sind keine vergleichbaren Experimente zu finden.

Es lässt sich anhand der hier erhobenen Daten festhalten, dass SDF-1 $\beta$ eine ähnlich starke chemotaktische und invasionssteigernde Wirkung wie SDF-1 a auf die Endometriumkarzinomzellen ausübt. Ein Unterschied der beiden Isoformen in Aktivität und Potenz am CXCR4 war nicht nachweisbar und bestätigt somit die zusammengefassten Ergebnisse eines Übersichtsartikels von Janowski (2009). Die SDF-1-Isoformen unterscheiden sich am C-terminalen Rest des Peptids, welcher nicht für die Rezeptoraktivierung ausschlaggebend ist (Crump et al. 1997; Janowski 2009). Das unterschiedliche Wirkspektrum der Isoformen ist lediglich bedingt durch unterschiedliche Prozessierung im Organismus (De La Luz Sierra et al. 2004). Die hier erhobenen Ergebnisse lassen daher den Rückschluss zu, dass die beiden Isoformen im Versuchsmedium keiner unterschiedlichen Prozessierung unterliegen.

Einen weiteren Diskussionsansatz liefert die Feststellung, dass durch Zugabe der SDF-1Isoformen bei den Ishikawa-Zellen eine größere Invasionssteigerung erreicht wurde als während der Kokultivierung mit Osteoblasten-ähnlichen MG-63-Zellen. Um eine mögliche Erklärung für dieses Ergebnis zu liefern, könnte in zukünftigen Arbeiten eine Untersuchung des SDF-1-Expressionsmusters der jeweiligen Zellinien hilfreich sein. Die quantitative SDF-1-Expression und -Sekretion der Endometriumkarzinomzellen könnte dabei Hinweise auf die essentielle Ausbildung eines positiven SDF-1-Gradienten liefern. Man könnte die Vermutung äußern, dass durch die Zugabe des exogenen SDF-1 ein größerer Gradient als in dem Kokultur-System geschaffen wurde, wodurch in diesem Assay mehr Ishikawa-Zellen invadierten.

Zusammenfassend kann man anhand der in dieser Arbeit erhobenen Daten ableiten, dass SDF-1 $\alpha$ und SDF-1 $\beta$ eine Induktion der Invasionsfähigkeit von Endometriumkarzinomzellen bewirken. 


\subsection{Inhibition der Invasionsfähigkeit humaner Endometriumkarzinomzellen durch Kisspeptin-10}

\subsubsection{Inhibition der Invasion humaner Endometriumkarzinomzellen im Kokultur- System durch Kisspeptin-10}

Wie bereits erwähnt, wurde in dieser Arbeit gezeigt, dass die Invasionsfähigkeit von Endometriumkarzinomzellen während der Kokultivierung mit der Osteoblasten-ähnlichen Zelllinie MG-63 signifikant zunimmt.

Die Durchführung weiterer Experimente und die Kisspeptin-10-Behandlung der Zellen waren aufgrund der oben genannten GPR54-Positivität angezeigt.

Durch die gezielte Behandlung der kokultivierten Endometriumkarzinomzellen mit exogenem Kisspeptin-10 wurde eine signifikante, dosisabhängige Reduktion der invadierten Zellen gegenüber unbehandelter Zellen erreicht. Für die Endometriumkarzinomzelllinie Ishikawa zeigte sich der stärkste antiinvasive Effekt des Kisspeptin-10 in einem Dosis-Fenster von $1 \times 10^{-13} \mathrm{M}$ bis $1 \times 10^{-11} \mathrm{M}$. Bei der Endometriumkarzinomzellinie HEC-1a wurde eine signifikante Reduktion der Invasion mit einer Kisspeptin-10-Konzentration von $1 \times 10^{-9} \mathrm{M}$ erreicht.

Der Unterschied in der benötigten Konzentration zwischen den Endometriumkarzinomzelllinien könnte durch ihr GPR54-Expressionsmuster erklärt werden, da die Liganden-Konzentration, die benötigt wird, um eine Zelle zu stimulieren, von der Dichte des Rezeptors abhängt. Dies müsste in Zukunft mittels repräsentativer quantitativer GRP54-Protein-Nachweise untersucht werden.

Olbrich et al. wiesen den oben genannten Fenstereffekt von Kisspeptin-10 bereits 2010 auf die Invasionsfähigkeit kokultivierter Mammakarzinomzellen nach. Durch die nun erhobenen Ergebnisse steigt die Evidenz eines dosisabhängigen Fenstereffekts von Kisspeptin-10 auf die Invasionsfähigkeit von Tumorzellen.

Fraglich ist jedoch, weshalb Kisspeptin-10 nur in diesem bestimmten Dosis-Fenster eine antiinvasive Wirkung auf Karzinomzellen ausübt, nicht aber bei steigender Konzentration. Höhere Kisspeptin-10-Konzentrationen $\left[1 \times 10^{-7} \mathrm{M}\right]$ führten bei Olbrich et al. zu keiner Reduktion, sondern zu einer tendenziellen Steigerung der Invasionsfähigkeit der Mammakarzinomzellen. In der vorliegenden Arbeit zeigte sich bei der Behandlung kokultivierter Ishikawa-Zellen mit Kisspeptin-10 $\left[1 \times 10^{-6} \mathrm{M}\right]$ sogar eine signifikante Steigerung der Invasionsfähigkeit dieser Endometriumkarzinomzellinie. Zajac et al. (2011) publizierten eine nachweisbare dosisabhängige Erhöhung der MDA-MB-231 Zellinvasion, nach 
Behandlung dieser Zellen mit verschiedenen Kisspeptin-10-Konzentrationen. Der stärkste

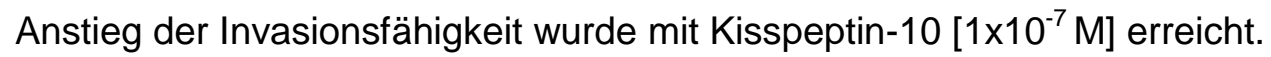

Die Daten lassen die Vermutung zu, dass Kisspeptin-10 dosisabhängig einen unterschiedlichen Effekt auf die Invasionsfähigkeit von Karzinomzellen ausüben könnte. Eine Bearbeitung dieser Fragestellung hätte den Umfang dieser Arbeit jedoch weit überstiegen und sollte Anlass für weitere Experimenten sein.

Eine weitere Arbeitsgruppe untersuchte in einem Zellinvasionsassay die Kisspeptin-10Wirkung auf die FCS-gerichtete Invasion von Ishikawa- und HEC-1a-Zellen. Zu erwähnen ist hierbei, dass HEC-1a-Zellen, aufgrund des RT-PCR-Ergebnisses als GPR54-negativ klassifiziert wurden. Eine Kisspeptin-10-Behandlung $\left[1 \times 10^{-6} \mathrm{M}\right]$ führte bei Ishikawa-Zellen, nicht aber bei HEC-1a-Zellen, zu einer Reduktion invadierter Zellen (Kang et al. 2011). Im Gegensatz dazu konnte in der vorliegenden Arbeit eine GPR54-Positivität der HEC-1a-Zellen nachgewiesen werden. Kontroversen ergeben sich auch hinsichtlich der Wirkung des Kisspeptin-10 auf die gerichtete Invasion. Die vorliegenden Daten zeigten, dass eine Kisspeptin-10-Behandlung mit einer Konzentration von $1 \times 10^{-6} \mathrm{M}$ bei kokultivierten IshikawaZellen keine Reduktion der Invasion, sondern sogar eine Invasionssteigerung verursacht. Ein direkter Vergleich dieser Daten erweist sich jedoch als problematisch, da verschiedene Versuchsaufbauten verwendet wurden. Kang et al. untersuchten lediglich die Kisspeptin-10Wirkung auf einen Zelltyp, wobei in der vorliegenden Arbeit ein System aus zwei unterschiedlichen Zellspezies untersucht wurde.

Der in dieser Arbeit gezeigte antiinvasive Effekt von Kisspeptin-10 ist vereinbar mit den Ergebnissen, die in Versuchen mit anderen Tumorspezies erhoben wurden, welche dem Kisspeptin eine Metastasen supprimierende Wirkung zusprechen. Bis heute konnte die Metastasen-Suppressor-Aktivität des Kisspeptin-Systems in Malignomen von Schilddrüse, Eierstock, Blase, Magen, Speiseröhre, Leber, Pankreas und Lunge identifiziert werden (Kirby et al. 2010).

Ergänzend sei noch erwähnt, dass aufgrund der nachgewiesenen KISS1-mRNA-Expression der HEC-1a-Zellen, bei der gezeigten Wirkung des exogenen Kisspeptin-10 zusätzliche endogene Kisspeptin-Effekte nicht ausgeschlossen werden können. Die intrinsische KISS1mRNA-Expression könnte über Translation zu einer endogenen Sekretion aktiver Kisspeptine führen. Dieses Kisspeptin könnte zu einer autokrinen und/oder parakrinen Stimulation der Zellen führen und die Wirkung des exogenen Kisspeptin-10 beeinflussen. Denkbar wäre zum Beispiel eine Herabsenkung der, für einen signifikanten Effekt erforderlichen, exogenen Kisspeptin-Konzentration, da GPR54 durch die endogene Kisspeptin-Sekretion bereits teilweise besetzt wäre. Diese Möglichkeit sollte bei der Interpretation der gezeigten Daten berücksichtigt werden. Eine zukünftige Untersuchung der 
Kisspeptin-Expression und -Sekretion der verwendeten Zellen würde, wie bereits erwähnt, die jetzigen Daten sinnvoll ergänzen.

Zusammenfassend steigt die Evidenz einer antiinvasiven Wirkung von Kisspeptin-10 auf Endometriumkarzinomzellen. Eine mögliche invasionsfördernde Wirkung von höher konzentriertem Kisspeptin-10 sollte in Zukunft untersucht werden.

4.3.2 Inhibition der SDF-1-induzierten Invasion humaner Endometriumkarzinomzellen durch Kisspeptin-10

In den vorangegangen Experimenten ließ sich bereits nachweisen, dass Kisspeptin-10 die Invasionssteigerung kokultivierter Endometriumkarzinomzellen reduziert. Auf der Suche nach möglichen Mechanismen in diesem System, fand sich zunächst, dass SDF-1, welches unter anderem von Osteoblasten-ähnlichen MG-63-Zellen sezerniert wird, eine Invasionssteigerung vergleichbar mit dem oben genannten „Kokultur-Effekt“ induziert.

Folgend zeigte sich, dass exogenes Kisspeptin-10 die SDF-1-induzierte Invasionssteigerung der Endometriumkarzinomzellen reduziert. Kisspeptin-10 reduzierte die Invasionssteigerung von Ishikawa-Zellen, die zuvor durch SDF-1 $\alpha$ und SDF-1 $\alpha / \beta$ in einer Konzentration von $50 \mathrm{ng} / \mathrm{ml}$ erreicht wurde. Die Invasionssteigerung der HEC-1a-Zellen, die zuvor durch SDF-1 $\alpha$ und SDF-1 $\beta$ in einer Konzentration von $50 \mathrm{ng} / \mathrm{ml}$ erreicht wurde, wurde ebenfalls durch Kisspeptin-10 reduziert. Die durch SDF-1 [100 ng/ml] zuvor signifikant gesteigerte Invasion der beiden Endometriumkarzinomzellen wurde durch eine Behandlung mit Kisspeptin-10 lediglich bei HEC-1a-Zellen, die zuvor mit SDF-1 $\alpha / \beta$ behandelt wurden, signifikant reduziert.

Navenot et al. (2005) beschäftigten sich mit einer ähnlichen Fragestellung, wobei ihre Daten die hier erhobenen Ergebnisse bestätigen. Exogenes Kisspeptin-10 reduzierte die SDF-1induzierte Invasionsfähigkeit von CHO-Zellen. Darüber hinaus lieferte diese Arbeitsgruppe einen möglichen Mechanismus hinter der Kisspeptin-10-vermittelten Reduktion der invasionsfördernden SDF-1-Wirkung. Sie zeigten, dass Kisspeptin-10 eine verlängerte Phosphorylierung von ERK $1 / 2$ (extracellular signal-regulated kinase 1/2) stimuliert und die SDF-1-induzierte Akt-Phosphorylierung inhibiert, wodurch die SDF-1- und CXCR4-vermittelte chemotaktische Antwort reduziert wird. Weitere mögliche Mechanismen werden im Kapitel 4.5. diskutiert.

Auch durch die hier erhobenen Ergebnisse steigt weiterhin die Evidenz einer antiinvasiven Wirkung des Kisspeptin-10 in vitro, wobei speziell eine Inhibition der SDF-1-gerichteten Invasion gezeigt wurde. 


\subsection{Kisspeptin-10 und das prometastatische SDF-1/CXCR4-System}

\subsubsection{Kisspeptin-10-vermittelte Effekte auf den Chemokinrezeptor CXCR4}

CXCR4 ist der überwiegend exprimierte Chemokin-Rezeptor in vielen menschlichen Tumoren. Sein Ligand ist das bereits erwähnte SDF-1. In Vergangenheit bestätigte sich, dass die Expression von CXCR4 positiv mit dem invasiven, metastatischen Potenzial und der Differenzierung vieler unterschiedlicher Malignome korreliert (Balkwill 2004). Zum Beispiel wurde gezeigt, dass die CXCR4-Expression in Endometriumkarzinomen, die mehr als die Hälfte des Myometriums invadierten, signifikant höher war, als bei denen, die weniger als die Hälfte des Myometriums invadierten (Tsukamoto et al. 2007). Auch Gelmini et al. fanden 2009 einen positiven Zusammenhang zwischen der CXCR4-mRNA-Expression und dem histologischen Grading des Endometriumkarzinoms; G1- und G2-Tumore zeigten eine signifikant geringere Expression als G3-Tumore. Die CXCR4-Expression korreliert nicht nur mit dem metastatischen Potenzial von Tumoren, sondern ist darüber hinaus auch direkt assoziiert mit einer verstärkten Invasion der Tumorzellen entlang eines SDF-1-Gradienten (Navenot et al. 2005; Müller et al. 2001; Lee B-C et al. 2004). Die große Rolle, die CXCR4 auch in der Invasion und Metastasierung von Endometriumkarzinomzellen zu spielen scheint, wurde mittels Blockade des CXCR4 mit monoklonalen Antikörpern gezeigt. Diese führte zu einer Hemmung der Fernmetastasierung von HEC-1a-Endometriumkarzinomzellen in Geweben mit hohen SDF-1-Konzentrationen im Xenograft-Maus-Modell (Gelmini et al. 2009).

Es gibt jedoch auch gegensätzliche Meinungen. Zwei Arbeitsgruppen berichteten über eine negative Korrelation zwischen Überexprimierung des SDF-1/CXCR4-Systems und der Sterblichkeit von Endometriumkarzinompatientinnen. Zum einen war die immunhistochemische CXCR4-Expression in G1- und G2-Tumoren höher als in G3-Tumoren (Mizokami et al. 2004). Zum anderen publizierten Felix et al. (2012), dass die Überlebensraten bei Patientinnen, die höhere Level von CXCR4 im Endometriumkarzinom exprimierten, signifikant besser seien.

Die Möglichkeit einer individuellen Beurteilung der Endometriumkarzinome hinsichtlich ihrer SDF-1- und CXCR4-Expression als Prognosefaktor ist zurzeit noch nicht hinreichend geklärt (Felix et al. 2010). Eine Aufklärung dieses Zusammenhanges könnte möglicherweise Therapiekonzepte hinsichtlich der Patientensterblichkeit verbessern.

In der vorliegenden Arbeit wurden die verwendeten Zelllinien zunächst auf eine mögliche CXCR4-Expression untersucht. Um die Mechanismen aufzuklären, die zum einen den Anstieg der Endometriumkarzinomzellinvasion im Kokultur-Invasionsassay und zum anderen den inhibierenden Einfluss von Kisspeptin-10 auf diese Invasion bewirken, wurde sowohl die 
Gen- als auch die Protein-Expression untersucht. Für die Behandlungen wurden die Konzentrationen gewählt, bei denen Kisspeptin-10 in den Kokultur-Invasionsassays die stärkste antiinvasive Wirkung entfaltete (Ishikawa: $1 \times 10^{-13} \mathrm{M}$; HEC-1a: $1 \times 10^{-11} \mathrm{M}$ ).

Es zeigte sich, dass die Endometriumkarzinomzellen sowohl molekularbiologisch als auch proteinbiochemisch eine positive Expression des Chemokinrezeptors aufweisen.

Anhand der in dieser Arbeit erhobenen Daten lässt sich ableiten, dass die Kokultivierung mit MG-63-Zellen nicht zu einer Erhöhung der CXCR4-mRNA- und Protein-Expression von Endometriumkarzinomzellen führt. Bezugnehmend auf die Literaturrecherche spielt CXCR4 zwar eine wichtige Rolle bezüglich der Invasionsfähigkeit von Endometriumkarzinomzellen, eine durch MG-63-Zellen stimulierte CXCR4-Mehr- oder Überexpression kann, laut der hier erhobenen Daten, jedoch nicht der Grund für die signifikante Steigerung der Endometriumkarzinomzellinvasion im Kokultur-Invasionsassay sein.

Weitere in dieser Arbeit durchgeführte Untersuchungen zeigten, dass exogenes Kisspeptin10 in geringer Konzentration bei kokultivierten Endometriumkarzinomzellen zu einer signifikanten Reduktion der CXCR4-mRNA- und Protein-Expression führt. Dies könnte einen Mechanismus der antiinvasiven Wirkung des Kisspeptin-10 darstellen. Navenot et al. publizierten 2005, dass der durch Kisspeptin-10-induzierte GPR54-Signalweg die CXCR4vermittelte chemotaktische Antwort vermindere. Die Fähigkeit von Kisspeptin-10, die direkte SDF-1-induzierte Migration zu inhibieren, wurde in den GPR54- und CXCR4-kotransfizierten CHO-Zellen nachgewiesen, wobei aber eine Reduktion des membranständigen CXCR4 nicht an der migrationshemmenden Wirkung von Kisspeptin-10 beteiligt sei.

Den ersten Nachweis eines direkten inhibierenden Effekts von Kisspeptin-10 auf die CXCR4Expression zeigten Olbrich et al. 2010 für Mammakarzinomzellen. Darüber hinaus publizierten sie, dass der MG-63-bedingte zelluläre Stimulus während der Kokultivierung zu einer Erhöhung der CXCR4-Expression führe und somit eine Erklärung für die gesteigerte Invasion von Mammakarzinomzellen im Kokultur-Invasionsassay liefere. Die vorliegende Arbeit bestätigt den inhibierenden Effekt von Kisspeptin-10 auf die CXCR4-Expression von Endometriumkarzinomzellen, zeigt aber keinen Einfluss der Kokultivierung auf die CXCR4Expression.

Die hier nachgewiesene direkte Kisspeptin-10-vermittelte Reduktion der endometrialen CXCR4-Expression könnte darüber hinaus auch einen möglichen Mechanismus der oben genannten Kisspeptin-10-vermittelten Reduktion der SDF-1-induzierten Invasionssteigerung monokultivierter Endometriumkarzinomzellen darstellen (Kapitel 4.3.2). Eine Beteiligung von CXCR4 kann hierbei jedoch nur vermutet, nicht aber bestätigt werden, da dies in der vorliegenden Arbeit nicht untersucht wurde. 


\subsubsection{Kisspeptin-10-vermittelte Effekte auf das Chemokin SDF-1}

Auch die SDF-1-Expression wurde in der vorliegenden Arbeit molekularbiologisch und proteinbiochemisch in den verwendeten Zellinien (Ishikawa, HEC-1a und MG-63) nachgewiesen. Entscheidend ist, dass die chemotaktischen Lockzellen MG-63 SDF-1 nicht nur exprimieren, sondern auch sezernieren, da dies für seine Aktivität als sezerniertes Protein ausschlaggebend ist.

In den Experimenten zeigte sich, dass monokultivierte MG-63-Zellen SDF-1 zwar molekularbiologisch und proteinbiochemisch exprimieren, aber kaum nachweislich sezernieren. Die Kokultivierung mit den Endometriumkarzinomzellen hingegen führte sowohl zu einer Steigerung der SDF-1-Expression als auch zu einer Steigerung der Sekretion des aktiven SDF-1. Es scheint, als würden die Endometriumkarzinomzellen während der Kokultivierung Signalmoleküle sezernieren, die die MG-63-Zellen stimulieren, ihre SDF-1Sekretion zu verstärken. Dieser Hypothese müsste in zukünftigen Arbeiten weiter nachgegangen werden.

Anhand dieser Daten lässt sich ableiten, dass SDF-1 eine wichtige Rolle in der Invasionssteigerung der Endometriumkarzinomzellen während der Kokultivierung zu spielen scheint. Tsukamoto et al. publizierten 2007 nicht nur, dass eine Kokultivierung von Endometriumkarzinomzellen mit Uterus-Myozyten eine Stimulation der Migration erziele, sondern auch, dass das durch die Myozyten sezernierte SDF-1 maßgeblich an der Migrationssteigerung beteiligt sei. Olbrich zeigte die Notwendigkeit einer SDF-1-Sekretion für die Invasionsfähigkeit kokultivierter Mammakarzinomzellen, indem eine Behandlung des Kokultur-Systems mit einem SDF-1-Antikörper zum Aufheben der vorher induzierten Invasionssteigerung führte. Zudem konnte sie zeigen, dass die Kokultivierung humaner Osteoblasten-ähnlicher MG-63-Zellen mit Mammakarzinomzellen fördernd auf die SDF-1mRNA-Expression und Protein-Sekretion der MG-63-Zellen wirkt (Olbrich 2010).

Die Ergebnisse der zitierten Arbeitsgruppen und die in dieser Arbeit erhobenen Daten, die unter anderem zeigen, dass exogenes SDF-1 die Invasion monokultivierter Endometriumkarzinomzellen induziert, können zusammenfassend die Hypothese erhärten, dass die Invasionssteigerung der Endometriumkarzinomzellen im Kokultur-Invasionsassay mit Osteoblasten-ähnlichen MG-63-Zellen unter anderem eine SDF-1-gerichtete Invasion ist. Eine Behandlung des Kokultur-Systems mit Kisspeptin-10 wiederum führte in der vorliegenden Arbeit zu einer Reduktion der SDF-1-Expression und -Sekretion der MG-63Zellen. Diese Kisspeptin-10-vermittelte Reduktion der SDF-1-Expression könnte an der antiinvasiven Wirkung des Kisspeptin-10 beteiligt sein. Den Nachweis einer inhibierenden Kisspeptin-10-Wirkung auf die SDF-1-Expression kokultivierter Osteoblasten-ähnlicher Zellen zeigten auch Olbrich et al. (2010). 
Interessant ist zudem, dass zwar die Kokultivierung der MG-63-Zellen mit beiden Endometriumkarzinomzellinien zu einer Steigerung der SDF-1-Expression führte, diese aber bei Kokultivierung mit HEC-1a tendenziell stärker ausfiel. Dieses Ergebnis könnte erklären, warum die HEC-1a-Zellen im Kokultur-Invasionsassay mit MG-63-Zellen eine deutlich größere Invasionssteigerung erfahren haben als die Ishikawa-Zellen. Die stärkere SDF-1Sekretion der MG-63-Zellen mit HEC-1a-Zellen könnte einen größeren SDF-1-Gradienten bedingen und dadurch die Invasion stärker fördern. Zusätzlich könnte diese stärkere Invasionszunahme auch durch die CXCR4-Dichte der Endometriumkarzinomzellen erklärt werden. Diesen Vermutungen müsste mittels repräsentativer, quantitativer Proteinbestimmungen in zukünftigen Arbeiten weiter nachgegangen werden. Zusammenfassend lässt sich festhalten, dass die gesamte zelluläre Interaktion zwischen MG-63- und HEC-1a-Zellen stärker zu sein scheint. Bei dieser Zellzusammenstellung erzielten auch die Behandlungen mit Kisspeptin-10 einen größeren Effekt, wobei der Grund für diese stärkere Kisspeptin-10-bedingte Reduktion der SDF-1-Protein-Expression weiterhin fraglich ist.

In den durchgeführten Experimenten zeigte sich darüber hinaus, dass auch die Endometriumkarzinomzellen Ishikawa und HEC-1a auf proteinbiochemischer Ebene SDF-1 exprimieren. Dieses Ergebnis liefert einen weiteren interessanten Diskussionsansatz.

Bekanntermaßen ist ein SDF-1-Gradient zwischen zwei Zellpopulationen notwendig, um die Invasion der einen Zellgruppe zu induzieren. Zwei unabhängige Arbeitsgruppen publizierten eine geringere SDF-1-Expression im Endometriumkarzinomgewebe im Vergleich zu gesundem Endometrium sowie eine Korrelation zwischen negativer SDF-1-Expression und positiver Metastasierung bei Endometriumkarzinompatientinnen (Gelmini et al. 2009; Felix et al. 2012). Eine SDF-1-induzierte Invasionssteigerung im Kokultur-System könnte in Frage gestellt werden, exprimieren doch sowohl die Endometriumkarzinom- als auch die Osteoblasten-ähnlichen Zellen SDF-1, wodurch eine positiver Gradient angezweifelt werden könnte. Dabei muss jedoch berücksichtigt werden, dass, wie oben erwähnt, die Kokultivierung mit Endometriumkarzinomzellen einen großen Anstieg der SDF-1-Expression und -Sekretion der MG-63-Zellen bedingt, wodurch ein positiver Gradient in Richtung dieser Zellen entstehen könnte. Es fehlen jedoch repräsentative Ergebnisse über die quantitative SDF-1-Expression und -Sekretion in den einzelnen Zellinien, um diese vergleichen und diese Fragestellung abschließend beantworten zu können. 


\subsection{Resultierender Mechanismus der Kisspeptin-10-vermittelten Invasions- und Expressionsreduktion}

Die Kokultivierung mit Osteoblasten-ähnlichen MG-63-Zellen führte zu einer Invasionssteigerung der Endometriumkarzinomzellen Ishikawa und HEC-1a. In Zusammenschau aller erhobenen Ergebnisse lässt sich vermuten, dass die Invasionssteigerung während der Kokultivierung zumindest teilweise durch eine MG-63bedingte SDF-1-Sekretion induziert wurde. Die CXCR4-Expression wurde nicht signifikant verändert.

Kisspeptin-10 reduzierte die gesteigerte Invasion kokultivierter humaner Endometriumkarzinomzellen. Dabei wurde eine GPR54-Expression sowohl auf der Osteoblasten-ähnlichen Zelllinie MG-63 als auch auf den Endometriumkarzinomzellinien Ishikawa und HEC-1a festgestellt. Auf der Suche nach den zu Grunde liegenden molekularen Mechanismen der antiinvasiven Kisspeptin-10-Wirkung, zeigte sich sowohl eine Reduktion der CXCR4-Expression kokultivierter Endometriumkarzinomzellen als auch eine Reduktion der SDF-1-Expression und -Sekretion kokultivierter MG-63-Zellen. Es ist somit davon auszugehen, dass das SDF-1/CXCR4-System sowohl für die Invasionssteigerung kokultivierter Endometriumkarzinomzellen eine bedeutsame Rolle spielt als auch an der Kisspeptin-10-vermittelten Inhibition dieser Invasionssteigerung beteiligt ist. Vermutlich wird die Invasion Kisspeptin-10-vermittelt sowohl durch eine Reduktion der SDF-1-Expression und -Sekretion der Osteoblasten-ähnlichen Zellen als auch durch eine CXCR4Expressionsreduktion der Endometriumkarzinomzellen inhibiert.

Der konkrete Mechanismus hinter dem inhibierenden Effekt von Kisspeptin-10 auf die Expression der Komponenten des SDF-1/CXCR4-Systems kokultivierter Zellen ist jedoch weiterhin ungeklärt.

Zum einen könnte durch Kisspeptin-10 eine direkte Stimulation der jeweiligen Zelltypen sowohl zu einer GPR54-vermittelten Reduktion der CXCR4-Expression der Endometriumkarzinomzellen als auch zu einer Reduktion der SDF-1-Expression der MG-63Zellen führen, da sowohl die Endometriumkarzinom- als auch die Osteoblasten-ähnlichen Zellen positiv für GPR54 getestet wurden.

Zum anderen sind Interaktionen der beiden verwendeten Zelltypen im Kokultur-System bezüglich des Kisspeptin-10-Effekts nicht ausgeschlossen. Olbrich führte in ihrer Arbeit unter anderem einen GPR54-knock-down in der Osteoblasten-ähnlichen Zelllinie MG-63 durch. Dadurch wurden im Kokultur-System erstaunlicherweise nicht nur die Effekte von Kisspeptin10 auf die SDF-1-Sekretion der MG-63-Zellen aufgehoben, sondern auch auf die CXCR4und P-Akt-Expression der Mammakarzinomzellen (Olbrich 2010). Diese Daten lassen die Vermutung zu, dass die Kisspeptin-10-vermittelte Invasionsreduktion lediglich durch einen 
Effekt auf die MG-63-Zellen zustande kommt. Dies würde bezogen auf die vorliegende Arbeit bedeuten, dass Kisspeptin-10 nicht nur am GPR54 der Endometriumkarzinomzellen bindet, sondern vor allem den GPR54 der Osteoblasten-ähnlichen Zelllinie MG-63 aktiviert und über diese Aktivierung im Rahmen einer interzellulären Interaktion die Gen- und ProteinExpression der Endometriumkarzinomzellen beeinflussen könnte. Dieser Mechanismus schließt den erst genannten jedoch nicht aus.

In der vorliegenden Arbeit wurde jedoch gezeigt, dass Kisspeptin-10 auch die SDF-1induzierte Invasion monokultivierter humaner Endometriumkarzinomzellen reduziert. Kisspeptin-10 scheint daher in der Lage zu sein, die Invasion lediglich durch eine Aktivierung des GPR54 der Endometriumkarzinomzellen reduzieren zu können. Eine Interaktion mit MG63-Zellen wurde in diesem Versuch umgangen, was verdeutlicht, dass für die Invasionshemmung der Endometriumkarzinomzellen nicht zwangsläufig die Kisspeptin-10 vermittelte SDF-1-Expressionsreduktion der MG-63-Zellen, beziehungsweise die zuvor genannten unbekannten interzelluläre Effekte, notwendig oder entscheidend sind. Die Kisspeptin-10-Behandlungen führten zu einer herabgesetzten Reaktionsfähigkeit der Endometriumkarzinomzellen gegenüber dem exogenen SDF-1. Spekulativ könnte an diesem Effekt eine direkte Kisspeptin-10-vermittelte Reduktion der CXCR4-Expression monokultivierter Endometriumkarzinomzellen beteiligt sein.

Nichts desto trotz ist ein zusätzlicher Effekt von Kisspeptin-10 auf die Osteoblastenähnlichen MG-63-Zellen nicht von der Hand zu weisen.

Zusammenfassend wird anhand dieser Ergebnisse die Komplexität der Kisspeptin-10Wirkung aufgezeigt. Es zeigte sich in den Kokultur-Versuchen eine Interaktion zwischen zwei verschiedenen Zellinien unterschiedlicher Gewebeherkunft und es wurde verdeutlicht, dass die antiinvasive Wirkung von Kisspeptin-10 auf kokultivierte Endometriumkarzinomzellen nicht nur auf eine Interaktion mit dem GPR54 der Endometriumkarzinomzellen zurückzuführen ist, sondern ebenso der GPR54 der MG-63-Zellen zwar nicht entscheidend, aber dennoch von Bedeutung ist. Um eine konkretere Aussage über die Mechanismen und die interzellulären Interaktionen der antiinvasiven Wirkung des Kisspeptin-10 treffen zu können, sind weitere Untersuchungen mit ergänzenden Versuchsdurchführungen erforderlich (Kapitel 4.7).

Eine mögliche Signalkaskade wurde in der vorliegenden Arbeit nicht untersucht. Jedoch gibt es zum jetzigen Zeitpunkt aus der Literatur folgende Ansätze bezüglich der Kisspeptin-10vermittelten GPR54-Aktivierung und der SDF-1-vermittelten CXCR4-Aktivierung zu betrachten.

Der Kisspeptin-10-Rezeptor GPR54 ist $\mathrm{G}_{\mathrm{q} / 11}$-gekoppelt. Eine Ligandenbindung führt zu einer Aktivierung des Phospholipase-C-Signalweges, woraus eine intrazelluläre Calciumerhöhung resultiert (Kotani et al. 2001, Ohtaki et al. 2001). 
SDF-1 soll bei Endometriumkarzinomzellen durch Bindung von CXCR4 über eine Aktivierung von ERK 1/2 den PI-3-K-(Phosphatidyl-Inositol-3-Kinase)-Signalweg stimulieren und daraufhin die Akt-Proteinkinase aktivieren (Zhao et al. 2006; Mizokami et al. 2004; Tsukamoto et al. 2007). Durch Aktivierung der Akt-Proteinkinase sollen eine Vielzahl intrazellulärer, antiapoptotischer Zielmoleküle phosphoryliert werden (Luo et al. 2003). Kisspeptin-10 hingegen verursacht keine vergleichbare Aktivierung und verhindert sogar die SDF-1-vermittelte Akt-Phosphorylierung (Castaño et al. 2009; Navenot et al. 2005).

Zusammenfassend sind der Mechanismus und die Signalkaskade, die den Effekt von Kisspeptin-10 auf die verminderte CXCR4- und SDF-1-Expression bewirken, noch weitestgehend unbekannt und verlangen weitere Aufklärung.

Die Abbildung 4.2 zeigt das aus dieser Arbeit resultierende Modell für die Rolle von Kokultivierung (blau) und Kisspeptin-10 (rot) auf Endometriumkarzinom- und Osteoblastenähnliche Zellen. Durch Kokultivierung werden vor allem die MG-63-bedingte SDF-1Expression und -Sekretion beeinflusst. CXCR4 wird nicht verändert. Die bisher noch weitestgehend unbekannte Signalkaskade, die durch Kisspeptin-10 über GPR54 der beteiligten Zellen aktiviert wird, führt sowohl zu einer Reduktion der CXCR4-Expression der Endometriumkarzinomzellen als auch zu einer Reduktion der SDF-1-Expression und -Sekretion der MG-63-Zellen. Mögliche Interaktionen der Zelltypen können nicht ausgeschlossen werden und werden in der Abbildung nicht berücksichtigt.

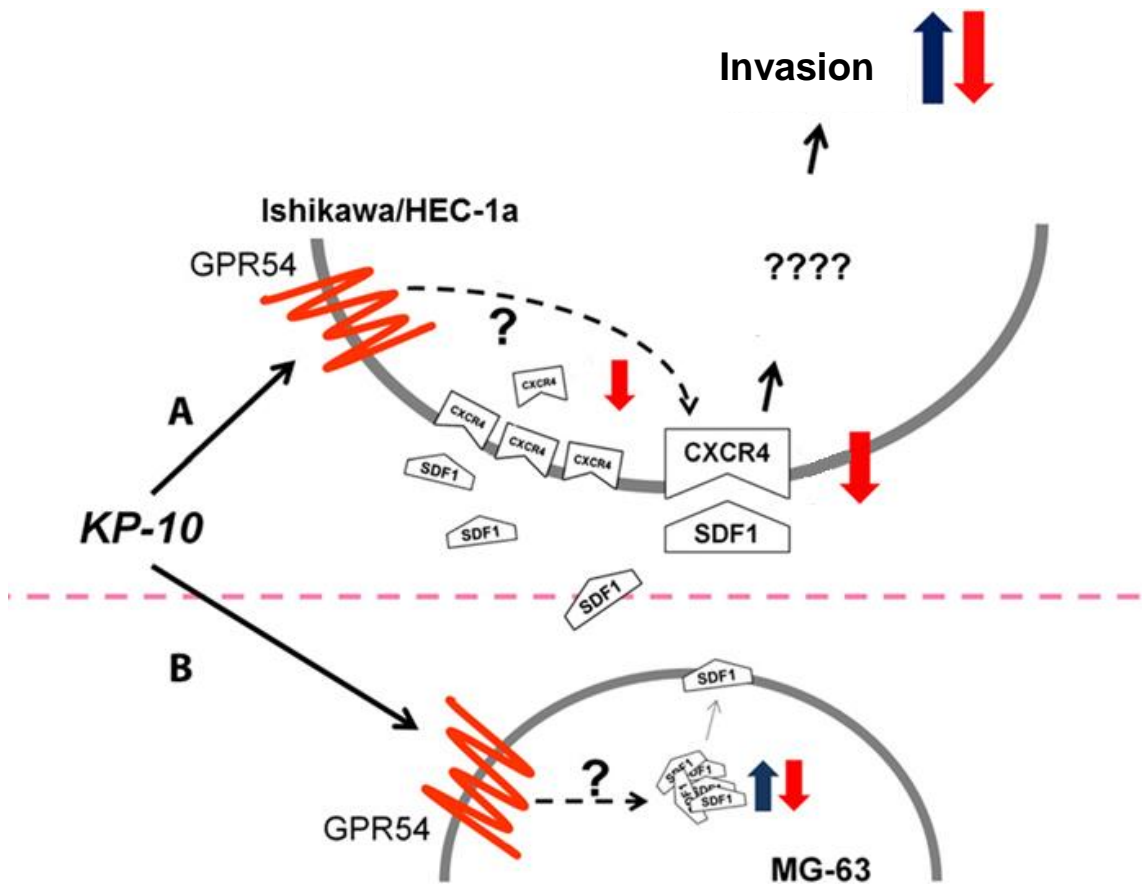

Abb. 4.1: Modell für die Rolle von Kokultivierung und Kisspeptin-10 in der Interaktion der MG-63Lockzellen und Endometriumkarzinomzellen (modifiziert nach Olbrich et al. 2010, S. 576). Kokultivierung führt zu einem Anstieg der SDF-1-Expression und -Sekretion von MG-63-Zellen. Kisspeptin-10 verringert durch die Inhibition des prometastatischen SDF-1/CXCR4-Systems die Fähigkeit der Endometriumkarzinomzellen durch eine matrigelbeschichtete Membran aufgrund des zellulären Stimulus der Osteoblasten-ähnlichen Zelllinie MG-63 zu invadieren. Die Aktivierung des GPR54 auf den Endometriumkarzinomzellen reduziert die CXCR4-Expression (A). Die Aktivierung des GPR54 der MG-63-Zellen hemmt sowohl die SDF-1-mRNA-Expression als auch die SDF-1-Sekretion (B). 


\subsection{Kisspeptin-10 und die Proliferationsfähigkeit humaner Endometriumkarzinomzellen}

\subsubsection{Kisspeptin-10-vermittelte Effekte auf die Proliferationsfähigkeit humaner Endometriumkarzinomzellen}

Kisspeptine sollen nicht nur eine Funktion in der Supprimierung von Invasion und Metastasierung besitzen. Ein Effekt auf die Proliferation von Tumorzellen ist ebenfalls Diskussionsgegenstand aktueller Forschung. Einige Arbeitsgruppen konnten eine Inhibition der Proliferation von Mammakarzinomzellen MDA-MB-435S und CHO-Zellen (Becker et al. 2005; Kotani et al. 2001) nachweisen, andere hingegen streiten eine Proliferationshemmung bei Endometrium- und Mammakarzinomzellen ab (Kang et al. 2011; Ziegler et al. 2013). Hinsichtlich eines antiproliferativen Effekts der Kisspeptine gibt es noch keine einheitlichen Erkenntnisse.

In der vorliegenden Arbeit wurde, mit Hilfe des Farbstoffs alamarblue $\Theta$, eine mögliche antiproliferative Wirkung des Kisspeptin-10 auf Endometriumkarzinomzellen untersucht.

Ein Effekt wurde hinsichtlich Zeit- und Dosisabhängigkeit sowohl durch eine Behandlung über $72 \mathrm{~h}$ und $168 \mathrm{~h}$ als auch durch eine Behandlung mit unterschiedlichen Kisspeptin-10Konzentrationen analysiert. Es zeigte sich bei den Ishikawa-Zellen weder über $72 \mathrm{~h}$ noch über $168 \mathrm{~h}$ eine Veränderung der Proliferationsfähigkeit. HEC-1a-Zellen wiesen jedoch bei einer 168-stündigen Behandlung mit Kisspeptin-10-Konzentrationen von $1 \times 10^{-9} \mathrm{M}$ und $1 \times 10^{-5} \mathrm{M}$ eine Reduktion der Proliferation um ca. $12 \%$ auf.

Neue Daten lassen vermuten, dass ein antiproliferativer Effekt des Kisspeptin-10 tumorzellspezifisch und offenbar mit der GPR54-Dichte beziehungsweise einer GPR54Überexpression assoziiert ist. Es wurden keine Effekte auf die Proliferation endogen GPR54 exprimierender Mammakarzinomzellen gezeigt. Die Proliferation transfizierter, GPR54 überexprimierender Zellen wurde durch Kisspeptin-10 hingegen deutlich gehemmt. Ein antiproliferativer Effekt des Kisspeptin-10 scheint somit von der GPR54-Konzentration der jeweiligen Zelltypen abhängig zu sein (Ziegler et al. 2013).

Dementsprechend könnte eine Erklärung für die antiproliferative Wirkung des Kisspeptin-10 auf HEC-1a-, nicht aber auf Ishikawa-Zellen, durch eine Betrachtung der quantitativen GPR54-Verteilung der beiden Endometriumkarzinomzelllinien gegeben werden. Entsprechende Daten könnten in zukünftigen Arbeiten erhoben werden. 


\subsubsection{Kisspeptin-10-vermittelte Effekte auf das proliferationsfördernde SDF-1}

In den durchgeführten Experimenten zeigte sich, dass auch die Endometriumkarzinomzellen Ishikawa und HEC-1a auf proteinbiochemischer Ebene SDF-1 exprimieren. Dieses Ergebnis liefert einen weiteren interessanten Diskussionsansatz.

In-vitro-Studien berichten, dass SDF-1 $\alpha$, neben seiner chemotaktischen und invasionsfördernden Wirkung, zusätzlich auch ein potenter Stimulator der Proliferation von Primärtumorzellen, wie auch von Endometriumkarzinomzellen, ist. Dabei soll in der Signaltransduktion eine Aktivierung von ERK und dem PI-3-K/Akt-Proteinkinase-Weg beteiligt sein (Zhao et al. 2006; Mizokami et al. 2004; Tsukamoto et al. 2007). Dies unterstützt die Hypothese, dass SDF-1 $\alpha$ auch in der Mikroumgebung unterschiedlicher Tumorarten sowohl von den Tumorzellen selbst als auch von den umgebenen Tumorzellen sezerniert wird und so auto- und parakrin die Proliferation und Entwicklung des Primärtumors fördert (Domanska et al. 2013).

In dieser Arbeit ließ sich nachweisen, dass Kisspeptin-10 die Proliferation der HEC-1a-Zellen hemmt. Um Ansätze für mögliche molekulare Mechanismen hinter dieser Proliferationsreduktion zu finden, wurde anschließend der Effekt von Kisspeptin-10 auf die SDF-1-Expression der Endometriumkarzinomzellen untersucht. Dabei zeigte sich, dass eine Behandlung monokultivierter Endometriumkarzinomzellen mit Kisspeptin-10 nicht zu einer Reduktion der zytosolischen SDF-1-Protein-Expression führt. Dementsprechend lässt sich die zuvor erläuterte Reduktion der Proliferationsfähigkeit der HEC-1a-Zellen durch Kisspeptin-10 nicht über den Mechanismus einer reduzierten SDF-1-Expression erklären. Weitere mögliche Mechanismen hinter der Kisspeptin-10-bedingten Proliferationsreduktion sollten in Zukunft untersucht werden.

\subsection{Fazit und Ausblick}

Durch diese in-vitro-Arbeit wurde erstmalig nachgewiesen, dass die Kokultivierung mit Osteoblasten-ähnlichen MG-63-Zellen und das Chemokin SDF-1 die Invasionsfähigkeit von Endometriumkarzinomzellen induziert und steigert. Darüber hinaus zeigen die Daten, dass der stärkste GPR54-Agonist, das Kisspeptin-10, diese Invasionssteigerung signifikant reduziert. Hierbei sind sowohl die in dieser Arbeit verwendeten Endometriumkarzinomzellen Ishikawa und Hec-1a als auch die Osteoblasten-ähnlichen MG-63-Zellen positiv für den Kisspeptin-10-Rezeptor GPR54.

Des Weiteren kann anhand der Ergebnisse abgeleitet werden, dass Kisspeptin-10 einen direkten inhibierenden Einfluss auf die Expression des SDF-1/CXCR4-Systems der kokultivierten Zellen besitzt. Dabei interagiert Kisspeptin-10 nicht nur mit den 
Endometriumkarzinomzellen, sondern auch mit den Osteoblasten-ähnlichen MG-63-Zellen. Die Daten verdeutlichen, dass die invasionsinhibierende Wirkung des Kisspeptin-10 durch einen Effekt auf beide Zelltypen erklärt werden könnte. Die Ergebnisse des SDF-1Invasionsassay lassen eine Beteiligung von SDF-1 in der Invasionssteigerung kokultivierter Endometriumkarzinomzellen vermuten. Hierbei zeigte sich außerdem, dass Kisspeptin-10 die SDF-1-gerichtete Invasion alleine durch Interaktion mit den Endometriumkarzinomzellen inhibieren kann.

Insgesamt wird deutlich, dass es sich bei der inhibierenden Wirkung von Kisspeptin-10 auf die Invasionsfähigkeit kokultivierter Endometriumkarzinomzellen um eine komplexe Interaktion zweier, aus verschiedenen Geweben stammenden, Zelllinien handelt.

Abschließend sollte beachtet werden, dass die Invasionssteigerung kokultivierter Endometriumkarzinomzellen nicht gänzlich durch Kisspeptin-10 inhibiert wird. Deswegen liegt die Vermutung nahe, dass noch weitere Mechanismen beteiligt sein könnten, welche in dieser Arbeit nicht untersucht wurden und in Zukunft betrachtet werden müssten.

Um den Wirkmechanismus des Kisspeptin-10 genauer beschreiben zu können, sollten in zukünftigen Arbeiten noch differenziertere Experimente durchgeführt werden. Es sollte weiter ermittelt werden, wie Kisspeptin-10 seine antiinvasiven Effekte entfaltet und welche Zellkonstellationen, zellulären Stimuli und sezernierten Faktoren hierfür nötig sind. Für diese Untersuchungen wäre zum Beispiel ein GPR54-knock-down der Endometriumkarzinom- und Osteoblasten-ähnlichen Zellen im Kokultur-Invasionsassay nützlich. Dadurch könnte untersucht werden, welcher Zelltyp ausschlaggebend für die antiinvasive Wirkung des Kisspeptin-10 ist und ob alleine die Kisspeptin-10-Wirkung auf einen der beiden Zelltypen ausreichend ist, um die Invasionssteigerung kokultivierter Endometriumkarzinomzellen zu hemmen. Außerdem könnte der Effekt von Kisspeptin-10 auf die CXCR4-Expression monokultivierter Endometriumkarzinomzellen und die SDF-1-Expression monokultivierter MG-63-Zellen untersucht werden. Ein Ausbleiben einer Expressionsreduktion würde die Hypothese erhärten, dass eine zelluläre Interaktion oder bestimmte Faktoren für die antiinvasive Wirkung des Kisspeptins ausschlaggebend sind.

Auch ist die Signalkaskade, die den direkten Effekt von Kisspeptin-10 auf die verminderte CXCR4- und SDF-1-Expression erklärt, noch weitestgehend unbekannt und verlangt weitere Aufklärung.

Insgesamt lässt sich festhalten, dass Kisspetin-10 nach heutigem Erkenntnisstand für eine antiinvasive Therapieoption beim Endometriumkarzinom in Frage kommen könnte. Die vorliegenden Forschungsergebnisse sollten daher Anlass für in-vivo-Untersuchungen sein. 


\section{Zusammenfassung}

Das Endometriumkarzinom ist ein Malignom, das vor allem lokal invasiv wächst. Es neigt vergleichsweise selten zur Ausbildung von Metastasen, wobei diese jedoch von großer Bedeutung sind, da die Mortalität der Patientinnen drastisch zunimmt. Weitaus häufiger leiden Patientinnen unter einer lokal fortgeschrittenen Invasion des Endometriumkarzinoms. Diese Diagnose macht eine große operative Therapie unumgänglich, wodurch die Morbidität der oftmals alten und adipösen Patientinnen stark ansteigen kann.

Dementsprechend sind Therapiekonzepte notwendig, die die Invasivität und das metastatische Potenzial der Tumorzellen eindämmen. Um diese Therapien entwickeln zu können, ist eine genaue Kenntnis der die Invasion und Metastasierung unterstützenden und beeinflussenden Faktoren notwendig.

Mit Hilfe des etablierten Kokultur-Systems wurden in der vorliegenden Arbeit sowohl die Interaktion von Endometriumkarzinomzellen mit Osteoblasten-ähnlichen Zellen als auch ihre Invasionsfähigkeit vor und nach der Behandlung mit Kisspeptin-10 untersucht. Bei Kisspeptin-10 handelt es sich um das kürzeste Peptid des als Metastase-Suppressor-Gen bekannten KISS1-Gens, welches die stärkste agonistische Potenz an seinem Rezeptor, GPR54, besitzt.

Es wurde in vitro das Invasionsverhalten GPR54-positiver humaner Endometriumkarzinomzellinien (Ishikawa und HEC-1a) analysiert. Hierbei wurde sowohl das unbeeinflusste Invasionsverhalten als auch die Invasionsfähigkeit im KokulturInvasionsassay geprüft. Es zeigte sich, dass die Ishikawa-Zellen eine deutlich höhere Grundinvasivität im Vergleich zu den HEC-1a-Zellen besitzen. Die Invasion der Endometriumkarzinomzellen wurde während Kokultivierung mit der Osteoblasten-ähnlichen Zellinie MG-63 signifikant gesteigert, wobei die Invasion der HEC-1a-Zellen während der Kokultivierung stärker stimuliert wurde, als die Invasion der Ishikawa-Zellen. Eine Analyse der KISS1-mRNA-Expression der Endometriumkarzinomzellinien zeigte, dass lediglich die HEC-1a-Zellen, nicht aber die Ishikawa-Zellen intrinsisch KISS1-mRNA exprimieren.

Der alleinige Einsatz des chemotaktischen SDF-1 resultierte in dem erwarteten Anstieg der Invasionsfähigkeit beider CXCR4-positiver Endometriumkarzinomzelllinien.

Eine Behandlung mit Kisspeptin-10 führte im Kokultur-Invasionsassay zu einer signifikanten Reduktion der Invasion beider Endometriumkarzinomzellinien und zeigte bei den IshikawaZellen einen dosisabhängigen Fenstereffekt. Die Kisspeptin-10-Behandlung führte außerdem zu einer signifikanten Reduktion der SDF-1-induzierten Invasion beider Endometriumkarzinomzelllinien. 
Die Untersuchung möglicher beteiligter invasionsfördernder Faktoren ließ während der Kokultivierung vor allem einen aktivierenden Effekt auf die SDF-1-Expression der Osteoblasten-ähnlichen Zellen nachweisen. Die Kisspeptin-10-Behandlung hingegen führte zu einer Reduktion der prometastatischen SDF-1- und CXCR4-Expression kokultivierter Endometriumkarzinom- und Osteoblasten-ähnlicher Zellen.

Da das Endometriumkarzinom vor allem lokal invasiv wächst, wurde zudem erforscht, ob Kisspeptin-10 einen Einfluss auf die Proliferation dieser Zellen besitzt. Ein antiproliferativer Effekt des Kisspeptin-10 konnte nicht für Ishikawa-Zellen, aber für HEC-1a-Zellen bestätigt werden. Bei der Suche nach beteiligten Komponenten fand sich, bezugnehmend auf die Literatur, SDF-1 als ein möglicher proliferationsfördernder Faktor von Primärtumorzellen. Kisspeptin-10 führte nicht zu einer Reduktion der zytosolischen SDF-1-Protein-Expression der Endometriumkarzinomzelllinien.

Diese Ergebnisse lassen zusammenfassend folgende Schlussfolgerungen zu.

Die höhere Grundinvasivität der Ishikawa-Zellen könnte durch die fehlende Expression des invasionssupprimierenden KISS1-Gens im Vergleich zu den HEC-1a-Zellen erklärt werden.

Da sich SDF-1 als ein Sekretionsprodukt der Osteoblasten-ähnlichen Zellen im KokulturSystem nachweisen ließ und sich zeigte, dass es ein invasionssteigerndes Potenzial auf die Endometriumkarzinomzellen besitzt, liegt die Vermutung nahe, dass SDF-1 eine wichtige Komponente der invasionssteigernden Prozesse im Kokultur-System ist. Die Ergebnisse lassen den Schluss zu, dass das SDF-1/CXCR4-System für die Invasionsfähigkeit kokultivierter Endometriumkarzinomzellen eine bedeutsame Rolle zu spielen scheint.

Da Kisspeptin-10 sowohl die Invasionssteigerung kokultivierter Endometriumkarzinomzellen als auch die SDF-1-induzierte Invasionssteigerung dieser Zellen hemmt, lässt sich vermuten, dass die Hemmung der Invasionsfähigkeit im Kokultur-Invasionsassay durch Kisspeptin-10 durch eine Inhibition der SDF-1-gerichteten Invasion bewirkt wird. Dabei ist mechanistisch sicherlich die nachgewiesene reduzierte CXCR4-Expression kokultivierter Endometriumkarzinomzellen, aber auch die nachgewiesene verminderte Expression und Sekretion des chemotaktischen SDF-1 der MG-63-Zellen involviert.

Alle Ergebnisse betrachtend wurde deutlich, dass es sich bei der inhibierenden Wirkung von Kisspeptin-10 auf die Invasionsfähigkeit kokultivierter Endometriumkarzinomzellen um eine komplexe Interaktion handelt.

Eine Beteiligung des SDF-1 an dem Mechanismus der Kisspeptin-10-bedingten Proliferationshemmung von HEC-1a-Zellen konnte vorerst ausgeschlossen werden.

Nach derzeitigem Kenntnisstand besitzt Kisspeptin-10 eine potenzielle SDF-1-gerichtete antiinvasive und geringe antiproliferative Wirkung auf das Endometriumkarzinom in vitro. $\mathrm{Ob}$ es somit auch für eine antiinvasive und -metastatische Therapieoption in vivo in Frage kommt, sollte in zukünftigen Forschungsarbeiten geklärt werden. 


\section{Literaturverzeichnis}

Von Alten J, Fister S, Schulz H, Viereck V, Frosch K-H, Emons G und Gründker C (2006): $\mathrm{GnRH}$ analogs reduce invasiveness of human breast cancer cells. Breast Cancer Res Treat 100, 13-21

Ambros RA, Sherman ME, Zahn CM, Bitterman P und Kurman RJ (1995): Endometrial intraepithelial carcinoma: A distinctive lesion specifically associated with tumors displaying serous differentiation. Hum Pathol 26, 1260-1267

Balkwill F (2004): Cancer and the chemokine network. Nat Rev Cancer 4, 540-550

Becker JAJ, Mirjolet J-F, Bernard J, Burgeon E, Simons M-J, Vassart G, Parmentier M und Libert F (2005): Activation of GPR54 promotes cell cycle arrest and apoptosis of human tumor cells through a specific transcriptional program not shared by other Gqcoupled receptors. Biochem Biophys Res Commun 326, 677-686

Bilban M, Ghaffari-Tabrizi N, Hintermann E, Bauer S, Molzer S, Zoratti C, Malli R, Sharabi A, Hiden U, Graier W, Knöfler M, Andreae F, Wagner O, Quaranta V und Desoye G (2004): Kisspeptin-10, a KiSS-1/metastin-derived decapeptide, is a physiological invasion inhibitor of primary human trophoblasts. J Cell Sci 117, 1319-1328

Billiau A, Edy VG, Heremans H, Van Damme J, Desmyter J, Georgiades JA und De Somer P (1977): Human interferon: mass production in a newly established cell line, MG-63. Antimicrob Agents Chemother 12, 11-15

Blecharz P, Urbański K, Mucha-Małecka A, Małecki K, Reinfuss M, Jakubowicz J und Skotnicki P (2011): Hematogenous metastases in patients with Stage I or II endometrial carcinoma. Strahlenther Onkol 187, 806-811

Bokhman JV (1983): Two pathogenetic types of endometrial carcinoma. Gynecol Oncol 15, $10-17$

Böing C und Kimmig R (2007): Therapieoptionen in der Rezidivsituation des Endometriumkarzinoms. Gynäkologe 40, 44-48

Boyden S (1962): The chemotactic effect of mixtures of antibody and antigen on polymorphonuclear leucocytes. J Exp Med 115, 453-466

Brabletz T, Jung A, Reu S, Porzner M, Hlubek F, Kunz-Schughart LA, Knuechel R und Kirchner T (2001): Variable beta-catenin expression in colorectal cancers indicates tumor progression driven by the tumor environment. Proc Natl Acad Sci USA 98, 10356-10361

Burger JA und Peled A (2009): CXCR4 antagonists: targeting the microenvironment in leukemia and other cancers. Leukemia 23, 43-52 
Caruz A, Samsom M, Alonso JM, Alcami J, Baleux F, Virelizier JL, Parmentier M und Arenzana-Seisdedos F (1998): Genomic organization and promoter characterization of human CXCR4 gene. FEBS Lett 426, 271-278

Castaño JP, Martínez-Fuentes AJ, Gutiérrez-Pascual E, Vaudry H, Tena-Sempere M und Malagón MM (2009): Intracellular signaling pathways activated by kisspeptins through GPR54: do multiple signals underlie function diversity? Peptides 30, 10-15

Castellano JM, Navarro VM, Fernández-Fernández R, Nogueiras R, Tovar S, Roa J, Vazquez MJ, Vigo E, Casanueva FF, Aguilar E, Pinilla L, Dieguez C und TenaSempere M (2005): Changes in hypothalamic KiSS-1 system and restoration of pubertal activation of the reproductive axis by kisspeptin in undernutrition. Endocrinology 146, 3917-3925

Chambers AF (1999): The metastatic process: basic research and clinical implications. Oncol Res 11, 161-168

Coghlin C und Murray GI (2010): Current and emerging concepts in tumour metastasis. J Pathol 222, 1-15

Crump MP, Gong JH, Loetscher P, Rajarathnam K, Amara A, Arenzana-Seisdedos F, Virelizier JL, Baggiolini M, Sykes BD und Clark-Lewis I (1997): Solution structure and basis for functional activity of stromal cell-derived factor-1; dissociation of CXCR4 activation from binding and inhibition of HIV-1. EMBO J 16, 6996-7007

Davis DA, Singer KE, De La Luz Sierra M, Narazaki M, Yang F, Fales HM, Yarchoan R und Tosato $\mathrm{G}$ (2005): Identification of carboxypeptidase $\mathrm{N}$ as an enzyme responsible for C-terminal cleavage of stromal cell-derived factor-1alpha in the circulation. Blood 105, $4561-456$

Domanska UM, Kruizinga RC, Nagengast WB, Timmer-Bosscha H, Huls G, De Vries EGE und Walenkamp AME (2013): A review on CXCR4/CXCL12 axis in oncology: No place to hide. Eur J Cancer 49, 219-230

Emons G, Hawighorst T und Hellriegel M (2011): Endometriumkarzinom. Der Gynäkologe 44, 701-707

Felix AS, Edwards R, Bowser R und Linkov F (2010): Chemokines and Cancer Progression: A Qualitative Review on the Role of Stromal Cell-derived Factor 1-alpha and CXCR4 in Endometrial Cancer. Cancer Microenviron 3, 49-56

Felix AS, Stone RA, Chivukula M, Bowser R, Parwani AV, Linkov F, Edwards RP and Weissfeld JL (2012): Survival outcomes in endometrial cancer patients are associated with CXCL12 and estrogen receptor expression. Int J Cancer 131, E114-E121

Fidler IJ (2003): The pathogenesis of cancer metastasis: the "seed and soil" hypothesis revisited. Nat Rev Cancer 3, 453-458 
Finas D, Hornemann A, Diedrich K und Altgassen C (2007): Prognosefaktoren und Prognose des Endometriumkarzinoms. Der Gynäkologe 40, 27-33

Fleisch MC und Bender HG (2003): Epidemiologie des Endometriumkarzinoms. Der Onkologe 9, 1195-1201

Gelmini S, Mangoni M, Castiglione F, Beltrami C, Pieralli A, Andersson K, Fambrini M, Taddei G, Serio M und Orlando C (2009): The CXCR4/CXCL12 axis in endometrial cancer. Clin Exp Metastasis 26, 261-268

Hall JM und Korach KS (2003): Stromal cell-derived factor 1, a novel target of estrogen receptor action, mediates the mitogenic effects of estradiol in ovarian and breast cancer cells. Mol Endocrinol 17, 792-803.

Hamm HE (1998): The Many Faces of G Protein Signaling. J Biol Chem 273, 669-672 Hanahan D und Weinberg RA (2000): The hallmarks of cancer. Cell 100, 57-70 Hanahan D und Weinberg RA (2011): Hallmarks of cancer: the next generation. Cell 144, 646-674

Harms JF, Welch DR und Miele ME (2003): KISS1 metastasis suppression and emergent pathways. Clin Exp Metastasis 20, 11-18

Hauge-Evans AC, Richardson CC, Milne HM, Christie MR, Persaud SJ und Jones PM (2006): A role for kisspeptin in islet function. Diabetologia 49, 2131-2135

Horikoshi Y, Matsumoto H, Takatsu Y, Ohtaki T, Kitada C, Usuki S und Fujino M (2003): Dramatic Elevation of Plasma Metastin Concentrations in Human Pregnancy: Metastin as a Novel Placenta-Derived Hormone in Humans. JCEM 88, 914-919

Horn L-C, Schierle K, Schmidt D, Ulrich U, Liebmann A und Wittekind C (2010): Aktuelle TNM/FIGO-Stadieneinteilung für das Zervix- und Endometriumkarzinom sowie maligne Müller-Mischtumoren. Der Pathologe 32, 239-243

Hugo H, Ackland ML, Blick T, Lawrence MG, Clements JA, Williams ED und Thompson EW (2007): Epithelial-mesenchymal and mesenchymal-epithelial transitions in carcinoma progression. J Cell Physiol 213, 374-383

Janneau J-L, Maldonado-Estrada J, Tachdjian G, Miran I, Motté N, Saulnier P, Sabourin J-C, Coté J-F, Simon B, Frydman R, Chaouat G und Bellet D (2002): Transcriptional expression of genes involved in cell invasion and migration by normal and tumoral trophoblast cells. J Clin Endocrinol Metab 87, 5336-5339

Janowski M (2009): Functional diversity of SDF-1 splicing variants. Cell Adh Migr 3, 243-249 Jiang T, Zhang S, Lin B, Meng L und Gao H (2005): [Expression and clinical significance of KISS-1 and GPR54 mRNA in endometrial carcinoma]. Zhonghua Zhong Liu Za Zhi 27, 229-231

Johann S, Santi A, Günthert A, Lössl K, Aebi S und Mueller M (2010): Das Endometriumkarzinom - Diagnostik, Therapie und Nachsorge. SMF 129-133 
Kang HS, Baba T, Mandai M, Matsumura N, Hamanishi J, Kharma B, Kondoh E, Yoshioka Y, Oishi S, Fuji N, Murphy SK und Konishi I (2011): GPR54 is a target for suppression of metastasis in endometrial cancer. Mol Cancer Ther 10, 580-590

Karnoub AE und Weinberg RA (2006): Chemokine networks and breast cancer metastasis. Breast Dis 26, 75-85

Kirby HR, Maguire JJ, Colledge WH und Davenport AP (2010): International Union of Basic and Clinical Pharmacology. LXXVII. Kisspeptin Receptor Nomenclature, Distribution, and Function. Pharmacol Rev 62, 565-578

Kommission Uterus der Arbeitsgemeinschaft für Gynäkologische Onkologie e.V.: Interdisziplinäre S2K-Leitlinie für die Diagnostik und Therapie des Endometriumkarzinoms; in: Leitlinien zum Zervixkarzinom, zum Endometriumkarzinom und zu den Trophoblasttumoren; hrsg. v. Kommission Uterus der Arbeitsgemeinschaft Gynäkologische Onkologie e.V. in der Deutschen Gesellschaft für Gynäkologie und Geburtshilfe e.V. sowie in der Deutschen Krebsgesellschaft; Zuckschwerdt, München 2008, 73-126

Kotani M, Detheux M, Vandenbogaerde A, Communi D, Vanderwinden JM, Le Poul E, Brézillon S, Tyldesley R, Suarez-Huerta N, Vandeput F, Blanpain C, Schiffmann SN, Vassart G und Parmentier M (2001): The metastasis suppressor gene KiSS-1 encodes kisspeptins, the natural ligands of the orphan $G$ protein-coupled receptor GPR54. J Biol Chem 276, 34631-34636

Kumar S, Shah JP, Bryant CS, Seward S, Ali-Fehmi R, Morris RT und Malone JM Jr (2009): Radiation-associated endometrial cancer. Obstet Gynecol 113, 319-325

Kuramoto H, Tamura S und Notake Y (1972): Establishment of a cell line of human endometrial adenocarcinoma in vitro. Am J Obstet Gynecol 114, 1012-1019

Kurman RJ und McConnell TG (2009): Histopathologie des Endometriumkarzinoms. Der Onkologe 15, 1239-1242

Kurman RJ, Kaminski PF und Norris HJ (1985): The behavior of endometrial hyperplasia. A long-term study of "untreated" hyperplasia in 170 patients. Cancer 56, 403-412

De La Luz Sierra M, Yang F, Narazaki M, Salvucci O, Davis D, Yarchoan R, Zhang HH, Fales $\mathrm{H}$ und Tosato $\mathrm{G}$ (2004): Differential processing of stromal-derived factor-1alpha and stromal-derived factor-1beta explains functional diversity. Blood 103, 2452-2459

Lacey JV, Sherman ME, Rush BB, Ronnett BM, loffe OB, Duggan MA, Glass AG, Richesson DA, Chatterjee N und Langholz B (2010): Absolute Risk of Endometrial Carcinoma During 20-Year Follow-Up Among Women With Endometrial Hyperplasia. J Clin Oncol 28, 788-792

Lee B-C, Lee T-H, Avraham S und Avraham HK (2004): Involvement of the chemokine receptor CXCR4 and its ligand stromal cell-derived factor 1alpha in breast cancer cell 
migration through human brain microvascular endothelial cells. Mol Cancer Res 2, 327-338

Lee DK, Nguyen T, O’Neill GP, Cheng R, Liu Y, Howard AD, Coulombe N, Tan CP, TangNguyen AT, George SR und O'Dowd BF (1999): Discovery of a receptor related to the galanin receptors. FEBS Lett 446, 103-107

Lee J-H und Welch DR (1997a): Identification of highly expressed genes in metastasissuppressed chromosome 6/human malignant melanoma hybrid cells using subtractive hybridization and differential display. Int J Cancer 71, 1035-1044

Lee J-H und Welch DR (1997b): Suppression of Metastasis in Human Breast Carcinoma MDA-MB-435 Cells after Transfection with the Metastasis Suppressor Gene, KiSS-1. Cancer Res 57, 2384-2387

Lee J-H, Miele ME, Hicks DJ, Phillips KK, Trent JM, Weissman BE und Welch DR (1996): KiSS-1, a Novel Human Malignant Melanoma Metastasis-Suppressor Gene. J Natl Cancer Inst 88, 1731-1737

Manetti M, Liakouli V, Fatini C, Cipriani P, Bonino C, Vettori S, Guiducci S, Montecucco C, Abbate R, Valentin G, Matucci-Cerinic M, Giacomelli R und Ibba-Manneschi L (2009): Association between a stromal cell-derived factor 1 (SDF-1/CXCL12) gene polymorphism and microvascular disease in systemic sclerosis. Ann Rheum Dis 68, 408-411

Mariani A, Dowdy SC, Cliby WA, Gostout BS, Jones MB, Wilson TO und Podratz KC (2008): Prospective assessment of lymphatic dissemination in endometrial cancer: a paradigm shift in surgical staging. Gynecol Oncol 109, 11-18

Mead EJ, Maguire JJ, Kuc RE und Davenport AP (2007): Kisspeptins are novel potent vasoconstrictors in humans, with a discrete localization of their receptor, $G$ proteincoupled receptor 54, to atherosclerosis-prone vessels. Endocrinology 148, 140-147

Mizokami Y, Kajiyama H, Shibata K, Ino K, Kikkawa F und Mizutani S (2004): Stromal cellderived factor-1alpha-induced cell proliferation and its possible regulation by CD26/dipeptidyl peptidase IV in endometrial adenocarcinoma. Int J Cancer 110, 652659

Muir AI, Chamberlain L, Elshourbagy NA, Michalovich D, Moore DJ, Calamari A, Szekeres PG, Sarau HM, Chambers JK, Murdock P, Steplewski K, Shabon U, Miller JE, Middleton SE, Darker JG, Larminie CGC, Wilson S, Bergsma DJ, Emson P, Faull R, Philpott KL und Harrison DC (2001): AXOR12, a Novel Human G Protein-Coupled Receptor, Activated by the Peptide KiSS-1. J Biol Chem 276, 28969-28975

Müller A, Homey B, Soto H, Ge N, Catron D, Buchanan ME, McClanahan T, Murphy E, Yuan W, Wagner SN, Barrera JL, Mohar A, Verástegui E und Zlotnik A (2001): Involvement of chemokine receptors in breast cancer metastasis. Nature 410, 50-56 
Navenot J-M, Wang Z, Chopin M, Fujii N und Peiper SC (2005): Kisspeptin-10-induced signaling of GPR54 negatively regulates chemotactic responses mediated by CXCR4: a Potenzial mechanism for the metastasis suppressor activity of kisspeptins. Cancer Res 65, 10450-10456

Navenot J-M, Fujii N und Peiper SC (2009a): KiSS1 metastasis suppressor gene product induces suppression of tyrosine kinase receptor signaling to Akt, tumor necrosis factor family ligand expression, and apoptosis. Mol Pharmacol 75, 1074-1083

Navenot J-M, Fujii N und Peiper SC (2009b): Activation of Rho and Rho-associated kinase by GPR54 and KiSS1 metastasis suppressor gene product induces changes of cell morphology and contributes to apoptosis. Mol Pharmacol 75, 1300-1306

Nishida M, Kasahara K, Kaneko M, Iwasaki H und Hayashi K (1985): [Establishment of a new human endometrial adenocarcinoma cell line, Ishikawa cells, containing estrogen and progesterone receptors]. Nippon Sanka Fujinka Gakkai Zasshi 37, 1103-1111

Ohtaki T, Shintani Y, Honda S, Matsumoto H, Hori A, Kanehashi K, Terao Y, Kumano S, Takatsu Y, Masuda Y, Ishibashi Y, Watanabe T, Asada M, Yamada T, Suenaga M, Kitada C, Usuki S, Kurokawa T, Onda H, Nishimura O und Fujino M (2001): Metastasis suppressor gene KiSS-1 encodes peptide ligand of a G-protein-coupled receptor. Nature 411, 613-617

Olbrich T: Einfluss von Kisspeptin-10 auf die knochengerichtete Migration und Invasion von Mammakarzinomzellen. Med Diss Göttingen 2010

Olbrich T, Ziegler E, Türk G, Schubert A, Emons G und Gründker C (2010): Kisspeptin-10 inhibits bone-directed migration of GPR54-positive breast cancer cells: Evidence for a dose-window effect. Gynecol Oncol 119, 571-578

Olumi AF, Grossfeld GD, Hayward SW, Carroll PR, Tlsty TD und Cunha GR (1999): Carcinoma-associated fibroblasts direct tumor progression of initiated human prostatic epithelium. Cancer Res 59, 5002-5011

Orimo A, Gupta PB, Sgroi DC, Arenzana-Seisdedos F, Delaunay T, Naeem R, Carey VJ, Richardson AL und Weinberg RA (2005): Stromal fibroblasts present in invasive human breast carcinomas promote tumor growth and angiogenesis through elevated SDF-1/CXCL12 secretion. Cell 121, 335-348

Parkin DM, Bray F, Ferlay J und Pisani P (2009): Global Cancer Statistics, 2002. CA Cancer $\mathrm{J}$ Clin 55, 74-108

Ponomaryov T, Peled A, Petit I, Taichman RS, Habler L, Sandbank J, Arenzana-Seisdedos F, Magerus A, Caruz A, Fujii N, Nagler A, Lahav M, Szyper-Kravitz M, Zipori D und Lapidot T (2000): Induction of the chemokine stromal-derived factor-1 following DNA damage improves human stem cell function. J Clin Invest 106, 1331-1339 
Robert Koch-Institut und die Gesellschaft der epidemiologischen Krebsregister in Deutschland e.V.: Krebs in Deutschland 2007/2008, 8. Ausgabe; Berlin 2012

Rossi D und Zlotnik A (2000): The Biology of Chemokines and their Receptors. Annu Rev Immunol 18, 217-242

De Roux N, Genin E, Carel J-C, Matsuda F, Chaussain J-L und Milgrom E (2003): Hypogonadotropic hypogonadism due to loss of function of the KiSS1-derived peptide receptor GPR54. Proc Natl Acad Sci U S A 100, 10972-10976

Sartori E, Laface B, Gadducci A, Maggino T, Zola P, Landoni F und Zanagnolo V (2003): Factors influencing survival in endometrial cancer relapsing patients: a Cooperation Task Force (CTF) study. Int J Gynecol Cancer 13, 458-465

Schmidt D (2003): Histopathologie und Stadieneinteilung des Endometriumkarzinoms und seiner Präkanzerosen. Der Onkologe 9, 1211-1218

Schubert-Fritschle G, Eckel R, Engel J und Hölzel D: Zur Epidemiologie der Malignome des Corpus Uteri; in: Empfehlung zur Diagnostik, Therapie und Nachsorge - Malignome des Corpus uteri; hrsg. v. Dannecker C, Kolben M, Kürzl R, Tumorzentrum München; Zuckschwerdt Verlag, München 2007, 1-7

Scully RE, Bonfiglio T, Kurman R, Silverberg S und Wilkinson E: Histological typing of female genital tract tumours (International histological classification of tumours), 2. Auflage; Springer, Berlin 1994

Seeber S: Influence of Kisspeptin-10 on Proliferation, Migration and Gene Expression of Endometrial Cancer in vitro. MSc Thesis Göttingen 2009

Seminara SB, Messager S, Chatzidaki EE, Thresher RR, Acierno JS Jr, Shagoury JK, BoAbbas Y, Kuohung W, Schwinof KM, Hendrick AG, Zahn D, Dixon J, Kaiser UB, Slaugenhaupt SA, Gusella JF, O'Rahilly S, Carlton MBL, Crowley WF Jr, Aparicio SAJR und Colledge WH (2003): The GPR54 gene as a regulator of puberty. N Engl J Med 349, 1614-1627

Silverberg S, Kurman RJ, Nogales F, Mutter GL, Kubik-Huch RA und Tavassoli FA: Tumours of the Uterine Corpus. Epithelial tumours and related lesions; in: World Health Organization Classification of Tumours, Pathology and Genetics of Tumours of the Breast and Female Genital Organs; hrsg. v. Tavassoli FA, Devilee P; IARC Press, Lyon 2003, 221-232

Stauber M und Weyerstahl T: Gynäkologie und Geburtshilfe, 3. Auflage; Thieme, Stuttgart 2007

Talmadge JE und Fidler IJ (2010): AACR centennial series: the biology of cancer metastasis: historical perspective. Cancer Res 70, 5649-5669 
Tashiro H, Isacson C, Levine R, Kurman RJ, Cho KR und Hedrick L (1997): p53 gene mutations are common in uterine serous carcinoma and occur early in their pathogenesis. Am J Pathol 150, 177

Thiery JP (2003): Epithelial-mesenchymal transitions in development and pathologies. Curr Opin Cell Biol 15, 740-746

Thiery JP, Acloque H, Huang RYJ und Nieto MA (2009): Epithelial-mesenchymal transitions in development and disease. Cell 139, 871-890

Tsukamoto H, Shibata K, Kajiyama H, Terauchi M, Nawa A und Kikkawa F (2007): Uterine smooth muscle cells increase invasive ability of endometrial carcinoma cells through tumor-stromal interaction. Clin Exp Metastasis 24, 423-429

Wang J, Loberg R und Taichman R (2006): The pivotal role of CXCL12 (SDF-1)/CXCR4 axis in bone metastasis. Cancer Metastasis Rev 25, 573-587

Wang JM, Deng X, Gong W und Su S (1998): Chemokines and their role in tumor growth and metastasis. J Immunol Methods 220, 1-17

Weidt C, Niggemann B, Kasenda B, Drell TL, Zänker KS und Dittmar T (2007): Stem cell migration: a quintessential stepping stone to successful therapy. Curr Stem Cell Res Ther 2, 89-103

West A, Vojta PJ, Welch DR und Weissman BE (1998): Chromosome localization and genomic structure of the KiSS-1 metastasis suppressor gene (KISS1). Genomics 54, $145-148$

Yang J und Weinberg RA (2008): Epithelial-mesenchymal transition: at the crossroads of development and tumor metastasis. Dev Cell 14, 818-829

Yu L, Cecil J, Peng S-B, Schrementi J, Kovacevic S, Pau D, Su EW and Wang J (2006): Identification and expression of novel isoforms of human stromal cell-derived factor 1. Gene 374, 174-179

Zajac M, Law J, Cvetkovic DD, Pampillo M, McColl L, Pape C, Di Guglielmo GM, Postovit LM, Babwah AV und Bhattacharya M (2011): GPR54 (KISS1R) Transactivates EGFR to Promote Breast Cancer Cell Invasiveness. PLoS One 6, e21599

Zhao D, Li X, Gao M, Zhao C, Wang J und Wei L (2006): Stromal cell-derived factor $1 \alpha$ stimulates human endometrial carcinoma cell growth through the activation of both extracellular signal-regulated kinase 1/2 and Akt. Gynecol Oncol 103, 932-937

Ziegler E, Olbrich T, Emons G und Gründker C (2013): Antiproliferative effects of kisspeptin10 depend on artificial GPR54 (KISS1R) expression levels. Oncol Rep 29, 549-554 


\section{Anhang}

\subsection{Abbildungsverzeichnis}

ABB. 1.1: SCHEMATISCHE DARSTELLUNG DER ROLLE DES SDF-1/CXCR4-SYSTEMS IN DER TUMORBIOLOGIE 10

AbB. 1.2: StRUKTUR DES PRÄ-PRO-KISSPEPTIN (KODIERT DURCH DAS KISS1-GEN) UND SEINEN PEPTIDPRODUKTEN. 13

ABB. 2.1: SCHEMATISCHE DARSTELLUNG DES KOKULTUR-SYSTEMS.. 26

ABB. 3.1: MOLEKULARBIOLOGISCHER GPR54-NACHWEIS IN DEN ENDOMETRIUMKARZINOMZELLEN ISHIKAWA UND HEC-1A SOWIE IN DEN OSTEOBLASTEN-ÄHNLICHEN MG-63-ZELLEN. 40

ABB. 3.2: PROTEINBIOCHEMISCHER GPR54-NACHWEIS IN DEN ENDOMETRIUMKARZINOMZELLEN ISHIKAWA UND HEC-1A SOWIE IN DEN OSTEOBLASTEN-ÄHNLICHEN MG-63-ZELLEN.

ABB. 3.3: IMMUNZYTOCHEMISCHER GPR54-NACHWEIS IN DEN ENDOMETRIUMKARZINOMZELLEN ISHIKAWA UND HEC-1A SOWIE IN DEN OSTEOBLASTEN-ÄHNLICHEN MG-63-ZELLEN.

ABB. 3.4: MOLEKULARBIOLOGISCHER KISS1-NACHWEIS IN DEN ENDOMETRIUMKARZINOMZELLEN ISHIKAWA UND HEC-1A. 42

ABB. 3.5: ZELLSPEZIFISCHES INVASIONSVERHALTEN VON ISHIKAWA- UND HEC-1A-ZELLEN......................... 43

ABB. 3.6: INVASIONSVERHALTEN MONO- UND KOKULTIVIERTER ISHIKAWA-ZELLEN .................................... 45

ABB. 3.7: INVASIONSVERHALTEN MONO- UND KOKULTIVIERTER HEC-1A-ZELLEN. …............................... 46

ABB. 3.8: EINFLUSS VON SDF-1 AUF DAS INVASIONSVERHALTEN VON ISHIKAWA-ZELLEN. ......................... 47

ABB. 3.9: EINFLUSS VON SDF-1 AUF DAS INVASIONSVERHALTEN VON HEC-1A-ZELLEN. .......................... 48

ABB. 3.10: EINFLUSS VON KISSPEPTIN-10 AUF DIE INVASION KOKULTIVIERTER ISHIKAWA-ZELLEN. ...............50

ABB. 3.11: EINFLUSS VON KISSPEPTIN-10 AUF DIE INVASION KOKULTIVIERTER HEC-1A-ZELLEN. ................ 51

ABB. 3.12: EINFLUSS VON KISSPEPTIN-10 AUF DIE SDF-1-INDUZIERTE INVASION VON ISHIKAWA-ZELLEN..... 53

ABB. 3.13: EINFLUSS VON KISSPEPTIN-10 AUF DIE SDF-1-INDUZIERTE INVASION VON HEC-1A-ZELLEN. ..... 54

ABB. 3.14: EINFLUSS VON KISSPEPTIN-10 AUF DIE PROLIFERATIONSFÄHIGKEIT VON ISHIKAWA-ZELLEN........ 56

ABB. 3.15: EINFLUSS VON KISSPEPTIN-10 AUF DIE PROLIFERATIONSFÄHIGKEIT VON HEC-1A-ZELLEN. ........ 57

ABB. 3.16: EINFLUSS VON KOKULTIVIERUNG UND KISSPEPTIN-10 AUF DIE CXCR4-MRNA-EXPRESSION VON ISHIKAWA-ZELLEN.

ABB. 3.17: EINFLUSS VON KOKULTIVIERUNG UND KISSPEPTIN-10 AUF DIE CXCR4-MRNA-EXPRESSION VON HEC-1A-ZELLEN.

ABB. 3.18: PROTEINBIOCHEMISCHER CXCR4-NACHWEIS IN DEN ENDOMETRIUMKARZINOMZELLEN ISHIKAWA UND HEC-1A SOWIE IN DEN OSTEOBLASTEN-ÄHNLICHEN MG-63-ZELLEN.

ABB. 3.19: EINFLUSS VON KOKULTIVIERUNG UND KISSPEPTIN-10 AUF DIE CXCR4-PROTEIN-EXPRESSION VON ISHIKAWA-ZELLEN..

ABB. 3.20: EINFLUSS VON KOKULTIVIERUNG UND KISSPEPTIN-10 AUF DIE CXCR4-PROTEIN-EXPRESSION VON HEC-1A-ZELLEN. 
ABB. 3.21: EINFLUSS VON KOKULTIVIERUNG UND KISSPEPTIN-10 AUF DIE SDF-1-MRNA-EXPRESSION VON MG-63-ZELLEN IM KOKULTUR-SYSTEM MIT ISHIKAWA-ZELLEN.

ABB. 3.22:EINFLUSS VON KOKULTIVIERUNG UND KISSPEPTIN-10 AUF DIE SDF-1-MRNA-EXPRESSION VON MG-63-ZELLEN IM KOKULTUR-SYSTEM MIT HEC-1A-ZELLEN.

ABB. 3.23: PROTEINBIOCHEMISCHER SDF-1-NACHWEIS IN DEN ENDOMETRIUMKARZINOMZELLEN ISHIKAWA UND HEC-1A SOWIE IN DEN OSTEOBLASTEN-ÄHNLICHEN MG-63-ZELLEN..

ABB. 3.24: EINFLUSS VON KISSPEPTIN-10 AUF DIE SDF-1-PROTEIN-EXPRESSION MONOKULTIVIERTER ISHIKAWA-ZELLEN.

ABB. 3.25: EINFLUSS VON KOKULTIVIERUNG UND KISSPEPTIN-10 AUF DIE SDF-1-PROTEIN-EXPRESSION VON MG-63-ZELLEN IM KOKULTUR-SYSTEM MIT ISHIKAWA-ZELLEN.

ABB. 3.26: EINFLUSS VON KISSPEPTIN-10 AUF DIE SDF-1-PROTEIN-SEKRETION VON MG-63-ZELLEN IM

KOKULTUR-SYSTEM MIT ISHIKAWA-ZELLEN.

ABB. 3.27: EINFLUSS VON KISSPEPTIN-10 AUF DIE SDF-1-PROTEIN-EXPRESSION MONOKULTIVIERTER

HEC-1A-ZELLEN. 68

ABB. 3.28: EINFLUSS VON KOKULTIVIERUNG UND KISSPEPTIN-10 AUF DIE SDF-1-PROTEIN-EXPRESSION VON MG-63-ZELLEN IM KOKULTUR-SYSTEM MIT HEC-1A-ZELLEN.. 68

ABB. 3.29: EINFLUSS VON KISSPEPTIN-10 AUF DIE SDF-1-PROTEIN-SEKRETION KOKULTIVIERTER MG-63-

ZELLEN IM KOKULTUR-SYSTEM MIT HEC-1A-ZELLEN.

ABB. 4.1: MODELL FÜR DIE ROLLE VON KOKULTIVIERUNG UND KISSPEPTIN-10 IN DER INTERAKTION DER MG-63-LoCKZELLEN UND ENDOMETRIUMKARZINOMZELLEN (MODIFIZIERT NACH OLBRICH ET AL. 2010, S. $576)$ 85

\subsection{Tabellenverzeichnis}

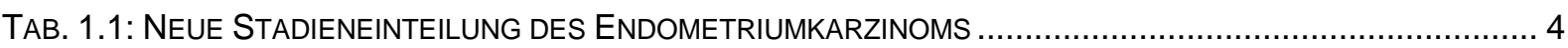

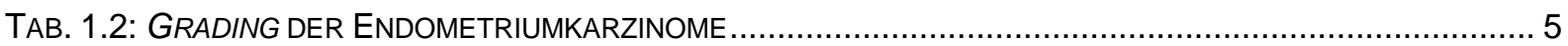

TAB. 1.3: NOMENKLATUR FÜR KISSPEPTIN UND SEINEN REZEPTOR …............................................... 13

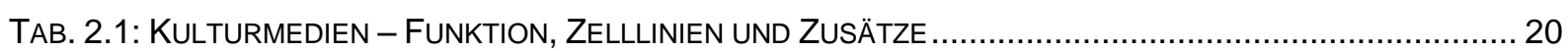

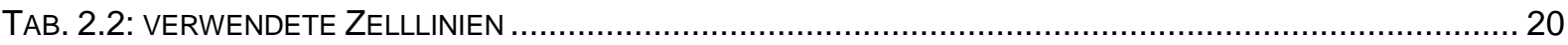

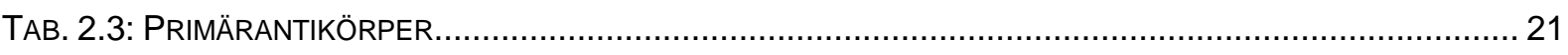

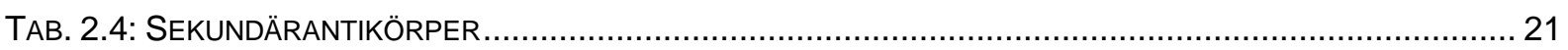

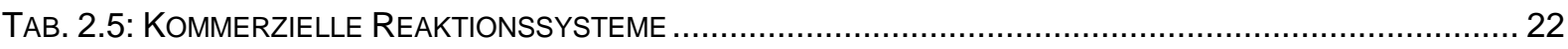

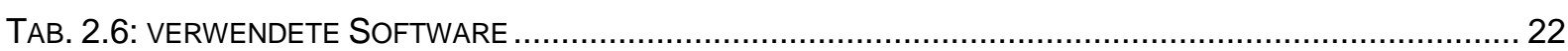

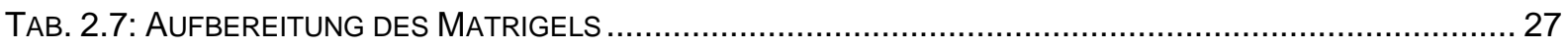

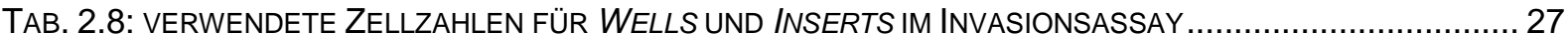

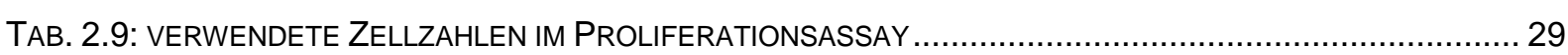

TAB. 2.10: SubStANZEN ZUR HERSTELLUNG DES ENZYM-MIX FÜR DIE REVERSE TRANSKRIPTION ............... 31

TAB. 2.11: SuBSTANZEN ZUR HERSTELLUNG DES PCR-REAKTIONSANSATZES.......................................... 32

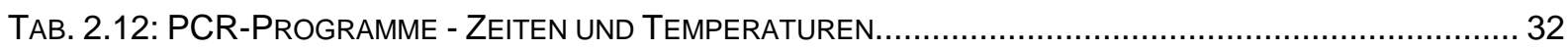

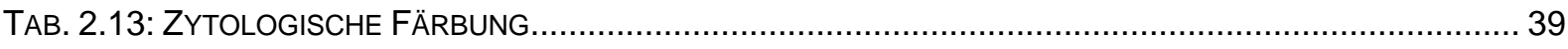

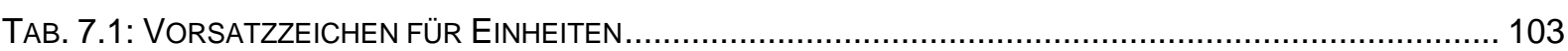




\subsection{Abkürzungsverzeichnis}

Abb.

ANOVA

ATCC

CD-FCS

CDNA

$\mathrm{CHO}$

CXCL12

CXCR4

$\mathrm{dH}_{2} \mathrm{O}$

$\mathrm{ddH}_{2} \mathrm{O}$

DMSO

DNA

dNTP

DTT

ECL

EDTA

EMT

FCS

FIGO

$\mathrm{FSH}$

$\mathrm{GnRH}$

GPR54

$\mathrm{K}$

KISS1R

KP-10

$\mathrm{LH}$

MEM

MET

mRNA

MW

$\mathrm{n}$

n.s.

PAGE

PCR

$\mathrm{P} / \mathrm{S}$
Abbildung

Analysis of variance

American Type Culture Collection

charcoal dextran-treated FCS

complementary DNA

Chinese Hamster Ovary

Chemokine (C-X-C motif) ligand 12

Chemokine ( $C-X-C$ motif) receptor 4

destilliertes Wasser

doppelt destilliertes Wasser

Dimethylsulfoxid

Desoxyribonukleinsäure (deoxyribonuclein acid)

Desoxyribonukleosid-Triphosphat

Dithiothreitol

enhanced chemiluminescens reaction

Ethylendiamin-N,N,N',N'-Tetraessigsäure-Na-Salz

epitheliale-mesenchymale Transition

fetales Kälberserum (fetal calf serum)

Fédération Internationale de Gynécologie et d'Obstétrique

Follikelstimulierendes Hormon

Gonadotropin-Releasing Hormon

G protein-coupled receptor 54

Kontrolle

KISS1-Rezeptor

Kisspeptin-10

luteinisierendes Hormon

minimal essential medium

mesenchymale-epitheliale Transition

messenger-RNA

Mittelwert

Anzahl durchgeführter Versuche

nicht signifikant

Polyacrylamid-Gel-Elektrophorese

Polymerase Kettenreaktion (polymerase chain reaction)

Penicillin/Streptomycin 


$\begin{array}{ll}\text { PVDF } & \text { Polyvinylidenfluorid } \\ \text { RNA } & \text { Ribonukleinsäure (ribonucleic acid) } \\ \text { RT } & \text { Reverse Transkription } \\ \text { S. } & \text { siehe } \\ \text { SDF-1 } & \text { stromal derived factor-1 } \\ \text { SDS } & \text { Natriumdodecylsulfat (sodium dodecyl sulfate) } \\ \text { SEM } & \text { Standardfehler des Mittelwertes (standard error of the mean) } \\ \text { SERM } & \text { selective Östrogenrezeptor-Modulatoren (selective estrogen } \\ & \text { receptor modulators) } \\ \text { Tab. } & \text { Tabelle } \\ \text { TBE } & \text { Tris-Borat-EDTA-Puffer } \\ \text { TBS } & \text { Tris-buffered saline } \\ \text { TBST } & \text { Tween-TBS Puffer } \\ \text { Tris } & \text { Tris(hydroxymethyl)aminomethan } \\ \text { UV } & \text { ultraviolett } \\ \text { vs. } & \text { versus } \\ \text { v/v } & \text { volume/volume } \\ \text { WHO } & \text { Weltgesundheitsorganisation (World Health Organization) } \\ \text { w } & \text { mit (with) } \\ \text { w/o } & \text { ohne (without) } \\ \text { w/v } & \text { Gewicht/Volumen (weight/volume) }\end{array}$

\subsection{Einheitenzeichen}

$\mathrm{Bp}$

${ }^{\circ} \mathrm{C}$

$\mathrm{Da}$

g

g

$\mathrm{h}$

I

M

m

$\min$

rpm

sec

U
Basenpaare

Grad Celsius

Dalton

Erdbeschleunigung, Gravitation $\left(g=9,81 \frac{\mathrm{m}}{\mathrm{s}^{2}}\right)$

Gramm

Stunde(n) (hour(s))

Liter

$\operatorname{Molar}\left(=\frac{m o l}{l}\right)$

Meter

Minute(n)

Umdrehungen pro Minute (rounds per minute)

Sekunde(n) (second(s))

Enzymeinheit (Unit) 
Tab. 7.1: Vorsatzzeichen für Einheiten

\begin{tabular}{lll}
\hline Vorsatzzeichen & Vorsatz & Faktor, mit dem die Einheit multipliziert wird \\
\hline $\mathrm{p}$ & Piko & $10^{-12}$ \\
$\mathrm{n}$ & Nano & $10^{-9}$ \\
$\mu$ & Mikro & $10^{-6}$ \\
$\mathrm{~m}$ & Milli & $10^{-3}$ \\
$\mathrm{c}$ & Zenti & $10^{-2}$ \\
$\mathrm{~d}$ & Dezi & $10^{-1}$ \\
& & $10^{0}$ \\
$\mathrm{da}$ & & $10^{1}$ \\
$\mathrm{~h}$ & Deka & $10^{2}$ \\
$\mathrm{k}$ & Hekto & $10^{3}$ \\
\hline
\end{tabular}

\subsection{Aminosäurecode für natürliche Aminosäuren}

\begin{tabular}{ll} 
Alanin & Ala \\
Arginin & Arg \\
Asparagin & Asn \\
Aspartat & Asp \\
Cystein & Cys \\
Glutamat & Glu \\
Glutamin & Gln \\
Glycin & Gly \\
Histidin & His \\
Isoleucin & Ile \\
Leucin & Leu \\
Lysin & Lys \\
Methionin & Met \\
Phenylalanin & Phe \\
Prolin & Pro \\
Serin & Ser \\
Threonin & Thr \\
Tryptophan & Trp \\
Tyrosin & Tyr \\
\hline
\end{tabular}




\section{Publikation}

Die in dieser Arbeit durchgeführten Untersuchungen haben zu folgender Publikation beigetragen:

Schmidt E, Haase M, Ziegler E, Emons G, Gründker C (2014): Kisspeptin-10 inhibits SDF1-induced invasion of human endometrial cancer cells. International Journal of Gynecological Cancer 24, 210-217 


\section{Lebenslauf}

Ich, Elena Schmidt, wurde am 2. August 1988 in Sande als Tochter der Grundschullehrerin Marianne Eifler-Schmidt und des Berufssoldaten Reinhard Schmidt geboren. Aufgrund einer dienstlichen Versetzung meines Vaters lebte ich vom November 1990 bis November 1993 in Virginia Beach/ VA/ USA. Aufgrund dieses Aufenthaltes konnte ich gute englische Sprachkenntnisse erlangen.

Anschließend besuchte ich in Wilhelmshaven die Grundschule und die Orientierungstufe Altengroden und die Cäcilienschule, ein staatlich anerkanntes freies Gymnasium in kirchlicher Trägerschaft. Im Jahr 2007 legte ich das Abitur mit der Note 1,8 ab.

Während der Schulzeit engagierte ich mich in der Schülervertretung und in den Schwimmvereinen „WSSV“ und "SG Weser-Ems“. Dabei nahm ich regelmäßig an den Landes- und Norddeutschen Meisterschaften teil. Mein größter persönlicher Erfolg war die Qualifikation und die Teilnahme an den Deutschen Meisterschaften.

Nach meiner Schulzeit bekam ich durch ein Freiwilliges Soziales Jahr im pflegerischen Bereich der kardiologischen Station des Nord-West-Krankenhauses in Sande Einblicke in die medizinische Berufswelt. Das FSJ musste ich aufgrund meiner Studienplatzzusage beenden. Im Wintersemester 2007/08 begann ich mit dem Studium der Humanmedizin an der GeorgAugust-Universität Göttingen. Während des vorklinischen Studienabschnitts absolvierte ich die Klausuren in Anatomie, Physiologie und Biochemie als eine der besten $5 \%$ des Semesters. Den 1. Abschnitt der Ärztlichen Prüfung schloss ich mit der Note „sehr gut“ ab. Seit Beginn des klinischen Studienabschnitts hatte ich im Labor der Molekularen Gynäkologie unter der Leitung von Herrn Prof. Dr. Gründker die Möglichkeit, im Rahmen einer experimentellen Dissertation meine wissenschaftlichen Kenntnisse zu vertiefen. Neben einer Anstellung als Tutorin im STÄPS der Universitätsmedizin Göttingen und einer ehrenamtlichen Anstellung als Übungsleiterin dreier Kinder-Schwimmgruppen des „MTV Rosdorfs" absolvierte ich Famulaturen in der gynäkologischen Praxis Dr. Teebken-Hilbig in Göttingen, in den Abteilungen für Allgemeinchirurgie, Anästhesiologie, Innere Medizin und Gynäkologie des Reinhard-Nieter-Krankenhauses Wilhelmshaven und in der Abteilung für Nuklearmedizin des Universitätsklinikums Göttingen. Aufgrund meiner bisher erbrachten Leistungen wurde ich 2011 durch das Auswahlverfahren der Georg-August-Universität Göttingen für den Erhalt des Niedersachsenstipendiums ausgewählt. Im Rahmen des praktischen Jahres absolvierte ich $2012 / 13$ das 1. Tertial in der Abteilung für Allgemein-, Viszeral- und Thoraxchirurgie im Nord-West-Krankenhaus in Sande, das Wahltertial Gynäkologie und Geburtshilfe im Kantonsspital Uri sowie im Klinikum Oldenburg und das 3. Tertial in dem Zentrum für Innere Medizin im Nord-West-Krankenhaus in Sande. 